\title{
An Assessment of Farmer Participation in the United States Department of Agriculture, Natural Resources Conservation Services' Conservation Technical Assistance Program in West
} Virginia

Matt D. Oliver

West Virginia University

Follow this and additional works at: https://researchrepository.wvu.edu/etd

Part of the Environmental Policy Commons, Environmental Studies Commons, Food Security Commons, Geographic Information Sciences Commons, Natural Resources and Conservation Commons, Natural Resources Management and Policy Commons, Public Administration Commons, Spatial Science Commons, and the Sustainability Commons

\section{Recommended Citation}

Oliver, Matt D., "An Assessment of Farmer Participation in the United States Department of Agriculture, Natural Resources Conservation Services' Conservation Technical Assistance Program in West Virginia" (2019). Graduate Theses, Dissertations, and Problem Reports. 3912.

https://researchrepository.wvu.edu/etd/3912

This Dissertation is protected by copyright and/or related rights. It has been brought to you by the The Research Repository @ WVU with permission from the rights-holder(s). You are free to use this Dissertation in any way that is permitted by the copyright and related rights legislation that applies to your use. For other uses you must obtain permission from the rights-holder(s) directly, unless additional rights are indicated by a Creative Commons license in the record and/ or on the work itself. This Dissertation has been accepted for inclusion in WVU Graduate Theses, Dissertations, and Problem Reports collection by an authorized administrator of The Research Repository @ WVU.

For more information, please contact researchrepository@mail.wvu.edu. 
An Assessment of Farmer Participation in the United States Department of Agriculture, Natural Resources Conservation Services' Conservation Technical Assistance Program in West Virginia

\author{
Matt D. Oliver, MS
}

\author{
Dissertation submitted to the \\ Davis College of Agriculture, Natural Resources, and Design \\ School of Natural Resources \\ at West Virginia University \\ in partial fulfillment of the requirements \\ for the degree of \\ Doctor of Philosophy \\ in \\ Resource Management and Sustainable Development: \\ Human and Community Development Track
}
Margaret Stout, Ph.D., Chair
Cheryl Brown, Ph.D.
Kathryn Gazal, Ph.D.
Joseph Hatton, M.S.
Michael Strager, Ph.D.

Division of Resource Economics \& Management

Morgantown, West Virginia

2019

Keywords: USDA NRCS, conservation, technical assistance, community capitals, coproduction, farmer-to-farmer methods

Copyright 2019 Matt D. Oliver 


\section{ABSTRACT \\ An Assessment of Farmer Participation in the United States Department of Agriculture, Natural Resources Conservation Services' Conservation Technical Assistance Program in West Virginia}

\section{Matt D. Oliver, MS}

Food and fiber production on America's farmlands have a major influence on the environment, therefore, soil and water conservation practices are critical. NRCS has provided no-fee technical assistance for nearly 100 years through the Conservation Technical Assistance (CTA) program. The CTA program is essential because it provides technical knowledge directly to farmers for planning and implementing conservation practices that are proven to benefit environmental health and on-farm production. CTA program funds support NRCS staff and training and are thereby the local service delivery vehicle for all NRCS programs. However, in recent years, funding for CTA has remained relatively constant while financial assistance program funds have increased dramatically. Because NRCS relies on federal appropriations, it's vitally important to make the case for additional CTA funds while also developing strategies to increase program effectiveness. The objectives of this study were to: (1) determine the factors that influence farmers' decisions to participate in the CTA program; (2) consider NRCS's organizational capacity to deliver it; and (3) describe how NRCS might increase participation. A theory of change to increase participation was developed based on the Asset-Based Community Development (ABCD) approach and Community Capitals Framework (CCF). This theoretical model was used to develop and test hypotheses through a sequential mixed methods research design. The first method utilized Geographic Information System (GIS) modeling to identify the sample population. Next, asset mapping was used to evaluate a potential causal relationship between participation and organizational assets. Then, interviews were conducted to understand motivations and barriers to participation and inform survey design. Lastly, data from a mailed questionnaire was quantitatively analyzed to assess farmer motivations and barriers to participation. Results showed that additional CTA funds are needed to increase NRCS staff and expand training to build public engagement and community development knowledge and skills. Furthermore, results indicate that the addition of coproduction strategies through partnerships and farmer-to-farmer methods could further increase CTA program participation. 


\section{Dedication}

"And whatever you do, whether in word or deed, do it all in the name of the Lord Jesus, giving thanks to God the Father through Him."

$\sim$ Colossians 3:17

I would never have accomplished this work without a great deal of help from other people. To my sweet wife, Salleah, thank you for the endless sacrifices you have made which allowed me to work full-time while also pursuing this research. You have toiled right alongside me. It's astonishing how you have taken care of our three energetic boys, as I burned the midnight oil, while also pouring into your own teaching career. Simply put, without your love and support this could not have happened. To my sons, Andrew, Noah, and Samuel, thank you for your patience, understanding, and ultimately, for giving up time with Dad. I'm looking forward to making special memories with each of you, and with our newest little man due to arrive this summer, Luke. I'm especially grateful for the encouragement and inspiration given to me by others that are also dear to my heart. To my sister, Sarah, whom I have always admired and sought to emulate. My parents, Ruth Barber Oliver and Reverend Dr. CD Oliver Jr., have been tireless in their help and support. Most importantly, I'm thankful they instilled in Sarah and me the eternal significance of loving and serving the Lord. To my grandparents, who modeled hard-work, humility, strength, kindness, and faith-you are giants.

"Then the Lord God took man and put him in the garden of Eden to work it and keep it." $\sim$ Genesis 2:15 


\section{Acknowledgements}

There were many people that contributed to this research. If not for them, completion of this dissertation would not have been possible. I would like to take a moment and acknowledge them for their time and efforts.

I would like to begin by showing appreciation for my advisor, Dr. Margaret Stout. Thank you for believing in me and for challenging me. I am incredibly grateful for your advice and encouragement that began long before my time as a $\mathrm{PhD}$ student. There is no doubt this work is tremendously better because of your careful and thoughtful guidance. It has been a pleasure working with you these last five years.

Next, I want to thank each committee member: Dr. Kathryn Gazal, Dr. Michael Strager, Dr. Cheryl Brown, and Deputy Commissioner of Agriculture, Joe Hatton. Thank you for your willingness to serve on this committee. I genuinely appreciate your investment in this project and the assistance that followed. The wisdom and expertise you provided during committee meetings and one-on-one interactions has been invaluable.

I am also grateful for the knowledge and experience provided by Louis Aspey, State Conservationist, and Laura Smith, Assistant State Conservationist for Programs at NRCS. Thank you for helping me with the practical application of this research. Your insights have facilitated a bridge between theory and practice. I also appreciate the support and encouragement you have provided. Most importantly, thank you for your friendship.

I owe gratitude to the Commissioner of Agriculture in West Virginia, Kent Leonhardt. Your letter of support included in the survey questionnaires assuredly bolstered the response rate from our local farmers. This data would not have been as robust if it were not for your efforts. Thank you for your interest in this research.

I am also beholden to my church family, fellow students, and co-workers at NRCS that volunteered their time to help prepare the survey mailings. This task could not have been accomplished without your assistance. Thank you so much for your service.

Last, but certainly not least, I would like to thank the faculty, staff, and my classmates, in the Davis College of Agriculture, Natural Resources, and Design; and the Eberly College of Arts and Sciences, at West Virginia University. You all have provided me with valuable insights and many, many fond memories. 


\section{Table of Contents}

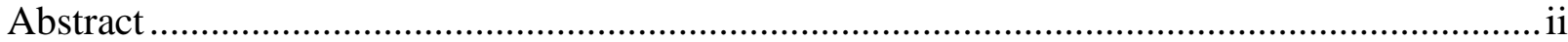

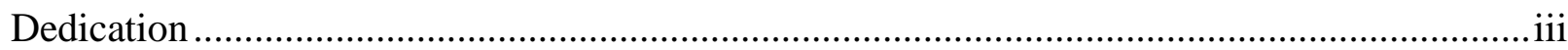

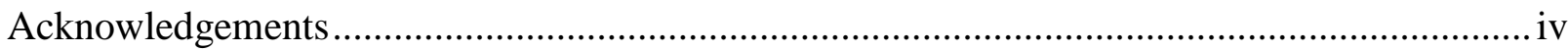

List of Tables ............................................................................................................... ix

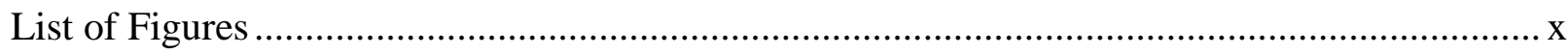

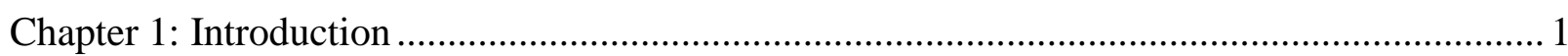

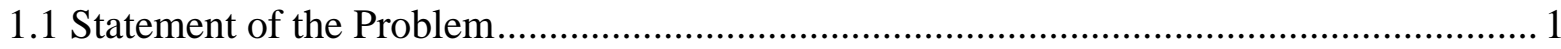

1.1.1 Agricultural Production's Effect on Natural Resources ............................................. 2

1.1.2 CTA Participation as Natural Resource Management ..................................................5

1.1.3 CTA Participation as a Community Development Activity ......................................... 14

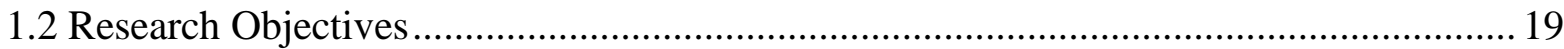

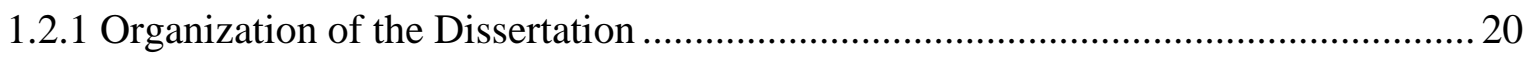

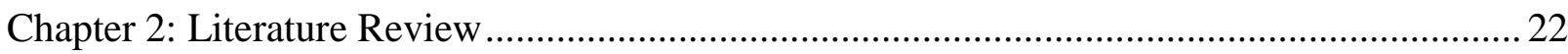

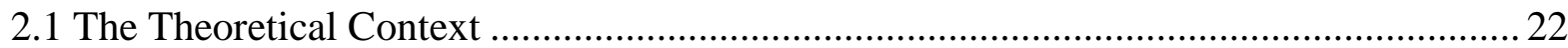

2.2 A Holistic Approach to Community Development …………………............................2 23

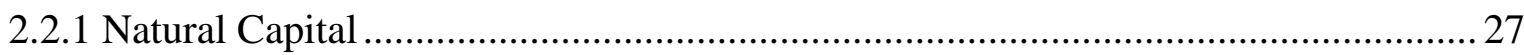

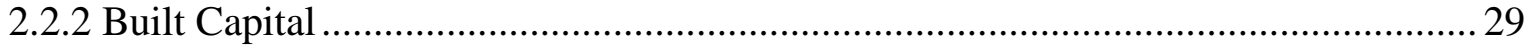

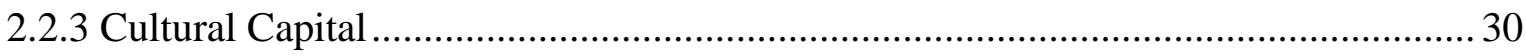

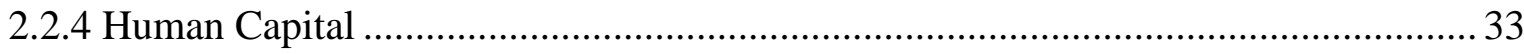

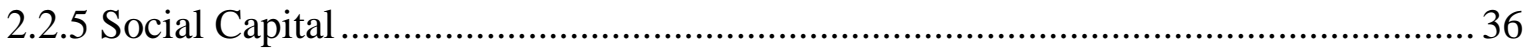

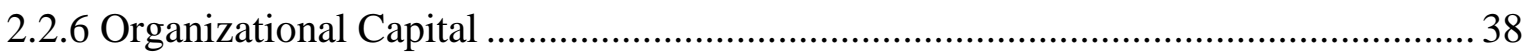

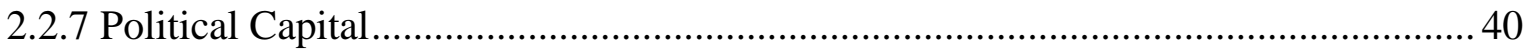

2.2.8 Financial Capital ............................................................................................ 41

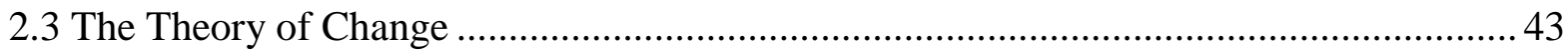

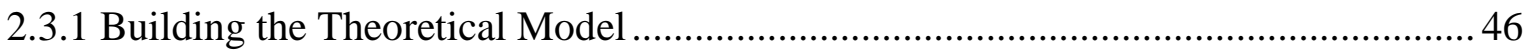

2.3.2 Conceptualizing the Dependent Variable ................................................................ 47

2.3.3 Conceptualizing the Primary Independent Variables .................................................4 47

2.3.4 Conceptualizing the Secondary Independent Variables ............................................. 48

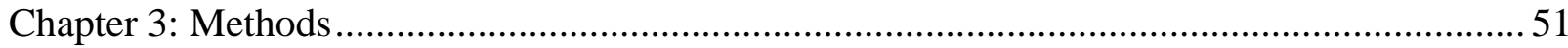

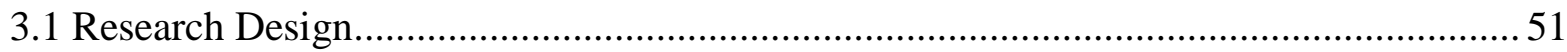




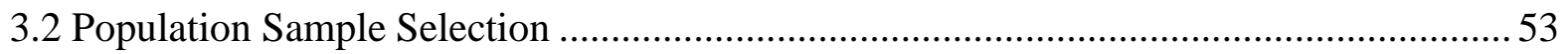

3.2.1 CTA Program Participation Modeling Process.........................................................54

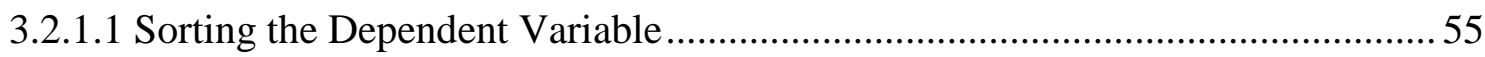

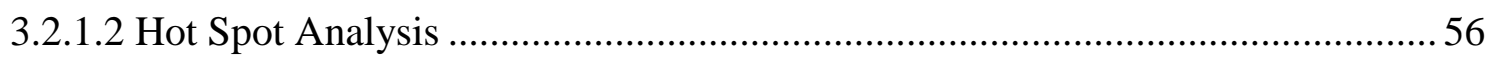

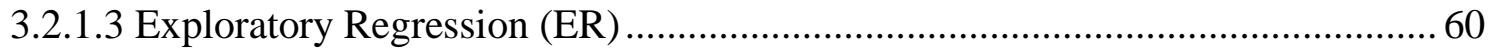

3.2.1.4 Ordinary Least Squares Regression (OLS) ....................................................... 64

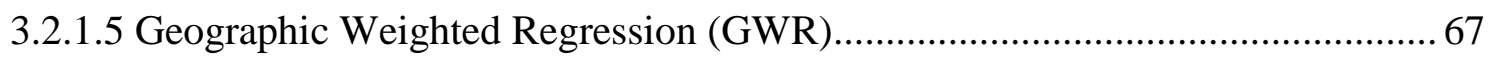

3.2.2 Identifying Representative Land Use Characteristics .............................................. 70

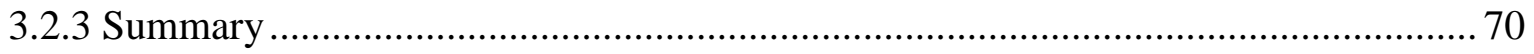

3.3 Organizational Asset Mapping Methods ……………................................................. 71

3.3.1 Preliminary Findings......................................................................................... 73

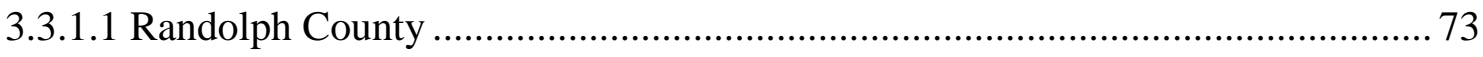

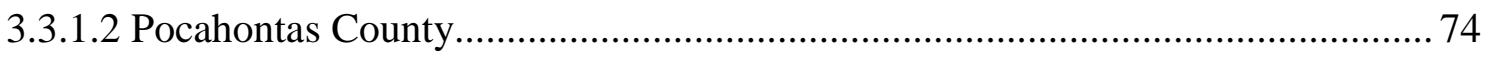

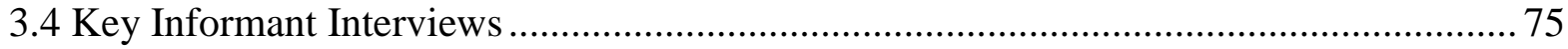

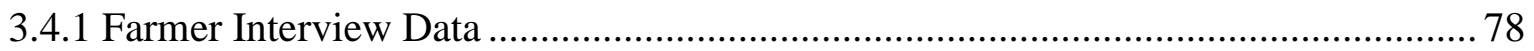

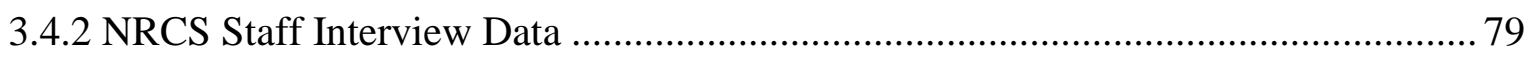

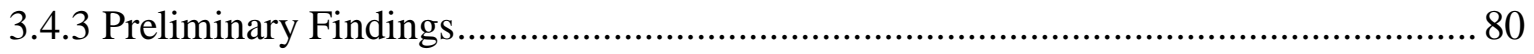

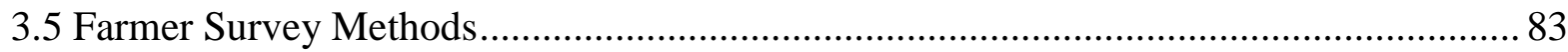

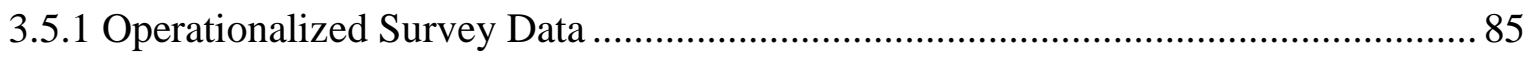

3.5.1.1 The Dependent Variable ................................................................................... 86

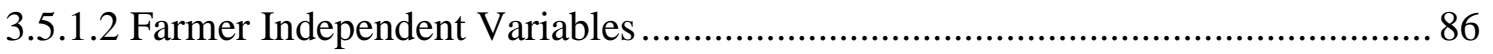

3.5.1.3 NRCS Independent Variables .................................................................... 92

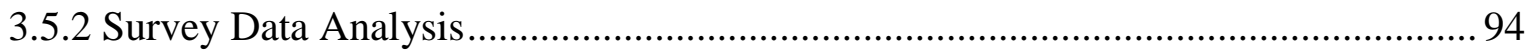

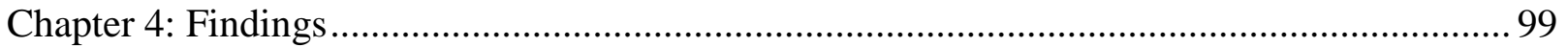

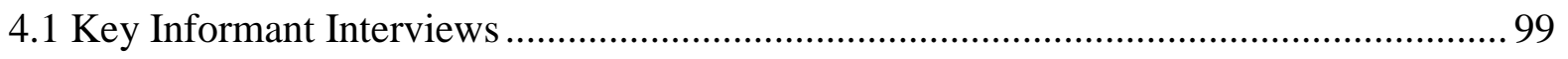

4.1.1 Farmer Interview Results ............................................................................. 99

4.1.1.1 CTA Participation: The Key to Conservation on the Ground........................... 100

4.1.1.2 Personal Attachment to the Land ...................................................................... 101

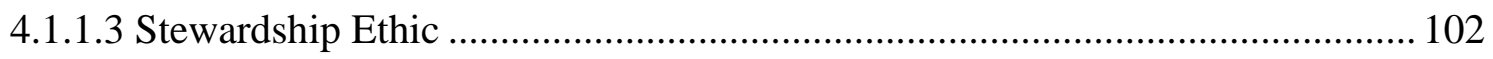

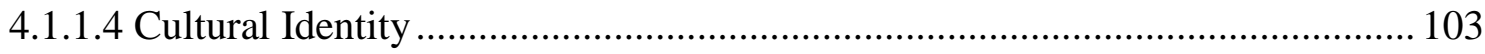

4.1.1.5 Barriers to Participation ................................................................................. 103 
4.1.1.6 Farmer-to-Farmer Methods.......................................................................... 108

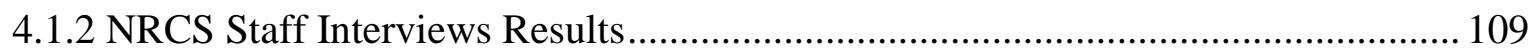

4.1.2.1 CTA Participation: The Key to Conservation on the Ground........................... 109

4.1.2.2 NRCS Customer Service Culture................................................................... 111

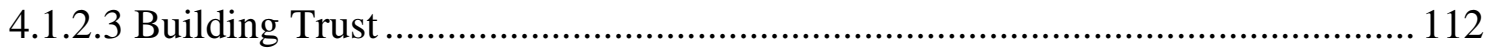

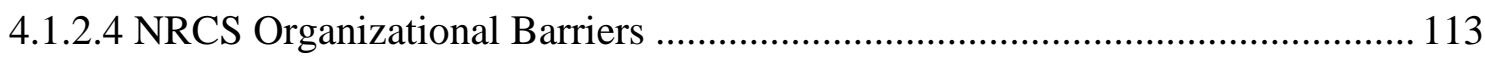

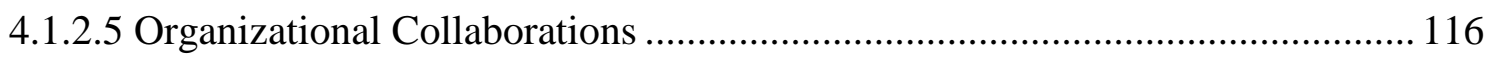

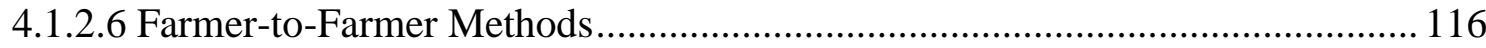

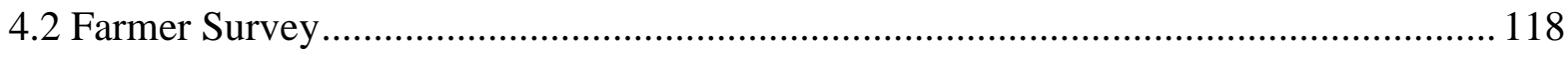

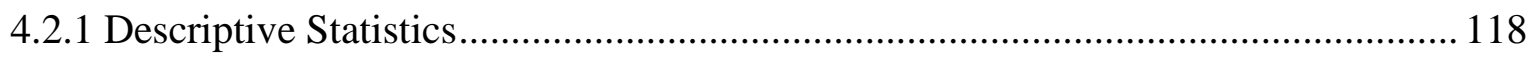

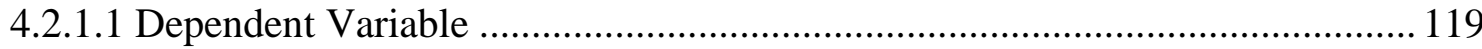

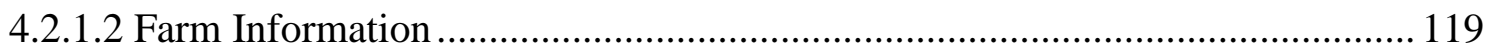

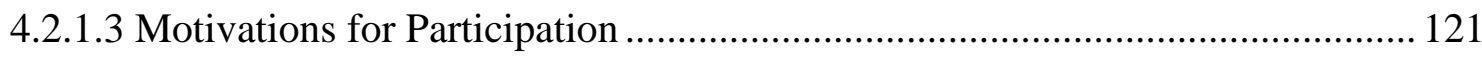

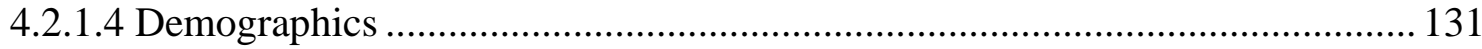

4.2.2 Modeling Likelihood of CTA Participation.......................................................... 134

Chapter 5: Discussion, Conclusion, and Recommendations …………………………......... 139

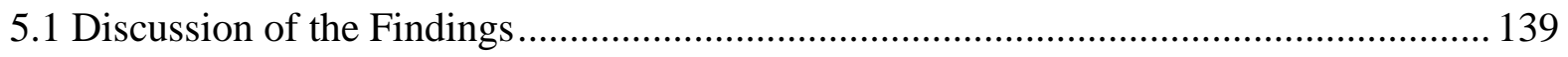

5.1.1 Farmer Side of the Theoretical Model ................................................................ 141

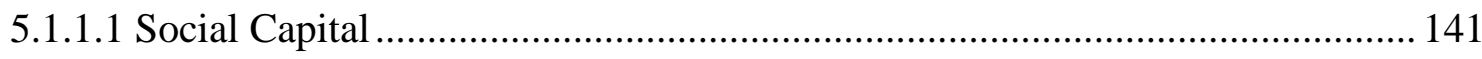

5.1.1.2 Human Capital ....................................................................................... 142

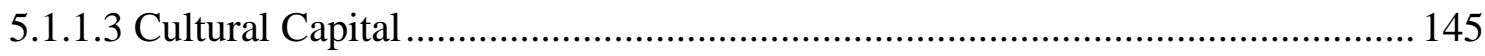

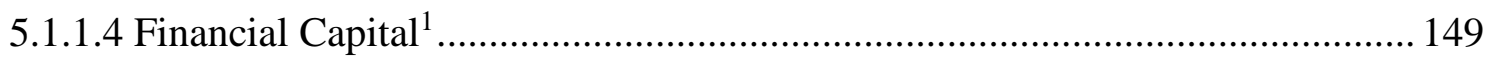

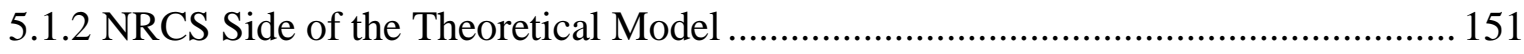

5.1.2.1 Political Capital and Financial Capital ${ }^{2}$......................................................... 152

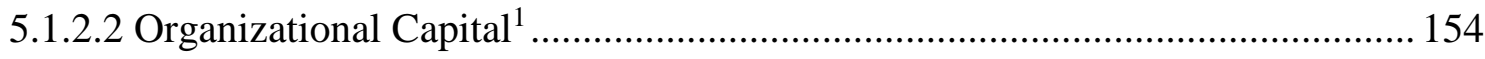

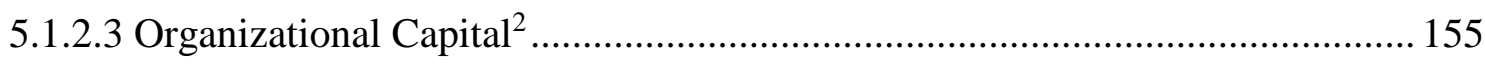

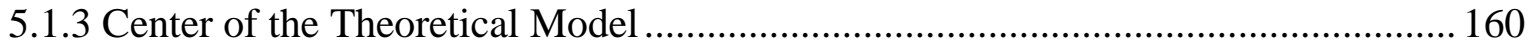

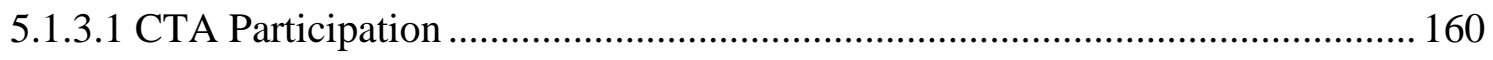

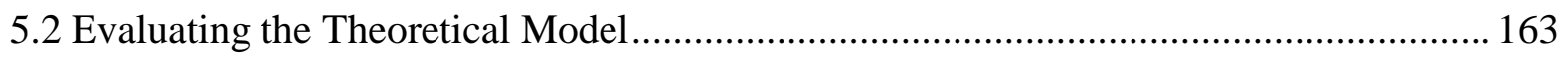

5.2.1 Assumptions, Delimitations, and Limitations........................................................... 164

5.2.2 Recommendations for Further Research................................................................ 167 
5.3 Conclusions and Recommendations for Practice....................................................... 170

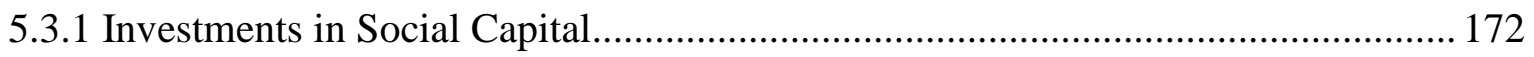

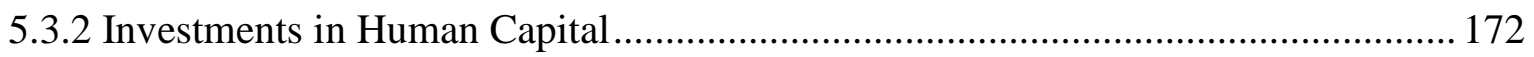

5.3.3 Investments in Cultural Capital ....................................................................... 172

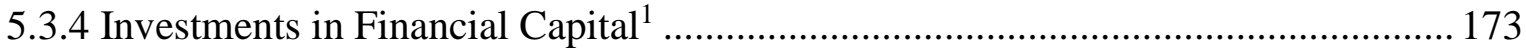

5.3.5 Investments in Political and Financial Capital ${ }^{2}$.................................................... 174

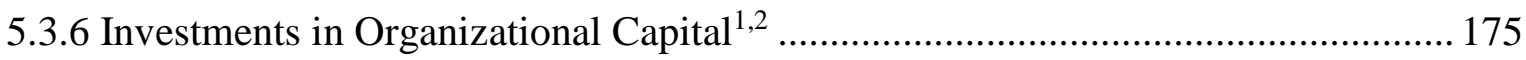

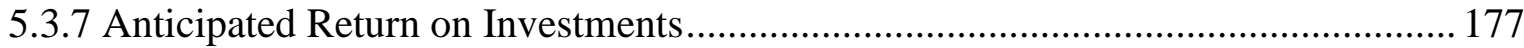

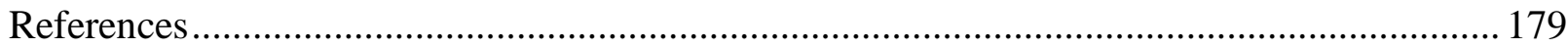

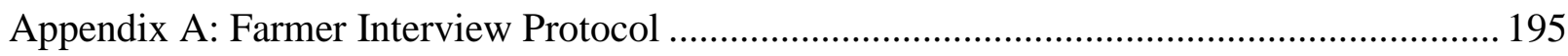

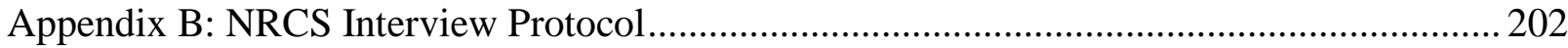

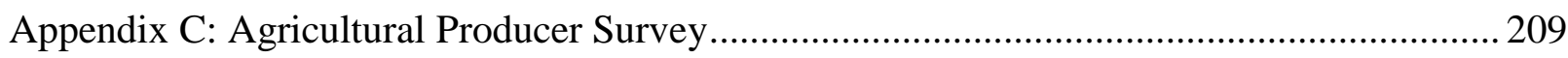

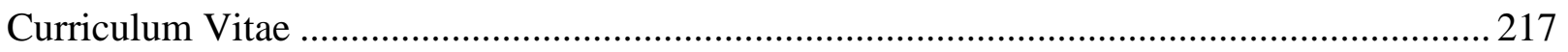




\section{List of Tables}

Table 3.1: Variable descriptions for CTA program participation modeling ........................... 61

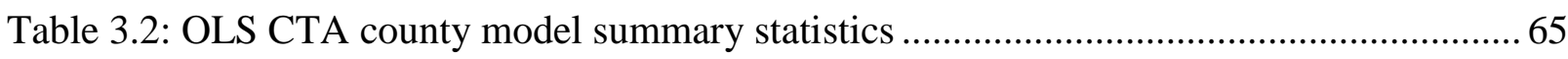

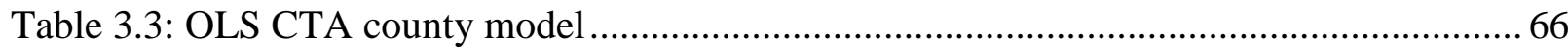

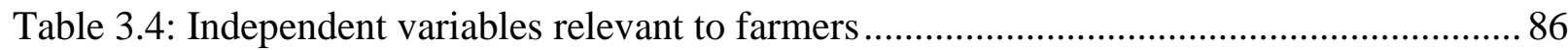

Table 3.5: Independent variables relevant to NRCS ........................................................ 93

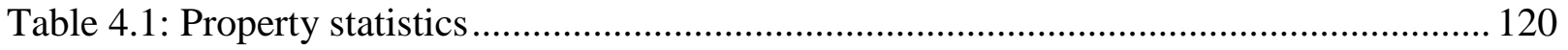

Table 4.2: Importance of land conservation and stewardship........................................ 123

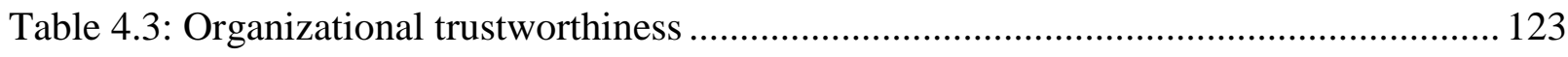

Table 4.4: Conservation practice knowledge and training ................................................. 124

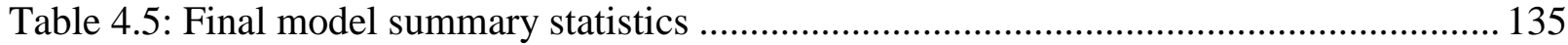

Table 4.6: Factors affecting participation in the CTA program........................................ 136 


\section{List of Figures}

Figure 1.1: NRCS planning process........................................................................... 9

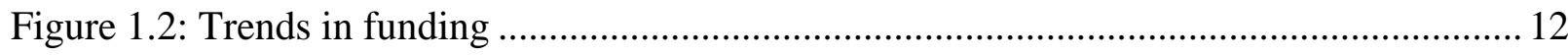

Figure 2.1: Community Capitals Framework (CCF) ......................................................25

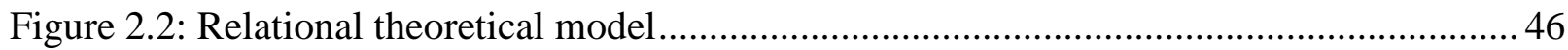

Figure 2.3: USDA NRCS Service Centers in West Virginia............................................. 49

Figure 3.1: Applied CTA practice points........................................................................ 56

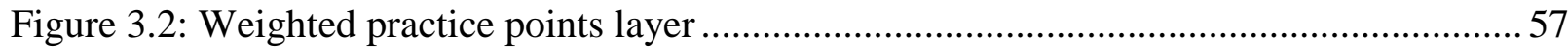

Figure 3.3: Hot and cold applied CTA practice point clusters ............................................58

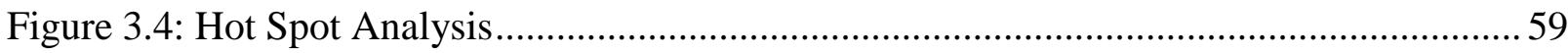

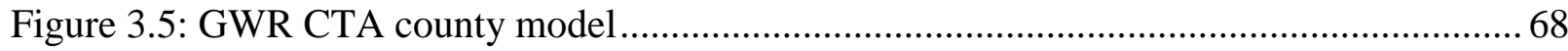

Figure 3.6: Randolph County organizational assets ..................................................... 74

Figure 3.7: Pocahontas County organizational assets .................................................... 75

Figure 3.8: Empirically informed theoretical model..................................................... 83

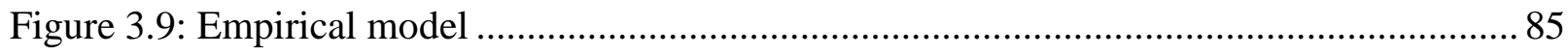

Figure 4.1: Would you ever consider participating in the NRCS CTA program?.................. 119

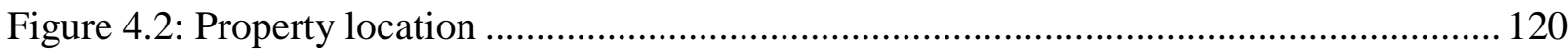

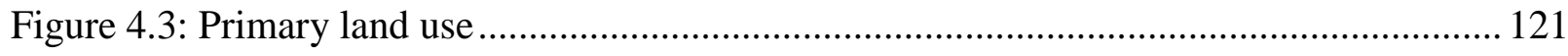

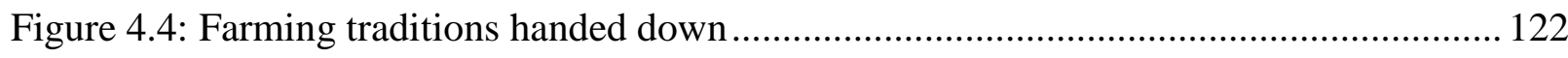

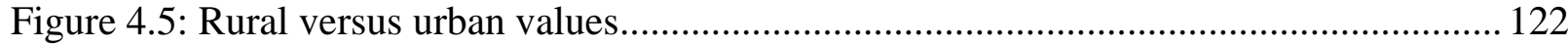

Figure 4.6: Primary teacher of NRCS conservation practices ........................................ 125

Figure 4.7: Secondary teacher of NRCS conservation practices ..................................... 125

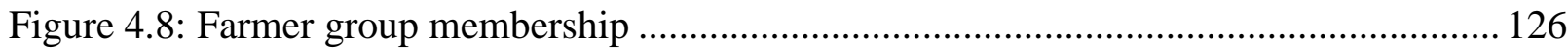

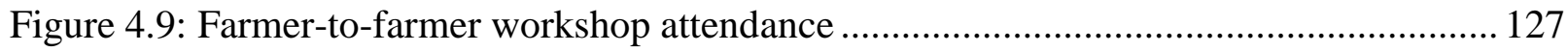

Figure 4.10: Willingness to promote NRCS conservation practices to other farmers ............. 127

Figure 4.11: Local capacity to provide technical assistance ........................................... 128

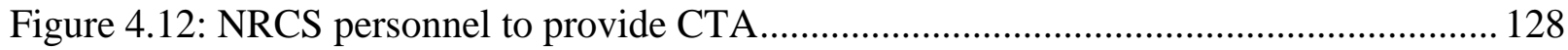

Figure 4.13: Primary barrier to NRCS conservation practice implementation...................... 129

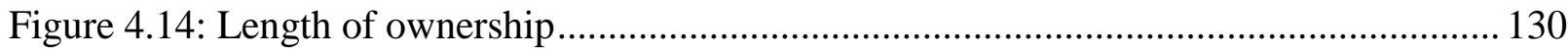

Figure 4.15: Whether respondents felt their property was a monetary investment ................ 130

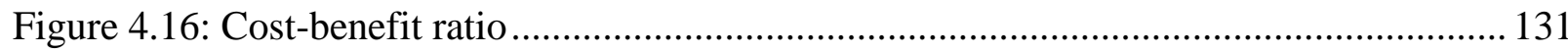


Figure 4.17: Location of primary residence ............................................................... 132

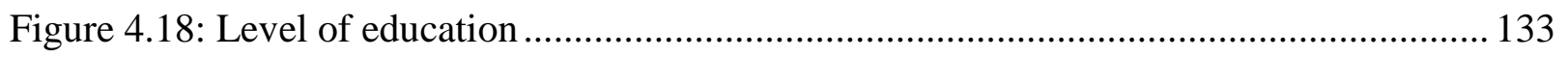

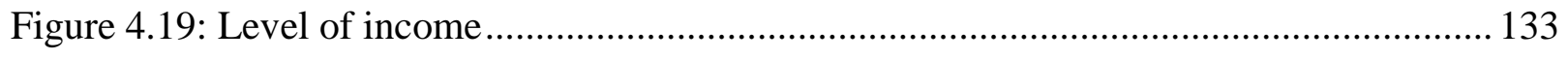

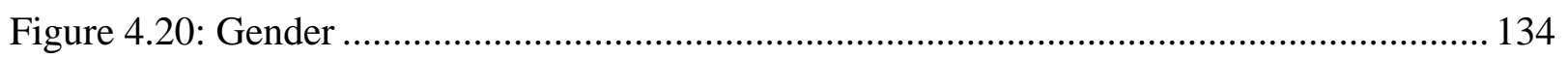

Figure 5.1: Theoretical model and key findings ........................................................ 140 


\section{Chapter 1: Introduction}

"From every conceivable angle-economic, social, cultural, public health, national defenseconservation of natural resources is an objective on which all should agree." $\sim$ Hugh Hammond Bennett

This chapter contextualizes the research undertaken and the problem it seeks to address, then introduces the research objectives and organization of the dissertation.

\subsection{Statement of the Problem}

Management of farmlands has a major influence on local and national economies through food and fiber production, but also on ecosystem health, soil erosion, water quality, and moreespecially in West Virginia where there are steep slopes and agricultural operations in valley bottoms near rivers and streams. The United States Department of Agriculture, Natural Resources Conservation Service (USDA NRCS) is a federal agency that provides financial and technical assistance to farmers to aid them with soil and water conservation. NRCS is locally-led and has offered no-fee technical assistance and conservation planning for nearly 100 years through the Conservation Technical Assistance (CTA) program, which encourages farmers to engage in voluntary conservation practices without financial incentives. The CTA program is important because it provides technical knowledge directly to farmers for planning and implementing conservation practices. This knowledge is based on conservation technology that has proven dependable in achieving the "benefits of a healthy and productive landscape" (USDA NRCS 2010, 525-A.1). However, because funding allocations to the CTA program have remained static over time, NRCS must make a case for increased funding while also becoming more effective in increasing conservation efforts through community development practices. 


\subsubsection{Agricultural Production's Effect on Natural Resources}

Public discourse about the importance of farmlands to society began with our country's founding and continues today (Mariola 2005, 209). However, "conventional agricultural practices, and especially the deep tilling of soils, have increasingly been seen as problematic by those concerned with the health of agroecosystems and ultimately global food security" (Knowler and Bradshaw 2007, 5). Furthermore, intensified agricultural methods, which are characterized by greater specialization in products that require processes that reduce crop and livestock species diversity, are essentially creating monocultures (Matson 1997, 504). It has become clear that this kind of agriculture causes local problems such as soil erosion, lower $\mathrm{pH}$ levels, and biodiversity loss, while also causing issues on a larger scale such as groundwater pollution and surface water eutrophication (Matson et al. 1997, 504). This presents a major problem because "water is one of the most important natural resources; it directly affects food security, socioeconomic development, and health" (Djoukeng et al. 2015, 206).

Despite this realization, there is still a dire need for increased agricultural production. An ever-growing worldwide population requires sustainable food and fiber for current and future generations. But intensified agriculture often uses economies of scale that increase inputs (e.g., pesticides, feed, fertilizer, etc.) that often generate harmful wastes, use large amounts of fossil fuels, and concentrate production in a manner that is "driving out small producers and undermining rural communities" (Horrigan et al. 2002, 445). Indeed, the many costs related to high-input, intensified agriculture — such as soil erosion, poor water quality, nutrient loss, plant and animal susceptibility to pests and disease, reduced human health, and decreased local community capacity — may not be worth the potential benefits of its high-output. Most 
practically, Tscharntke et al. (2012) contend the increased yields related to intensified agriculture are not directly correlated to the reduction of world hunger (57).

To be sure, humanity is every bit as dependent on the land today as before urbanization (Loomis 1984, 449). On average, each farmer provides food for approximately 51 people worldwide and the United States provides over half of the global grain exports (Mariola 2005, 210). Similarly, grazing lands are the largest land use in the United States and therefore their conservation is essential to all citizens (Krueger et al. 2002, 1). In fact, "modern agriculture now feeds 6,000 million people" (Tilman et al. 2002, 671). In addition, agriculture is often the economic foundation of rural economies (Mariola 2005, 211). However, food production is increasingly endangered by anthropogenic induced degradation, including, but not limited to: soil erosion, organic matter depletion, compaction, contamination, flooding, desertification, and many other adverse effects (Blum 2013, 11). Thus, environmental degradation is a threat to local economies, healthy communities, and food production alike (Smit and Smithers 1992, 1).

Studies have shown that most Americans believe land conservation to be a major contributor to the economic and social health of communities (Gustanski and Squires 2000, 13). These views are warranted because over half the land in the lower forty-eight states consists of farmland (Cox 2007; Lambert et al. 2006). The prevalence of these agricultural lands causes them to have a tremendous effect on environmental quality (Prokopy et al. 2014, 1). Moreover, the understanding of ecosystems has become prevalent in conservation policy today. Ecosystems are defined as organisms associating with one another and their surrounding physical environment, so that energies are exchanged and elements are cycled (Encyclopedia of Earth, 2014). Such ecosystems are considered to be life support for all living things (Benedict and McMahon, 2002). This conceptualization of natural resources and the environment considers the 
full range of their physical aspects and uses by humans and wildlife. Agriculture undoubtedly transforms these ecosystems in order to supply food, fiber, and fuel (Ma et al. 2010, 1).

Regions across the globe have growing concern over the broader implications of conventional agricultural to soil health (Knowler and Bradshaw 2007, 26). The degradation of soil resources negatively influences the environment as well as farmland production (Prager and Posthumus 2010, 1). “Farming practices adopted by America's roughly 2 million farm operators have a major impact on the health of the ecosystem and on soil erosion, sedimentation levels in streams and rivers, nutrient and pesticide runoff, groundwater contamination, and air quality” (Lambert et al. 2006, 1). However, because many of the negative externalities associated with farmland degradation are "beyond the farm gate," there is little incentive for their mitigation through conservation practices (Ma et al. 2010,2). Therefore, engaging and educating farmers in conservation efforts and gaining their cooperation in implementation is vitally important to achieving the agricultural and ecological sustainability upon which we all depend.

The State of West Virginia defines farmland as real property, of any size, useable for cultivation or grazing together with any associated wetlands and forestlands (WV Code $\S 8 \mathrm{~A}-12$ 11). Agricultural land in West Virginia has a particularly high impact on natural resources because most of the soil is situated on steep slopes susceptible to erosion, has shallow depth to bedrock, is acidic, and lacks phosphorous (Sperow 2012). Given the topography of the state, much of the most suitable farmland is in valleys and bottoms close to streams, lakes, and rivers. Farmers utilize the hillsides and flood prone areas for pastureland (Williams 1993, 224). These locations increase the potential for agricultural non-point source pollutants to enter surface and groundwater. In addition, the majority of West Virginia's landscape does not allow for large scale commodity crop production. As such, there is potential for the intensification of ruminant 
agriculture and hay production. If not properly managed, this could lead to accelerated natural resource degradation. Undeniably, soil and water conservation on farmland is needed to sustain and improve ecosystems, agricultural productivity, local economies, rural communities, and natural resources in the Mountain State.

\subsubsection{CTA Participation as Natural Resource Management}

The idea of conservation as "wise use" of natural resources was first championed by Gifford Pinchot at the turn of the twentieth century (Hays 1959). Pinchot developed the principle of the greatest good for the greatest number for the long run (Cubbage et al. 1993, 228). The two basic tenets of this paradigm are equity, meaning an even distribution of natural resources (for both current and future generations) and efficiency in the use of natural resources (Callicott 1990). To be sure, equity and efficiency are closely related to agricultural sustainability. "Sustainable agricultural systems are based on relatively small, profitable farms that use fewer off-farm inputs, integrate animal and plant production where appropriate, maintain a higher biotic diversity, emphasize technologies that are appropriate to the scale of production, and make the transition to renewable forms of energy" (Horrigan et al. 2002, 446). These kinds of efficiencies allow for the current use of agricultural land while maintaining its availability for future farmers. Indeed, sustainable agriculture acknowledges natural resources are limited and promotes "equity in resource allocation" across generations (Horrigan et al. 2002, 452).

USDA NRCS is a federal agency that seeks to address a variety of natural resource concerns to support agricultural and natural resource sustainability. NRCS, previously named the Soil Erosion Service (SES) and then the Soil Conservation Service (SCS), has a long history of leading conservation efforts to sustain working landscapes (USDA NRCS n.d.[a].). Hugh Hammond Bennett is considered the "father of Soil Conservation" because, as a surveyor, he 
realized the devastating effects of wind and water erosion on agricultural productivity and its capacity to sustain the rural communities depending on their products (USDA NRCS n.d.[a].). Campaigning for the conservation of soil and water through public speaking and writing, Bennett influenced the establishment of soil erosion experiment stations and, under President Franklin D. Roosevelt, became the first Chief of the SES in 1933 (USDA NRCS n.d.[a].). Yet, it was the period known as the Dust Bowl, and particularly a large dust storm in 1934, that drove home the severity of the problem (USDA NRCS n.d.[a].). As Bennett took the floor at a Congressional hearing, the dust clouds were just passing over Washington, D.C., and he used that opportunity to further illustrate the problem.

Because of Bennett's advocacy and the ample evidence of need provided across the plains states, the Soil Conservation Act (SCA) was passed in 1935, authorizing the SCS as a permanent agency of the USDA (USDA NRCS n.d.[a].). Congress agreed that "the wastage of soil and moisture resources on farm, grazing, and forest lands... is a menace to the national welfare" (USDA NRCS n.d.[a].). Therefore, the SCS began to develop conservation plans at the individual farm and areawide scales. Watershed planning became an important element to the SCS mission in the 1940s and 1950s because Bennett recognized the necessity of addressing flood control along with soil and water conservation at this scale as well (Stubbs 2010b, 8; USDA NRCS n.d.[a].). During the 1960s, SCS initiated the Resource Conservation and Development (RC\&D) program which allowed the agency to work with landowners at an even larger geographic scope than watersheds to create economic development plans (USDA NRCS n.d.[a].).

The Food Security Act, or Farm Bill, is an omnibus law that regulates various agricultural programs and, since the Dust Bowl, its amendments have largely focused on support for key 
commodity crops such as corn and soybeans (Johnson and Monke 2017, 1). The 1985

amendment was a watershed moment because it included additional conservation provisions that led to a "rapid evolution of the conservation agenda" (Zinn 2005, 1), adding conservation compliance and wetland compliance to the technical responsibilities of the agency (Stubbs 2010b, 26). Indeed, throughout the years, the agency's role has continued to expand in order to address a wide variety of natural resource concerns that promote overall sustainability. Finally, in 1994, the SCS was renamed NRCS due to changing national priorities that reorganized USDA (Stubbs 2010b, 27).

To protect farmlands and the natural ecosystems within which they are situated, NRCS provides financial and technical assistance to private landowners, local Conservation Districts, tribes, and other entities to develop conservation plans and administer conservation programs and activities (USDA NRCS 2014, 600-A.1). The balance between natural resources and the importance of agricultural production to local communities is central to the NRCS mission: "We achieve this [conservation] by providing voluntary assistance through strong partnerships with private landowners, managers, and communities to protect, restore, and enhance the lands and waters upon which people and the environment depend" (USDA NRCS 2013). To that end, NRCS has developed the scientific expertise necessary to design interventions that conserve natural resources so that they support the needs of the entire ecosystem-including the need for agricultural production.

NRCS defines natural resources as soil, water, air, plants, animals, energy, and human considerations [SWAPAE+H] (USDA NRCS 2014, 600-A.2). Conservation plans outline the implementation of several individual conservation practices meant to sustain both on-farm resources and the surrounding ecosystem. These plans are a "record of decisions and supporting 
information for treatment of a unit of land meeting planning criteria for one or more identified natural resource concerns as a result of the planning process" (USDA NRCS 2014, 600-A.1). Planning criteria are defined as the desired future condition of a resource that meets a sustainable level of use according to the latest tools and technology (USDA NRCS 2014, 600-A.17).

Conservation planning is the agency's theoretical approach to resource management. It employs a three-phase, nine-step process as illustrated in Figure 1.1 (USDA NRCS 2014, 600B.4). However, despite its numerical organization, this process is iterative rather than linear. According to USDA NRCS (2014), Phase I is Collection and Analysis which includes steps 1-4: (1) identify problems and opportunities; (2) determine objectives; (3) inventory resources; and (4) analyze resource data. Phase II is Decision Support and consists of steps 5-7: (5) formulate alternatives; (6) evaluate alternatives; and (7) make decisions. Lastly, Phase III is Application and Evaluation: (8) implement the plan; and (9) evaluate the plan (600-B.4). NRCS uses the National [Conservation] Planning Procedures Handbook (NPPH) as the guide for developing conservation plans. Results from research studies, such as that which is conducted herein, are direct inputs into Phase I. 


\section{NRCS Planning Process}

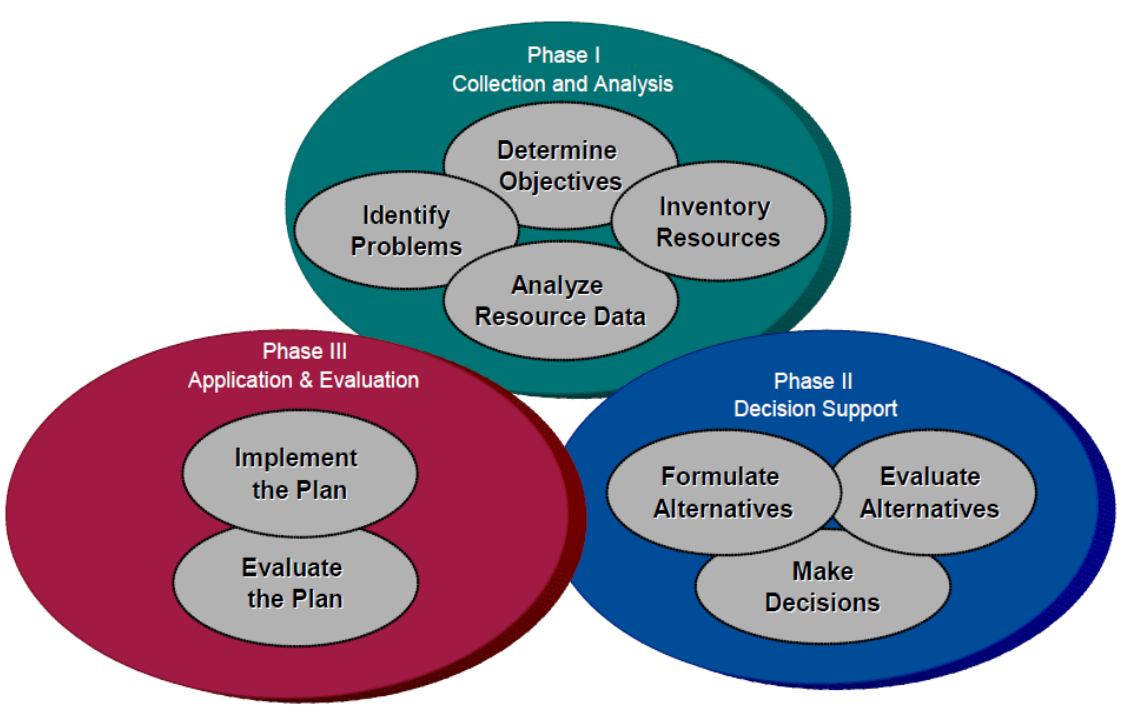

Figure 1.1: NRCS planning process (USDA NRCS 2014, 600-B.4)

Conservation planning focuses on ecological principles and processes (USDA NRCS 2014, 600-A.2) but includes human elements in the equation as well (USDA NRCS 2014, 600A.15). To be sure, "considering the client's facilities, machinery, and economic situation" (USDA NRCS 2014, 600-A.2) are core principles of conservation planning. The objective is to implement natural resource conservation while also improving the landowner's operations and agricultural productivity. When conservation practices are allowed to work in concert with "high quality conservation plans [they] can transform our future by giving landowners and operators step-by-step recommendations they can use to improve wildlife habitat, pest management, soil health, and yields while reducing energy and input costs" (NCPP n.d., 5).

The Farm Bill, the Code of Federal Regulations (CFR) (the "Rule"), program manuals, periodic agency guidance, and state-level leadership all guide NRCS policy concerning the incentives and disincentives for conservation programs. According to Stone (2002), "rules" demand individuals to behave in a particular manner (284), while "inducements" modify actions with incentives or penalties (265). NRCS is not a regulatory organization like the Environmental 
Protection Agency (EPA). Therefore, command and control policies are not utilized by NRCS; rather, voluntary participation is incentivized by providing no-fee technical assistance as well as financial assistance.

The inducement for financial assistance programs is the cost-sharing aspect of the contract between the producer and NRCS. The Environmental Quality Incentives Program (EQIP) is the largest of the Farm Bill programs that provides financial assistance for implementing conservation practices (Stubbs 2010c, 6). Funding for EQIP is mandatory, meaning its allocations are required by law. Nationally, the program received approximately \$1.31 billion in FY 2009 to approximately \$1.75 billion in FY 2012 (Stubbs 2010a, 12). Annual allocations in recent years have been about $\$ 1.5$ billion (USDA 2018, 52). The program assists producers with implementing management, vegetative, and structural conservation practices to address natural resource concerns, with about $60 \%$ of the funding going to cattle farmers (Stubbs 2010a; Cowan and Johnson 2008). In a broader sense, the program is intended to facilitate farmland production, sustainable forestry, and environmental stewardship by helping landowners comply with federal regulations and assisting them with implementation of conservation practices (USDA NRCS 2016, 515-A.1). However, NRCS policy considers all technical assistance provided to a producer before entering into a financial assistance contract, and all technical assistance provided after that contract's expiration, as participation in the CTA program (Stubbs 2010b, 4). Therefore, CTA is an important component of financial assistance programs_-including EQIP.

Indeed, the importance of the CTA program to the NRCS conservation mission cannot be overstated. CTA funds are used in direct support of NRCS staff, training, and other costs related to conservation planning and program delivery (USDA NRCS 2010, 525-A.5). As such, the 
program supports the local service delivery system and is the technical knowledge base for all NRCS programs, as well as other state and local programs (Cox 2007, 141). The CTA program brings technical expertise, conservation planning, and implementation assistance to nearly every county and territory in the nation (Cowan and Johnson 2008; Stubbs 2010a; Stubbs 2010b). NRCS is recognized worldwide for providing natural resource conservation, largely due to the CTA program and the technical assistance it provides (USDA NRCS 2010, 525-A.0). In sum, CTA is foundational to the conservation services offered by NRCS to agricultural producers (USDA NRCS n.d.[b].).

The inducement for technical assistance is no-fee consultation with conservation professionals and access to the latest tools and technology. Technical assistance is vital because it "is funded through virtually every USDA mandatory and discretionary conservation program" (Stubbs 2010b, 2). Technical assistance is provided first and foremost in order to help farmers identify natural resource concerns. Then, once a conservation plan is developed, financial assistance programs can play a supporting role to implementation (USDA NRCS 2010, 525A.1). Thus, the CTA program provides the technical knowledge needed to plan and implement conservation on the ground (Cox 2007, 141). The program utilizes science-based technology to assist farmers in implementing conservation without regard to financial assistance programs (USDA NRCS 2010, 525-A.1).

However, demands on human and financial capital, coupled with limited technological capacities and an expanded list of natural resource concerns, have subjected technical assistance funding to ongoing debate in Congress (Stubbs 2010b, 1). In fact, Cox (2007) claims the infrastructure for technical assistance is unraveling altogether (134). While mandatory programs (e.g., EQIP) do receive some technical assistance funds, discretionary funds continue to be the 
primary source of CTA funding (Stubbs 2010b, 4). This means the CTA budget is subject to revenue allocations from Congress each year (Cowan and Johnson 2008, 3). Conservation Operations (CO) is the biggest discretionary account and provides the most funding to the CTA program (Stubbs 2010b, 3).

Nationally, the CTA program received approximately \$675 million in fiscal year 2007 and about $\$ 750$ million in 2010 for implementation (Stubbs 2010b, 3). Since then, funding allocations have remained relatively flat (USDA 2018, 52). Funding for mandatory conservation programs is currently five times the amount allocated to discretionary programs (Stubbs 2014, 4). Furthermore, as seen in Figure 1.2, funding for technical assistance remained relatively constant between 1985 and 2005, while support for financial assistance nearly tripled (Stubbs 2010b; Cox 2007).

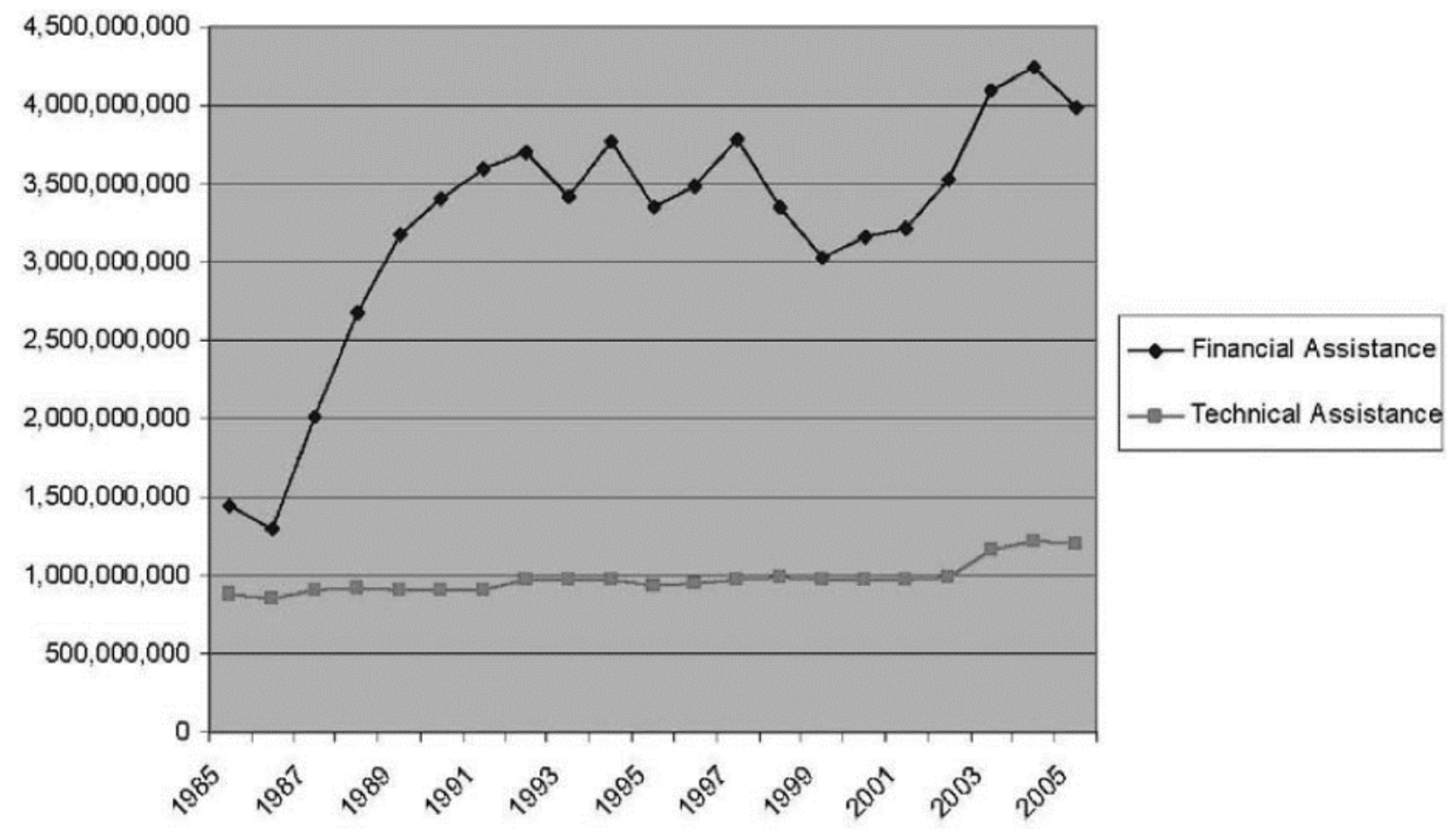

Figure 1.2: Trends in funding $(\operatorname{Cox} 2007,135)$ 
The shift in focus from techncial assistance programs to financial assistance programs is reflected in conservation policy. Environmental interests had greater influence on agricultural policy in the 1996 Farm Bill and, ultimately, this resulted in the creation of the EQIP program (Cox 2007, 118). These trends continued beyond 1996 and have produced increased funding levels and generated new programs that address additional natural resource concerns (Zinn 2005, 1), thus expanding the Farm Bill in its depth and breadth (Johnson and Monke 2017, 1). To be sure, this shift in conservation policy is the most salient in the conservation arena since the 1930s (Cox 2007, 130). Naturally, these federal decisions trickle down to the state level and CTA expenditures in West Virginia have also decreased in recent years (USDA NRCS 2017). Congress continues to discuss technical assistance while many interest groups call for addtional support—but given current budget restraints, an increase in funding seems unlikely (Stubbs 2010b, 23).

These changes in policy have a direct impact on natural resources and agricultural producers. Some view the lack of technical assistance funding as the biggest barrier to implementation of conservation practices and participation in other programs (Stubbs 2010b, 1). Indeed, not enough attention has been given to the low cost of implementing conservation practices through technical assistance and education rather than financial assistance (Cox 2007, 136). Increasing demands on time and resources has required conservation agencies to seek new ways to improve services and business operations (Stubbs 2010b, 20). In effect, the CTA program must find new ways to do more with less. This is vital because, ultimately, "by allowing our technical infrastructure to fray, we are not only erecting a barrier to ecological integrity and economic resilience of US farmland, we are missing a major opportunity for cost-effective and lasting change" (Cox 2007, 135). Therefore, given the current status of funding levels and the 
mission-critical nature of voluntary participation in the CTA program, it is imperative that participation rates and barriers to participation become central to NRCS program evaluation.

Participation in the CTA program is defined as the voluntary application of conservation systems consisting of one or more conservation practices on private land (Stubbs 2010a; Cowan and Johnson 2008). To that end, organizational capacity requires funding for NRCS staff costs including, but not limited to: salary and benefits, education and training, and other activities related to providing conservation planning and technical assistance (USDA NRCS 2010, 525A.5). In combination, increased voluntary participation and organizational capacity to deliver technical assistance enable achievement of a key component of the NRCS mission- to get conservation on the ground for America's farmlands.

\subsubsection{CTA Participation as a Community Development Activity}

NRCS has long recognized the social aspect of its programming: NRCS helps farmers "to operate in an ecologically sustainable, economically sound and socially acceptable manner within the client's social values" (USDA NRCS 2014, 600-A.1). To be sure, SES/SCS/NRCS created "a new kind of professional — the soil conservationist - a man trained to bring combined skills of all the physical and biological sciences. Backing up this brand of technician [are] small groups of specialists in engineering, wildlife management, soils, the plant sciences, economics and others, as needed, for training, advice, and consultation on special problems" (Sampson 1985 , 18). However, working directly with farmers to implement voluntary conservation practices, these conservationists require yet another type of expertise-public engagement and community education. Through technical assistance, NRCS staff must persuade farmers to voluntarily participate in conservation planning and implementation in order to achieve conservation goals — with or without financial assistance. 
Through locally-led conservation and other voluntary processes, NRCS uses public engagement to "effectively help people conserve soil, water and other resources" (USDA NRCS 2014, 600-F.1). The voluntary nature of this work relies heavily on relationships and social networks, the very same characteristics of other community development practices. Indeed, as Stone and Nyaupane (2014) argue, there must be a "sense of community in conservation projects" for them to be effective (18). Therefore, NRCS staff must understand community development in order to succeed in natural resource management through the voluntary, no-fee, no financial assistance CTA program.

EQIP's Focused Conservation Approach (FCA) in West Virginia is of special interest in this regard because it integrates participatory planning with conservation planning through Local Work Groups (LWGs) to "solve high priority resource challenges in a strategic, effective, and efficient business manner" (USDA NRCS n.d.[c].). FCA LWGs are comprised of individuals, organizations, Conservation Districts, and other local agency representatives who advise NRCS on program implementation (USDA NRCS 2014, 600-A.14) and assist in developing project proposals that are competitively chosen to receive EQIP funds each fiscal year. LWGs are salient because social groups have proven to be central to increasing farmer participation in conservation programs (Arbuckle et al. 2018; Prokopy et al. 2014; Reimer et al. 2014; Reimer and Prokopy 2014; Baumgart-Getz et al. 2012; Prokopy et al. 2008; Knowler and Bradshaw 2007; Pannell et al. 2006; Mathijs 2003). However, this approach is not used beyond the EQIP program.

Research has shown there are few, if any, universal factors that influence farmer adoption of conservation practices (Arbuckle et al. 2018; Reimer et al. 2014; Baumgart-Getz et al. 2012; Prokopy et al. 2008; Knowler and Bradshaw 2007). However, factors that are often positively 
associated with implementation include, but are not limited to: farm size, education level, income and capital, access to information, environmental attitudes and awareness, and social networks (Arbuckle et al. 2018; Baumgart-Getz et al. 2012; Prokopy et al. 2008). While no-fee technical assistance can overcome limitations to knowledge about the value of conservation practices; the cost of implementation is often a barrier for many (Perry-Hill and Prokopy 2014, 277). Even if a long-term cost benefit can be demonstrated, the up-front costs can be prohibitive- - for some even with financial assistance programs. More fundamental, however, are the social values and cultural beliefs relevant to conservation as a goal and attitudes toward the practices themselves. These dispositions can be strong barriers that can be influenced through social networks to motivate participation.

Recent studies show that social networks are central to the decision to participate in conservation programs (Arbuckle et al. 2018; Prokopy et al. 2014; Reimer et al. 2014; Reimer and Prokopy 2014; Baumgart-Getz et al. 2012; Prokopy et al. 2008; Knowler and Bradshaw 2007; Pannell et al. 2006; Mathijs 2003). This is because, "the people farmers trust and talk to, as well as the message that they hear from those people - play key roles in the adoption process" (Prokopy et al. 2014, 3). In fact, motivations for adopting conservation practices are influenced so much by peers that it is recognized as being a potentially universal causal factor (Knowler and Bradshaw 2007, 45); albeit one that needs further research (Reimer et al. 2014; Knowler and Bradshaw 2007). Specifically, more research is needed to understand how these social networks function and how they might be used to increase conservation practice adoption (Reimer et al. 2014, 59A). If this argument holds true, it would follow that the capacity to understand and work with social networks to promote social values and cultural beliefs that motivate participation in 
conservation activities would need to be integrated into the CTA program delivery model. This expansion would require new types of NRCS staff training and development.

However, even if the demand for conservation technical assistance increases, NRCS funding and personnel limitations are a secondary constraint to participation. Research suggests that the accessibility of expert advice may help to increase the adoption of conservation practices (Lambert et al. 2006, 28). Unfortunately, NRCS staff decreased seven percent (7\%) between 1985 and 2005, despite the large increase in financial incentive conservation programs (Cox 2007, 134). Thus, organizational capacity may be insufficient to meet greater demand. Indeed, “time is clearly a limiting factor for conservation personnel" (Perry-Hill and Prokopy 2014, 277). To be sure, based on this information, it is more than likely that additional CTA funding will be necessary to increase NRCS staffing levels in order to provide adequate technical assistance.

However, another community development practice becomes relevant here as wellcollaborative coproduction. Coproduction can be loosely defined as organizational and individual participation in the provision of public goods and services (Bovaird 2007; Brudney and England 1983; Whitaker 1980). It also brings together multiple stakeholders with government agencies to engage in decision-making (Ansell and Cash 2007, 543); similar to the EQIP FCA LWGs. Potential coproducers include, but are not limited to: clients, community volunteers, nongovernmental organizations (NGOs), government agencies, and others (Alford 2002, 32). Because this alternative requires coordinated collaboration between service providers and users_-public participation is fundamental to its success (Stout 2019a). To be sure, the results of this approach extend beyond consumers merely benefiting from public services and include interactions where a diverse set of values are exchanged (Alford 2002, 51). 
NRCS does indeed work alongside a network of non-federal organizations and individuals to increase overall capacity for technical assistance. Examples of these institutions include, but are not limited to: state agencies and local governments, for-profit and non-profit businesses, universities, Conservation Districts, and others (Stubbs 2010b, 10). These partnerships are increasingly important because, as conservation technologies become more complex, technical assistance becomes even more challenging (Lambert et al. 2006, 28). Unfortunately, Technical Service Providers (TSPs) fell in number from over 2,100 to below 1,200 nationally between 2004 and 2009 (Stubbs 2010b, 15).

With internal and external technical assistance resources in decline, there is one other coproduction practice that could be drawn upon—-peer-to-peer practices. In other countries around the world, agricultural extension programs have worked in tandem with farmer-to-farmer networks to expand technical assistance while promoting soil and water conservation practices under the methodological umbrella of agroecology (Holt-Giménez 2006). Agroecology focuses on both production and the "ecological sustainability of the production system" (Altieri 1995, 4) — a principle that Hugh Hammond Bennett identified as important nearly three quarters of a century ago (USDA NRCS 2014, 600-A.2). Deemed the science of sustainable agriculture, agroecology is "based on the understanding of ecosystem functions in agriculture" (HoltGiménez 2006, 175).

Farmer-to-farmer methods are well-suited to forward this principle. It has been noted across the globe that traditional top-down extension methods of transferring information are hamstrung by personnel limitations and institutional budgets constraints (Sosa et al. 2013, 68); and have been "largely unsuccessful at solving our most pressing environmental problems" (Reimer et al. 2014, 60A). Farmer-to-farmer methods allow conservation-oriented and 
experienced farmers to share their techniques with one another (Enshayan et al. 1992, 128). Moreover, this approach has the ability to reach farther and faster than traditional technical assistance by focusing more on social processes rather than specific practices (Sosa et al. 2013, 68). These are the very same social network processes the literature has shown to be central to farmer participation in conservation programs (Arbuckle et al. 2018; Prokopy et al. 2014; Reimer et al. 2014; Reimer and Prokopy 2014; Baumgart-Getz et al. 2012; Prokopy et al. 2008; Knowler and Bradshaw 2007; Pannell et al. 2006; Mathijs 2003).

Taken together, community development practices of social network development, coproduction, and farmer-to-farmer methods can all figure into CTA participation, in particular the elements that are socially, culturally, or value-based.

\subsection{Research Objectives}

In sum, the vast amount of agricultural land in America, and our dependence upon that land for collective survival and local community capacity, requires good stewardship. Indeed, natural resource conservation is critical to food and fiber production, ecosystem health, and rural economic strength - especially in West Virginia where steep terrain increases the potential for non-point source pollution. NRCS is a goverment agency that seeks to accomplish these conservation goals through both voluntary and financially incentivized private efforts. Moreover, the NRCS CTA program is central to implementing voluntary conservation across the whole of the United States. But since recent funding allocations for CTA have remained relatively static over time, NRCS must show the need for additional funding to Congress while simultaneously becoming more effective in service delivery. Toward that end, alternative practices drawn from the field of community development should be explored. Specifically, engaging in collaborative coproduction of technical assistance with conservation partners is one alternative. In addition, 
understanding the relationship between the cultural beliefs of farmers and their motivation to engage in conservation practices, along with the use of social networks through farmer-to-farmer methods to influence those attitudes (i.e., coproduction), may be useful to increase the effectiveness of the CTA program.

Because "understanding motivations for (as well as barriers to) participation in voluntary [conservation] programs is important for the design of future policy and effective outreach" (Reimer and Prokopy 2014, 318), a goal of this inquiry is to understand variable farmer motivations and develop recommendations that are flexible and easy to implement and sustain. Toward this end, the specific objectives of this study are to: (1) determine the factors that influence farmers' decisions to participate in the CTA program; (2) consider NRCS's organizational capacity to deliver the CTA program; and (3) describe how NRCS might increase participation in the CTA program. The results should prove useful to researchers, practitioners, and communities seeking to increase both agricultural productivity and ecological integrityultimately benefiting agriculture, local economies, rural communities, and natural resource sustainability in West Virginia.

\subsubsection{Organization of the Dissertation}

This chapter argued for the necessity of soil and water conservation practices on agricultural lands and how that relates to farmer participation in the CTA program. In Chapter 2, a theory of change to increase participation in voluntary conservation practices through CTA program revisions is proposed, drawing from the Asset-Based Community Development (ABCD) approach (Kretzmann and McKnight 1993) and the Community Capitals Framework (CCF) (Flora and Flora 2013). These revisions could include more funding for the CTA program, increased training in participatory community development practices, and the usage of 
coproduction in the form of organizational partnerships and farmer-to-farmer methods. In Chapter 3, a research design for collecting and analyzing data to test causal hypotheses derived from this theory of change is described. Chapter 4 presents the research findings. Lastly, Chapter 5 discusses these results and draws conclusions that inform recommendations regarding CTA program funding levels as well as recommendations for future NRCS strategies that may increase farmer participation in voluntary conservation practices, particularly in light of current NRCS organizational capacity limitations. Ideas for future research are also proposed. 


\section{Chapter 2: Literature Review}

"The conservation of natural resources is the fundamental problem. Unless we solve that problem, it will avail us little to solve all others."

Theodore Roosevelt

In consideration of the constraints embedded in the contemporary policy and funding context, to achieve its conservation goals given organizational capacity restraints, the CTA program may require additional implementation strategies. This chapter considers relevant research in both natural resource management and community development theory and practice to understand and address this challenge. Using these literatures, a theory of change for increasing CTA program participation is developed.

\subsection{The Theoretical Context}

Natural resource management is a continuously evolving field where managers "strive to balance natural resource issues with economic and social needs" (USDA NRCS 2014, 600-A.3). Community development is a field of study and practice that engages all aspects of human sustainability—social, economic, and environmental. While natural resource management informs the environmental aspects, economic development is a process whereby individuals and organizations are assisted in establishing and building economic capital to better their own quality of life as well as that of the community's (Anglin 2011, 1). Economic development relies heavily on community development, which builds social, human, and cultural capacities to leverage political will and financial capacity to address both the natural and built environments (Phillips and Pittman 2015, 13). Thus, a combination of these disciplinary literatures could contribute to a more robust theory of change for increasing conservation efforts.

Public participation is central to NRCS resource management in identifying and recording resource concerns, practice implementation, and outcome assessment (USDA NRCS 
2010, 525-A.1). In addition, field experience has shown that community-wide management of natural resources is effective at improving natural resources as well as community health (Gutierrez-Montes et al. 2009, 220). Because communities have the most interest and familiarity with their natural resource concerns, inviting input and feedback from a wide range of local individuals, groups, stakeholders, organizations, Tribes, and others is an essential element to locally-led conservation (USDA NRCS 2010, 525-A.3). Because NRCS programs are voluntary and target private land and local communities, inducements to incentivize participation are integral to the accomplishment of its agricultural and natural resource management mission (USDA NRCS 2013). Furthermore, not all NRCS programs offer financial incentives for doing so; the no-fee CTA program is a case in point. Therefore, understanding the drivers and barriers to participation in no-fee technical assistance services is critical to achieving the NRCS mission as well as the capacity of the local communities they support. This requires turning to theories of public engagement found in the community development literature.

\subsection{A Holistic Approach to Community Development}

Asset Based Community Development (ABCD) is a theoretical approach to building community capacity and relies on three principles of positive community change (Kretzmann and McKnight 1993, 9). The first is that inquiry is asset-based and focuses on strengths present within the community—not on what is lacking. Next, action is internally-focused, meaning agenda setting and problem solving are decisions ultimately afforded to the local residents, groups, and organizations, rather than external interventionists. Third, the entire process of inquiry, planning, and action is relationship-driven and requires continual relationship building among community members and with external program representatives. 
$\mathrm{ABCD}$ turns the traditional needs-based approach to community development on its head. The approach "rests on the principle that the recognition of strengths, gifts, talents, and assets of individuals and communities is more likely to inspire positive action for change than an exclusive focus on needs and problems" (Mathie and Cunningham 2002, 2). In doing so, the approach capitalizes on the opportunities in a given place and the strengths and talents of local people and their social networks in order to build community capacity. The founders of ABCD discovered that more effective community development was occurring where local assets were understood, identified, and leveraged (Kretzmann and McKnight 1993, 5). Moreover, once the assets, skills, and abilities of the local community were discovered and connected in meaningful ways - their positive influence increased exponentially. Thus, $\mathrm{ABCD}$ can be an avenue for increasing community capacity, act as a catalyst for synergy and, ultimately, be the driver toward overall social, economic, and environmental sustainability.

Community capacity is the sum of the physical characteristics of a place and the individual abilities of its people to work collaboratively to solve problems and maintain the welfare of the community (Chaskin et al. 2001, 7). Kretzmann and McKnight (1993) similarly define community assets as individual parts working together to resolve problems and better the community as a whole (5). While most of the assets described by ABCD fall into social, human, and organizational categories, Kretzmann and McKnight (1993) do refer to physical and other assets as well. However, to augment ABCD's deficiencies, the Community Capitals Framework (CCF) is useful. Flora and Flora (2013) contend there are seven "community capitals:" (1) natural; (2) cultural; (3) human; (4) social; (5) political; (6) financial; and (7) built (10). Kretzmann and McKnight (1993) include formal organizations as a community asset with their approach to community development (6). They contend institutions - private businesses, profit 
and non-profit organizations, public agencies, and such — are essential components to building community capacity (Kretzmann and McKnight 1993, 6). Therefore, Stout (2019b) adds an eighth capital to the CCF framework, organizational capital (Figure 2.1). Together, these eight community capitals create a holistic framework within which natural resource management, community development, and economic development theory can be integrated.

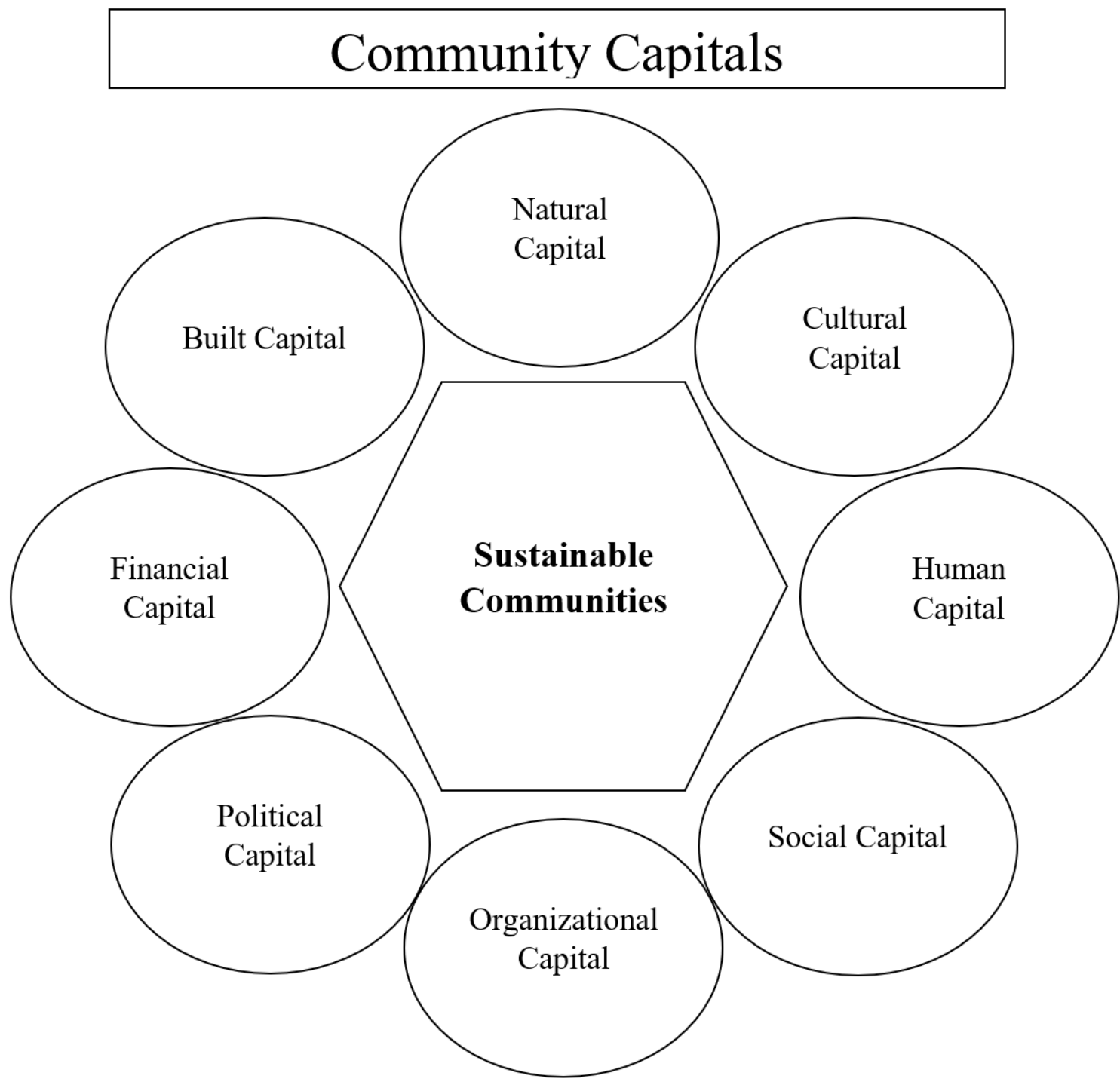

Figure 2.1: CCF (adapted from Flora et al. n.d. and Kretzmann and McKnight 1993) 
Jacobs (2007) considers capital as a kind of resource with the capacity to beget further resources. Simply put, community capitals are various local assets that can be "invested, saved or used up" (Jacobs 2007). When material resources are used up rather than conserved, they detract from the sustainability of the community. Similarly, when social and human assets are not utilized they deteriorate as well (Emery et al. 2006, 1). Conversely, when investments in these resources are made, they transform into available capital, such as political and financial capital, for the community (Flora and Flora 2013, 10).

In addition to providing a meaningful way to categorize assets, the CCF was developed "as a useful and integrative approach to analyze and understand dynamics within rural communities" (Gutierrez-Montes et al. 2009, 221). Due to the interconnectedness of the community capitals, a change in one can influence the status of another (Emery et al. 2006, 5). Indeed, the CCF "offers a way to analyze community and economic development efforts from a systems perspective by identifying the assets in each capital (stock), the types of capital invested (flow), the interaction among capitals, and the resulting impact across capitals" (Emery and Flora 2006, 20). ABCD, in turn, describes the principles that undergird capacity building practices that are proven to achieve positive results.

By applying these causal models to the research problem, propositions can be developed and tested to better understand why farmers choose to participate, or not participate, in the NRCS CTA program. Moreover, findings from such research could inform strategies to increase participation in the CTA program, while also considering NRCS organizational capacity. Toward that end, each capital must be defined and understood in light of the research problem before considering their potential interrelationships. Therefore, the following subsections define each 
community capital and explore their relevance to farmer participation in the NRCS CTA program.

\subsubsection{Natural Capital}

Natural resources can be thought of as a form of capital that has the potential for investment, savings, or utilization (Jacobs 2007). A few examples of these assets are: soil, bodies of water, air quality, plants, animals, farms, forests, parks, and other natural amenities such as climate and scenery (Emery et al. 2006; Jacobs 2007). Farmlands are comprised of a variety of these natural resources. Unfortunately, "humans often have sought to use natural capital to build other forms of capital" (Flora and Flora 2013, 49). This is particularly true in the Appalachian region, where the exchange of natural capital for financial capital is often controlled by out-ofstate entities, which typically results in a decrease of both types of capital in rural communities (Flora and Flora 2013, 30). Episodes like the drastic overconsumption of high elevation subalpine coniferous forests in West Virginia at the turn of the nineteenth century show the results of use without savings or investment. Thus, positive economic outcomes must be balanced with the stewardship of natural resources to sustain West Virginia's agricultural lands.

NRCS utilizes quantitative and qualitative assessments to identify natural resource concerns and determine whether conservation practices are needed to help them meet a sustainable level of use (i.e., planning criteria). Examples of these assessments include, but are not limited to: the Revised Universal Soil Loss Equation (RUSLE), the Stream Visual Assessment Protocol (SVAP), the Pasture Condition Score sheet (PCS), and the Wildlife Habitat Suitability Index (WHSI). Conservation Practice Standards (CPS) are regularly updated to reflect the most recent conservation practice science and technology. Each standard can be found in Section IV of the Electronic Field Office Technical Guide [eFOTG] (USDA NRCS n.d.[d].). 
These practice standards are either management, vegetative, or structural techniques (USDA NRCS 2014, 600-A.10). NRCS practices that fall within the management and vegetative categories are investments in natural capital.

For example, an erosion resource concern could be addressed by a Conservation Crop Rotation. This management practice is a planned rotation of various crops grown in the same field over time (USDA NRCS n.d.[d].). Nutrient Management specifies the "amount, source, placement and timing of plant nutrients and soil amendments" to maximize nutrient uptake by crops and forages while minimizing nutrient loss and overload to ground and surface waters (USDA NRCS n.d.[d].). Prescribed Grazing is also a management technique that times the harvest of forages based on site production, plant growth rates, and the physiological needs of the plants and animals on-site in order to maintain the desired species composition and improve overall plant health and vigor (USDA NRCS n.d.[d].). Other management practices include, but are not limited to: Brush Management, Integrated Pest Management, Residue and Tillage Management, and Upland and Wetland Wildlife Habitat and Management.

There are many vegetative practices in the NRCS toolbox as well. A Forage and Biomass Planting can be implemented to address an inadequate feed and forage natural resource concern for animals. Critical Area Planting is another vegetative technique used to stabilize highly erodible areas that have difficulty establishing vegetation (USDA NRCS n.d.[d].). Cover Crop is a vegetative practice intended to reduce erosion and compaction, increase organic matter, fix nitrogen, suppress weeds, reduce particulate emissions, and more (USDA NRCS n.d.[d].). Other vegetative practices include, but are not limited to: Filter Strip, Riparian Herbaceous and Riparian Forest Cover, Tree/Shrub Establishment, Hedgrow Planting, Windbreak/Shelterbelt Establishment, and Vegetative Barriers. 
The farmer-to-farmer methodology promotes agroecology (Holt-Giménez 2006), for which the goals are the same as NRCS conservation practices-ecological and agricultural sustainability. In fact, Sosa et al. (2013) illustrates how agroecology employs management conservation practices such as minimum tillage (129) and vegetative conservation practices such as cover crops (26) to address natural resource concerns. Moreover, Holt-Giménez (2006) discusses how farmer-to-farmer methods use crop rotations that improve soil health, diversify production, and increase yields (9). To be sure, agroecological practices have shown an ability to improve the natural resource base by restoring the fertility of degraded soils (Sosa et al. 2013, 28).

In sum, use of any one of the management or vegetative practices described is an investment in natural capital and represents CTA participation, which has implications for the theory of change.

\subsubsection{Built Capital}

Built capital refers to improvements on the land that sustain human beings and the growth of their communities. Built capital includes, but is not limited to: roads, power plants, parks, sewer systems, water facilities, structures which support technology, and buildings (Emery et al. 2006; Jacobs 2007). Developing the built capital within a community provides more recreational and business opportunities, better transportation, improved amenities and facilities, affordable housing, and jobs. Investing in infrastructure improvements supports these built capitals by increasing their carrying capacity.

While not included in these particular descriptions, built capital also includes landscape design used in parks and other open spaces. As applied to farmland, structural conservation practices such as a Terrace to reduce erosion, a Pond to improve water quality and quantity, a 
High Tunnel System to extend the growing season and improve plant and soil health, or a Waste Storage Facility for cattle operations, are all examples of built capital. Waste Storage Facilities allow manure to be stockpiled and then applied as fertilizer in accordance with a Nutrient Management Plan during the growing season-which reduces nutrient losses to ground and surface waters. Other similar practices include, but are not limited to: Dam, Dike, Fence, Grassed Waterway, Heavy Use Area Protection, Livestock Pipeline, Watering Facility (i.e., troughs), and many more.

Moreover, the agroecological practices associated with farmer-to-farmer methods integrate these kinds of built capital as well — such as contour farming and gully control structures (Sosa et al. 2013, 121). Furthermore, in Mesoamerica where mountainous topography and soil and water erosion are limiting factors to production, "conservation practices such as ditches and terraces are often the first measures to be implemented in the transition from conventional to sustainable agriculture" (Holt-Giménez 2006, 92).

These structural conservation practices are investments in built capital that ultimately benefit natural capital. Therefore, these practices also represent CTA participation and have relevance to the theory of change.

\subsubsection{Cultural Capital}

Cultural capital has to do with shared values, along with an understanding and celebration of shared heritage (Flora et al., n.d.). Local traditions, recurring festivals, and shared occupations are examples of this asset (Jacobs 2007). "Cultural capital includes the values and symbols reflected in clothing, music, machines, art, language, and ways of knowing and behaving" (Flora et al. 2016, 78). Chaskin et al. (2001) contend there are two facets of community culture: (1) physical boundaries, and (2) shared attributes such as language and/or customs (8). According to 
Jacobs (2007), cultural capital is similar to a common attitude. Together, these features establish community identity. Failing to invest in the community's cultural capital may result in the decline of multi-generational trades as well as lost economic opportunities.

Cultural capital shapes who community members are influenced by and receptive to (Emery et al. 2006, 5), which interacts closely with social and human capitals. An intrapersonal example of cultural capital would be parents handing down their understanding of society, individual roles, and acceptable values and attitudes to their children, which in turn influence their actions (Flora and Flora 2013, 55). There are interpersonal cultural influences as well. Culture is not only handed down generationally, but reinforced by the community context. Several scholars claim that rural residents perceive rural values to be different from urban values (Flora et al. 2016, 74), including the worth of college degrees and technical certifications. This difference in values can lead to mistrust of experts. Similarly, rural values such as "frugality, independence, hard work, patriotism, plus fear [of] outsiders" (Flora et al. 2016, 75) can establish a cultural identity that presents a barrier to conservation practices that are contrary to multi-generational traditions, attitudes, and values.

Rural West Virginian norms such as fear of outsiders and defense of independence (Flora et al. 2016, 75) can generate a general distrust toward government that could create barriers to farmer participation in NRCS programs. Indeed, Oliver (2011) found that organizational trustworthiness played a role in private landowner participation in conservation easement programs (77). West Virginians who perceived government agencies and non-governmental organizations (NGOs) as trustworthy institutions were more likely to enroll. Other studies have similarly found that trust determines the influence experts have on certain aspects of landowner decisions (Pannell et al. 2006, 1420). 
Research has also shown that farmers often appreciate cultural/tidy landscapes (Burton 2012; Burton et al. 2008; Schmitzberger et al. 2005; Ryan et al. 2003). Cultural landscapes are those which have been influenced by anthropogenic activity, effectively becoming "works of art, narratives of culture, and expressions of regional identity" (The Cultural Landscape Foundation n.d.). Studies in Europe have shown incentive-based conservation programs do not induce lasting change from traditional productivist methods found in conventional farming communities (Burton et al. 2008, 16). This is due in part to aesthetics because pro-conservation landscapes appear "messy" while cultural/tidy landscapes are viewed as good farming practices (Burton et al. 2008, 30).

Several studies have found that positive environmental attitudes increase the likelihood of participation in conservation programs (Arbuckle et al. 2018; Prokopy et al. 2014; BaumgartGetz et al. 2012; Ma et al. 2010; Prokopy et al. 2008). Moreover, some farmers are inclined to implement conservation practices because of their desire to be good land stewards (Prokopy et al. 2014; Greiner and Gregg 2011). However, while some research has shown farmer attitudes toward conservation to be improving, there are still many who prefer cultural (or, "tidy") landscapes that do not always align with conservation objectives (Schmitzberger et al. 2005, 287). Thus, "where landscapes contain cultural symbols that are significant for a given social field, aesthetic appreciation becomes closely (inadvertently and subconsciously) tied with the process of social judgement—-determining the cultural position of the owner of the display" (Burton 2012, 54). Therefore, "the most effective means of guaranteeing a lasting attitudinal shift is for that shift—and accompanying environmental behavior — to become embedded in the farming community at a cultural level” (Burton et al. 2008, 18). 
Determining what these intrapersonal and interpersonal cultural attributes might be has direct relevance to the theory of change. There is "a need not just to produce an attitudinal change at the level of individual landowners but [to] create a culturally embedded social change" (de Snoo et al. 2012, 69). Cultural traits could be used to better establish relationships between NRCS and West Virginia farmers. For example, outreach strategies that celebrate aspects of Appalachian heritage could begin to break down the intrapersonal barriers to participation. In the long-term, these participation experiences could increase acceptance of NRCS methods of resource management as the new cultural norm.

However, given the importance of "insider" status in West Virginia, it is more likely that asking trusted community members to promote participation among their peers will be more effective. "Norms can be reinforced through a variety of processes: forming groups, developing a common view of a shared future, forming or reinforcing collective identity, and engaging in collective action" (Flora et al. 2016, 139). Farmer-to-farmer methods support these kinds of investments as agricultural producers often hold a common worldview. Moreover, the farmer-tofarmer culture of solidarity and mutual aid promotes sharing of both knowledge and resources (Holt-Giménez 2006, 112). Indeed, Vanclay and Lawrence (1994) advocate for this kind of shared learning approach because barriers to conservation practice adoption are unlikely once new practices have entered the farming subculture (73). Ultimately, these kinds of investments in cultural capital would be expected to increase participation in the CTA program, and are therefore relevant to the theory of change.

\subsubsection{Human Capital}

Human capital includes the knowledge, skills, and abilities of individual community members (Jacobs 2007). Thus, “investments in people are just as important, if not more 
important, than investments in other community capitals" (Jacobs 2007). Similarly, Kretzmann and McKnight (1993) contend that everyone has unique abilities and that both the person and the community benefit when these gifts are employed (13). Human capital has one of the strongest causal relationship to the other capitals, because people are who get things done in communities (Jacobs 2007). For example, a community can invest vast amounts of time and resources into the land, organizations, buildings, and community finances. Yet, it will all be in vain if no one is interested in, or capable of, managing and maintaining those investments.

It is essential to increase the capacity of the individuals within the community to engage in conservation practices. A general lack of knowledge and exposure to conservation methods can be an intrapersonal barrier to participation (Oliver 2011, 73). Indeed, there may be an absence of knowledge in rural communities that investing in human capital can help alleviate. Prokopy et al. (2014) saw "inadequate on-farm conservation measures on small farms caused by an overall lack of awareness" (2). Therefore, educating West Virginia farmers on the multiple benefits of conservation and how to implement conservation practices is a logical component of a theory of change.

Formal education has historically been a challenge for rural communities because there are few suitable jobs for those who attain higher levels of education (Flora and Flora 2013, 110). This barrier, then, increases the need for building human capital through informal means-a long-held primary function of agricultural extension community education programs (Rivera and Qamar 2003, 7). To be sure, West Virginia Extension Services, along with NRCS personnel and other natural resource professionals, provide informal training and education on the benefits of conservation practices. Therefore, collaboratively planning and promoting educational field days 
and/or workshops would be an investment in human capital toward increasing farmer participation in the CTA program.

Bruening and Martin (1992) found that field demonstrations and local meetings were effective methods of introducing soil and water conservation issues (8). Farmer Field Schools (FFSs) provided informal and practical education to farmers concerning a variety of environmentally friendly production practices as well as Integrated Pest Management (IPM) (Mancini et al. 2008, 17). IPM is "a site-specific combination of pest prevention, pest avoidance, pest monitoring, and pest suppression strategies" (USDA NRCS n.d.[d].). This kind of intensive boot camp style teaching and learning can increase human capital in significant amounts within a short timeframe. For example, Mancini et al. (2008) found this educational effect of FFSs on producer ability to implement IPM on agricultural land in India (16). Similarly, Enshayan et al. (1992) ascertain the benefits of on-farm research and education toward effecting changes in practice (130).

However, these educational methods require significant staff resources to accomplishwhether they are conducted by NRCS or its potential partners (see Organizational Capital). Traditional top-down models of diffusing such knowledge can be expanded to include farmer-tofarmer, farmer-to-university, and farmer-to-consumer transfers of knowledge as central components to education, research, and practice (Enshayan et al. 1992, 127). Farmer-to-farmer methods can be defined as the betterment of agricultural systems toward greater production and sustainability based on the principle that farmers themselves are inherent to both (Sosa et al. 2013, 73). This methodology shares information through farm visits, teaching demonstrations, testimonials, innovation and produce exhibits, stories, artwork and many other strategies (HoltGiménez 2006; Sosa et al. 2013). A basic principle of the farmer-to-farmer methodology is to 
grow human capacities through experimentation with new technologies that, when found successful, are shared and mutually reinforced (Holt-Giménez 2006, 79). Farmer-to-farmer transfers of technology are often underappreciated, but are representations of "a deeper, culturally embedded exchange in which knowledge is generated and shared" (Holt-Giménez 2006, 78). Indeed, producers who have attended regional farmer-to-farmer workshops claim the experience assisted them in connecting with peers, as well as learning about how conservation and farm profitably were viable (Enshayan et al. 1992, 129).

While it is clear that investments in human capital are necessary to increase participation in the CTA program and its recommended conservation practices, the theory of change should consider multiple strategies for increasing awareness and delivering training and educational opportunities.

\subsubsection{Social Capital}

Social capital is composed of the relationships that connect individuals within groups and across groups within a community, as well as externally to other communities and organizational resources (Jacobs 2007). Thus, there are two kinds of social capital. The first is closed social capital, or what Putnam (2000) calls bonding social capital (22), which encompasses the relationships that help individuals work well in groups on community projects (Jacobs 2007). The second is open social capital, or bridging social capital (Putnam 2000, 22), which enables the local group to build bridges across differences and between their community and the wider world (Jacobs 2007).

Putnam (1995) defines social capital as elements of "social organization such as networks, norms, and social trust that facilitate coordination and cooperation for mutual benefit" (67). Generating social capital is a process which takes time, yet results in better relationships 
and communication (Flora and Flora 2013, 139). Community leaders need to facilitate and nurture these connections to build strong networks. These networks, then, can become a resource for knowledge, volunteerism, funding, and many other benefits (Jacobs 2007). Social capital has a positive influence on "tasks such as planning, evaluating, mobilizing resources, coordinating activities, and resolving conflicts" (Jacobs 2007). Indeed, peer-to-peer dialogue and support can improve performance and increase capacity (Klerx and Gildemacher n.d., 227). When there is an abundance of social capital, goal setting and decision making are achieved through consensus (Jacobs 2007). Furthermore, social capital connects internal resources to external ones-which may lead to new ideas, new funding opportunities, new collaborations, and other important connections also. Ultimately, social capital is the "glue that make(s) things happen" (Emery et al. 2006, 6).

Social capital is thus critical to collective action of all sorts, including conservation efforts. The influence of social networks on farmer behavior is well-established in the literature (Arbuckle et al. 2018; Prokopy et al. 2014; Reimer et al. 2014; Reimer and Prokopy 2014; Baumgart-Getz et al. 2012; Prokopy et al. 2008; Knowler and Bradshaw 2007; Pannell et al. 2006; Mathijs 2003). Mathijs (2003) developed an empirical model to evaluate countryside stewardship schemes, finding social capital to be an important factor to the adoption of sustainable farming practices (13). Indeed, building social capital is critical to increasing farmer participation in NRCS conservation programs, effectively accomplishing goals, and also to access external resources. This is especially the case for the CTA program since the conservation practices recommended are installed at the producer's expense.

The development of social capital requires interpersonal interactions that build trust and a generalized sense of reciprocity (Putnam 1995). Therefore, Pannell et al. (2006) encourage 
participatory processes to marshal local knowledge, generate better programs, and improve landowner trust in research, development, and outreach (1418). This local focus is vital because "if the messages you send don't address local concerns your outreach campaign will have limited success" (Prokopy et al. 2014, 5). These relational strategies are aligned with the farmer-tofarmer methodology that fosters local people's resourcefulness in solving their own problems, rather than the traditional top-down approaches common to agricultural extension (Sosa et al. 2013, 22).

NRCS is aware of the value of social capital to conservation practices. Specifically, the EQIP program uses LWGs to develop FCA projects and implement conservation practices. Therefore, social capital has key relevance to the theory of change.

\subsubsection{Organizational Capital}

While many organizations_-including businesses, social enterprises, and nonprofitscontribute to community capacity, anchor institutions are of particular importance in community development. Anchor institutions are enduring organizations that are essential to their communities and economies (Maurrasse 2016). Such institutions include, but are not limited to: hospitals, schools, law enforcement agencies, parks and recreation organizations, fire departments, and social service agencies (Kretzmann and McKnight 1993, 8). The involvement of formal institutions in the community and the degree to which they allow the community to influence their decisions for the good of the populace are key ingredients to community development success (Kretzmann and McKnight 1993, 8). Chaskin et al. (2001) takes this a step further and contend inter-organizational collaboration facilitates problem resolution, the distribution of resources, access to outside resources, and the attainment of shared goals (123). 
However, there are also barriers and constraints to institutional assets within community development. Each community is unique in its composition and setting. There may be more institutions present in, or within reasonable distance to, some rural communities than in others. In fact, there are some communities that can be considered "institution-rich" (Kretzmann and McKnight 1993), while "even the most devastated community is the site of at least some business activity, along with a combination of public and nonprofit institutions" (171). Yet, while the same program may be offered to both "institution-rich" and "institution-poor" communities, the former could logically see more participation than the latter. It follows that there is a potential causal relationship between easily accessible organizational capital and program participation, therefore organizational capital is relevant to the theory of change.

Communities that are conservation institution-rich have access to organizations such as NRCS Service Centers, Conservation Districts/West Virginia Conservation Agency (CDs/WVCA), the West Virginia Department of Environmental Protection (WV DEP), the West Virginia Department of Agriculture (WVDA), West Virginia University (WVU) Extension Service, and the West Virginia Farm Bureau (WVFB). There are also non-profit organizations, such as the West Virginia Land Trust (WVLT), the West Virginia Chapter of the Nature Conservancy (WV TNC), and the West Virginia Food and Farm Coalition (WV FFC) — a nonprofit policy advocacy and member-serving organization. These institutions have staff trained in the fields of agriculture, conservation, and policy who can bring about greater awareness, provide technical assistance, and inform farmers about conservation programs and opportunities. They can also apply for grant funding in support of conservation projects, and facilitate volunteerism for their implementation. NRCS recognized the importance of locally-led 
conservation early on, and has since established and maintained partnerships with local Conservation Districts nationwide.

However, personnel within these other organizations can also be a barrier to program participation. If there are insufficient staff to complete outreach, education, workshops, technical assistance, and program administration, then program participation may still suffer. Referring back to the discussions in Cultural Capital, Human Capital, and Social Capital, "the development literature has often described 'farmer to farmer' as an innovative and cost-effective method of transferring sustainable agricultural technologies" (Holt-Giménez 2006, 78). Shared work is a founding principle of farmer-to-farmer methods in Mesoamerica where farmer groups often help on one member's farm one week and another's the next (Holt-Giménez 2006, 92). Moreover, Holt-Giménez (2006) also explains how teams of "promotores" (i.e., advocate farmers) volunteer two or three times a week to provide technical assistance to other local farmers in sustainable agriculture practices and special projects such as school orchards and garden programs (9). Furthermore, the use of volunteer teams allows for diversity in technical expertise as some are good teachers while others are better at experimenting (Holt-Giménez 2006, 9).

In sum, both physical and internal organizational capital should be considered in the theory of change.

\subsubsection{Political Capital}

Political capital exists when access to power influences the distribution of resources (Jacobs 2007). Common resources associated with such power include public policy decisions, budget allocations, votes, and appointments to offices (Stone 2002, 34). Civic engagement can help to build political capital in a community. At a personal level, individuals can accomplish this by staying connected to their community, voting, and engaging in political discourse (Jacobs 
2007). Community groups can also establish political capital by mobilizing individuals and groups and helping them become active and develop political influence. "Groups such as these have more power, more voice, and more leverage because they act together for a common cause" (Jacobs 2007).

The use of political capital can influence the public policy process. Simply stated, the public policy process begins with the identification of root causes to shared problems which are then given to representatives to find a resolution; an evaluation of alternatives ensues and policy solutions are chosen, followed by budget allocations, program implementation, and assessment (Sabatier 2007, 3). Communities need to build political capital so they can participate in the policy process and be an influential advocate for problem solving in their community. Indeed, government agencies like NRCS rely on community and political support to continue their program operations through budgetary allocations from policy makers.

Because NRCS is dependent upon Congressional budget decisions for CTA program funding, political capital is relevant to the theory of change. Farmers can build and leverage political capital to ensure NRCS is able to provide the assistance they desire.

\subsubsection{Financial Capital}

Financial capital is the simplest community capital to conceptualize; it includes all monies available to support individual and community capacity, the business sector, and community development endeavors (Emery et al. 2006, 6). Money is an easily measurable asset (Jacobs 2007). Examples of financial capital include household income, businesses such as agribusiness or family farm operations, and the ability of individuals, businesses, and governments to access financing. Other financial assets include bonds to help community economic development organizations (CEDs), grant funds, tax breaks, charitable gifts, and the 
like (Jacobs 2007). Ultimately, communities rely on financial capital for investments in all other community capitals and overall sustainability (Jacobs 2007).

Setting aside the issue of NRCS funding levels (see Organizational and Political Capitals), financial capital is an important element of the research problem because implementation of conservation practices can be an expensive endeavor. These economic considerations are the "keys to successful conservation planning" (USDA NRCS 2014, 600B.12) and are vital to increasing farmer participation in the no-fee, no financial assistance CTA program. If these alternatives are not considered feasible or profitable - they are not likely to be adopted because:

Each system is characterized by distinct production functions and soil conservation functions, and each generates a different optimal path. From the household's perspective, the problem is whether returns under the optimal path of the new, more conserving system are sufficiently greater than returns under the optimal path of the current, more degrading system [to] justify the cost of switching. (Lutz et al. 1994, 277)

Zhou et al. (2009) did find that many (but not all) practices such as Grassed Waterways, Filter Strips, and Terraces had net positive returns in the long run (321). But when these alternatives have delayed economic benefits, certain insecurities in land tenure may become a barrier (Lutz et al. 1994, 278). For example, when land is not owned and operated by the same individual—longterm investments may not be as attractive to either the owner or the operator. Moreover, farmers that engage in agriculture during retirement or as a low-sale residential operation-and consequently rely on off-farm income - may not have the necessary financial position to participate as do higher sales operations that are focused on farming for production (Lambert et al. 2006, 10). 
A proper cost-benefit analysis (CBA) would influence whether agricultural producers choose to adopt conservation practices and/or participate in NRCS programs. The intuitive logic is that participation is positively correlated to scenarios where the benefits outweigh the costs. However, the value of lost soil and its fertility should be incorporated into such assessments (Zhou et al. 2009, 314). These kinds of discrete factors (e.g., value of soil, ecosystem services, personal connections to land, etc.) are difficult to quantify and incorporate into CBA, decreasing its usefulness as a singular predictor of participation. To be sure, "profitability of conservation practices is a necessary but not always [a] sufficient condition for their adoption" (Lutz et al. 1994, 287). This is because "farm operators can value land stewardship and the environment apart from any profit motive" (Lambert et al. 2006, 9).

Nonetheless, in sum, because conservation practices can be costly, financial capital is relevant to the theory of change from both NRCS and farmer perspectives.

\subsection{The Theory of Change}

Arbuckle et al. (2018) did a meta-review of the conservation practice adoption literature and found that most studies were lacking in theoretical foundations and theory building. Therefore, based on the relevance of the community capitals to conservation practices and the ultimate goal of increasing CTA program participation, this section proposes a theory of change to be used in researching the motivations and barriers to participation.

A theory of change consists of several anticipated causal relationships that can be hypothesized and explored (Knowlton and Phillips 2012). As demonstrated in the previous section, all capitals in the expanded CCF have direct relevance to the research problem. Furthermore, while there are definitive meanings for each community capital, each one is interrelated with one or more of the others (Jacobs 2007). Studies have shown that investments in 
one or more capitals can initiate a positive rippling effect across many other capitals, causing a spiraling-up phenomenon in which an increase in one community capital causes an increase in the other capitals (Emery and Flora 2006; Guiterrez-Montez 2005). Conversely, the opposite effect is possible as well-declines in a particular capital can cause a downward spiral in others (Jacobs 2007). These causal relationships are the basis on which theoretical models can be built.

Research conducted in Valley County, Nebraska, showed investments in social, human, and financial capital had immediate and positive correlations to most all the other capitals (Emery and Flora 2006, 28). It became clear that by focusing limited resources in a few areas, these investments systematically improved several other capitals. Emery and Flora (2006) contend "that the best entry point to spiraling-up is social capital" (23). The key to lasting change, then, is to allow the investment in certain targeted capitals - particularly social capitalto be compounded by the interrelationships and synergistic influence those investments have across the other different capitals (Guiterrez-Montez 2005, 122). Therefore, the theory of change will seek to describe a spiraling-up effect grounded in social capital to increase CTA program participation by farmers.

The relationships between NRCS and farmers can be further understood through the ABCD principles. First, approaching the capitals from an appreciative stance encourages NRCS to nurture and leverage them toward its conservation mission, rather than seeing them as barriers to success. Second, approaching public engagement from an internal perspective enables NRCS to see individual farmers, and their community networks and groups, as equal partners in generating and realizing a shared conservation mission, rather than attempting to convince them of the benefits of conservation or to adhere to NRCS standards and specifications. Third, a greater awareness of, and new appreciation for, the voluntary nature of Farm Bill programs helps 
NRCS to see the truly relational character of its work-without establishing strong and trusting relationships with agricultural producers, program participation will be hindered.

According to the ABCD approach, the CTA program will be most successful if it engages in activities that are asset-based, community-led, and relationship-driven. These principles are embodied in the current NRCS locally-led philosophy, but also manifest in the farmer-to-farmer methodology described relative to each of the community capitals. Similar to Emery and Flora's (2006) recommendation to start with investments in social capital (23), the farmer-to-farmer approach relies on and builds human assets and relationships already existing in the community, rather than relying solely on external organizational capital. In sum, this aspect of the theory of change suggests that a shared commitment to conservation practices among farmers can be generated through a combination of social network formation and informal education that spirals-up to produce conservation-oriented cultural attitudes.

Furthermore, increased implementation of conservation practices could be achieved through the spiraling-up effect of combining NRCS support to farmer-to-farmer networks in partnership with other organizations, voluntary mutual aid activities and peer lending among farmers, and farmer political advocacy for increased CTA program funding, which will in turn support additional NRCS staffing levels and training in public engagement. From this theory of change, rather than carrying the burden for all of these activities, NRCS could continue to deliver the CTA program as designed, while augmenting it through coproduction strategies.

In sum, NRCS investments in farmers' social and human capital spiral-up to produce increased cultural and financial capital, CTA participation, and political capital, which in turn increase financial and organizational capital within NRCS. Thus, the relational theory of change generates a self-sustaining, ongoing increase in conservation practices. 


\subsubsection{Building the Theoretical Model}

Translating this theory of change into a theoretical model, barriers to program participation must be considered on both sides of the relationship between farmers and NRCS. The dependent variable is participation in the NRCS CTA program, which is represented by investments in: (1) natural capital in the form of management and vegetative conservation practices; and/or (2) built capital in the form of structural conservation practices. On the farmer side of the relationship, the primary independent variables affecting participation are social, human, cultural, and financial capitals. On the NRCS side of the relationship, the secondary independent variables limiting participation are political and financial capital—-determined largely by external sources_-and organizational capital. Figure 2.2 illustrates the interactions between these capitals in a conceptual model of this theory of change.

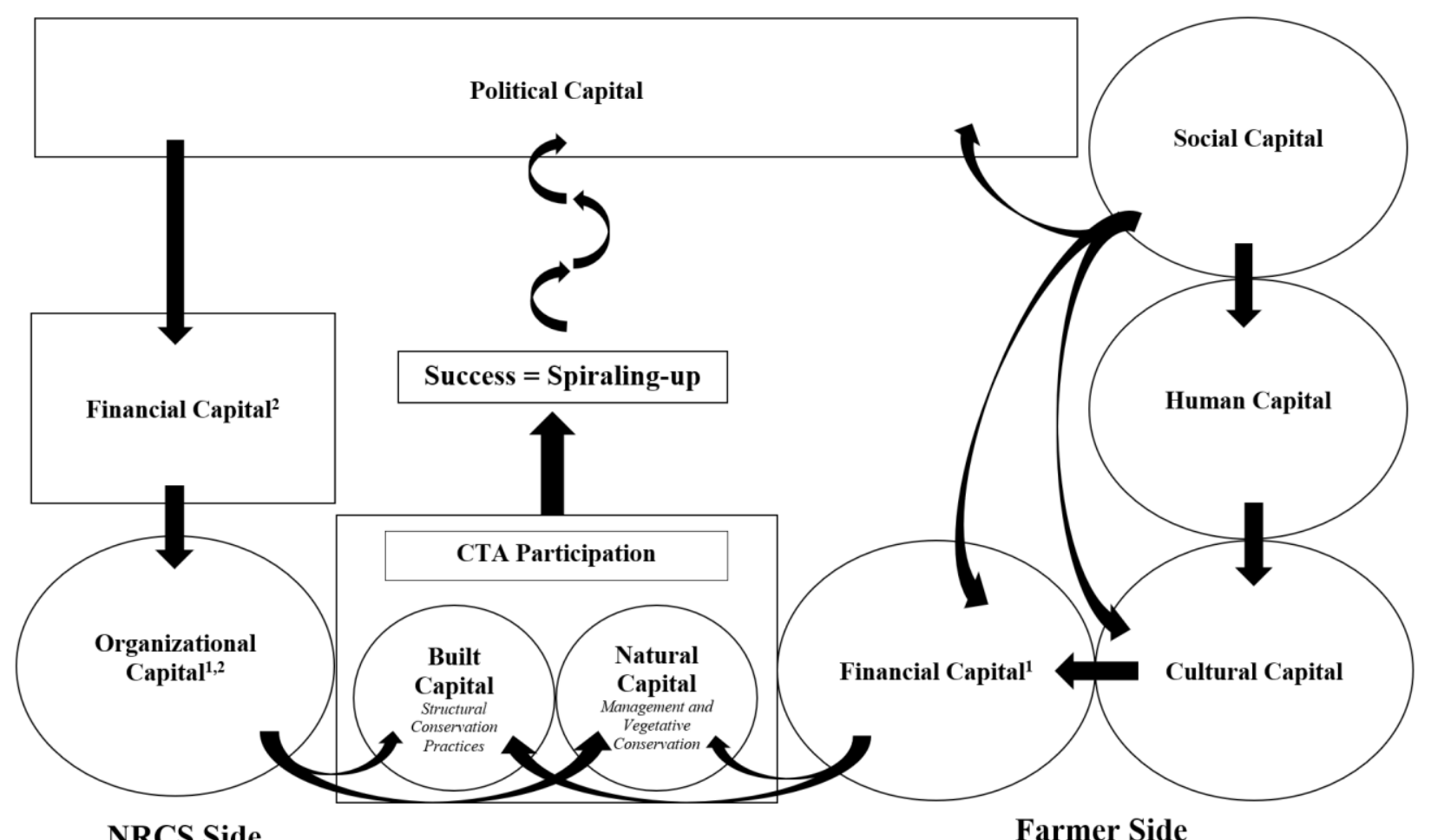

Figure 2.2: Relational theoretical model 
In order to move from this theoretical model to an empirical study, an assessment of how the current situation compares to the theory of change must be conducted to guide the research design. Dependent variable datum must consist of information that relates to investments in natural and built capital — the desired outcome. Primary independent variable data gathered on the farmer side of the participation equation must be relevant to the social, human, cultural, and financial capitals in the theory of change. The NRCS side of the equation deals with the political, financial, and organizational data salient to program delivery — the secondary independent variables. Each of these independent and dependent variables must be operationalized to bridge the gap between theoretical concepts and empirical evidence (see Chapter 3). The following sections explain how the dependent variable and the primary and secondary independent variables are conceptualized within the theoretical model.

\subsubsection{Conceptualizing the Dependent Variable}

As explained in regard to the natural and built capital elements of this model, participation in the CTA program includes managerial, vegetative, and structural conservation practice implementation. These practices increase agricultural sustainability and improve the natural resource base over time. NRCS considers use of any and all conservation practices to be program participation; therefore, the practices listed in both the natural and built capital sections are examples of the dependent variable (CTA Participation) in the theoretical model. This aspect of the model can be conceptualized as follows:

Built Capital + Natural Capital $=$ CTA Participation

\subsubsection{Conceptualizing the Primary Independent Variables}

On the farmer side of the participation equation, a conservation-minded and changeoriented culture cultivates openness to learning new practices and, with support from farmer 
social groups, can increase participation in the CTA program - thereby implementing conservation practices. However, cultural barriers can include reticence toward change and a lack of trust in scientific expertise, outside influences, government agencies, and NGOs in general. Human capital deficiencies include a lack of knowledge and understanding of conservation practices and their benefits to both environmental and economic bottom lines. Farmers' social networks may reinforce negative attitudes toward conservation, resulting in nonparticipation in the CTA program. Furthermore, the cost of implementing conservation practices may be a hindrance as well. This part of the model is conceptualized as follows:

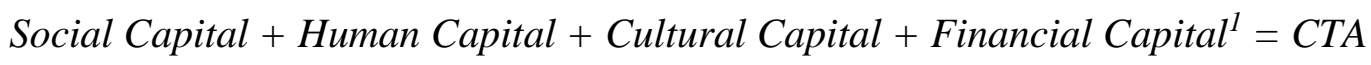
Participation

\subsubsection{Conceptualizing the Secondary Independent Variables}

As a result of legislative budget decisions, organizationally, NRCS may lack the actual number field offices necessary to adequately serve all geographic regions. Furthermore, NRCS may need to increasingly rely upon volunteers and partners to expand its organizational reach. Agricultural producers living near conservation agencies and organizations may be more likely to implement conservation practices. As such, the distance between farmers and their nearest USDA Service Center potentially plays a role in CTA participation (see Figure 2.3). 


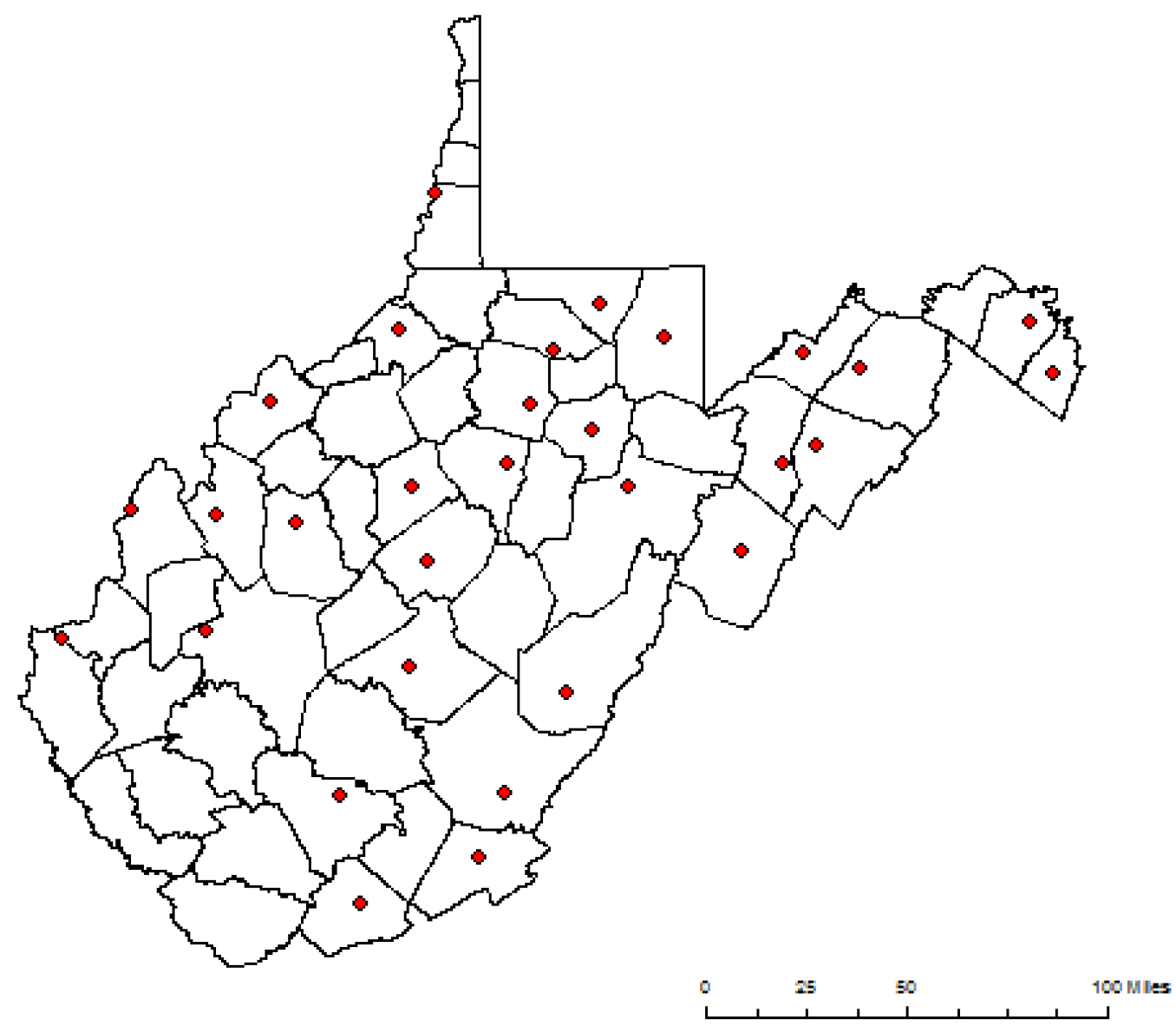

Figure 2.3: USDA NRCS Service Centers in West Virginia

This portion of the theoretical model is conceptualized as follows:

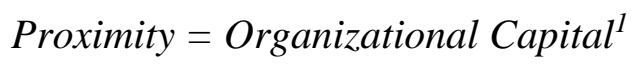

As a government agency, NRCS relies on political capital to sustain the financial capital necessary for the organizational capital to adequately staff field offices in all geographic regions, which results in the possibility of program participation. Furthermore, NRCS staff need regular technical training to continue delivering the CTA program as designed. Moreover, conservationists may not receive any training in the practices of public engagement $-\mathrm{a}$ critical skill needed to encourage participation in voluntary government programs and in promoting farmer-to-farmer methods that increase organizational capacity. Therefore, NRCS staffing levels 
and training opportunities are a critical form of organizational capital. This portion of the theoretical model is conceptualized as follows:

\section{Staff Capacity $=$ Organizational Capital $^{2}$}

Of course, both forms of organizational capital are ultimately a function of political capital that results in allocations of financial capital. These aspects of the causal model are largely out of NRCS's purview because mandatory and discretionary funding allocations are established through legislative processes. Therefore, citizen advocacy, especially from farmers, and program success are required to produce the political will necessary to increase the number of field offices and partnerships, NRCS staff, and training —elements supported by CTA program funding (USDA NRCS 2010, 525-A.5). This part of the model can be conceptualized as follows:

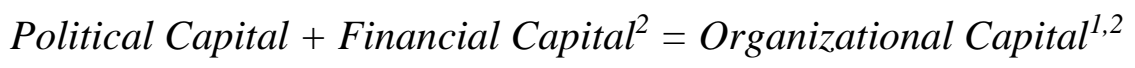

Consequently, both forms of organizational capital potentially influence the adoption of voluntary conservation practices as follows:

Organizational Capital $^{1}+{\text { Organizational } \text { Capital }^{2}=\text { CTA Participation }}$ 


\section{Chapter 3: Methods}

"The whole of science is nothing more than a refinement of everyday thinking." Albert Einstien

Farmers and NRCS staff are the subject populations for this study because of the tremendous influence that American farmland management has on agricultural productivity, environmental quality, and rural community quality of life. Moreover, because social groups and culture are so important to farmer behavior, "future research should probably aim to produce results that are meaningful for local management rather than for universal understanding" (Knowler and Bradshaw 2007, 45). The NPPH states locally-led conservation is the best method for solving natural resource concerns (USDA NRCS 2014, 600-B.1). Furthermore, most community development practices occur locally — where people live, learn, work, and recreate. Therefore, a local context is the setting for this study—considering farmers and NRCS staff in two West Virginia counties.

\subsection{Research Design}

The research design employed multiple methods in sequential order, with the results of earlier methods informing latter methods. Therefore, preliminary results are included in the sections that follow. Spatial modeling based on secondary data was conducted first to faciliate selection of the two counties for primary data collection. It should be noted that, while relevant and readily available secondary data are predictive of CTA program participation to a certain degree, based on the theoretical model, they are not sufficient to answer the research questions. Therefore, this spatial modeling should not be confused with the logistic regression model performed later in the sequential mixed-methods design that utilized the primary data collected to test anticipated causal relationships from the theory of change. Conversely, the spatial modeling was employed to provide a justifiable manner in which to select counties and was 
necessary because time and funding constraints would not allow primary data collection for all of West Virginia. To ensure a diverse yet representative population sample, the spatial modeling identified two counties for primary research based on secondary data indicating low NRCS CTA program participation (underserved) and high NRCS CTA program participation (overserved). In addition, due to the importance of pasture and hayland to agriculture in West Virginia (Sperow 2012; Frame 1940), another criterion for county selection was the predominance of grassland in comparison to cropland acres.

Once the population sample was identified, the primary and secondary independent variables from the theoretical model were operationalized in order to explore, "What factors influence farmer participation in the NRCS CTA program?" First, organizational asset mapping was conducted using GIS to evaluate organizational capacity in each of the chosen counties to determine possible barriers to participation on the NRCS side of the participation equation. Next, agency staff and farmers were interviewed in both counties to acquire local knowledge, better understand the motivations and barriers to participation, and inform the development of a survey instrument. The interview protocols connected the theoretical model to empirical data for both sides of the participation equation. Lastly, a mail survey was sent to all the farmers in the population sample counties to further understand farmer motivations and barriers to CTA participation. The written questionnaire also gathered additional data for both the NRCS and farmer sides of the theoretical model.

Primary data was collected in the two counties from early spring to mid-fall 2018 through a combination of interviews and written surveys. The late fall of 2018 and spring of 2019 were reserved for data analysis and reporting. The research was completed in March 2019. 


\subsection{Population Sample Selection}

To identify the population sample, a spatial modeling process using relevant and readily available secondary data was used to identify two counties - one that was underserved and one that was overserved by the NRCS CTA program. This analysis provided a population sample of farmers who have not participated very much (underserved) and those who have participated a lot (overserved) — allowing for a more comprehensive spectrum of potential respondents from a programmatic perspective. Inclusion of these two extremes was more likely to produce the most robust data because inadvertently selecting two like counties (e.g., two underserved counties or two overserved counties) may not have been representative of the whole state.

The CTA program participation modeling process consisted of several sequential steps. The first task was to extract CTA practice points that had been applied on the ground from existing GIS data on the NRCS practice points layer, which included both planned and applied practice points for all programs. Next, a Hot Spot Analysis was conducted to inform the modeling process and provide an indication of whether spatial autocorrelation was present. Then, Exploratory Regression (ER) was run as an initial attempt to find a well-fit model. The results helped determine the independent variables included in a non-spatial Ordinary Least Squares (OLS) regression model. OLS was conducted again in ArcMap for the significant variables only which were found in the non-spatial OLS model. This model was then evaluated for trustworthiness according to established metrics. Because spatial autocorrelation was present, Geographic Weighted Regression (GWR) was conducted in GIS to account for this common occurrence. Ultimately, GWR controlled for spatial autocorrelation and provided a trustworthy model which explained approximately 63\% (adjusted r-squared 0.63) of the variation in CTA 
practice points applied given the independent variables. The model residuals (i.e., the under- and over-predictions) were then used to identify the under- and overserved counties.

In order to determine if these counties were fairly representative of the state as a whole from a landscape perspective, land uses in these counties were evaluated as well. West Virginia's terrain does not allow for widespread conventional plantation agriculture. Therefore, pastureland supports beef cattle production which has been firmly established as the most secure industry, while the amount of hay acreage has also been steadily high (Sperow 2012). Indeed, experience has shown that grassland farming is the best suited agricultural practice in the state (Frame 1940). Therefore, the amount of cropland compared to pastureland in these counties was given consideration. Counties with a majority of pastureland were chosen for the sample population to allow for more representative results.

Taken together, the spatial modeling of CTA program participation and land use characteristics resulted in the selection of two counties as the population sample; one underserved county and one overserved county that provided good programmatic representation - both of which had farmland characteristics that were representative of the state of West Virginia.

\subsubsection{CTA Program Participation Modeling Process}

The first criterion for identifying the sample population was that they be the most underand overserved counties according to the CTA program participation modeling process - thereby making the range of possible respondents more representative of the entire state programmatically. The second criterion of pastureland was used to ensure those counties were also representative of most farmland in West Virginia. 
There are six assessments needed to identify a trustworthy model. These tests are: (1) the coefficient's sign should support the hypotheses; (2) independent variables should be significant; (3) the Global Moran's I statistic should indicate model residuals are not spatially autocorrelated-meaning they are not clustered spatially or in value; (4) the Jarque-Bera test should determine these residuals are normally distributed; (5) the Variable Inflation Factor (VIF) should indicate no multicollinearity (i.e., no two factors telling the same story); and (6) the adjusted r-squared value should demonstrate the model performs well (Strager 2016b). These evaluations were conducted throughout the modeling process used to identify the population sample.

In order to determine the level of program participation, I replicated and adapted the spatial modeling from the Zimmerman et al. (2016a) study of the distribution of all NRCS programs in West Virginia to serve the purpose of this study. Furthermore, I utilized their NRCS conservation practice point data in this procedure, which is referred to herein as "original data." The steps employed were as follows: (1) sorting the dependent variable; (2) conducting a Hot Spot Analysis; (3) conducting ER ; (4) conducting OLS regression; (5) conducting GWR; and (6) calculating and evaluating land use characteristics. I utilized ArcMap 10.3.1 and STATA 15.1 to repeat and adapt the Zimmerman et al. (2016a) analysis of census tracts and all NRCS practices. This new examination employed non-spatial models (ER/OLS) and a spatial econometric model (GWR) at the county level of analysis, considering CTA practice points only.

\subsubsection{Sorting the Dependent Variable}

The original data layer included conservation practice points that were both planned and applied through all NRCS programs in West Virginia from 1985 to 2016 . The initial step was to separate the CTA program practice points from the total practice points layer in the original data. 
Next, these data were then summarized by county. Lastly, all planned practice points were removed leaving only practices points that had been applied. This analysis resulted in a practice point layer consisting of 80,441 CTA conservation practices implemented between 1995 and 2016 (Figure 3.1). This became the dependent variable for all the following regression models (CTA_APPLD).

$$
1
$$

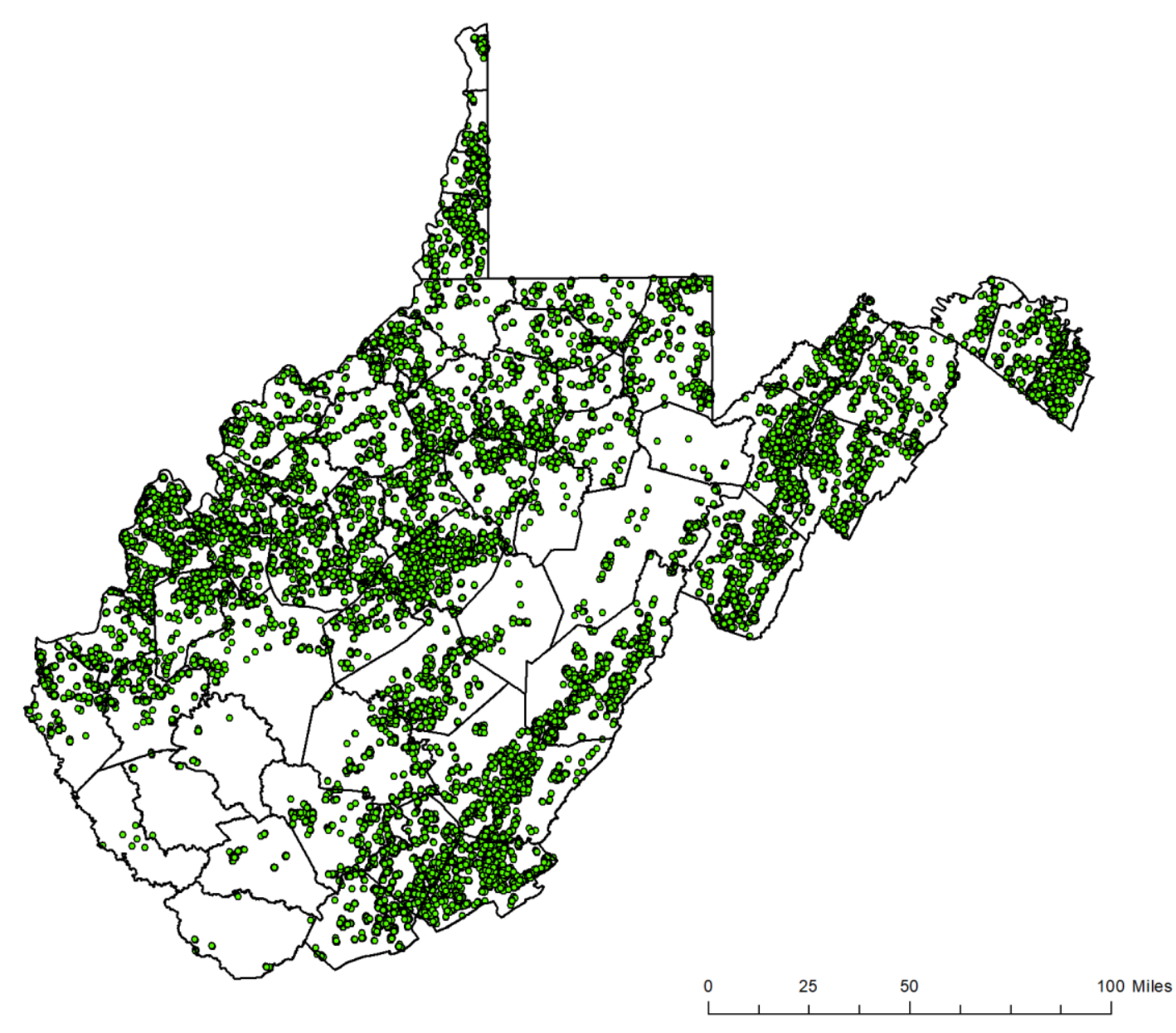

Figure 3.1: Applied CTA practice points

\subsubsection{Hot Spot Analysis}

Hot Spot Analysis employs the Getis-Ord Gi* statistic to determine statistically significant spatial clustering — hot and cold spots—-which are more pronounced than what would come from a random distribution (ESRI 2016). Hot Spot Analyses help to determine potential 
model variables and are also a good indication of whether spatial autocorrelation is present prior to conducting modeling exercises (Strager 2016a).

I began the Hot Spot Analysis by making a copy of the applied CTA practice points layer to integrate all the points within a half mile of each other. This was necessary to run the Collect Events command, found in the Spatial Analyst toolbox, which counts those integrations and creates a weighted practice point layer (Figure 3.2).

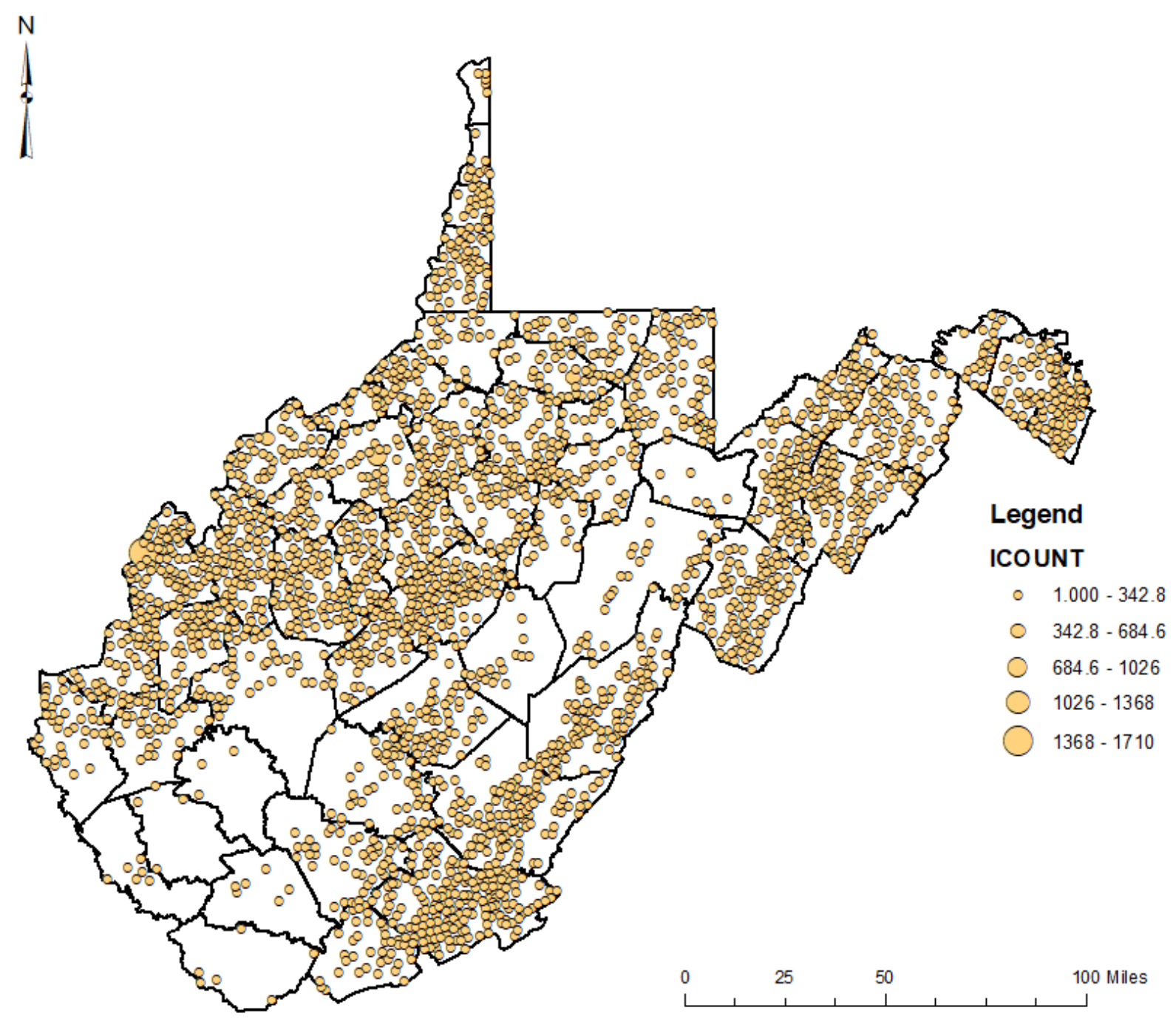

Figure 3.2: Weighted practice points layer

This weighted practice point layer was then used to run the Incremental Spatial Autocorrelation (ISA) tool to retrieve the distance at which spatial clustering is most definite 
(ESRI 2016). According to the ISA tool, spatial clustering was the strongest for CTA practice points in West Virginia at approximately 26.5 miles. This distance was then used with the weighted practice point layer in the Hot Spot command to determine the statistically significant hot and cold applied CTA practice point clusters in West Virginia (Figure 3.3). The z-scores corresponding to these clusters provided a magnitude of significance for each point (ESRI 2016).

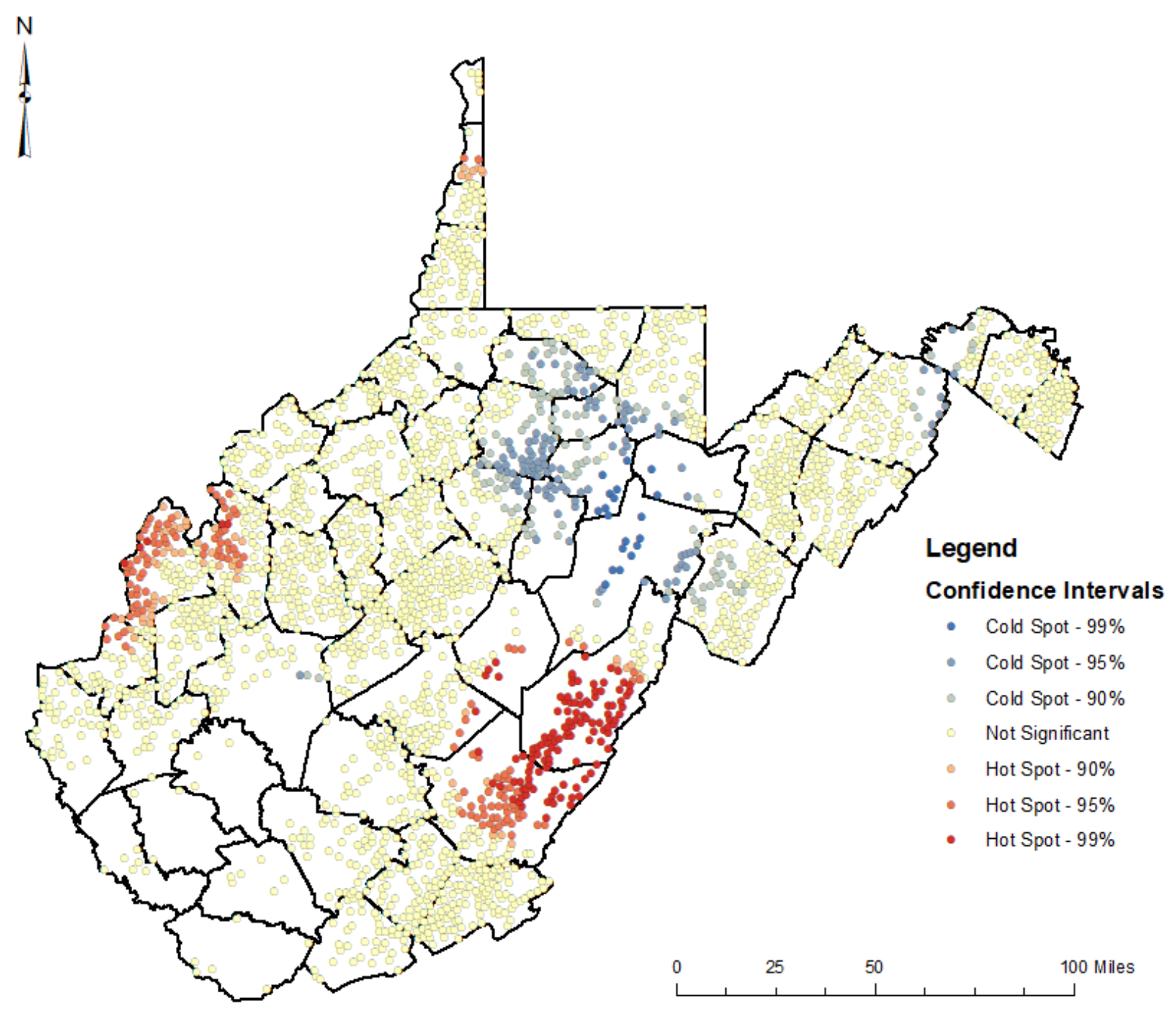

Figure 3.3: Hot and cold applied CTA practice point clusters

These magnitudes were then used for interpolation. Interpolation is "the estimation of surface values at unsampled points based on known surface values of surrounding points" (ESRI n.d.). The inverse distance weighted (IDW) command in Spatial Analyst creates this surface by 
assuming the point being mapped has less influence with greater distance (ESRI 2016). The result is a smoothed surface which correlates to the statistically significant hot and cold clusters of applied CTA practice points. This interpolated surface is illustrated in Figure 3.4.

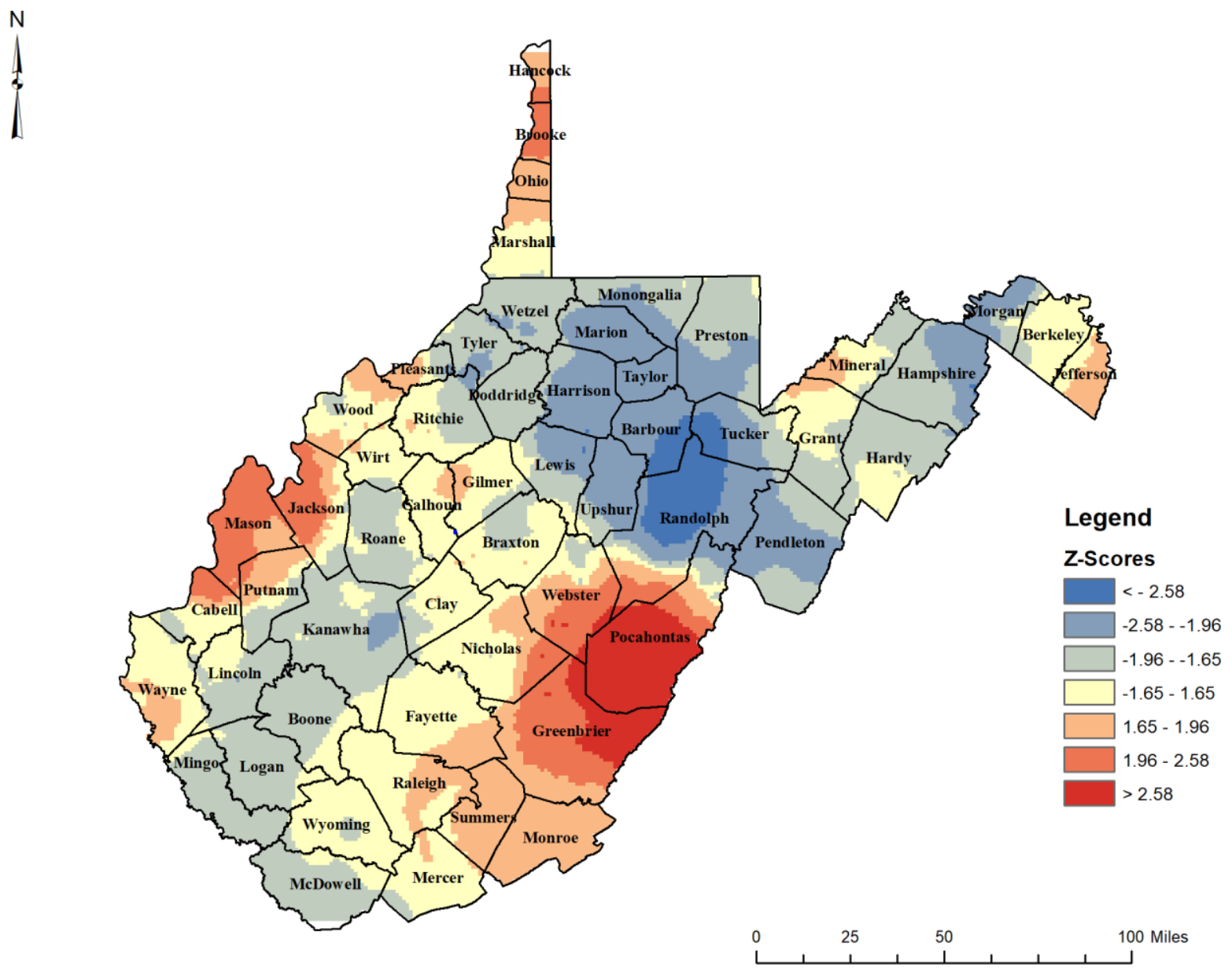

\section{Figure 3.4: Hot Spot Analysis}

The results of the Hot Spot Analysis showed particularly cold spots in Randolph,

Barbour, and Tucker Counties. Conversely, especially hot spots were found in Pocahontas, Greenbrier, Cabell, Mason, Jackson, and Brooke Counties. Interestingly, there were no deep reds or blues in the eastern panhandle of West Virginia where there is high quality farmland coupled with high development pressure (American Farmland Trust 2002). Nevertheless, the presence of these cold and hot spots in the above-named counties did indicate the possibility of spatial autocorrelation and therefore additional model variables were considered. 


\subsubsection{Exploratory Regression (ER)}

Similar to Zimmerman et al. (2016c), ER was then conducted to search for a well-fit model (2). ER is somewhat of an "all-in" approach to modeling which includes all theoretically relevant independent variables. In addition, a spatial weights matrix was created which incorporates spatial elements into computations and is thereby a "quantification of the spatial relationships that exist" (ESRI 2016).

The goal of variable selection was to predict, as accurately as possible, applied CTA practice points at the county level using relevant and readily available statewide data sources. Then, the under- and over-predictions of the final model, if it is well-fit, would give a good indication of which counties are under- and overserved. This diversity of program participation helps capture a wider range of potential respondents, thereby facilitating a more representative sample of the entire state from a CTA program perspective.

Zimmerman et al. (2016a) did not account for acres of crop or pastureland in their nonspatial county level model (2). Therefore, I retrieved the total amount of acres for these land uses

per county from the US Census of Agriculture (USDA NASS 2012). Moreover, I combined these two categories into one to differentiate whether their individual or collective influences would be significant when modeling. I also gathered the total amount of cattle per county to include in the model (USDA NASS 2012) due to the importance of grassland agriculture in West Virginia (Sperow 2012; Frame 1940). The response variable was the number of CTA practice points applied (CTA_APPLD). As such, this model is specified as follows: 


$$
\begin{aligned}
& \text { CTA_APPLD }=\beta_{0}+\beta_{1} S T R E A M+\beta_{2} C R O P L A N D+\beta_{3} P A S T U R E+\beta_{4} A G L A N D+ \\
& \beta_{5} S T A T E+\beta_{6} F E D+\beta_{7} C A T T L E+\beta_{8} E Q I+\beta_{9} D E V E L O P+\beta_{10 M I N E}+\beta_{11} B A C H+ \\
& \beta_{12} \text { POP } 55 U P+\beta_{13} D I S A B I L I T Y+\beta_{14} \text { FIELDOFFICE }+\beta_{15} I N C O M E+\beta_{16} P O V E R T Y+ \\
& \beta_{17 F A R M C O U N T}+\beta_{18} F A R M S I Z E+\varepsilon
\end{aligned}
$$

In this formula, $\beta i=$ the model coefficients; and $\varepsilon=$ random or unexplained error. An explanation of the additional variables, as well as those utilized in the Zimmerman et al. (2016a, 2) analysis,

\begin{tabular}{|c|c|c|}
\hline Variable Name & Description & Source \\
\hline \multicolumn{3}{|c|}{ Dependent Variable } \\
\hline CTA_APPLD & Number of CTA practices applied from 1995-2016. & USDA NRCS \\
\hline \multicolumn{3}{|c|}{ Independent Variables } \\
\hline STREAM & Total $24 \mathrm{~K}$ stream miles in the county. & NRAC \\
\hline CROPLAND & Total cropland acres in the county. & USDA NASS \\
\hline PASTURE & Total pastureland acres in the county. & USDA NASS \\
\hline AGLAND & Total crop and pastureland in the county. & USDA NASS \\
\hline STATE & Percent state-owned land. & State/Fed Land \\
\hline FED & Percent federally-owned land. & State/Fed Land \\
\hline CATTLE & Total cattle in the county. & USDA NASS \\
\hline EQI & Environmental quality index (2016). & EPA \\
\hline DEVELOP & Percent of land with low, medium, or high development. & NLCD \\
\hline MINE & Percent of land in a surface mining permitted area. & WV DEP \\
\hline $\mathrm{BACH}$ & Percent of population with bachelor's degree or higher. & Census \\
\hline POP55UP & Percent of total population 55 and up. & Census \\
\hline DISABILITY & Percent of population with disability status. & Census \\
\hline FIELDOFFICE & NRCS Field Office in the county. $1=$ yes. $0=$ no. & USDA NRCS \\
\hline INCOME & Household median income in thousands of dollars. & Census \\
\hline POVERTY & Percent of population with poverty status in prior year. & Census \\
\hline
\end{tabular}
are described in Table 3.1.

Table 3.1: Variable descriptions for CTA program participation modeling (adapted from Zimmerman et al. 2016a) 


\begin{tabular}{|c|l|l|}
\hline \multicolumn{2}{|c|}{ Independent Variables Continued } \\
\hline FARMCOUNT & Number of farms in the county. & USDA NASS \\
\hline FARMSIZE & Average size of farms in the county. & USDA NASS \\
\hline
\end{tabular}

STREAM, CROPLAND, PASTURE, and AGLAND are natural resources. As such, these variables are expected to be positively correlated to the dependent variable, CTA_APPLD. Indeed, it is logical to assume that the more natural resources are present, the greater the opportunity for conservation practice implementation. The STATE and FED land variables represent natural resources on the landscape as well. While NRCS largely provides technical assistance to private landowners, it also supports units of government (USDA NRCS 2014, 600A.1). As such, these two factors representing public lands are expected to have positive coefficients also.

Natural resource concerns are "an expected degradation of the soil, water, air, plant, or animal resource base to the extent that the sustainability or intended use of the resource is impaired" (USDA NRCS 2014, 600-A.17). Therefore, another representation of natural resources in this model are lands utilized for grazing. These lands have greater potential for overgrazing, soil compaction, and other degradation that might lead to natural resource concerns - thereby increasing the need for conservation practices. Thus, CATTLE is hypothesized to have a positive association to practice implementation. Furthermore, the Environmental Quality Index (EQI) is a measure of overall environmental condition created by the EPA that integrates data from air, water, land, built, and sociodemographic domains (EPA 2017). Land with less environmental quality is expected to need more conservation practices. Consequently, EQI is posited to have a negative correlation to the dependent variable. The DEVELOP and MINE variables are incongruent land uses with agriculture and natural resources and are therefore expected to have a negative association to CTA_APPLD as well. 
Baumgart-Getz et al. (2012) found that education is a common measure used in the conservation practice adoption literature (20). Accordingly, BACH is expected to be positively associated to CTA_APPLD. The average age for farmers in West Virginia is 56 years old (WVU 2017). Therefore, the variable POP55 is likely to have a positive coefficient because, since farmers in the state are typically this age, counties that have a wealth of this demographic are likely to have more farmers to implement conservation practices. In addition, it is logical to assume the DISABILITY variable would be negatively correlated to the installation of conservation practices.

Kretzmann and McKnight (1993) argue that the institutions present in a community are key elements to their success (8). Hence the FIELDOFFICE variable is hypothesized to have a positive sign in the model meaning there is a greater likelihood of practice implementation in a county with a field office than in a county without one. Rural communities are dependent on financial resources for sustainability (Jacobs 2007); and considering the farmer's economic situation is central to conservation planning (USDA NRCS 2014, 600-A.2). Indeed, conservation practices cost money to implement and it follows that INCOME would have a positive relationship to practice implementation. Conversely, it is intuitive to assume that POVERTY would be negatively correlated to the dependent variable. Lastly, FARMCOUNT and FARMSIZE are characteristics that increase the possibility of farmland conservation as they themselves increase. As such, it is assumed both indicators will be positively correlated to the number of conservation practices applied.

The ER analysis found several adjusted r-squared values that were above 0.50 . However, there were no models that passed all six tests for dependability. Moreover, there was multicollinearity found between the FARMCOUNT and FARMSIZE variables used in the 
Zimmerman et al. (2016a) county model (3); and the additional variables included in the ER CTA county models (CROPLAND, PASTURE, AGLAND, and CATTLE). As such, the variables were reduced back to the same factors included in the Zimmerman et al. (2016a) analysis (3); and were used to: (1) replicate their non-spatial OLS county level model; and (2) regress those same independent variables on CTA practice points only (as opposed to all NRCS programs) and compare the results.

\subsubsection{Ordinary Least Squares Regression (OLS)}

OLS is a global model that employs a single equation to evaluate the processes being studied (ESRI 2006). It is the most well-known of all regression methods and is the proper starting point for spatial analysis (ESRI 2009). Therefore, OLS was employed as the next step in the modeling process. OLS is estimated as follows:

$$
Y=\beta_{0}+\beta_{1} X_{1}+\beta_{2} X_{2}+\beta_{3} X_{3}+\ldots \beta_{n} X_{n}+\varepsilon
$$

In this formula, $\mathrm{Y}=$ the dependent variable being predicted; $\mathrm{X}=$ the independent variables used to predict the dependent variable; $\beta=$ the model coefficients; and $\varepsilon=$ random or unexplained error.

Summary statistics for the OLS CTA county model variables are displayed in Table 3.2. These variables were computed in the aforementioned statistical software (STATA 15.1). In addition, diagnostics were run in Microsoft Excel 2016. These diagnostics evaluated the type and strength of relationships and checked for normality. The FARMCOUNT variable showed to have a particularly strong positive linear relationship to practice implementation. As a whole, linear relationships were found between all the independent variables and the dependent variable. In addition, the overall distributions of these factors appeared relatively bell-shaped, except for FIELDOFFICE which is a categorical indicator. 
Table 3.2: OLS CTA county model summary statistics

\begin{tabular}{|l|l|l|l|l|}
\hline \multicolumn{7}{|l|}{ Variable Name } & Mean & Standard Deviation & Minimum & Maximum \\
\hline \multicolumn{5}{|c|}{ Dependent Variable } \\
\hline CTA_APPLD & $1,462.56$ & $1,273.44$ & 13.00 & $6,311.00$ \\
\hline \multicolumn{7}{|c|}{ Independent Variables } \\
\hline FIELDOFFICE & 0.54 & 0.5 & 0 & 1 \\
\hline FARMCOUNT & 429.42 & 261.31 & 15 & $1,048.00$ \\
\hline FARMSIZE & 150.05 & 52.6 & 41 & 313 \\
\hline POP55UP & 31.59 & 3.07 & 20.45 & 37.7 \\
\hline INCOME & 38.95 & 6.84 & 23.61 & 66.2 \\
\hline BACH & 15.06 & 6.1 & 5.8 & 38.8 \\
\hline POVERTY & 18.73 & 4.27 & 10.5 & 33.8 \\
\hline DISABILITY & 37.49 & 7.86 & 20.1 & 57.1 \\
\hline EQI & -0.12 & 0.8 & -1.74 & 1.38 \\
\hline STREAM & 999.24 & 475.1 & 174.68 & $2,352.70$ \\
\hline STATE & 2.3 & 2.29 & 0 & 9.87 \\
\hline FED & 5.27 & 10.82 & 0 & 51.65 \\
\hline DEVELOP & 2.52 & 2.42 & 0.19 & 9.45 \\
\hline MINE & 2.42 & 4.54 & 0 & 22.05 \\
\hline
\end{tabular}

The Zimmerman et al. (2016a) county model found FARMCOUNT and FARMSIZE to be significant at the 0.01 level while STATE was significant at the 0.10 level (3). All three were positively correlated to NRCS practice implementation. The adjusted r-squared value for this model was 0.66 . The OLS CTA county model showed FARMCOUNT and FARMSIZE to be significant at the 0.01 level and STATE to be significant at the 0.10 level as well (Table 3.3). However, DISABILITY was also significant at the 0.05 level in this model. All these coefficients were consistent with their hypotheses except for DISABILITY. This could be due to the fact that many state and federal programs have been developed to help farmers with disabilities continue farming (WVU 2017). The adjusted r-squared value for this OLS CTA county model was 0.48 . 
Table 3.3: OLS CTA county model

\begin{tabular}{|c|c|c|c|c|c|c|}
\hline Source & SS & \multicolumn{2}{|l|}{ df } & MS & $\begin{array}{l}\text { Num. of } \\
\text { obs. }\end{array}$ & 55 \\
\hline Model & 53752968.2 & \multicolumn{2}{|l|}{14} & 3839497.73 & $F(14,40)$ & 4.54 \\
\hline Residual & 33815541.3 & \multicolumn{2}{|c|}{40} & 845388.534 & Prob > F & 0.0001 \\
\hline \multirow[t]{3}{*}{ Total } & 87568509.5 & \multicolumn{2}{|c|}{54} & 1621639.07 & r-squared & 0.6138 \\
\hline & & & & & adj. r-sq. & 0.4787 \\
\hline & & & & & Root MSE & 919.45 \\
\hline CTA_APPLD & Coef. & Std. Err. & $\mathbf{t}$ & $P>t$ & \multicolumn{2}{|c|}{ [95\% Conf. Interval] } \\
\hline FIELDOFFICE & 380.719 & 407.429 & 0.934 & 0.356 & -442.726 & 1204.164 \\
\hline FARMCOUNT & 2.339 & 0.824 & 2.839 & $0.007 * * *$ & 0.674 & 4.004 \\
\hline FARMSIZE & 12.887 & 4.189 & 3.076 & $0.004 * * *$ & 4.420 & 21.355 \\
\hline POP55UP & 53.343 & 69.406 & 0.769 & 0.447 & -86.932 & 193.619 \\
\hline INCOME & 4.311 & 44.594 & 0.097 & 0.923 & -85.817 & 94.439 \\
\hline $\mathrm{BACH}$ & 61.829 & 51.530 & 1.200 & 0.237 & -42.316 & 165.974 \\
\hline POVERTY & -83.694 & 60.261 & -1.389 & 0.173 & -205.485 & 38.098 \\
\hline DISABILITY & 86.358 & 37.660 & 2.293 & $0.027 * *$ & 10.246 & 162.471 \\
\hline EQI & -300.933 & 384.465 & -0.783 & 0.438 & -1077.965 & 476.100 \\
\hline STREAM & -0.163 & 0.415 & -0.393 & 0.696 & -1.001 & 0.675 \\
\hline STATE & 115.691 & 62.347 & 1.856 & $0.071 *$ & -10.317 & 241.698 \\
\hline FED & -2.556 & 20.011 & -0.128 & 0.899 & -43.000 & 37.888 \\
\hline DEVELOP & 42.792 & 118.978 & 0.360 & 0.721 & -197.672 & 283.257 \\
\hline MINE & 5.496 & 46.588 & 0.118 & 0.907 & -88.663 & 99.654 \\
\hline _cons & -6385.165 & 4569.237 & -1.397 & 0.170 & -15619.940 & 2849.609 \\
\hline
\end{tabular}

Next, OLS was run in ArcMap for just these key variables (FARMCOUNT, FARMSIZE, DISABILITY, and STATE) to see whether they passed the six tests for a trustworthy model.

Following estimation, the STATE variable was no longer significant. NRCS works with private landowners more than with state and local governments. Furthermore, according to the summary statistics, the average amount of state owned land per county is only $2.3 \%$ and therefore does not account for a large proportion of land. With this in mind, the insignificance of the STATE variable is sensible. This model passed the remaining checks except for spatial autocorrelation. 
Therefore, GWR was also conducted in ArcMap for these key variables to control for this all too common phenomenon.

\subsubsection{Geographic Weighted Regression (GWR)}

GWR is a local regression model, as opposed to a global one like OLS, which accounts for various spatial relationships by generating an equation for every feature in the data (ESRI 2016). GWR helps to account for spatial autocorrelation. A phenomenon related to Waldo Tobler's first law of geography that states, "everything is related to everything else, but near things are more related than distant things" (Westlund 2013, 919). Spatial dependence, spatial association, and spatial interdependence have also been utilized to describe this affect (Getis 2007, 492). Taking spatial dependence into account, one would expect that estimating a model at a specific location should provide greater weights to nearby observations (Charlton and Fotheringham 2009, 5). Indeed, "the non-parametric GWR model relies on a sequence of locally linear regressions to produce estimates for every point in space by using a sub-sample of data information from nearby observations" (LeSage 1999, 206). Therefore, a GWR version of the

OLS model was employed last and is expressed as follows:

$$
Y_{i}(u)=\beta_{0 i}(u)+\beta_{1 i}(u) X_{1 i}+\beta_{2 i}(u) X_{2 i}+\beta_{3 i}(u) X_{3 i}+\ldots \beta_{n i}(u) X_{n i}+\varepsilon
$$

In this formula, the notation $(u)$ represents that parameter's relationship at location $(u)$ which is unique to that area (Charlton and Fotheringham 2009, 5).

GWR solved the spatial autocorrelation that was present and increased the adjusted $r$ squared value to 0.63 . Consequently, this model passed all the necessary assessments in order to be considered trustworthy. Therefore, the model residuals illustrating the actual number of CTA practices applied that were below the model prediction (displayed in blue) and the actual number 
of CTA practices applied that were above the model prediction (displayed in red) are shown in Figure 3.5.

$$
1^{N}
$$

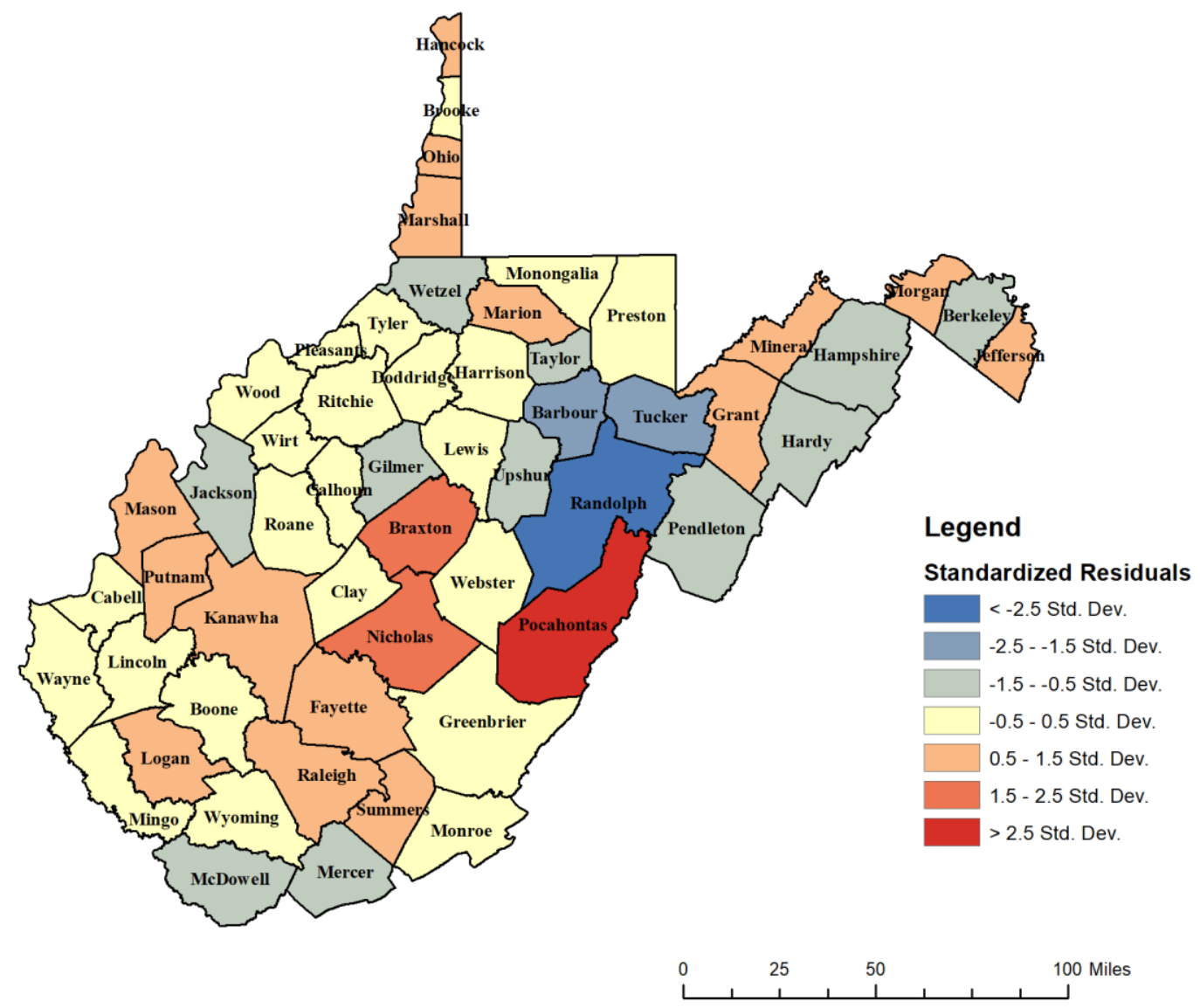

Figure 3.5: GWR CTA county model

According to this spatial modeling, the most under- and overserved counties for the CTA program in West Virginia are Randolph and Pocahontas, respectively. The GWR CTA county model showed these areas to be less than (Randolph) and greater than (Pocahontas) 2.5 standard deviations away from the number of CTA conservation practices predicted by the model. Similarly, the Hot Spot Analysis found these same counties to be statistically significant hot and cold areas as well. Assuredly, the CTA program participation modeling results illustrate the need to conduct an in-depth investigation of these counties at the local level to answer the research questions with primary data based on the theory of change. 
Furthermore, results from the census tract analysis conducted by Zimmerman et al. (2016b) for all NRCS programs indicated Randolph County had multiple underserved census tracts while Pocahontas County had several overserved census tracts also. However, when comparing the census tract level analysis for all NRCS programs to the county level analysis for the CTA program we must acknowledge the Modifiable Areal Unit Problem (MUAP). There are two aspects of MUAP to consider. The first is the scale problem where results can be influenced when data is aggregated from a smaller scale to a larger one (Openshaw and Taylor 1979, 128). Secondly, there is the aggregation problem where "alternative combinations of base units at equal or similar scales" causes results to vary as well (Openshaw and Taylor 1979, 128).

Basically, MUAP arises when spatial extents are randomly determined in a manner that creates units of different sizes or spatial arrangements (Jelinski and Wu 1996, 130). At present, there is no consensus on a solution to the problem (Yang n.d., 1). "Even with the numerous options suggested, none provide a comprehensive solution that is capable of easily and accurately quantifying the effects of MUAP" (Dark and Bram 2007, 476). However, Fotheringham et al. (2002) suggest utilizing a local regression model, such as GWR, rather than a global one (3), such as OLS. GWR was used in the Zimmerman et al. (2016c, 2) census tract analysis. Moreover, GWR was also employed for the county level CTA program participation modeling conducted here as well. As such, the similarities between the under- and overserved areas for the two modeling exercises are indeed noteworthy. Nonetheless, any subsequent analysis in GIS should also recognize this problem and attempt to address it (Dark and Bram 2007, 476). 


\subsubsection{Identifying Representative Land Use Characteristics}

The topography of West Virginia limits mechanized production and, as a result, hay is the leading crop and beef cattle production, which requires pastureland, dominates agricultural output (NASDA 2017; WVU 2017). Indeed, West Virginia is a grassland state in which hay production and grazing lands are central to the agriculture industry (Sperow 2012; Frame 1940). For this reason, the land use characteristics of Randolph and Pocahontas Counties were evaluated to determine if they were mostly pasture like the rest of the state. I calculated the proportion of crop and pasturelands per county by dividing the total amount of these land use acres, according to USDA NASS (2012), by the total amount of acres per county in ArcMap. On average, counties around the state contain $6 \%$ cropland and $11 \%$ pastureland-a $5 \%$ differential. Randolph and Pocahontas Counties both have 3\% cropland. In addition, Randolph has 7\% pastureland while Pocahontas has 9\% which is a $4 \%$ and $6 \%$ differential respectively. These counties, then, are indeed mostly pasture as compared to cropland. As such, they are a good representation of most counties around the state from a land use perspective.

\subsubsection{Summary}

The Hot Spot Analysis indicated the applied CTA practice points might be spatially autocorrelated. Therefore, several new variables, in addition to the ones utilized in the Zimmerman et al. (2016a) census tract level modeling for all NRCS programs (3), were included for ER. Ultimately, ER showed these new variables were multicollinear with the initial ones. As such, a non-spatial OLS county level model was regressed on applied CTA practice points using the original Zimmerman et al. (2016a) independent variables (3). Next, OLS was conducted in GIS for just the four significant variables found in the non-spatial OLS model, but the results were still spatially autocorrelated. 
Therefore, a GWR CTA county level model was performed on these same four predictors in ArcMap to account for this factor. The results indicated that Randolph and Pocahontas Counties were the most under- and overserved counties in the state with regard to the CTA program. A subsequent analysis of the land uses in these counties found them to be good representations of West Virginia as a grassland state in the traditional sense. As such, Randolph and Pocahontas Counties were selected for primary data collection in order to test the theory of change through organizational asset mapping, local interviews, and a mail survey.

The results of these sequential analyses identified a population sample that is reasonably representative of the whole state from both a CTA program participation and land use perspective. However, these results are insufficient for understanding the motivations and barriers to CTA program participation — which is a complex human behavior research problem. How can the theoretical model shed light on this problem? Primary data analysis is required to provide the answer. Therefore, organizational asset mapping, local interviews, and a survey of agricultural producers (i.e., farmers) were conducted in these two counties to draw conclusions and provide recommendations that are rooted in theory and prior research.

\subsection{Organizational Asset Mapping Methods}

An important element of the ABCD framework, and thus the theory of change for this study, is the local community's organizational assets. Therefore, taking inventory of local institutions that support the community provides crucial information (Kretzmann and McKnight 1993, 171). Furthermore, these data connect the theory of change to empirical evidence for Organizational Capital. ${ }^{1}$ NRCS organizational capacity could be enhanced by coproduction of technical services by other organizations. Naturally, an institution-rich county would be expected to have higher participation in the CTA program. Such counties would have more immediate 
opportunities for coproduction, while an institution-poor county may need to be linked to new collaborators.

Spatial data for NRCS field office locations in West Virginia was already on-hand. Mapping of both NRCS and other conservation organizations-such as the CDs/WVCA, WVU Extension, WVFB, WV Division of Forestry (WV DOF), WVLT, WV FFC, and othersoperationalizes accessibility of Organizational Capital $^{1}$ (Chaskin et al. 2001; Kretzmann and McKnight 1993). An assessment of the number and location of other conservation organizations was completed by conducting internet searches and reviewing secondary sources. Furthermore, eight of the nine local NRCS staff were asked, via email, this follow-up question to their interviews: "Are you aware of any other conservation agencies and/or organizations within your county? If so, can you list them and their general location?" There was no contact information for one NRCS Participant given this was an impromptu interview that was conducted on-site during a field visit to the county. Six of the eight NRCS staff responded and provided additional data for analysis.

Analysis of the data collected was conducted using ArcMap 10.5.1. Addresses of the local conservation agencies and/or organizations obtained were entered into an online latitude and longitude locator where their coordinates were gathered. Next, these coordinates were placed in the ArcMap XY tool to locate the organization in GIS for mapping. The Add Point feature in the $\mathrm{XY}$ tool was then used to insert a graphic within the county boundary to illustrate the institution's location. 


\subsubsection{Preliminary Findings}

The organizational asset mapping procedure produced baseline data to augment survey results, and are therefore preliminary findings. The results from each county are presented in turn in the following subsections.

\subsubsection{Randolph County}

There were seven conservation agencies and/or organizations physically located in Randolph County (Figure 3.6). These included the NRCS Field Office, United States Department of Agriculture Farm Service Agency (USDA FSA), the West Virginia Department of Natural Resources (WV DNR), the United States Forest Service (USFS), the United States Fish and Wildlife Service (USFWS), WVU Extension, and the Appalachian Forest Heritage Area (AFHA). Each of these were located in Elkins at the northern end of the county. These organizations were found close to the agricultural land which is surrounded by majority forest. In addition, the Tygarts Valley Conservation District (TVCD) is a traditional NRCS partner that does a lot of work in Randolph County, but is located in adjacent Barbour County (not pictured). 


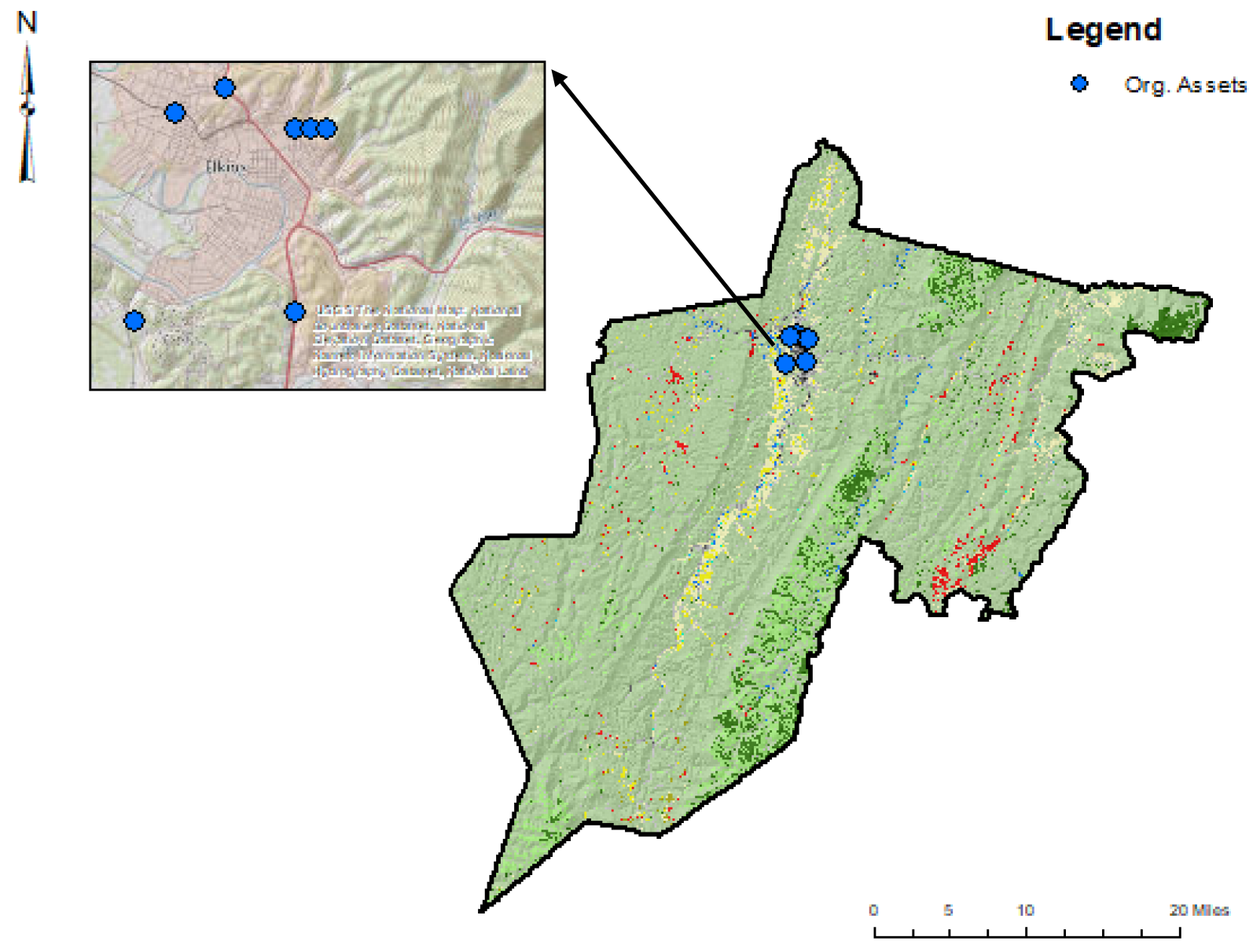

Figure 3.6: Randolph County organizational assets

\subsubsection{Pocahontas County}

As expected, Pocahontas County had more organizational assets than Randolph. There were ten conservation agencies and/or organizations found to be physically located in the overserved county (Figure 3.7). These organizations consisted of the NRCS Field Office, USDA FSA, WV DOF, WV DNR, USFS, WVU Extension, the Pocahontas County Water Resources Task Force, the Greenbrier Land Conservation Trust, the Eight Rivers Council, and the Greenbrier River Trail Association. Most were found in the southern end of the county with more than half of them being located in the town of Marlinton. Similar to Randolph County, all were located near the agricultural land uses because, much like the state as a whole, the 
remainder of the county is heavily forested. In addition, NRCS works closely with the Greenbrier Valley Conservation District (GVCD) which is an extension of WVCA. However, while GVCD services Pocahontas County its office is located in neighboring Greenbrier County (not pictured).

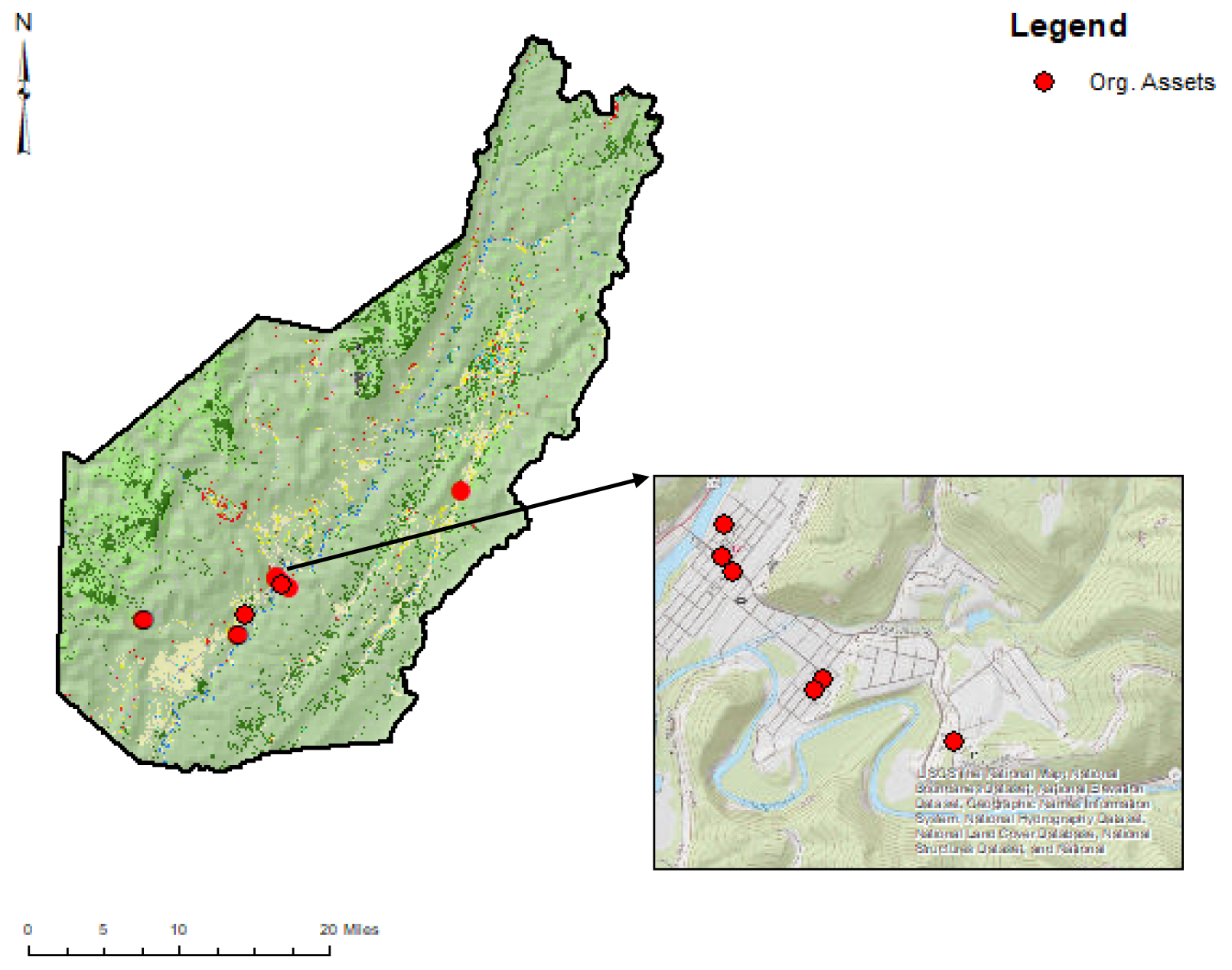

Figure 3.7: Pocahontas County organizational assets

\subsection{Key Informant Interviews}

$\mathrm{ABCD}$ is grounded in Appreciative Inquiry (AI) which is a strategy for positive change in communities and institutions that focuses on previous successes (Mathie and Cunningham 2002, 4). Interviews and stories are utilized to recall these positive memories that, following collective analysis, become the reference point for community action (Mathie and Cunningham 2002, 4). Therefore, this research component was comprised of semi-structured, open-ended interviews 
with key local informants in the subject counties in order to understand motivations and barriers to NRCS program participation and to design a written survey instrument for further data collection and analysis. Each of the final interview protocols had five sections: (1) an introduction; (2) building rapport; (3) evoking stories; (4) question statements; and (5) a conclusion. Key local informants included interviewees on both sides of the theoretical model's CTA program participation relationship, farmers and NRCS staff, in order to join each of the variables from the theory of change to empirical evidence.

All recruitment letters and interview protocols were approved by the WVU Institutional Review Board (IRB) before being utilized. Data collection began in late March 2018 and proceeded through early May 2018. All interviews of both the farmer and NRCS staff were either conducted by telephone or held in a private room at the local NRCS field office.

To identify farmer participants, a list of individuals whose property taxes were assessed as farm use were obtained from the County Tax Assessor's offices for the study areas. Farmers were then randomly selected from this database using the RAND function in Microsoft Excel 2016. This function assigns a random value to each person on the list. The database was then sorted by these random values from smallest to largest. The first twenty participants on the sorted list were sent a recruitment letter. Numerically moving down the sorted list, letters were repeatedly disbursed until at least ten interviews had been conducted in each county. No one who volunteered to be interviewed was excluded.

In order to reach the desired threshold, 480 total cover letters were mailed-240 to each county — of which fifteen were returned undeliverable. Ultimately, ten farmer interviews were conducted in the underserved county while fifteen were obtained from the overserved county. All but one of the twenty-five farmer interviews were recorded and later transcribed for coding and 
analysis. One farmer participant did not wish to be taped and therefore the data for that interview consisted of the researcher's field notes only.

Staff members who had worked in either of the subject counties were recruited for participation in the NRCS interviews. Recruitment letters were sent to the relevant field offices and participant addresses. There were eleven letters distributed and eight recipients agreed to participate. A ninth participant consented to an interview at a chance meeting during one of the researcher's visits to the county NRCS field office. In the end, there were four NRCS staff interviews conducted in the underserved county while five staff from the overserved county participated. All of the participants allowed the researcher to record the interview. These recordings were later transcribed for coding and analysis.

Farmers from within the subject counties were interviewed to better understand their perspectives on CTA program participation. The interview protocol (see Appendix A) for agricultural producers was designed by considering the literature in light of the theoretical model to gather information on the dependent variable (CTA Participation) and each primary independent variable (Social, Human, Cultural, and Financial ${ }^{1}$ Capitals). Ultimately, this data provided a deeper understanding of local farmers in these under- and overserved counties, their motivations, and potential barriers to CTA program participation.

NRCS field office staff were also interviewed as the primary organizational informants to better understand service delivery factors that may effect CTA program participation. The NRCS staff interview protocol (see Appendix B) was guided by the theory of change and informed by academic research and NRCS technical resources to identify aspects of the dependent variable (CTA Participation) and the secondary independent variable Organizational Capital $^{2}$. NRCS staff are well-trained in the technical expertise necessary to implement conservation activities. 
However, other skills may be needed to secure CTA program participation. Therefore, these interviews emphasized a deeper understanding of NRCS organizational capacity, agency staff and their motivations, and how skilled staff are in public engagement and community development techniques.

\subsubsection{Farmer Interview Data}

To gather data on CTA Participation, the farmer interviews asked participants to describe ways they had engaged with NRCS in the past.

For Social Capital, farmers were asked to describe their connections to other farmers (Arbuckle et al. 2018; Prokopy et al. 2014; Reimer et al. 2014; Reimer and Prokopy 2014; Baumgart-Getz et al. 2012; Prokopy et al. 2008; Knowler and Bradshaw 2007; Pannell et al. 2006; Mathijs 2003) and how they share conservation and farming techniques with one another (Sosa et al. 2013; Holt-Giménez 2006; Enshayan et al. 1992). Furthermore, participants were asked to give an example of a time where they learned conservation practices from another farmer. Questions were also posed about their attendance at any farmer-to-farmer workshops or similar trainings, and whether another farmer had ever referred them to NRCS.

To gather empirical data on Human Captial, participants were asked about their general knowledge and level of familiarity with conservation practices (Prokopy et al. 2014; Oliver 2011) and to describe any field demonstrations or on-farm educational opportunities they had attended concerning soil and water conservation practices (Mancini et al. 2008; Bruening and Martin 1992). In addition, each informant was asked whether they had ever engaged in participatory approaches (Prokopy et al. 2014; Pannell et al. 2006) such as NRCS LWGs.

The Cultural Capital variable was operationalized by asking participants to recall stories about when implementing a new conservation practice proved beneficial (i.e., change is good); 
or when working with NRCS was helpful (i.e., outsiders are good) (Flora et al. 2016, 75).

Farmers were also asked about how the traditions and values handed down to them by their parents and grandparents had influenced their relationship to the land (Flora and Flora 2013, 55).

They were further questioned on Cultural Captial as to whether values held by country folks are different from those who live in the city (Flora et al. 2016, 74). Participants were also asked if NRCS conservation practices reflected their own values (Flora et al. 2016, 78).

Lastly, Financial Capital $^{1}$ was operationalized from the theoretical model by asking participants to describe the biggest barrier to implementing the conservation practices recommended by NRCS — such as cost (Lambert et al. 2006, 10).

\subsubsection{NRCS Staff Interview Data}

The questions employed in the interview protocol for NRCS staff to operationailize CTA Participation from the theoretical model asked what it means to provide technical assistance to NRCS customers and to describe the conservation planning process (Stubbs 2010b; USDA NRCS 2014). Furthermore, staff were asked to define participation in the CTA program and describe its purpose (USDA NRCS 2010; Stubbs 2010a; Cowan and Johnson 2008).

Regarding Organizational Capital ${ }^{2}$, participants were asked to describe a time when work satisfaction was both high and low in an effort to determine current levels of organizational capacity (Reimer and Prokopy 2014; Stubbs 2010b; Cox 2007; Helms 2005). NRCS staff were also asked about the percentage of time they spend on the CTA program in comparison to financial assistance programs. Staff were also questioned regarding the kinds and types of training they had recieved throughout their NRCS career-including whether they had recieved any public engagement and community development related training (USDA NRCS 2010, 525A.1). 
To further operationalize Organizational Capital ${ }^{2}$, participants were questioned about the efficacy and frequency of collaborations with other organizations in order to gather empirical evidence on the present state of coproduction of technical assistance through partnerships (Chaskin et al. 2001; Kretzmann and McKnight 1993). The protocol also included questions about NRCS usage of participatory approaches with farmers (USDA NRCS 2014; USDA NRCS 2010; USDA NRCS n.d.[c]). Lastly, participants were asked to provide an example of when farmer-to-farmer methods helped to get the NRCS conservation message out and their level of engagement with farmer-initiated groups, associations, or unions (Sosa et al. 2013; HoltGiménez 2006; Enshayan et al. 1992).

\subsubsection{Preliminary Findings}

Interview analysis was designed to achieve two objectives: (1) to adjust the theoretical model with understandings derived from empirical data; and (2) to develop a written survey of farmers. Therefore, preliminary analysis of the results are included in this section in order to describe the final research method employed.

The Basics of Qualitative Research was the technical guide for analysis of the interview results (Corbin and Strauss 2008). Memos were written about blocks of raw data in order to explore their properties and dimensions (Corbin and Strauss 2008, 159). These memos were generated, sorted, and stored using Microsoft Word 2016. Some researchers choose to employ Qualitative Data Analysis (QDA) software packages. However, these tools are an option that are not integral to the process (Corbin and Strauss 2008, xi). Indeed, computers are excellent analytic tools, but the thought process provided by the human element is most important (Corbin and Strauss 2008, 201). Therefore, in this manner, data was analyzed and coded into concepts. The most prominent analytic devices utilized in this endeavor was to ask questions and make 
comparisons. These tools are the linchpin of analysis for many qualitative researchers (Corbin and Strauss 2008, 68). As the analysis progressed, data were further categorized into higher-level categories, or themes, some of which had one or more lower-level sub-concepts.

Higher-level categories, and their lower-level sub-concepts, provided insights into the motivations and barriers to CTA Participation from both the farmer and NRCS staff perspective. There were six major categories revealed in the farmer interviews. The first being that "CTA participation is the key to conservation on the ground" which included the "good contracts come from CTA" sub-concept. Next, participants tended to have a "personal attachment to their land" that developed over time. The third category came from the fact that many farmers displayed a strong "stewardship ethic."

There was also a "cultural identity" that differentiated between country and city folks among the participants. Another major category was the "barriers to participation" that became evident. The sub-concepts that arose from the data to support this category included the "NRCS personnel barrier," the "knowledge barrier," "fear of restrictions," "distrust of government," the "bureaucracy barrier," and the "cost barrier." However, "farmer-to-farmer methods" developed as a higher-level theme that may provide additional strategies to overcome the challenges to CTA

\section{Participation.}

The NRCS staff interviews had six major categories as well—some of which were crosscutting with the farmer interview results. For starters, CTA Participation was again found to be the "key to conservation on the ground" because so often "good contracts come from CTA." The "NRCS customer service culture" was a major theme because a service ethic was readily visible in the staff interview data. However, "building trust" was also a major theme where NRCS staff explained how, as conservationists, they must establish meaningful relationships with farmers. 
However, "NRCS organizational barriers" were also revealed as part of the findings. The sub-concepts that were found within this higher-level category included the "shift in agricultural and conservation policy" that was initiated by the 1985 Farm Bill (Johnson and Monke 2017; Cox 2007; Helms 2005; Zinn 2005). This sub-concept is embedded in the Political and Financial Capital $^{2}$ aspects of the theory of change-ultimately showing how this policy shift affected the CTA program at the field office level and resulted in the "NRCS personnel barrier" similar to the farmer interviews findings. In addition, there was also a "participatory training need" that emerged as well.

“Organizational collaboration" was a major category that arose from the data also. Results showed that NRCS staff continue to utilize the same traditional partnerships they have used in the past. Similar to the farmer interviews, "farmer-to-farmer methods" were a salient theme in the NRCS staff interviews. However, a sub-concept that developed within this category is that farmer groups are currently being "underutilized" by the agency. The manner in which these empirically-derived higher-level categories and lower-level sub-concepts revised the relational theoretical model is illustrated in Figure 3.8. 


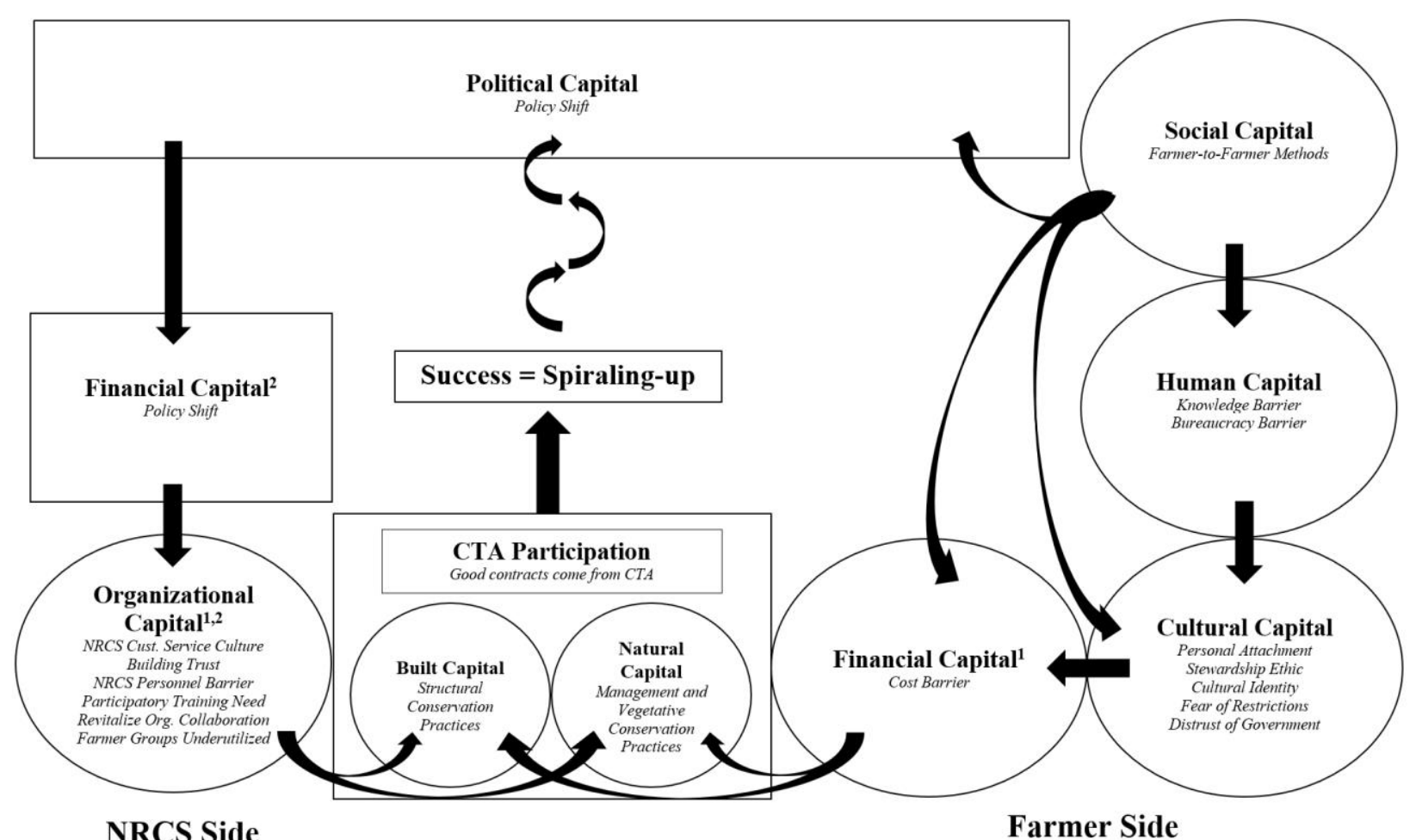

NRCS Side

Farmer Side

Figure 3.8: Empirically informed theoretical model

\subsection{Farmer Survey Methods}

The third and final method used was a written questionnaire that was distributed via US

Mail. The survey questionnaire and its associated letters were all approved by WVU IRB prior to distribution. Internet, Mail, and Mixed-Mode Surveys: The Tailored Design Method (Dillman et al. 2009) was the practical guide used to create and administer the survey. Mail survey data was collected in early August 2018 through late October 2018. Farmers were the subject population, while the under- and overserved counties were the geographic extent of distribution.

Survey questions were directed by the theory of change developed from the academic literature, with adjustments made as a result of the analysis of interview data. Each of the primary (Social, Human, Cultural, and Financial ${ }^{1}$ Capitals) and secondary (Organizational

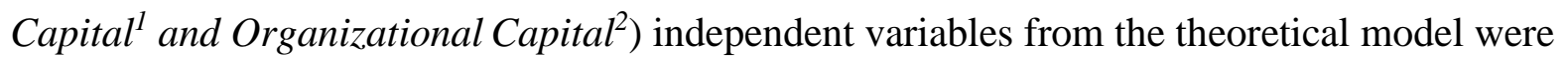
operationalized in order to gather further empirical evidence necessary to evaluate their 
relationship to the dependent variable —CTA Participation. The questionnaire itself (see Appendix C) was organized in three sections: (1) farm information; (2) motivations for participation; and (3) demographics.

Farmer contact information was obtained from the County Tax Assessor's office for individuals assessed as agricultural producers, or farmers, on their property taxes. Surveys were sent to all 1,458 farmers in the subject counties - 551 in the underserved and 907 in the overserved. To determine whether the physical space between a farmer and their local USDA Service Center is an influential factor to program participation, numerical identifiers unique to each respondent in the database were placed on the business reply envelopes that were provided so their location in relation to the nearest NRCS field office could be calculated in GIS.

Three mailings were sent to encourage participation and obtain the best possible response rate. The first mailing included a letter of support that was generously provided by the Commissioner of Agriculture in West Virginia, Kent Leonhardt. It also consisted of an initial cover letter and the questionnaire. This was followed by a reminder letter two weeks later. Another two weeks later, a final mailing that included the letter of support from the Commissioner, an updated cover letter, and the same questionnaire was sent. Due to funding and time constraints there were no further mailings. According to Dillman et al. (2009), nonresponse error occurs when the participants who respond to the survey are different from those who do not respond (17). Comparing early respondents to late respondents is one manner in which to test for this potential bias (Radhakrishna and Doamekpor 2008; Lindner et al. 2001), the logic being that late respondents are likely to be similar to nonrespondents (Radhakrishna and Doamekpor 2008; Miller and Smith 1983). Therefore, the unique identifiers on the business reply envelopes used to track location were also color coded to differentiate between response waves. 
Surveys were returned to the Division of Resource Economics and Management at WVU. A total of 173 of the 1,458 surveys came back as either undeliverable, the farmer was deceased, or the respondent did not own farmland. Ultimately, 458 useable questionnaires were returned and constituted the database for this analysis. Thus, the final survey response rate was $35.6 \%$.

Survey data were coded and manually entered into Microsoft Excel 2016. Four different techniques were then used to display and analyze data from each section of the survey: (1) the Point Distance feature in ArcMap; (2) descriptive statistics; (3) summary statistics; and (4) regression analysis.

\subsubsection{Operationalized Survey Data}

Variables from the survey instrument were operationalized and given a code, as shown in relation to the theoretical model in Figure 3.9. An explanation of each variable is provided in the following subsections.

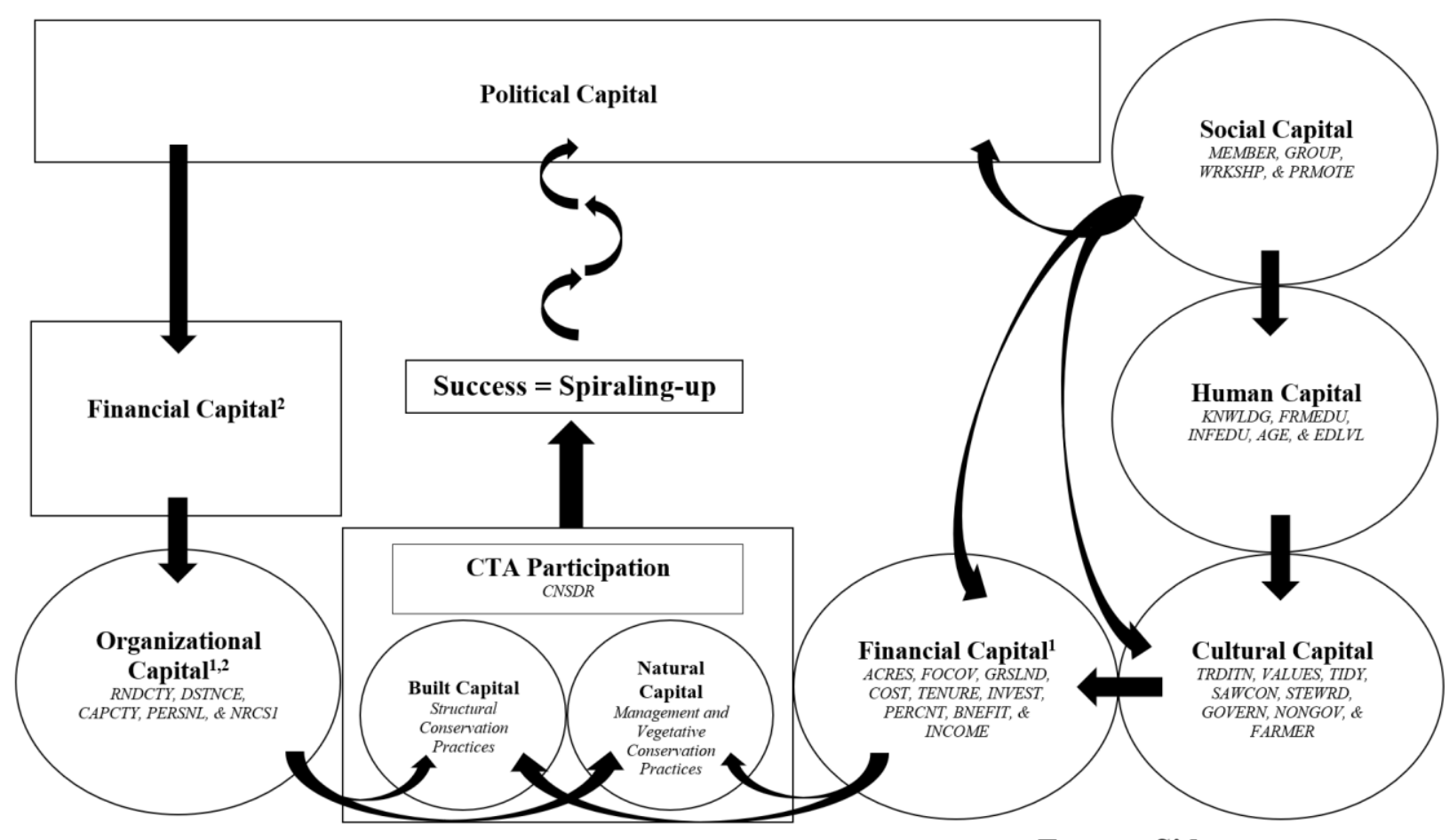

NRCS Side

Farmer Side

Figure 3.9: Empirical model 


\subsubsection{The Dependent Variable}

To operationalize the dependent variable of CTA Participation, participants were asked whether they would ever consider participating in the NRCS CTA program. Phrasing the question in this manner accounted for those who had participated in addition to those who would consider participating in the future - which provided a more comprehensive sample of everyone who is willing to participate in the CTA program. This variable was coded as CNSDR and was given a value of " 1 " for yes and " 0 " for no.

\subsubsection{Farmer Independent Variables}

The independent variables relevant to the farmer side of the theoretical model are described in Table 3.4.

Table 3.4: Independent variables relevant to farmers

\begin{tabular}{|c|l|l|}
\hline \multicolumn{3}{|c|}{ Independent Variables: Farmer Side } \\
\hline MEMBER & Social Capital & $\begin{array}{l}\text { Whether the respondent was a member of a local farmer group, } \\
\text { association, bureau, or union. 1 = yes. 0 = no. }\end{array}$ \\
\hline GROUP & Social Capital & $\begin{array}{l}\text { How the respondent rated the importance of being involved in a local } \\
\text { farmer group, association, bureau, or union. Likert scale with values } \\
1-5.1=\text { not. 5= extremely. }\end{array}$ \\
\hline WRKSHP & Social Capital & $\begin{array}{l}\text { Whether the respondent had ever attended a farmer-to-farmer } \\
\text { workshop or similar training. 1 = yes. 0 = no. }\end{array}$ \\
PRMOTE & Social Capital & $\begin{array}{l}\text { Whether the respondent would consider promoting NRCS } \\
\text { conservation practices to other farmers. 1 = yes. 0 = no. }\end{array}$ \\
KNWLDG & Human Capital & $\begin{array}{l}\text { How the respondent rated their knowledge of management, } \\
\text { vegetative, and structural conservation practices. Likert scale with } \\
\text { values 1-5. 1 = nothing. 5 = expert. }\end{array}$ \\
\hline FRMEDU & Human Capital & $\begin{array}{l}\text { How much formal education the respondent had received regarding } \\
\text { NRCS conservation practices. Likert scale with values 1-5. 1 = none. } \\
5=\text { extensive. }\end{array}$ \\
\hline INFEDU & Human Capital & $\begin{array}{l}\text { How much informal education the respondent had received regarding } \\
\text { NRCS conservation practices. Likert scale with values 1-5. 1 = none. } \\
5=\text { extensive. }\end{array}$ \\
\hline AGE & Human Capital & Respondent's age. Discrete variable. \\
\hline EDLVL & Human Capital & $\begin{array}{l}\text { Level of education received by the respondent. 1 = associate degree } \\
\text { or further. 0 = GED or high school. }\end{array}$ \\
\hline
\end{tabular}




\begin{tabular}{|c|c|c|}
\hline \multicolumn{3}{|c|}{ Independent Variables: Farmer Side Continued } \\
\hline TRDITN & Cultural Capital & $\begin{array}{l}\text { Whether the respondent's farming techniques had been } \\
\text { influenced by their parents or grandparents. } 1=\text { yes. } 0=\text { no. }\end{array}$ \\
\hline VALUES & Cultural Capital & $\begin{array}{l}\text { Whether the respondent felt that values held by country folks } \\
\text { are different than values held in urban areas. } 1=\text { yes. } 0=\text { no. }\end{array}$ \\
\hline TIDY & Cultural Capital & $\begin{array}{l}\text { How important the respondent felt it was for the landscape } \\
\text { on their farm to look tidy. Likert scale with values } 1-5.1= \\
\text { not. } 5 \text { = extremely. }\end{array}$ \\
\hline SAWCON & Cultural Capital & $\begin{array}{l}\text { How the respondent rated the importance of soil and water } \\
\text { conservation practices. Likert scale with values } 1-5.1=\text { not. } \\
5=\text { extremely. }\end{array}$ \\
\hline STEWRD & Cultural Capital & $\begin{array}{l}\text { How the respondent rated the importance of their role as a } \\
\text { land steward. Likert scale with values } 1-5.1=\text { not. } 5= \\
\text { extremely. }\end{array}$ \\
\hline GOVERN & Cultural Capital & $\begin{array}{l}\text { How the respondent rated the trustworthiness of federal and } \\
\text { local agencies of government. Combination of two } 1-5 \\
\text { Likert scale variables. } 1=\text { not. } 5=\text { extremely. }\end{array}$ \\
\hline NONGOV & Cultural Capital & $\begin{array}{l}\text { How the respondent rated the trustworthiness of NGOs. } \\
\text { Likert scale with values } 1-5.1=\text { not. } 5=\text { extremely. }\end{array}$ \\
\hline FARMER & Cultural Capital & $\begin{array}{l}\text { How the respondent rated the trustworthiness of farmer } \\
\text { groups. Likert scale with values } 1-5.1=\text { not. } 5=\text { extremely. }\end{array}$ \\
\hline ACRES & Financial Capital $^{l}$ & $\begin{array}{l}\text { Amount of acres the respondent owns or leases. Discrete } \\
\text { variable. }\end{array}$ \\
\hline FOCOV & Financial Capital $^{l}$ & $\begin{array}{l}\text { The approximate percentage of forest cover on the } \\
\text { respondent's property. Discrete variable. }\end{array}$ \\
\hline GRSLND & Financial Capital ${ }^{1}$ & $\begin{array}{l}\text { Primary use of land. } 1=\text { pastureland or hayland. } 0=\text { all other } \\
\text { land uses. }\end{array}$ \\
\hline COST & Financial Capital $^{1}$ & $\begin{array}{l}\text { What the respondent felt was the primary barrier to } \\
\text { implementing the conservation practices recommended by } \\
\text { NRCS. } 1=\text { cost. } 0=\text { all others. }\end{array}$ \\
\hline TENURE & Financial Capital $^{l}$ & $\begin{array}{l}\text { How long in years the respondent had leased or owned their } \\
\text { farmland. } 1 \text { = greater than } 20 \text { years. } 0=\text { less than } 20 \text { years. }\end{array}$ \\
\hline INVEST & Financial Capital $^{l}$ & $\begin{array}{l}\text { Whether the respondent considered their farmland an } \\
\text { investment that would provide economic returns in the long } \\
\text { run. } 1=\text { yes. } 0=\text { no. }\end{array}$ \\
\hline PERCNT & Financial Capital $^{l}$ & $\begin{array}{l}\text { Approximate percentage of income the respondent derives } \\
\text { from their farmland. Discrete variable. }\end{array}$ \\
\hline BNEFIT & Financial Capital $^{l}$ & $\begin{array}{l}\text { Whether the respondent thinks the cost of implementing } \\
\text { NRCS conservation practices is worth the benefit. } 1=\text { yes. } 0 \\
=\text { no. }\end{array}$ \\
\hline INCOME & Financial Capital $^{l}$ & $\begin{array}{l}\text { Approximate annual income of the respondent in dollars. } 1= \\
\text { greater than } \$ 90,000.0=\text { less than } 90,000 .\end{array}$ \\
\hline
\end{tabular}


Social Capital was operationalized by inquiring whether respondents were members of any farmer groups, associations, bureaus, or unions (Arbuckle et al. 2018; Prokopy et al. 2014; Reimer et al. 2014; Reimer and Prokopy 2014; Baumgart-Getz et al. 2012; Prokopy et al. 2008; Knowler and Bradshaw 2007; Pannell et al. 2006; Mathijs 2003). They were also asked to rate the importance of being involved in their local farmer group, association, bureau, or union (Jacobs 2007). Participants were asked whether they had attended any farmer-to-farmer workshops or similar trainings and if they would ever consider promoting NRCS conservation practices to other farmers (Sosa et al. 2013; Holt-Giménez 2006; Enshayan et al. 1992).

MEMBER is expected to be positive because of the importance of social groups to farmer adoption of conservation practices (Arbuckle et al. 2018; Prokopy et al. 2014; Reimer et al. 2014; Reimer and Prokopy 2014; Baumgart-Getz et al. 2012; Prokopy et al. 2008; Knowler and Bradshaw 2007; Pannell et al. 2006; Mathijs 2003). For this same reason, farmers who find it important to be active in their local farmer groups (GROUP) are expected to have a positive correlation to CNSDR as well. Due to the efficacy of farmer-to-farmer methods evidenced in the literature (Sosa et al. 2013; Holt-Giménez 2006; Enshayan et al. 1992), respondents that have participated in a farmer-to-farmer workshop (WRKSHP) are expected to be more willing to consider participation than those who have not. Moreover, farmers willing to promote NRCS conservation practices to other farmers (PRMOTE) are likely to have a positive coefficient also - meaning they are more likely to participate than those not willing to be an advocate.

Data was gathered on Human Capital by inquiring about the respondent's general knowledge of management, vegetative, and structural conservation practices (Prokopy et al. 2014; Oliver 2011). Questions regarding how much formal (Baumgart-Getz et al. 2012, 21) and informal (Baumgart-Getz et al. 2012; Mancini 2008; Bruening and Martin 1992) education they 
had received were posed. Lastly, respondents were also asked to report their age (Arbuckle et al. 2018; Prokopy et al. 2008) and education level.

KNWLDG is expected to be positive given prior studies have indicated lack of knowledge and awareness is a potential barrier to participation in conservation programs (Prokopy et al. 2014; Oliver 2011). Furthermore, Baumgart-Getz et al. (2012) did a review of the adoption literature and found education — both formal and informal—was present in each study as a measure of human capacity (21). As such, FRMEDU, and INFEDU are measured here as well and expected have a positive relationship to CNSDR. According to Prokopy et al. (2008), younger farmers may be more receptive to outreach concerning conservation practice adoption (310). Arbuckle et al. (2018) also found age to have a negative relationship to adoption. Therefore, AGE is expected to be negatively correlated to CNSDR. Education is a logical proxy for human capital within a community. It is a common variable in research studies related to farmer conservation behavior (Baumgart-Getz et al. 2012, 21). As such, EDLVL is hypothesized to be positive, illustrating how those with an associate degree or further are more likely to consider participating in the program than those with less education.

Empirical evidence for Cultural Capital was obtained by asking respondents whether their farming techniques had been influenced by their parents or grandparents (Flora and Flora $2013,55)$ and whether they thought values held by rural folks differed from those who live in urban areas (Flora et al. 2016, 74). They were also asked to rate the importance of indicators such as cultural landscapes (Burton 2012; Burton et al. 2008; Schmitzberger et al. 2005; Ryan et al. 2003), their role as land stewards (Prokopy et al. 2014; Greiner and Gregg 2011), and conservation practices in general (Arbuckle et al. 2018; Prokopy et al. 2014; Baumgart-Getz et al. 2012; Ma et al. 2010; Prokopy et al. 2008). Furthermore, participants were provided a Likert 
scale to rate the trustworthiness of several kinds of groups and organizations (e.g., Federal agencies, local government, NGOs, and farmer groups) (Flora et al. 2016; Oliver 2011).

According to Flora and Flora (2013), parents often influence their children by passing down their attitudes, societal views, understanding of roles, and value systems (55). Therefore, given the likely presence of rural cultural norms — such as hard work and independence (Floral et al. 2016, 75), and because conservation practices represent change in the subject counties, TRDITN is hypothesized to be negative in the model, meaning respondents with these influences are less likely to participate than those without. Moreover, according to the literature and interview results, rural folks often perceive rural values to be in opposition to urban values which can lead to a cultural identity that fears outsiders (Flora et al. 2016, 74). Therefore, similar to TRDITN, VALUES is also expected to be negative for the same reason. Farmers tend to prefer tidy landscapes that are not always congruent with conservation goals (Schmitzberger et al. 2005, 287). As such, TIDY is assumed to have a negative relationship to farmer participation in conservation programs.

Environmental attitudes have often been positively correlated to the adoption of conservation practices (Arbuckle et al. 2018; Prokopy et al. 2014; Baumgart-Getz et al. 2012; Ma et al. 2010; Prokopy et al. 2008). Therefore, SAWCON is expected to be positively correlated to CNSDR. Similarly, some farmers are driven to adopt conservation practices due to a stewardship ethic (Prokopy et al. 2014; Greiner and Gregg 2011). As such, STEWRD is also hypothesized to be positively correlated to CNSDR. Previous research has shown that organizational trustworthiness is a motivator to participation in conservation programs (Oliver 2011, 77). Therefore, GOVERN, NONGOV, and FARMER are expected to have positive relationships to CNSDR as well. 
Financial Capital ${ }^{l}$ was also gauged by asking participants how many acres they owned (Ma et al. 2010; Lambert et al. 2006). In addition, given hay and pastureland are central to agricultural production in West Virginia (NASDA 2017; WVU 2017; Sperow 2012; Frame 1940), respondents were questioned about their primary land uses. They were also asked how long they had owned or leased their farmland (Lutz et al. 1994, 278) and whether they considered it a financial investment that would provide economic returns in the long run. Furthermore, respondents were questioned about their annual household income and what percentage of that income came from on the farm (Lambert et al. 2006, 10). Participants were also asked whether the cost of implementing conservation practices is worth the benefit (Zhou et al. 2009; Lambert et al. 2006).

Farm size has shown to be an important Financial Capital ${ }^{l}$ indicator to the adoption of conservation practices because larger operations can better absorb the costs of implementation (Ma et al. 2010; Lambert et al. 2006). Therefore, it is hypothesized that ACRES will be positively associated with CNSDR. Similarly, FOCOV represents a financial asset that increases with acreage and is thereby expected to have a positive coefficient in the model. Hay and pastureland are the most prominent agricultural land uses in West Virginia when excluding silviculture (NASDA 2017; WVU 2017; Sperow 2012; Frame 1940). As such, GRSLND is expected to be positive meaning those listing these as their primary land uses are more likely to consider participation than those listing other land uses as primary. Conversely, it is logical to propose that COST would have a negative sign in the model given it was identified by many interview participants as the greatest of all the barriers mentioned in the questionnaire.

Lutz et al. (1994) contends long-term financial returns could present a barrier to participation due to insecure land holdings (278). Therefore, TENURE is expected to be positive 
illustrating how those owning or leasing farmland for twenty plus years are more likely to participate than those who have controlled their land for a shorter amount of time. Likewise, INVEST should provide a similar result as it is natural to assume those who consider their property to be a monetary investment - one that is expected to bring economic returns in the long run - would be more inclined to participate than those who do not consider their land to be this type of asset.

Lambert et al. (2006) claims that farmers relying on off-farm income may not have the financial capacity to participate (10). Therefore, PERCNT is hypothesized to have a positive correlation to CNSDR. Profitability is not always the primary driver for the adoption of conservation practices (Lutz et al. 1994, 287). However, it is logical to assume that those who think the cost of implementing conservation practices is worth the benefit are more likely to participate than those who feel otherwise. As such, BNEFIT is hypothesized to be positive. Lambert et al. (2006) included off-farm income in their evaluation of farmer participation in conservation programs (18). Naturally, farmers that have an annual household income that is greater than $\$ 90,000$ per year (INCOME) are hypothesized to be more likely to participate than those who earn less.

\subsubsection{NRCS Independent Variables}

Table 3.5 provides descriptions for the independent variables relevant to the NRCS side of the empirical model. 
Table 3.5: Independent variables relevant to NRCS

\begin{tabular}{|c|c|c|}
\hline \multicolumn{3}{|c|}{ Independent Variables: NRCS Side } \\
\hline RNDCTY & Organizational Capital ${ }^{1}$ & $\begin{array}{l}\text { Farmland location. Randolph County }=1 \text {. Pocahontas } \\
\text { County }=0 .\end{array}$ \\
\hline DSTNCE & Organizational Capital ${ }^{1}$ & $\begin{array}{l}\text { Distance in miles the respondent's primary residence is } \\
\text { from the county USDA Service Center. Discrete } \\
\text { variable. }\end{array}$ \\
\hline CAPCTY & Organizational Capital ${ }^{1}$ & $\begin{array}{l}\text { Whether the respondent felt there was enough } \\
\text { conservation organizations to provide farming-related } \\
\text { technical support to everyone that wants it. } 1=\text { yes. } 0= \\
\text { no. }\end{array}$ \\
\hline PERSNL & Organizational Capital ${ }^{2}$ & $\begin{array}{l}\text { Whether the respondent felt NRCS has enough staff } \\
\text { capacity to provide conservation technical assistance to } \\
\text { everyone in the county that wants it. } 1=\text { yes. } 0=\text { no. }\end{array}$ \\
\hline NRCS1 & Organizational Capital ${ }^{2}$ & $\begin{array}{l}\text { Who the respondent identified as teaching them the } \\
\text { most about NRCS conservation practices. } 1=\text { NRCS } \\
\text { staff. } 0=\text { all others. }\end{array}$ \\
\hline
\end{tabular}

Respondents were asked if their farmland was found in Randolph or Pocahontas County to see whether location influenced their decision to participate in the CTA program. The distance of survey questionnaire respondents from NRCS field offices further linked Organizational Capital $^{1}$ to empirical data. Another indicator for Organizational Captial ${ }^{1}$ asked farmers whether their county had enough conservation organizations to provide farming-related technical support to everyone who wants it (Chaskin et al. 2001; Kretzmann and McKnight 1993). Relatedly, farmers were asked whether NRCS has enough personnel to provide CTA, which operationalized Organizational Captial $^{2}$ (Reimer and Prokopy 2014; Stubbs 2010b; Cox 2007; Helms 2005). Lastly, respondents were also asked to indicate, in order of rank, who had taught them the most about NRCS conservation practices (Organizational Captial $^{2}$ ).

According to the CTA program participation modeling results, Randolph County (RNDCTY) is underserved while Pocahontas County is overserved. The assumption is that the closer one is to the local NRCS field office the more likely they are to participate in the CTA program. As such, RNDCTY is expected to have a negative coefficient meaning farmers with 
land in RNDCTY are less likely to consider participating than those with farmland in Pocahontas County. Similarly, given the importance of anchor institutions and inter-organizational collaboration to sustainable communities (Chaskin et al. 2001; Kretzmann and McKnight 1993), DSTNCE is expected to have a negative relationship to CNSDR.

Respondents who felt their community had an adequate amount of conservation organizations (CAPCTY) are expected to be more willing to participate-thereby CAPCTY should be positive (Chaskin et al. 2001; Kretzmann and McKnight 1993). The literature and local interviews described a personnel barrier to NRCS programs (Reimer and Prokopy 2014; Stubbs 2010b; Cox 2007; Helms 2005). As such, those who have not experienced this obstacle are hypothesized to be more willing to consider CTA program participation than those who have experienced this impediment. Therefore, PERSNL is expected to be positive in the model. According to Lambert et al. (2006), the availability of conservation experts may increase conservation practice implementation (28). Therefore, NRCS1 is expected to be positive meaning farmers that learned about conservation practices from NRCS staff are more likely to consider participating than those who learned about them from other sources.

\subsubsection{Survey Data Analysis}

To test for nonresponse error, the first and last mailings were color coded so they could be differentiated as wave one and wave two upon return. T-tests with an alpha threshold of 0.05 are regularly used for this evaluation (Johnson and Shoulders 2017, 304). Therefore, these were the metrics employed here. The discrete variables for acreage, percent forest cover, and age were tested, and no significant differences were found between the two groups. As such, findings were determined representative of the target population and therefore generalizable. 
To determine if distance between farmers and NRCS field offices affected CTA program participation (DSTNCE), the latitude and longitude of each respondent's primary residence, made known by the unique identifiers on the business reply envelopes, were determined by using an online locater and then entered into ArcMap 10.5.1. Farmers living outside the subject counties were excluded from the distance calculation so as not to misrepresent the results given those respondents are likely to visit the NRCS Service Center nearest to them. Distances between the farmers in the county and the local field office were then calculated by using the Point Distance feature in ArcToolbox. This tool measures the distance from an input feature, such as the NRCS field office, to all the nearby points in a specified extent. These distances were then exported to Microsoft Excel 2016.

The data for the remaining variables were analyzed through the estimation of a nonspatial regression model in STATA 15.1 to explore the factors influencing farmer participation. This regression analysis estimated the significance and statistical strength of the primary and secondary independent variables from the theoretical model given CNSDR as the dependent variable. The null hypothesis is that farmers in West Virginia that are willing to consider participating in the CTA program are the same as farmers not willing to consider. Conversely, the alternative hypothesis contends farmers in West Virginia who are willing to consider participating in the CTA program have different and measurable characteristics than farmers who are not willing to consider participating. As such, the null and alternative hypotheses are expressed as follows:

Ho: $\boldsymbol{\beta}=0$; There is no difference between farmers willing to consider and those unwilling to consider.

Ha: $\boldsymbol{\beta} \neq 0 ;$ Farmers willing to consider are not the same as those unwilling to consider. 
The response variable, then, is binary. Since there are only two possible outcomes for the dependent variable, the data is binomially distributed. To explain further, the link function (logit, probit, and complementary log-log) in non-normal distributions connects "the linear predictor to the mean of the response" and is a central concept of generalized linear models (GLMs) (Faraway 2006, 27). GLMs are used for binomial, multinomial, and Poisson distributions. Logistic regression - the logit link function - again, extends the linear model to include nonnormal responses (Agresti 2002, 116) that typically result from a non-linear relationship (Agresti 2002, 121). Logistic regression is the most salient model for categorical response data (Agresti $2002,165)$ and is therefore employed for estimation of the whole model. This estimation is as follows:

$$
\operatorname{Pr}(y=1 \mid x)=[\exp (\beta x)] /[1+\exp (\beta x)]
$$

In this formula, $\mathrm{y}=$ the probability that a respondent is willing to consider enrollment given $\mathrm{x} ; \mathrm{x}$ $=$ the independent variables; and $\beta=$ the model coefficients.

Regarding model specification, the dependent variable is whether or not the respondent was willing to consider participating in the CTA program-CNSDR (i.e., CTA Participation from the theoretical model). Therefore, if the participant responded affirmatively they were coded as " 1 " and if they were not willing to consider they were coded " 0 ." This empirical model is specified as follows: 


$$
\begin{aligned}
& C N S D R=\beta_{0}+\beta_{1} M E M B E R+\beta_{2} G R O U P+\beta_{3} W R K S H P+\beta_{4} P R M O T E+\beta_{5} K N W L D G+ \\
& \beta_{6} F R M E D U+\beta 7 I N F E D U+\beta 8 A G E+\beta 9 E D L V L+\beta 10 T R D I T N+\beta 11 V A L U E S+ \\
& \beta_{12} T I D Y+\beta 13 S A W C O N+\beta 14 S T E W R D+\beta{ }_{15} G O V E R N+\beta 16 N O N G O V+\beta 17 F A R M E R+ \\
& \beta_{18 A C R E S}+\beta_{19} F O C O V+\beta_{20} G R S L N D+\beta_{21} C O S T+\beta_{22} \text { TENURE }+\beta_{23} I N V E S T+ \\
& \beta_{24} P E R C N T+\beta 25 B E F I T+\beta 26 I N C O M E+\beta_{27} R N D C T Y+\beta 28 D S T N C E+\beta{ }_{29} C A P C T Y+ \\
& \beta 30 P E R S N L+\beta 31 N R C S 1+\varepsilon
\end{aligned}
$$

In this formula, $\beta \mathrm{i}=$ the variable coefficients; and $\varepsilon=$ random or unexplained error.

The averages and percentages for every question on the survey were calculated as descriptive statistics. There were no statistical tests conducted for this reporting as the intent of these descriptive statistics are to show the averages and percentages directly related to the responses provided by the participants. Summary statistics were reported for all the significant variables that were in the final model. These statistics included the mean and standard deviation for each predictor along with their minimum and maximum value.

The final model was selected using backward stepwise regression which starts with the full model containing all the independent variables. Beginning with this more complex model, backward stepwise elimination systematically removes insignificant variables with the highest $\mathrm{p}$ values until further deletions would result in a significantly worse model fit (Agresti 2002, 214). Forward stepwise regression was performed also which is the opposite approach. Beginning with no predictors, this method adds variables sequentially that provide the greatest improvement until further additions do not enhance the model fit (Agresti 2002, 2013).

Of course, stepwise methods should be used with caution (Agresti 2002, 214). As such, manual selection was conducted as well to allow for subject matter expertise and to compare findings. However, the model derived from the backward stepwise process ultimately provided 
the best results while also passing important diagnostic tests. Naturally, the primary goal is to select a model "that predicts well or explains the relationships in the data" (Faraway 2005, 130). To that end, the final model was selected to accomplish the latter purpose. 


\section{Chapter 4: Findings}

"CTA to me is what the Soil Conservation Service [NRCS] is all about. That is why it was established." $\sim$ NRCS Participant 8

This chapter presents the results of each method that contributes information useful to solving the research problem directly. While much of the interview results were used to design the farmer survey, findings are also directly relevant to answering the research questions, as discussed in the following section. Moreover, important findings are drawn from the results of the farmer survey data and analysis as well.

\subsection{Key Informant Interviews}

Farmers and NRCS staff were interviewed using protocols consisting of semi-structured, open-ended questions. The protocols had five sections: (1) an introduction; (2) building rapport; (3) evoking stories; (4) question statements; and (5) a conclusion. Each section was comprised of questions generated from the theory of change. The primary data collected was utilized to evaluate and adjust the theoretical model and develop a written survey. Results from both groups of participants are presented in each of the following subsections along with a brief statement of their analytic meaning.

\subsubsection{Farmer Interview Results}

Themes identified in the data from the farmer interviews can be placed into six major categories. Some of these categories consist of important sub-concepts. These categories and sub-concepts are as follows:

1. CTA participation: the key to conservation on the ground a. Good contracts come from CTA

2. Personal attachment to the land

3. Stewardship ethic

4. Cultural identity 
5. Barriers to participation
a. NRCS personnel
b. Knowledge
c. Fear of restrictions
d. Distrust of government
e. Bureaucracy
f. Cost

6. Farmer-to-farmer methods

For brevity, the passages reported in this section as support for these categories and their subconcepts have been limited to five exemplars per theme. However, additional quotes under most categories and/or sub-concepts reinforce these results.

\subsubsection{CTA Participation: The Key to Conservation on the Ground}

"Good contracts come from CTA" is an in-vivo code which means this sub-concept was derived from the actual words of a research participant (Corbin and Strauss 2008, 65). It refers to a phenomenon prominent in both the farmer and NRCS datasets that means participation in the CTA program often results in participation in other NRCS programs that include financial assistance. The following data reveal this cross-cutting sub-concept:

- I know that my dad did things with it [NRCS]. You know how you are when you're growing up you don't pay much attention. In later years, they have come out and we received assistance with the big tires. We received a grant for that. And fencing, to fence off the meadows, they helped with that. We're getting ready right now to build a feed shed. They helped us with the access road to build the feed shed. (Farmer Participant 1)

- I knew NRCS since childhood. I took the farms over from my mother who also used the programs. I think they picked up on the ones [programs] that we had in existence and we just followed on and as new programs became available and so forth. (Farmer Participant 8) 
- My father participated in a lot of soil conservation projects on the farm, helped us out quite a bit with lime and fertilizer and keeping the property in good shape. So, that's the sort of history of it, I would say. Oh, and on my farm, I was able to participate in the Conservation Reserve Program. It helped me fence off one of my ponds and I have a hook up that runs to a frost proof waterer and also helped me fence off the run off from the pond if it over flowed, we fenced off that area down to the road, to a culvert. So, that program helped me a lot. (Farmer Participant 10)

- Ever since I got the original plans done where all the fields were laid out, and the acreage was figured out, what was pasture, what was woods, that's how I started. Then we started talking about different programs I could work with. So, over the years I've had help with liming and fertilizing, help with fixing some erosion areas, the high tunnel, that was one of the biggest ones, a feed pad, a water trough, then three self-waterers which I couldn't have done earlier because I didn't have a well. I'm along the [Name] river so I conserve all the woodland along the edge of the river. (Farmer Participant 14)

- Participating in it gives you knowledge of how they operate and the agents they are very helpful here to let you know what is available to work you through it. (Farmer Participant 20)

These results were expected as this is the manner in which the CTA program is conceptualized in policy (CTA Participation). Initial technical assistance is provided to identify natural resource concerns and once a conservation plan is in place, financial assistance programs may be used to support implementation (USDA NRCS 2010, 525-A.1).

\subsubsection{Personal Attachment to the Land}

Many farmers indicated a "personal attachment to the land." The following quotes embody this theme:

- I grew up with my father as a big farmer. I guess I wanted to carry on his legacy somewhat. (Farmer Participant 1)

- I am a native of West Virginia and grew up on a farm and the farm has been in the family for many years... This is land I would never sell. (Farmer Participant 8)

- I want to see it be a farm for a hundred years and I don't want to see it turned into a second home development. That would just break my heart. (Farmer Participant 14)

- Just to keep it in the family, we have no intention of selling it. We've seen many examples of beautiful farms being sold and turned into trailer parks and camps and we have no intention of doing that. (Farmer Participant 15) 
- It's been in the family for quite a number of years and at the same time I really just understand the true importance of agriculture. (Farmer Participant 23)

This theme represents a form of Cultural Capital, in that an attachment was generally derived from a familial devotion that was passed down over time. This was an expected result because prior research has shown that participation in conservation programs can be motivated by a personal connection to the land (Oliver 2011; Farmer 2009).

\subsubsection{Stewardship Ethic}

"Personal attachment to the land" is intricately related to a farmer's desire to be a good steward (Ryan et al. 2003, 33). Indeed, these results indicate the presence of a "stewardship ethic" and "positive attitudes" toward conservation. The following data reflect this category:

- I have a strong stewardship ethic in me and a feeling of protectionism for the current land use. It needs to stay the same to keep its character. I saw the value in the farm and wanted it to persist. Actually, I wanted to improve it. (Farmer Participant 5)

- My Dad always had a saying that he always wanted to keep any land that he owned in better shape than when he bought it and that always stuck with me. (Farmer Participant 10)

- I really feel like as a farmer you should be a good steward. It's not just what I can get off of it this year. I'm hoping this farm will be here for generations to come. (Farmer Participant 11)

- They [NRCS] advocate conservation and that is what am I firmly attached to is conserving, making the best of what you have, but not drastically changing the environment of it. (Farmer Participant 20)

- I would say deeply devoted [to the land]. We try do what is right to preserve what we have worked for and what's been passed down or what we have all worked for at this point, so we can share with future generations. (Farmer Participant 22)

As expected, these findings reveal that most participants have a "stewardship ethic" and/or "positive attitude" toward conservation (Cultural Capital). Previous research has shown that land stewardship influences the adoption of conservation practices by farmers (Prokopy et al. 2014; Greiner and Gregg 2011). Moreover, farmer attitudes have shown to be a positive motivator as 
well (Arbuckle et al. 2018; Prokopy et al. 2014; Baumgart-Getz et al. 2012; Ma et al. 2010;

Prokopy et al. 2008).

\section{$\underline{\text { 4.1.1.4 Cultural Identity }}$}

Results show that rural West Virginia farmers often adhere to a "cultural identity" that distinguishes between "country folk" and "city folk." The following data represent this differentiation:

- It's definitely different in the city. I think they like to go out on an outing on a farm or to [Name] or something like that, but I think they are more wasteful in the city and that we conserve more. We're more conservative toward our land. I don't think they understand that part of it. (Farmer Participant 1)

- Well, most people don't live in the country and don't have a concept of land ownership or inter-generational stewardship. It's not part of their intellectual universe. (Farmer Participant 2)

- You appreciate more of the land, I mean people in the city have no idea. (Farmer Participant 9)

- I think urban areas have no clue what it means to farm and maintain the land. They would like other people to maintain the land as long as they can continue to build suburbs and they can buy cheap groceries, not that they realize the cost, the lifetime cost for people that are actually doing the work and maintaining the land. (Farmer Participant 11)

- It is a completely different way of life. I think the farmers take very good care of the land, you get somebody out of the city they wouldn't know how to take care of anything. It's just a piece of property to them. (Farmer Participant 18)

Several scholars contend that rural values are perceived by rural people to be in contrast to urban values (Flora et al. 2016, 74). These findings forward this aspect of Cultural Capital, as there is a stark dichotomy between how participants viewed "country folk" and "city folk."

\subsubsection{Barriers to Participation}

The most prominent "barrier to participation" was "NRCS personnel” (Organizational Capital $^{2}$ ). The following quotes illustrate this sub-concept: 
- I got trapped in the middle of staff turnover. I would start something with one guy and have to finish it with another. That was difficult. (Farmer Participant 5)

- I'd say, "Why don't you do that?" And they'd [another farmer] say, "Oh, I don't want to fool with all that paperwork." Now, if the [NRCS] guy came out and talked to them and helped them fill out the papers, that's fine. (Farmer Participant 7)

- [Barriers to participation are] Not all time restraints of the farmers, but time restraints of staff, too. (Farmer Participant 8)

- We were really excited. We thought we were going to get all of this help [from NRCS] and we didn't really care about the financial side, but we were starting literally from scratch. We had no fencing, we needed all kind of soils testing, and we needed everything. We were like literally building a farm from the ground up, and we were so excited because we thought we're going to get all this help instead of being out here in the dark not knowing what on earth we're doing, but we really did not have that happen. So, we ended up using a lot of YouTube. (Farmer Participant 12)

- I think it is the state of employment with the NRCS, at least from my perspective. I don't know if it's funding or personnel or what, but they don't seem to be as active as they use to be years ago to get out and do a farm plan. The farm plans that I have for this farm here, just out of curiosity, I thought it would be fun to have someone redo it, get new photos and all that, but they don't have the personnel to do it. At least that is what I was told several years ago, we can get on a list, but we can't get it done. That's why I was so interested in your thing, I'm very much involved in this and I'm glad you are working on this. I think a plan in any endeavor is good to follow. The farmer, coming out and educating a young 20 -year-old like myself or maintaining a relationship with a 60 -yearold like I am now is a good conservation step and its money well spent. I don't think there is enough of it anymore. (Farmer Participant 13)

These results were expected due to the policy shift that began with the 1985 Farm Bill (Johnson and Monke 2017; Cox 2007; Helms 2005; Zinn 2005), which eventually increased the workload of NRCS staff (Reimer and Prokopy 2014; Stubbs 2010b; Cox 2007; Helms 2005).

There was also a "lack of knowledge" "barrier to participation" found in the data. The following excerpts reveal this impediment:

- I really don't feel like I know enough about what NRCS is doing because I wasn't able to get very far there. (Farmer Participant 12)

- I think other people do not know that resource is out there, was out there, or can be. (Farmer Participant 13) 
- I think the biggest barrier is just learning about it, that first contact and to get the ball rolling. Even with the Golden Winged Warbler thing, I loved that, but I didn't even know where to start. (Farmer Participant 16)

- My general knowledge of conservation I would say my level is below average. (Farmer Participant 18)

- Maybe some smaller and larger scale farmers don't have education, aren't maybe as involved in conservation practices so they don't know what is available to them. (Farmer Participant 22)

Compounding this problem, the data also revealed a lack of participation in, and awareness of, field demonstrations and NRCS LWG meetings. For example, when asked about attending and participating in these opportunities, the majority of farmers said:

- No, I actually have not heard of that. (Farmer Participant 1)

- No, I haven’t [been to any]. (Farmer Participant 4)

- I didn't hear about it. (Farmer Participant 5)

- None, zero. (Farmer Participant 9)

- I didn't even know about it. I've never heard of it. (Farmer Participant 11)

As expected, these findings reveal a dearth of knowledge (Human Capital) regarding conservation practices. Formal education in rural areas has traditionally been a challenge (Flora and Flora 2013, 110); while a lack of detailed knowledge and awareness of conservation practices and programs has also been cited as a potential "barrier to participation" (Prokopy et al. 2014; Oliver 2011).

"Fear of restrictions" was another "barrier to participation" that was evident in the data. Farmers were concerned that participation might restrict what they could do with their private property (Cultural Capital). The following comments depict this fear:

- Sometimes I think they may go overboard a little bit with the wildlife habitat. (Farmer Participant 1) 
- I do not want strings attached to my decisions. (Farmer Participant 2)

- [Describe the biggest barrier you find] Maybe not having enough control over my farm. (Farmer Participant 4)

- I have a brother that's got a farm and he said he didn't want anybody down telling him how to do it or anything like that. (Farmer Participant 9)

- It's going to limit my choices for what I can do with the property. (Farmer Participant 10)

These sentiments were an expected result, given the cultural identities common in rural communities that often lead to a fear or mistrust of outsiders (Flora et al. 2016, 75).

Similarly, given the "fear of restrictions" that is widespread amongst farmers and other private landowners, it is logical to assume there is a general "distrust of government" as well. Indeed, this sub-concept was also found to be a "barrier to participation." These sentiments are embodied in the following passages:

- The reasons [for non-participation] are I warmly distrust the government. I do not want anybody's nose in my business. (Farmer Participant 2)

- Years ago, don't know which agency, there was an agency when I first moved here that had a lovely collection of aerial photos of land in the county and I remember looking at those pictures and I thought that was a great resource... I mean, I don't know how I feel about that kind of information being cataloged by the government, but I thought it was lovely to go and look at. (Farmer Participant 2)

- Speaking for some of my neighbors and a lot of people are resistant to any program, any government anything, including farm programming. (Farmer Participant 10)

- I think a lot of the large farmers, other than it benefits them financially like crop insurance the subsidies or whatever, tend to have more of a distrust, but that might just be my bias. (Farmer Participant 11)

- I say this, the farmers down there that I know, and I don't know a whole lot of them, maybe two or three, they seem to know what products they need to put on their farm to get the proper grazing and all that and I think the government ought to stay out their way. That's my opinion. (Farmer Participant 18) 
These findings reveal a lack of trust between farmers and the government (Cultural Capital).

These sentiments were expected, given that the literature discusses rural landowners and their negative perceptions of organizational trustworthiness (Flora et al. 2016; Oliver 2011).

Several participants expressed that there is a "bureaucracy" "barrier to participation." The following excerpts embody this notion:

- First of all, the system is very dense. There is a certain lingo and methodology. Also, the staff are used to the bureaucracy, but the farmer may not be. (Farmer Participant 5)

- [Describe the biggest barrier] Probably the paperwork and finance. (Farmer Participant 7)

- I'm a little intimidated because when you read some of the material, I understand the point where you have to design programs and you have the guidelines that this is what you have to do to get to this, and I want to be comfortable with following all the guidelines explicitly. (Farmer Participant 11)

- They are sticklers for details, I mean they do want you to do it just the way they want you to do it... I think it's a barrier for some people. (Farmer Participant 14)

- I don't know how they are now because it's been years since I used them, but back then they were rigid and a few times I had my neighbor, who worked for them, and he looked at some things for me, and I said, "I don't agree with that," and he said, "Neither do I, but that is what the government said." (Farmer Participant 21)

Indeed, other studies have alluded to a "bureaucracy barrier," and therefore this Human Capital obstacle was expected. For example, Reimer and Prokopy (2014) showed that program requirements and eligibility were barriers to participation in NRCS programs (326).

Lastly, many farmers described a "cost" "barrier to participation." These data illustrate that impediment:

- I think the budget is the big thing. (Farmer Participant 1)

- Depends on the recommendation, but in general the two greatest barriers are personnel and money. (Farmer Participant 2) 
- We worked on a project to fence cows out of the headwaters of [Place]. The neighbors weren't as interested in work like this because it doesn't immediately affect the pocket book... A lot of people don't have the time or the resources to do something like that. (Farmer Participant 5)

- Well, it would be finances, I mean if I am the one mostly doing it. (Farmer Participant 19)

- You have to watch out a little bit just in regards to the cost and the farm economy as it dips and turns. (Farmer Participant 23)

This Financial Capital ${ }^{l}$ barrier was expected since small-scale farmers relying on off-farm income may lack the financial resources to make conservation investments (Lambert et al. 2006,

$10)$.

\subsubsection{Farmer-to-Farmer Methods}

The importance of "farmer-to-farmer methods" was evident in both the farmer and NRCS interviews. The following quotes illustrate this central theme:

- I mean that's [farming] all they discuss. That's all you discuss if you go to a restaurant and there is another farmer in there. That's what they're doing. That's all they talk. (Farmer Participant 1)

- Just word-of-mouth, maybe seeing somebody doing something and they tell you what they are doing, explaining a little, but it's just word-of-mouth from neighbors. (Farmer Participant 9)

- We all get around and work, we are having our annual ramp supper next week and we all sit around, and we've cleaned about seventy-five bushels of ramps. We got about twothirds done and we all get around and work on that and talk about stuff. (Farmer Participant 13)

- The conversations at the store in the morning, probably forty or fifty percent of it, involves raising cattle, harvesting grain, good techniques for maximizing yield. In fact, until this very conversation it never dawned on me how much our casual conversation is directed at the practicality of maximizing the productivity on the farm. Pretty interesting for me to think about. (Farmer Participant 15)

- That is really the way a lot of things get shared, just say your neighbor has something that seems to be working well, you start asking questions as to how they came up with that or where it came from. If NRCS name comes up, then it's something you have to investigate a little bit more. (Farmer Participant 23) 
As reflected in these comments, the many benefits of "farmer-to-farmer methods" are expressed in the literature (Sosa et al. 2013; Holt-Giménez 2006; Enshayan et al. 1992) and the importance of social networks to farmer decisions is also thoroughly documented (Arbuckle et al. 2018; Prokopy et al. 2014; Reimer et al. 2014; Reimer and Prokopy 2014; Baumgart-Getz et al. 2012; Prokopy et al. 2008; Knowler and Bradshaw 2007; Pannell et al. 2006; Mathijs 2003). Therefore, these Social Capital results were expected based on this wealth of secondary evidence.

\subsubsection{NRCS Staff Interview Results}

Themes identified in the data from the NRCS staff interviews can be classified into six major categories as well. Similar to the farmer interviews, some of these categories have salient sub-concepts. These categories and sub-concepts are as follows:

1. CTA participation: the key to conservation on the ground
a. CTA defined
b. Good contracts come from CTA

2. NRCS customer service culture

3. Building trust

4. NRCS organizational barriers
a. Shift in agricultural and conservation policy
b. Personnel
c. Participatory training need

5. Organizational collaboration

6. Farmer-to-farmer methods

a. Underutilization of farmer groups

For brevity, quotations have been limited to five exemplars per category and/or sub-concept.

\subsubsection{CTA Participation: The Key to Conservation on the Ground}

The CTA program has been, and continues to be, elemental to NRCS as an agency.

NRCS staff defined CTA Participation as follows: 
- Just them stopping by and asking for help on anything. Every year when Southern States said they were going to take book prices on fertilizer, because this time of year before its more expensive, they would come to me and bring all their soil tests. And they'd say, "Hey [Name], tell me what I need to put on my fields." And I would sit and go through their soil tests and make fertilizer recommendations. And they had big farms and it would take a couple days. But that instead of them putting down nutrients they didn't need. (NRCS Participant 1)

- Participation is actively seeking your advice, listening to it, implementing it, and with follow-up, refining it and making adjustments to it. (NRCS Participant 2)

- I would consider them participating in the program if I just give them advice. (NRCS Participant 4)

- It could be as simple as a customer with a phone call and a conversation, that route, and on the other end of that, doing face-to-face visits and developing a conservation plan and implementing it - that's probably going to involve numerous visits. (NRCS Participant 5)

- The best example, that just occurred to me, of performing CTA in the field, a guy came in and asked if we would come over and lay out contours and we just sort of shot several grades and laid stakes for him and that was it. No plans were written, no contracts were written. We were helping him reach a conservation goal. (NRCS Participant 7)

These results were unanticipated, given that the literature defines participation in the program as the voluntary implementation of at least one conservation practice on private land (Stubbs 2010a; Cowan and Johnson 2008). These interview responses indicate NRCS staff adhere to a much broader definition of program participation that ranges from simply providing advice to developing conservation plans and designing practices that require multiple field visits.

The concept that "good contracts come from CTA" is the in-vivo code that cross-cut both the farmer and NRCS interviews. The centrality of CTA to the other available programs is presented by NRCS staff in the following comments:

- I guess the main thing on the CTA, we've just gotten into writing contracts so much. And when we go to measure success, it's all about number of contracts written and the number of contracts completed... But the good contracts come from the CTA. (NRCS Participant 1)

- FA [financial assistance] should start with CTA. But CTA shouldn't always lead to FA. (NRCS Participant 2) 
- Most of the farmers when they come in they have a goal in mind. When they apply for cost sharing they know what they are wanting to do. I think the CTA program can get them interested in the cost share program by telling them, "Hey, you can do this, if you would build a fence through here, and develop water there, and you got a problem here with water erosion in the winter time with a lot of manure seeping into streams, you can move the cattle farther back." I think they would start thinking, and it is critical in a lot of cases. (NRCS Participant 3)

- It should start with the advice and the planning, coming up with the plan. And then taking from the plan if there is an opportunity for financial assistance. It works best to start with CTA. (NRCS Participant 4)

- I think it [CTA] is the foundation for financial assistance. (NRCS Participant 5)

These and other participants made it abundantly clear the intent of CTA Participation is to play an initiating role to financial assistance programs. This result was expected, given that the CTA program is designed to "serve as a springboard for those interested in participating in NRCS financial assistance programs" (USDA NRCS n.d.[b].).

\subsubsection{NRCS Customer Service Culture}

An "NRCS customer service culture" arose from the data that is reflective of the agency's motto of "helping people help the land." The next quotations symbolize this culture as the participants discuss the most rewarding aspects of their careers:

- Whenever I went out on a farm and I was able to see a situation that was giving a farmer a lot of trouble and being able to say, "Here's what we have to offer-there's a better way!" (NRCS Participant 1)

- CTA with farmers. Working where they didn't really expect to get a financial incentive, but were just looking for advice. (NRCS Participant 2)

- It was rewarding to see farmers happy with the assistance they received. (NRCS Participant 3)

- When I see a customer learn about conservation and implement, then be thankful for what it has done to their land, I see them with that fulfillment, that is rewarding. To see them be productive from the standpoint of conservation and be happy about that. (Participant 5) 
- I would say the most rewarding aspects of my job would be working with a producer, convincing them of a plan of attack to meet their goals, and to meet our goals as an agency, and when the two of those goals are achieved by a plan that myself and others have worked on, and I have significant input on, comes to pass, and it works and building a relationship with that producer from there on. (NRCS Participant 9)

These Organizational Capital ${ }^{2}$ results were expected, given that NRCS delivers services through field offices so that trained conservationists can easily work one-on-one with farmers (Helms 2005, 1).

\subsubsection{Building Trust}

While customer service is an agency value, it will fall woefully short where there is distrust between staff and clients. NRCS staff expressed that establishing relationships with farmers is an important aspect of their jobs. The following quotes illustrate this need:

- Sometimes you have to sit there and pet the dog, meet the kids, and meet the wife. Because that's part of getting that trust. A lot of people rush back to the office. These are rural people and when you rush in and say, "Let's put the trough here, now sign here, sign there- they start backing up." (NRCS Participant 1)

- Actually, I was learning more from the farmers than they were getting from me. My boss, knowing my lack of experience said, "[Name] you just shut up and listen." I never pretended to know more than I did. I did, I shut up and listened, and asked a lot of questions. The reward came a few years down the road when I was able to give them some information that was based on the training that I had, the seat of the pants learning from the farmers, and the research that I would do on my own. (NRCS Participant 2)

- I think that was probably more of the job [prior to the policy shift], that of being out and about, having more of a relationship where you just stop by. (NRCS Participant 7)

- When I started it was a different scenario because I grew up in the [Name] end of the county and I established a rapport with people in that area. (NRCS Participant 8)

- We say it's a job, but a lot of these plans create friendships and relationships. (NRCS Participant 9)

These results show that NRCS staff must invest the time and energy required to "build trust" with farmers (Organizational Capital $^{2}$ ). These findings were expected because studies have 
shown that recommendations from people whom farmers trust play an important role in their adoption of conservation practices (Prokopy et al. 2014, 3).

\subsubsection{NRCS Organizational Barriers}

The following passages illustrate a "shift in agricultural and conservation policy" as experienced by the NRCS staff.

- When we took over EQIP, it really changed. A lot of people stopped making conservation planning a priority. And there wasn't time, because when you have to dot every "I" and cross every "T." There is only so much time. (NRCS Participant 1)

- After '97 the technical began to dwindle as the cost share programs became far more popular. (NRCS Participant 3)

- [Work satisfaction was highest] When I first started and I was out in the field meeting with a lot of people before the contracts and paperwork started piling up. I would say over fifty percent in the field verses the office compared to now, it's a rare day when I get in the field. (NRCS Participant 4)

- Usually we have the cart ahead of the horse. There's an application being signed before there is a conservation plan ninety percent of the time. (NRCS Participant 7)

- Well, like I said, back when we was in the field four days a week, and when I say in the field, I don't mean you were there for an hour and then back to the office, I mean eight hours a day, if not longer, depending on what you was doing. And now you may get out in the field two or three hours a day or two or three hours a week. So, you can't get a full day out of the office for actual CTA work, or actual planning work. (NRCS Participant 9)

These results relate to Political Capital and Financial Capital $^{2}$, and were expected due to the overarching macro context being the policy shift found in the literature (Johnson and Monke 2017; Cox 2007; Helms 2005; Zinn 2005). However, they do reveal that, despite the importance of the 1985 Farm Bill and its significant conservation provisions, this policy shift did not influence CTA implementation in the field until much later.

NRCS staff who took part in this study overwhelmingly indicated the presence of a "personnel barrier." The following excerpts are evidence of this limitation: 
- I feel like it's [CTA] kinda fallen by the wayside and that's just because there's only so much time in the day. (NRCS Participant 1)

- Getting the most conservation on the ground [is the purpose of the CTA program]. The most, for the most people, and the most acres. That is what really bothers me about what we have become. Because we are servicing a lot fewer people than we were years ago. (NRCS Participant 2)

- There was more back then than now. Back then every field office was full staffed and there was at least one Soil Conservationist, [Soil Conservation] Technician, and DC [District Conservationist] in every office at least. (NRCS Participant 4)

- We are a technical agency and need to be spending a lot of time in the field, but because of my job responsibilities, I have to spend more time in the office. (NRCS Participant 5)

- I'm not sure a lot of people know that we can do as much as we can with technical assistance. But between, I almost don't want a lot of it, like with the limitations of our time and resources. (NRCS Participant 7)

As expected, the data reveals the primary "NRCS organizational barrier" to CTA program participation is a shortage in "personnel” (Reimer and Prokopy 2014; Stubbs 2010b; Cox 2007;

Helms 2005). Since the policy shift (Johnson and Monke 2017; Cox 2007; Helms 2005; Zinn 2005) there has not been enough staff to implement the CTA program as originally designed (Cox 2007, 135)—a deficit in Organizational Capital ${ }^{2}$.

Moreover, a distinct "participatory training need" emerged from the data due to the low participation rates in the EQIP Focused Conservation Approach (FCA) and its Local Work Groups (LWGs) in West Virginia, as reported by the participants. The following references illustrate this shortfall:

- It has been difficult getting good participation and I think other [Titles] have had the same thing. Even some of the District Supervisors don't seem to be, despite that, there are farmers themselves don't seem to have the ideas and forethought for what needs to be done. I don't like to lead them in any direction, but we don't seem to be getting much from them. And I have tried to involve other partner agencies and you just don't get much participation. It's really difficult to get participation. (NRCS Participant 2) 
- There was a few [LWG members] that tried to hand pick, but there were some folks who didn't have something personal to gain and were trying to do it for the watershed. But I think it could be useful. It has to be managed properly. Some people just turn it over to a group. It's good to get ideas from a group, but there needs to be management over it. (NRCS Participant 3)

- Currently, I've noticed with our group meetings we don't get a lot of outside participation. (NRCS Participant 4)

- Bad thing about it, our meetings were during the work day. I mean, you're not going to get, whether it's a producer that's not a full-time farmer, you're not going to get them because obviously they're working or full-time farming is busy. So, to me, I think you could probably work around other meetings and plan them more for the evenings. (NRCS Participant 6)

- I think it's a great idea. I think we should start doing it! There just wasn't a whole lot of local participation. (NRCS Participant 7)

Unfortunately, there has been little to no professional development related to public participation and community engagement (Organizational Capital $^{2}$ ). Most all of the participants had received abundant technical training. However, there was a conspicuous lack of training in public participation methods. The following passages illustrate this deficiency:

- So, there was some on the job training, but nothing formal. (NRCS Participant 1)

- I don't recall any. It might have been a small part of some training I had, but I don't remember any. (NRCS Participant 2)

- No, I haven’t [had training]. Yes, that would be good. (NRCS Participant 3)

- [Have you received any public participation or community development related training?] Mmm, not really. (NRCS Participant 4)

- No. That [public participation training] would be interesting. (NRCS Participant 7)

This lack of training in public participation and community development was expected, due to the fact that CTA funding levels have remained the same over recent years (USDA 2018; Reimer and Prokopy 2014; Stubbs 2010b; Cox 2007). Moreover, while LWGs have been used by NRCS for watershed scale and areawide conservation planning in the past (USDA NRCS 2014; USDA 
NRCS n.d.[a].), LWGs for the FCA approach is new to West Virginia. As such, this need for training may just be coming to light.

\subsubsection{Organizational Collaborations}

When asked about "organizational collaborations," NRCS staff focused on the following agencies and organizations:

- They sublet me to the Forest Service. The Mon National Forest didn't have a [Title]. They didn't have enough funding for their own person. (NRCS Participant 1)

- The 319 Programs where West Virginia Department of Agriculture, and DEP had involvement in that as far as funding I guess, and then the flood work with the [Conservation] Districts and the West Virginia Conservation Agency. (NRCS Participant 3)

- Extension has been a partner and helper along the way. (NRCS Participant 5)

- We worked with the Forest Service and provided a lot of technical assistance because they were providing the money because it was their contract. (NRCS Participant 6)

- I do enjoy the fact that we do reach out, or are reached out to by Trout Unlimited, different partners, like the Forest Service, and I've had a couple of conversations with local governments recently. (NRCS Participant 7)

These findings, which are related to Organizational Capital ${ }^{2}$, show that NRCS has historically worked with partners such as the West Virginia Division of Forestry (WV DOF), West Virginia Department of Agriculture (WVDA), West Virginia Department of Environmental Protection (WV DEP), the local Conservation Districts/West Virginia Conservation Agency (CDs/WVCA), WVU Extension, and Trout Unlimited (TU). These results were expected, given that NRCS as a whole has a long background of working with such agencies and organizations (Stubbs 2010b, $10)$.

\subsubsection{Farmer-to-Farmer Methods}

"Farmer-to-farmer methods" are a cross-cutting category between the farmer and NRCS interviews. The following data are responses that support this category: 
- Yeah, [Name]'s Gas Station down at [Place]. There's a big group of them that would get together every morning and they would talk. You learned really quick that you had to be consistent because they talked amongst themselves. They'd talk and then come in and ask you about it. (NRCS Participant 1)

- Oh yeah, honestly, I think word-of-mouth is very important. I think that more so than the media. Truthfully, I've seen that happen a lot. (NRCS Participant 3)

- Because it's not just an employee standing out there talking, but it was a producer talking about what he did, how it helped his bottom line, and how he improved his operation. (NRCS Participant 6)

- Yes, landowner number one would say to landowner two, "You ought to call the [Soil] Conservation Service, they helped me out on this spring development." And they would listen to that maybe greater than us trying to follow-up with everybody. Word-of-mouth recommendations, people followed that very easily. (NRCS Participant 8)

- I think that, I really believe, the message you put in newspapers are probably a waste compared to a meeting with the more prominent producers involved in that meeting you actually get more outreach done that way than a newspaper article. (NRCS Participant 9)

These results illustrate the effectiveness of "farmer-to-farmer methods" as discussed in the literature (Sosa et al. 2013; Holt-Giménez 2006; Enshayan et al. 1992). Moreover, they also corroborate the well-established centrality of social groups (Arbuckle et al. 2018; Prokopy et al. 2014; Reimer et al. 2014; Reimer and Prokopy 2014; Baumgart-Getz et al. 2012; Prokopy et al. 2008; Knowler and Bradshaw 2007; Pannell et al. 2006; Mathijs 2003). However, the "underutilization of farmer groups" emerged as a sub-concept within this category. The following passages highlight this underutilization:

- No, [we worked with] the [Conservation] Districts, but I never had any involvement where farm groups were involved. (NRCS Participant 3)

- There're some groups that I've heard of we don't reach out to I guess. (NRCS Participant 4)

- I hate to say we don't have any new innovative ways of going about it, but we have done it from the stand point of our field days, educational meetings, we have gotten good assistance from our State Office, folks in the public outreach department to put advertisements in our local paper as events and programs are announced. (NRCS Participant 5) 
- At the field office level, we don't have a lot of direct contact with farmer groups or organizations. (NRCS Participant 6)

- Well, we didn't work with the groups, so hypothetically if we were involved with that, just trying to let people know what was available to them. (NRCS Participant 8)

This finding was unexpected because of the effectiveness of these methods and their potential to increase not only Organizational Capital ${ }^{2}$ but also Natural Capital, as found in the literature (Sosa et al. 2013; Holt-Giménez 2006; Enshayan et al. 1992). Furthermore, the West Virginia Food and Farm Coalition has been actively promoting and supporting peer-to-peer farmer networks since 2010. Indeed, these results show that, to-date, there has not been much agency engagement where farmer groups are concerned.

\subsection{Farmer Survey}

A written questionnaire was mailed to all the farmers in Randolph and Pocahontas Counties. The surveys had three sections: (1) farm information; (2) motivations for participation; and (3) demographics. Each section contained a series of questions based on the theory of change. Variables derived from these survey questions were included in an empirical model that was used to evaluate the theoretical model.

\subsubsection{Descriptive Statistics}

Descriptive statistics for each section are shown in the subsections that follow. These results are provided primarily to show the direct responses to survey questions given by the respondents and to better understand the underlying data used in the empirical model. 


\subsubsection{Dependent Variable}

The dependent variable for this study (CNSDR) is whether or not the farmland owner was willing to consider participating in the NRCS CTA program. Only a slight majority of respondents $(55.8 \%)$ were willing to consider participating. Respondent willingness to consider participating in the CTA program is illustrated in Figure 4.1.
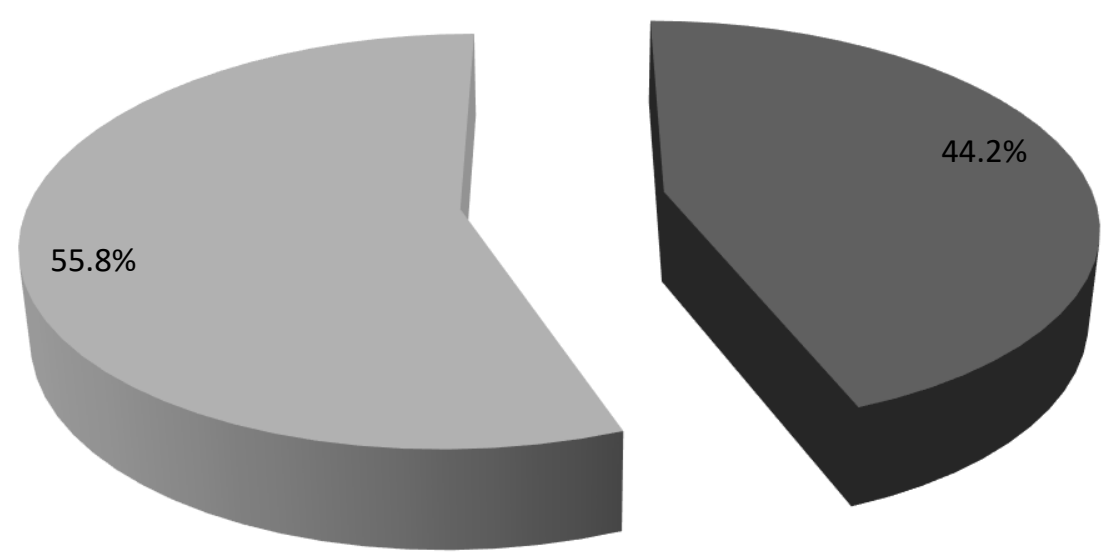

$$
\begin{aligned}
& \text { No } \\
& \text { Yes }
\end{aligned}
$$

Figure 4.1: Would you ever consider participating in the NRCS CTA program? As reported by farmland owners in Randolph and Pocahontas County, WV, 2018 (n=398).

\subsubsection{Farm Information}

As shown in Figure 4.2, most of the farmlands owned by respondents were located in Pocahontas County (64.8\%), while the remaining 35.2\% were in Randolph County $\left(\right.$ Organizational Capital $\left.^{1}\right)$. 


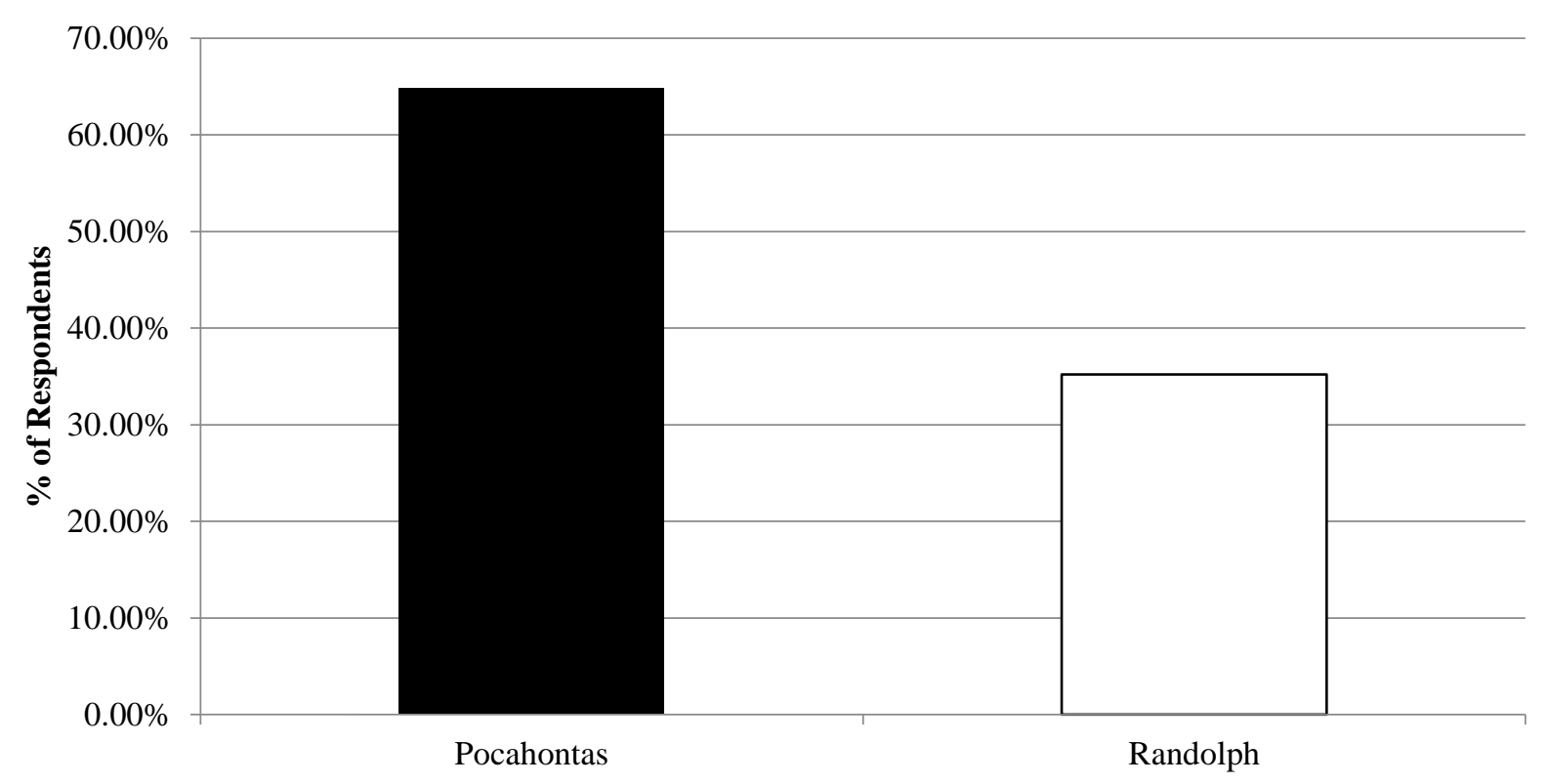

Figure 4.2: Property location as reported by farmland owners in Randolph and Pocahontas County, WV, $2018(n=455)$.

Table 4.1 presents the averages for the continuous variables in the farm information section of the survey. Farmers were asked how many acres they owned and what percentage of the property had forest cover (Financial Capital $^{1}$ ). Respondents reported an average of 230.37 acres, of which a little less than half (43.0\%) was comprised of forestland. In addition, distances $\left(\right.$ Organizational Capital $^{1}$ ) from the respondent's property to the local NRCS Field Office were calculated in GIS. Results showed this mean distance to be 11.78 miles.

Table 4.1: Property statistics as reported by farmland owners in Randolph and Pocahontas County, WV, 2018.

\begin{tabular}{|l|c|}
\hline \multicolumn{1}{|c|}{ Description } & Mean \\
\hline Acres owned & 230.37 \\
\hline Percent forest cover & 43.01 \\
\hline Distance from Field Office (miles) & 11.78 \\
\hline
\end{tabular}

Respondents were also asked to identify their primary and secondary land uses (Financial Capital $^{1}$ ). Hay (45.7\%) and pastureland (38.8\%) were most common for primary with timber, hunting, cropland, and "other" cited much less (Figure 4.3). The findings were similar for 
secondary land uses where hay and pasture were again the leading categories with a notable disparity between these two land uses and the others (not pictured).

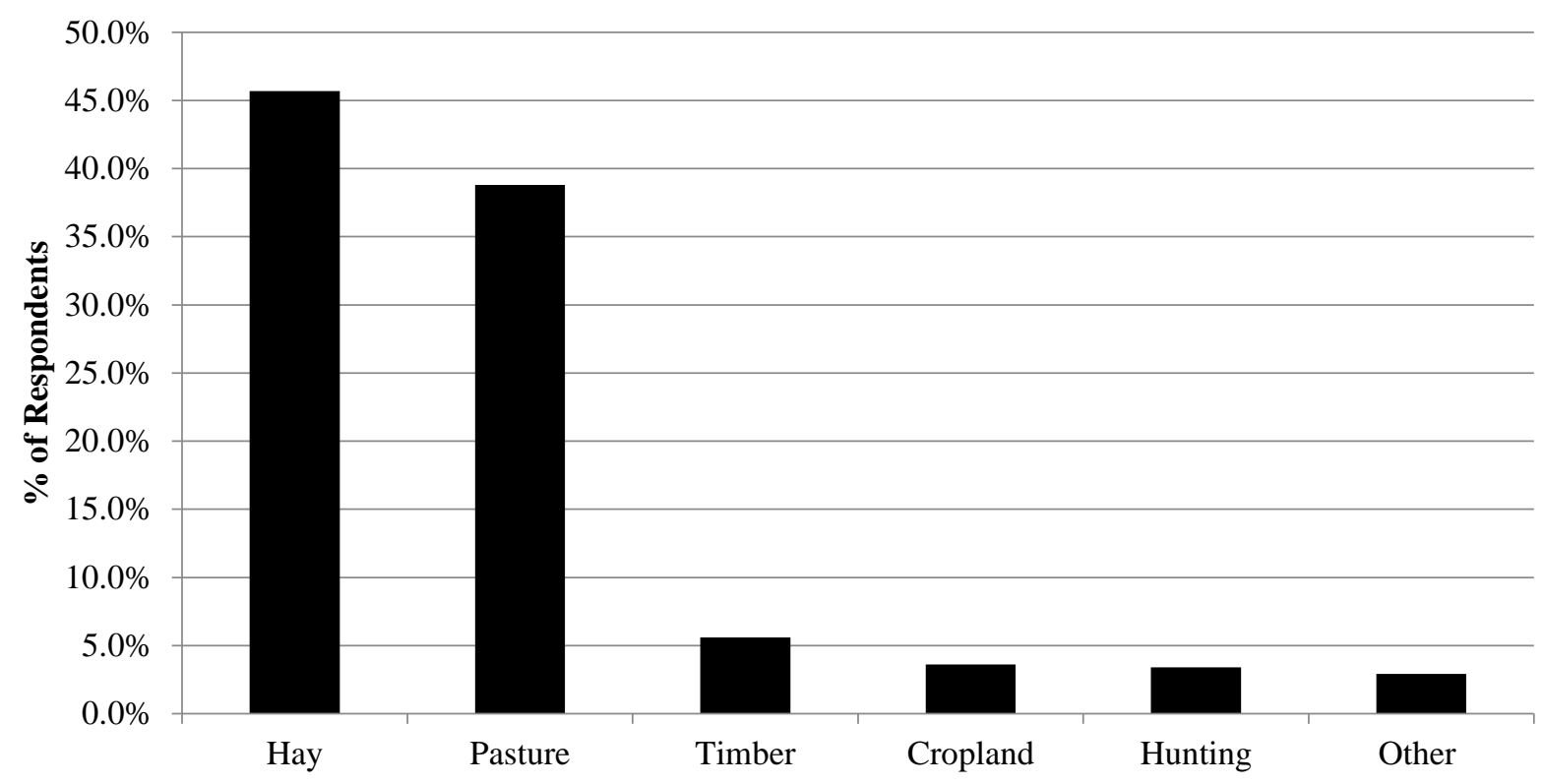

Figure 4.3: Primary land use as reported by farmland owners in Randolph and Pocahontas County, WV, $2018(n=446)$.

\subsubsection{Motivations for Participation}

Respondents whose farming techniques had been influenced by their parents or grandparents (Cultural Capital) constituted $72.5 \%$ of the sample population (Figure 4.4).

Moreover, Figure 4.5 shows an overwhelming majority of farmers $(96.2 \%)$ felt values held by rural folks were different than those held by folks in urban areas (Cultural Capital). 


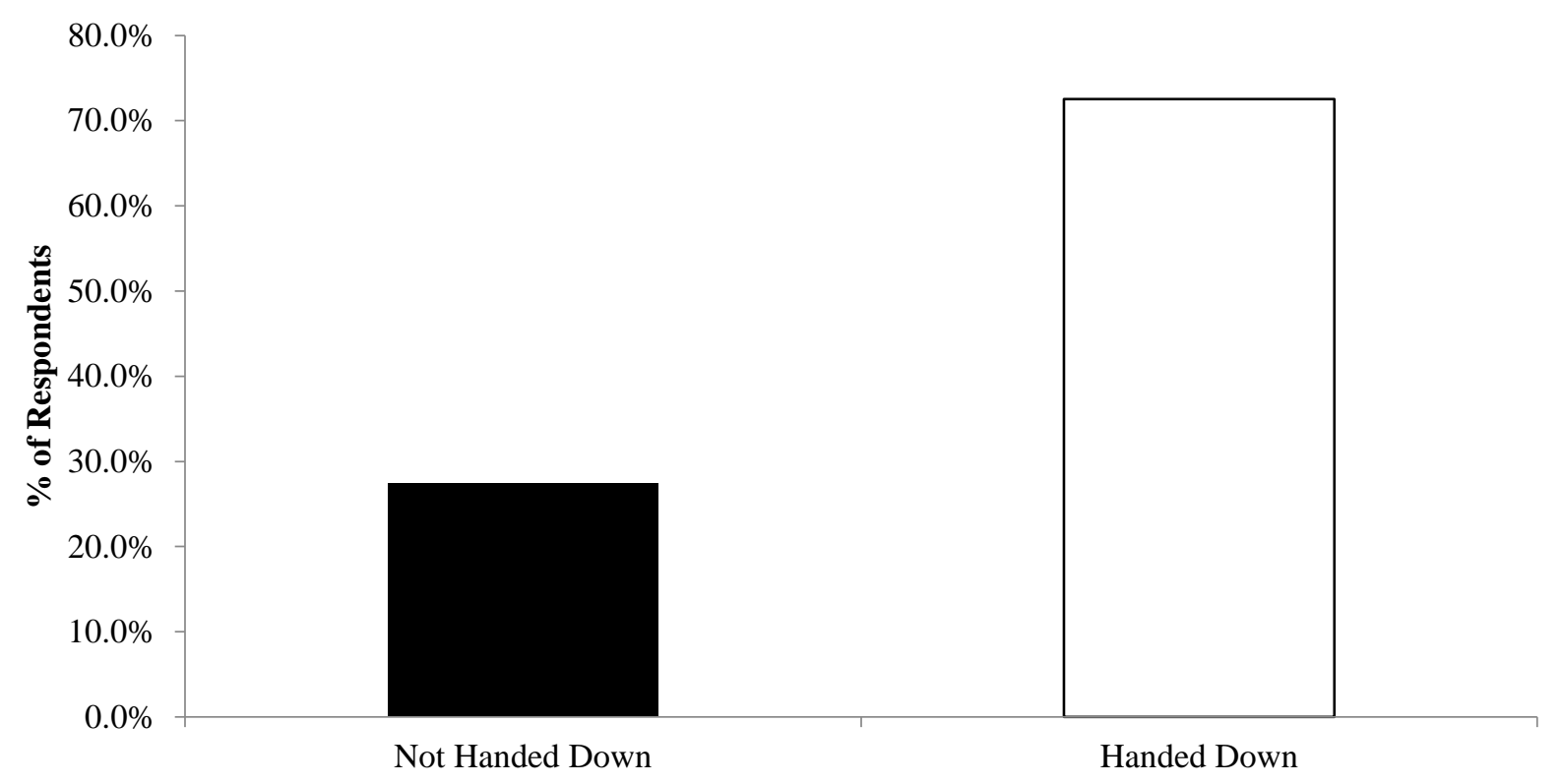

Figure 4.4: Farming traditions handed down as reported by farmland owners in Randolph and Pocahontas County, WV, $2018(n=448)$.

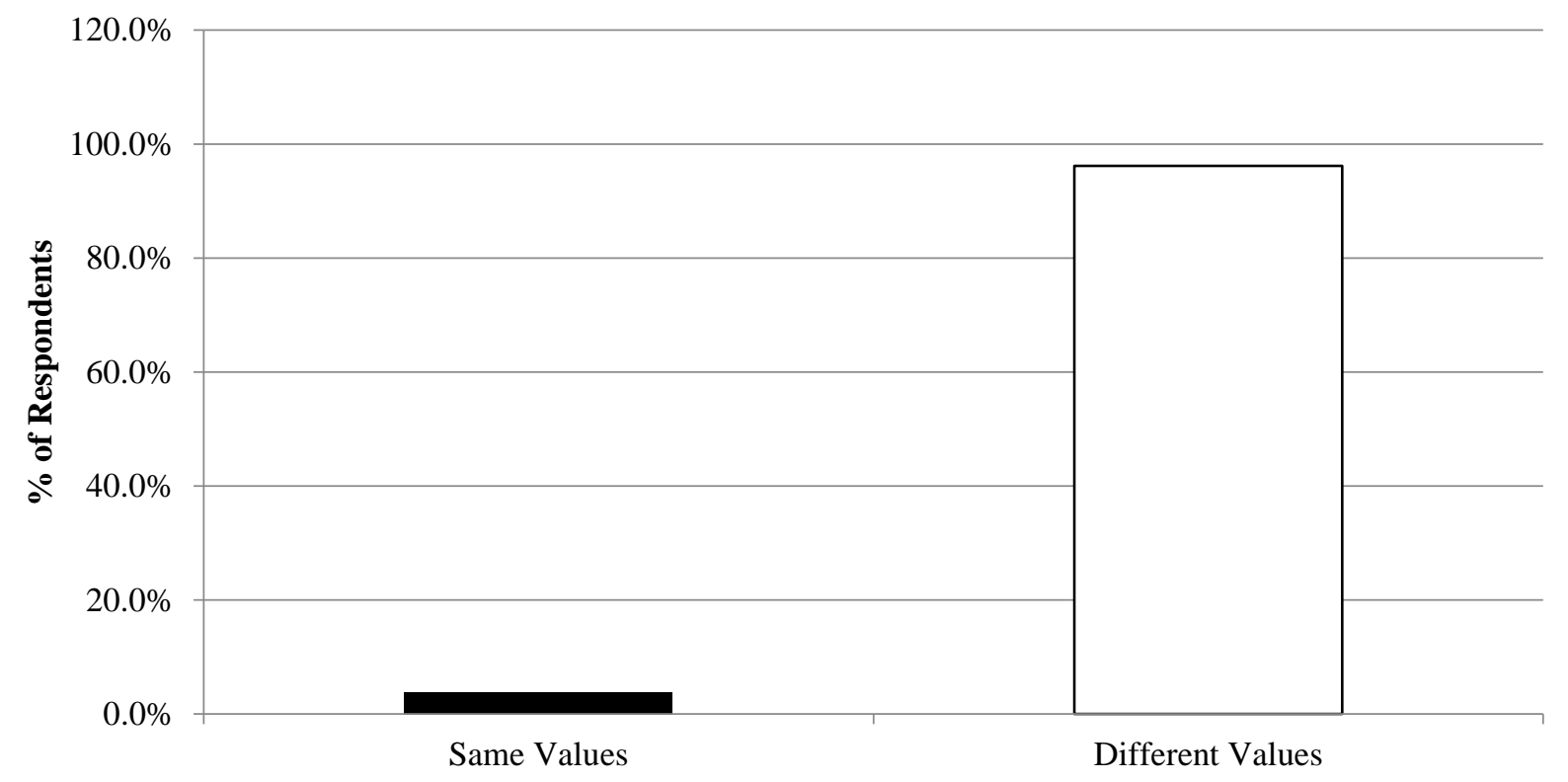

Figure 4.5: Whether the respondent thought values held by country folks differed from values held by folks in urban areas as reported by farmland owners in Randolph and Pocahontas County, WV, $2018(n=443)$.

Farmers were asked a series of Cultural Capital questions related to the importance of land conservation and stewardship (Table 4.2). Answers to these survey questions were ordinal in nature, with Likert scale scores ranging from one to five. Farmers felt fairly strong about their 
role as a land steward provided this category had the highest average score of 4.10. Furthermore, results showed that respondents generally felt soil and water conservation practices were important as well (3.96). The mean scores related to importance of aesthetically tidy-looking as well as aesthetically natural-looking landscapes were rather high at 3.70 and 3.69 respectively. Lastly, mean scores for the importance of NRCS conservation practices were lowest of the five categories, at 3.35.

Table 4.2: Importance of land conservation and stewardship as reported by farmland owners in Randolph and Pocahontas County, WV, 2018.

\begin{tabular}{|l|c|}
\hline \multicolumn{1}{|c|}{ Description } & $\begin{array}{c}\text { Mean Likert Score: 1 = not important } \\
\text { and 5 = extremely important }\end{array}$ \\
\hline Land stewardship & 4.10 \\
\hline Soil and water conservation practices & 3.96 \\
\hline Aesthetically tidy-looking farming landscapes & 3.70 \\
\hline Aesthetically natural-looking farming landscapes & 3.69 \\
\hline NRCS conservation practices & 3.35 \\
\hline
\end{tabular}

Respondents were also asked about their perception of organizations (Cultural Capital) that have the potential to provide conservation technical assistance (Table 4.3). Each farmer was asked to rate the trustworthiness of federal (e.g., USDA) and state agencies (e.g., WVCA), NGOs (e.g., WVLT), and farmer organizations (e.g., Farm Bureau). Respondents reported the most trust in farmer groups (3.18) while local agencies were close behind (3.14). Federal agencies came third with an average of 2.93, while NGOs received the lowest score at 2.79.

Table 4.3: Organizational trustworthiness as reported by farmland owners in Randolph and Pocahontas County, WV, 2018.

\begin{tabular}{|l|c|}
\hline \multicolumn{1}{|c|}{ Description } & $\begin{array}{c}\text { Mean Likert Score: 1 = not trustworthy } \\
\text { and 5 = extremely trustworthy }\end{array}$ \\
\hline Farmer groups, etc. (e.g., Farm Bureau) & 3.18 \\
\hline Local agencies (e.g., WVCA) & 3.14 \\
\hline Federal agencies (e.g., USDA) & 2.93 \\
\hline Non-governmental organizations (e.g., WVLT) & 2.79 \\
\hline
\end{tabular}


Conservation practice knowledge and training (Human Capital) was assessed in the questionnaire as well (Table 4.4). Specifically, farmers were asked to rate their understanding of management, vegetative, and structural conservation practices. Respondents reported a moderate grasp of these activities, with a mean score of 2.79 on the five point scale. In addition, farmers had received comparatively more informal than formal training, with average scores of 2.08 and 1.70 , respectively.

Table 4.4: Conservation practice knowledge and training as reported by farmland owners in Randolph and Pocahontas County, WV, 2018.

\begin{tabular}{|l|c|}
\hline \multicolumn{1}{|c|}{ Description } & $\begin{array}{c}\text { Mean Likert Score: } \mathbf{1}=\text { none and 5 = } \\
\text { extensive }\end{array}$ \\
\hline Knowledge of conservation practices & 2.79 \\
\hline Informal training (e.g., field days, etc.) & 2.08 \\
\hline Formal training (e.g., conferences, etc.) & 1.70 \\
\hline
\end{tabular}

Organizational Capital ${ }^{2}$ was measured further by asking respondents to rank (by indicating 1,2, and 3) who had taught them the most about NRCS conservation practices. As illustrated in Figure 4.6, farmers were primarily taught by other farmers (29.9\%), their parents (21.7\%), and NRCS staff (20.2\%). A large decrease occurred between these top three groups and the other categories. Furthermore, when it came to the secondary teaching role, other farmers and NRCS were cited first (23.8\%) and third (14.2\%) again (Figure 4.7). Lastly, sources of knowledge ranked as third-most in teaching conservation practices to farmers were rather evenly distributed (not pictured). 


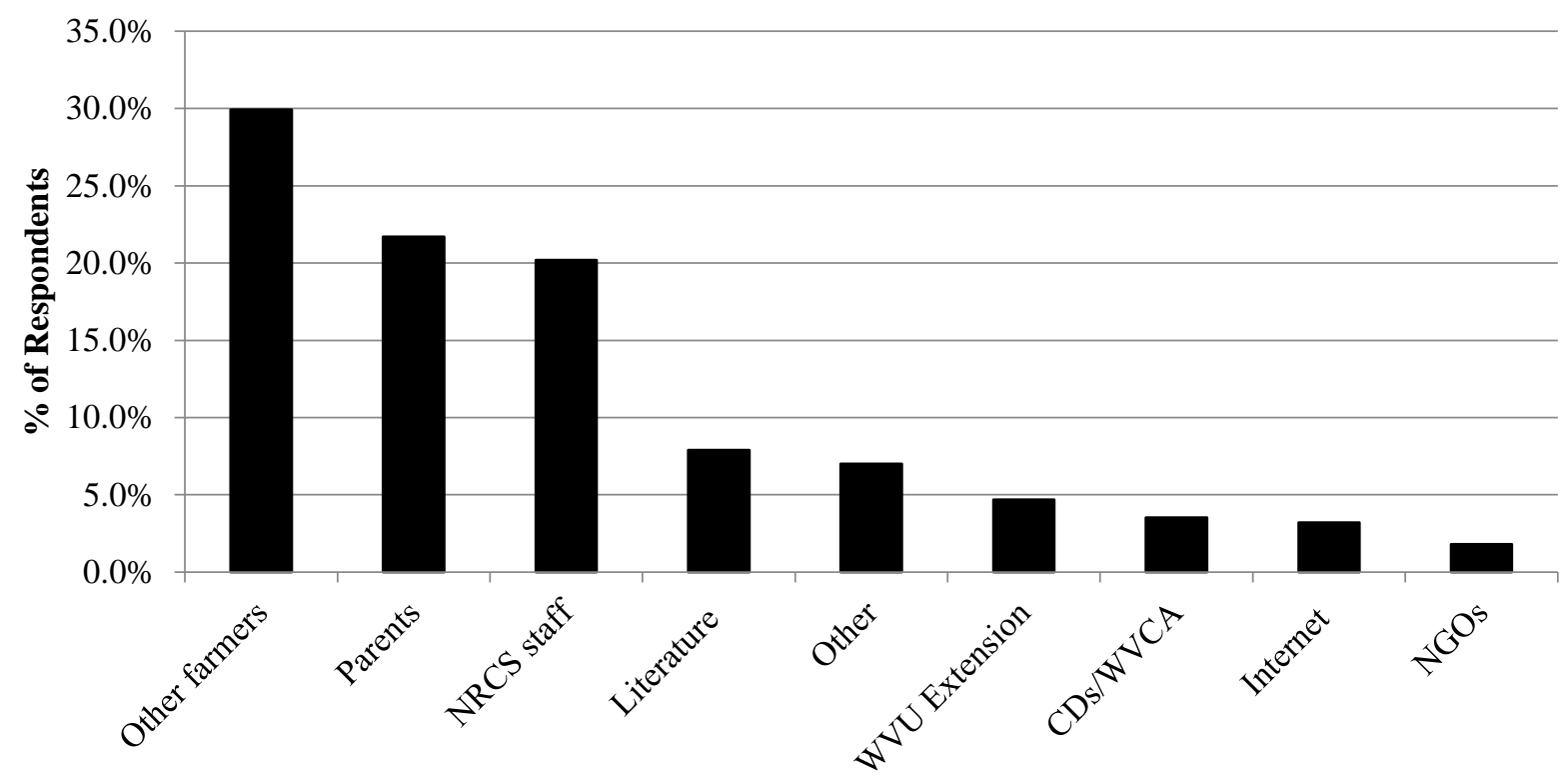

Figure 4.6: Primary teacher of NRCS conservation practices as reported by farmland owners in Randolph and Pocahontas County, WV, 2018 (n=341).

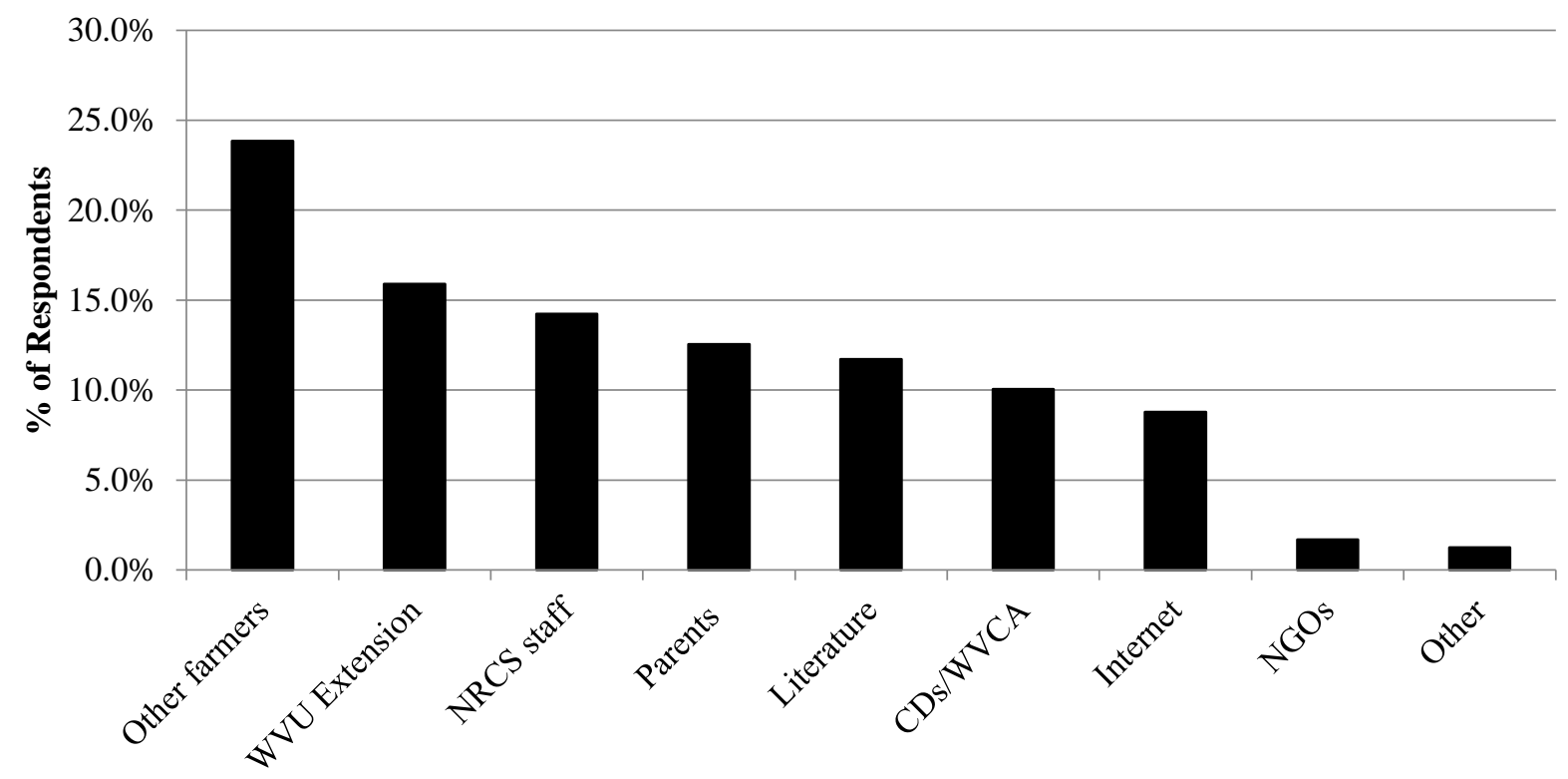

Figure 4.7: Secondary teacher of NRCS conservation practices as reported by farmland owners in Randolph and Pocahontas County, WV, 2018 (n=239).

Farmers were questioned about their membership in local farmer groups, associations, bureaus, and/or unions (Social Capital). Most of the respondents did not claim membership in any such group (68.1\%) while about one-third (31.9\%) did report involvement (Figure 4.8). 


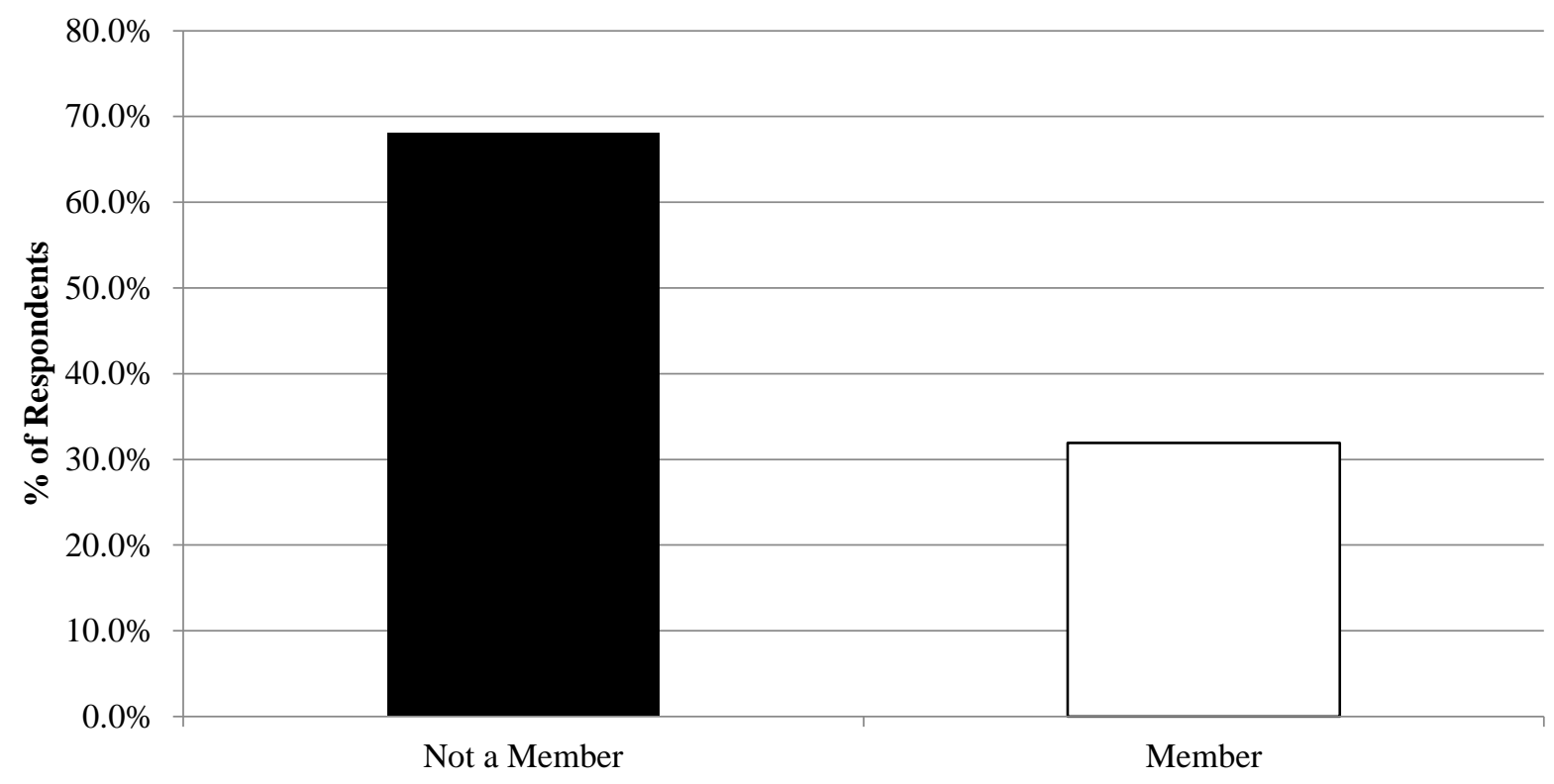

Figure 4.8: Farmer group membership as reported by farmland owners in Randolph and Pocahontas County, WV, $2018(n=448)$.

The importance of farmer group membership (Social Capital) to the respondents was evaluated using a five-point Likert scale. Participants felt being active in a farmer group was somewhat important—recording a mean score of 2.62. Respondents who had attended a farmerto-farmer workshop style training (Social Capital) comprised a much smaller proportion of the population than those who had not attended (Figure 4.9). The former accounted for $21.4 \%$ while the latter consisted of $78.6 \%$. However, farmers who said they would be willing to promote (Figure 4.10) NRCS conservation practices to other farmers (Social Capital) were nearly half $(50.9 \%)$ 


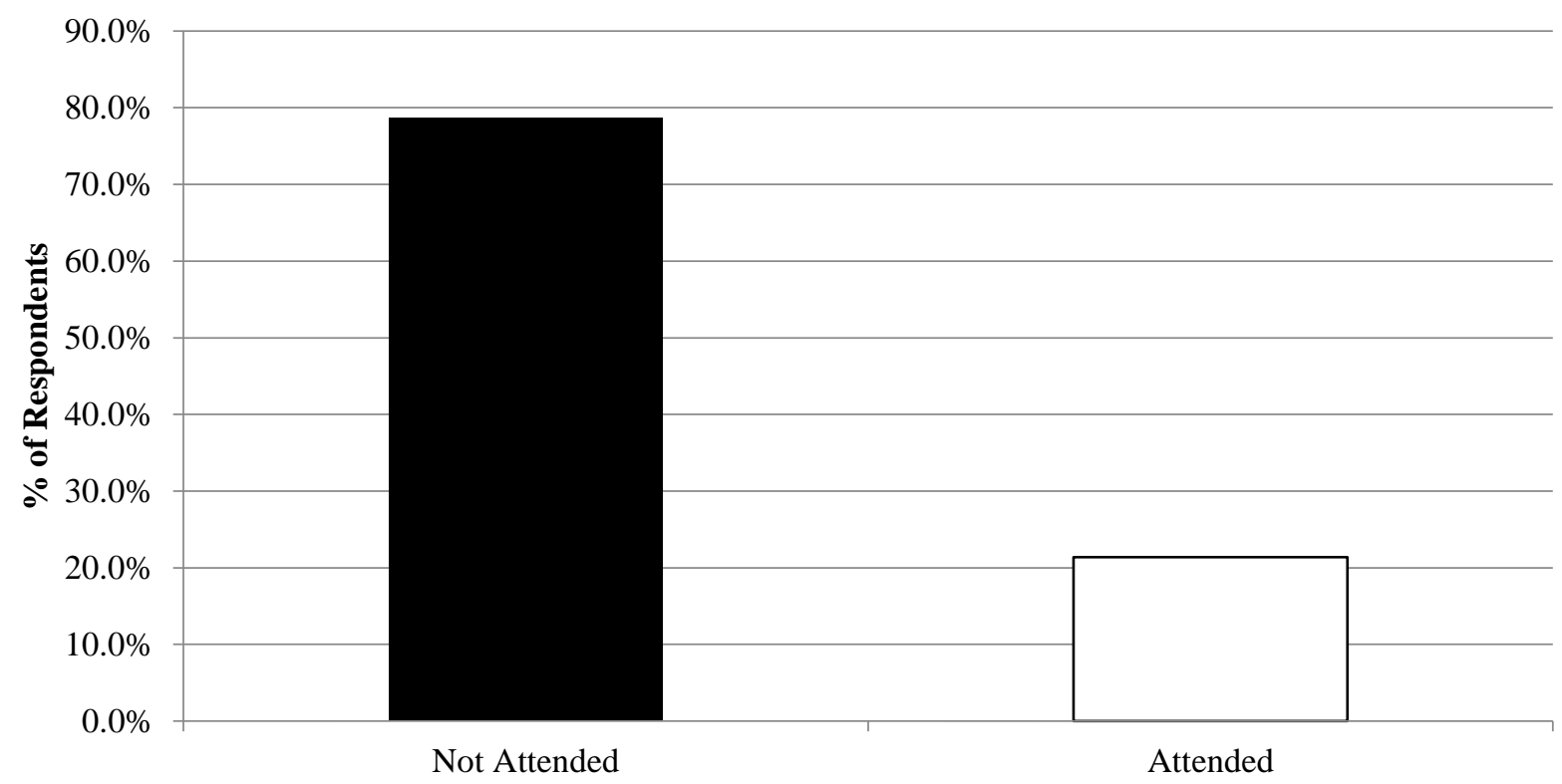

Figure 4.9: Farmer-to-farmer workshop attendance as reported by farmland owners in Randolph and Pocahontas County, WV, 2018 (n=435).

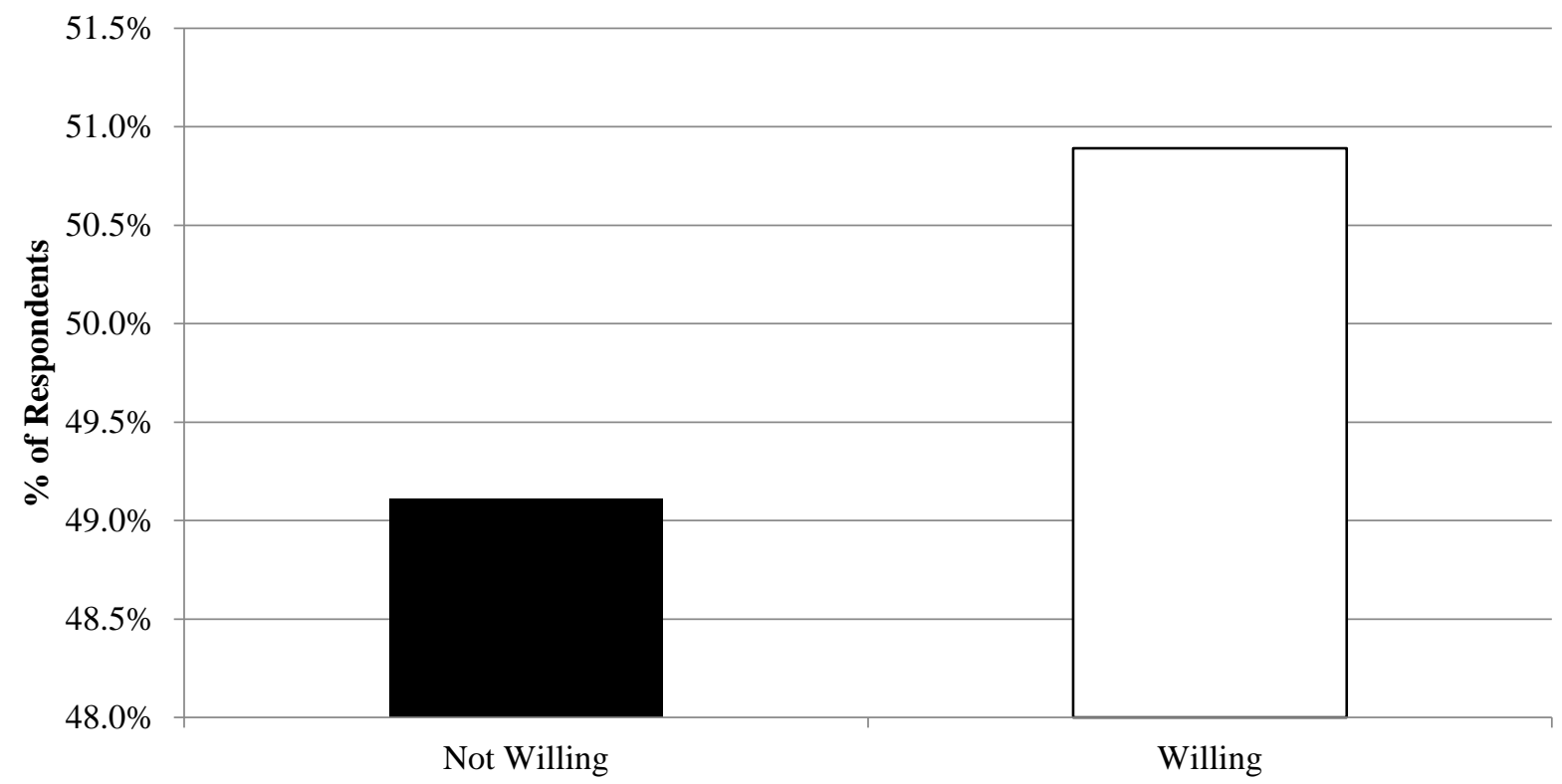

Figure 4.10: Respondent willingness to promote NRCS conservation practices to other farmers as reported by farmland owners in Randolph and Pocahontas County, WV, 2018 $(n=393)$.

Most farmers (63.5\%) felt there were enough conservation organizations (Organizational Capital $^{1}$ ) to provide farming-related technical support to everyone interested (Figure 4.11). 
Conversely, the majority of farmers (52.3\%) felt NRCS did not have enough personnel

(Organizational Capital $^{2}$ ) to provide CTA to everyone (Figure 4.12).

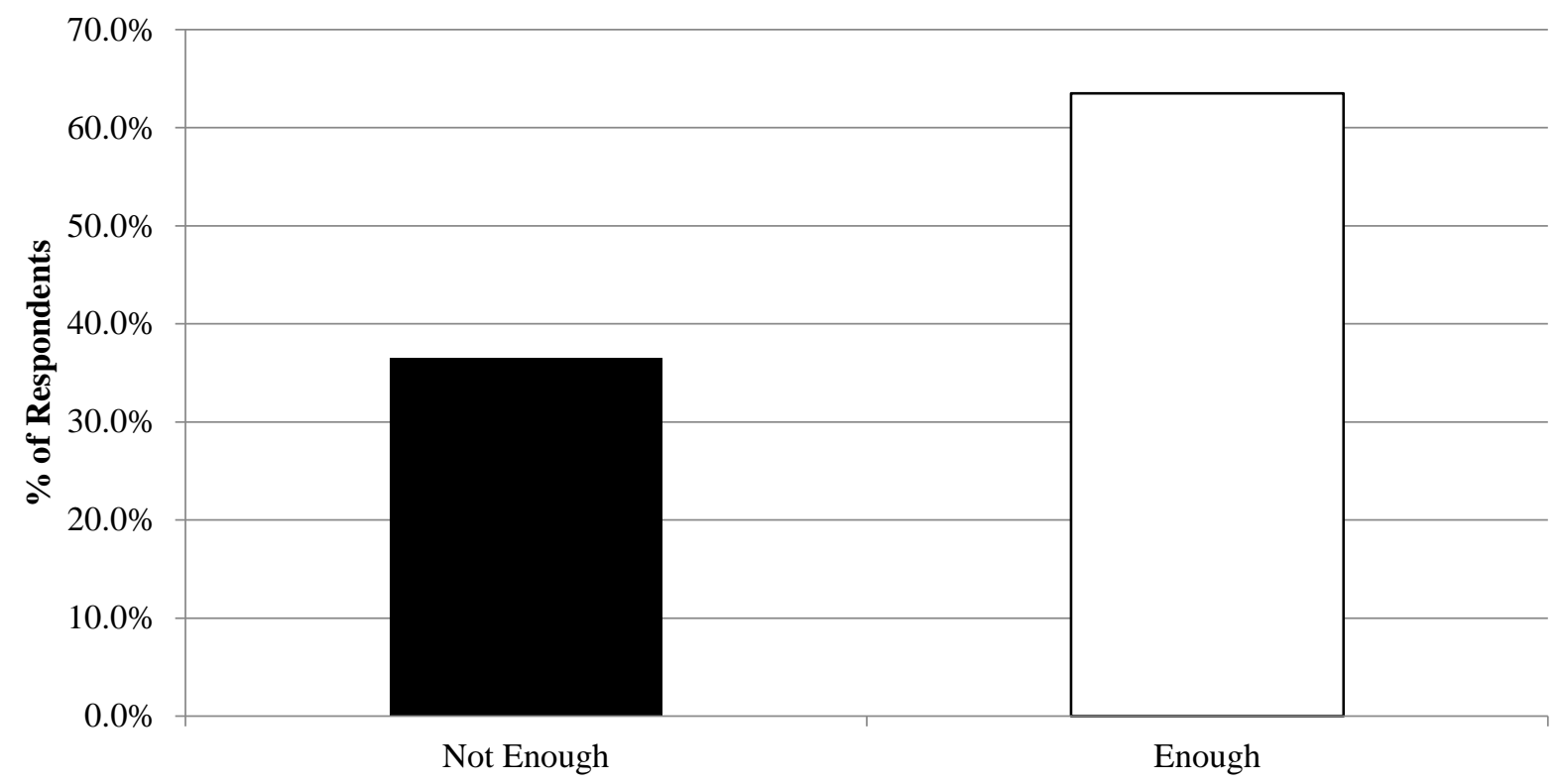

Figure 4.11: Local capacity to provide technical assistance as reported by farmland owners in Randolph and Pocahontas County, WV, 2018 (n=389).

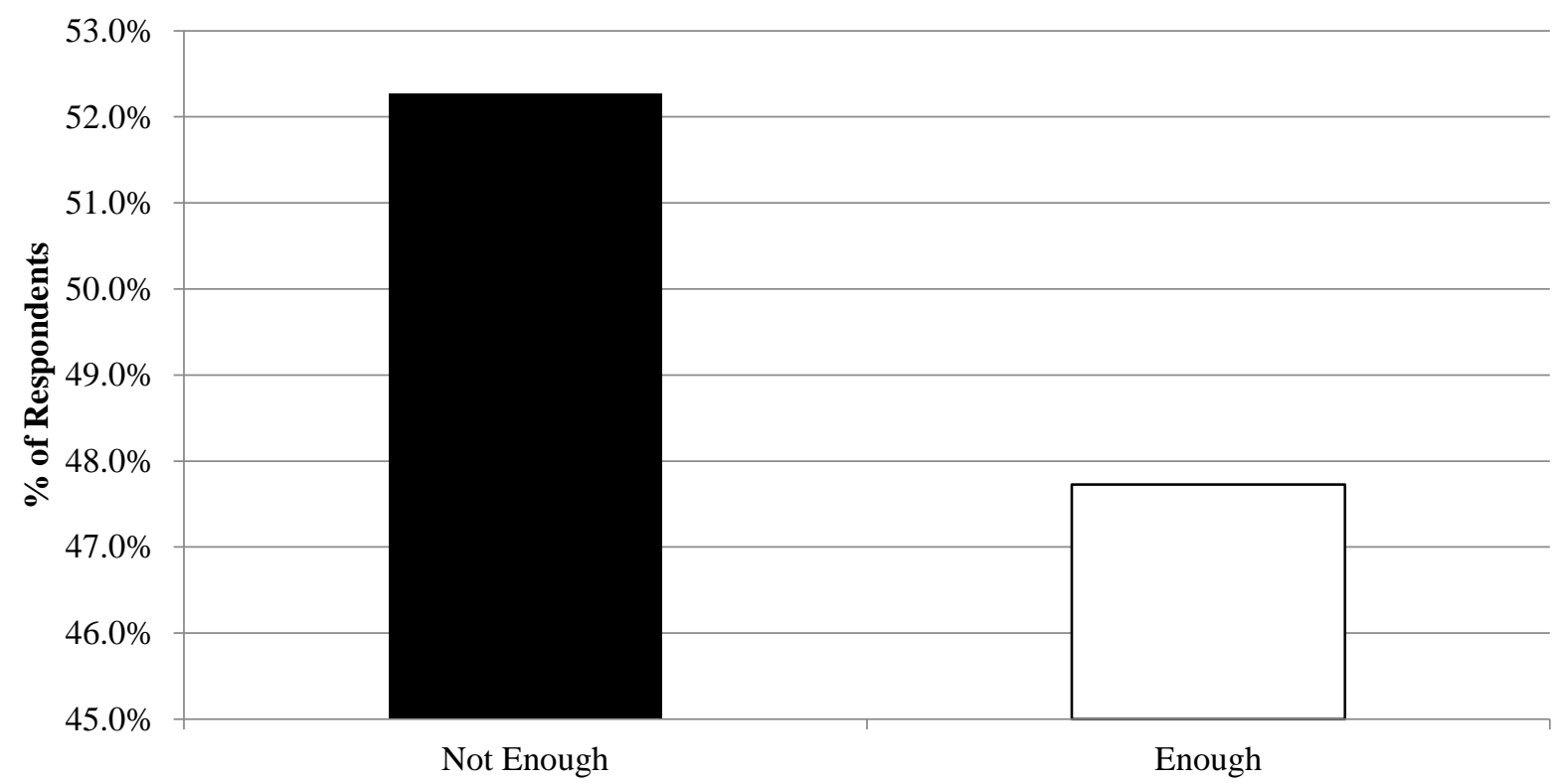

Figure 4.12: NRCS personnel to provide CTA as reported by farmland owners in Randolph and Pocahontas County, WV, 2018 (n=352). 
As an indicator for several of the primary and secondary independent variables from the theoretical model, farmers were asked to rank (by specifying 1, 2, and 3) what they found to be the biggest barriers - from a list obtained in the local interviews - to implementing the conservation practices recommended by NRCS (Figure 4.13). Cost (Financial Capital ${ }^{1}$ ) was identified most often as being the primary barrier (27.7\%). Lack of knowledge (Human Capital) was cited by $19.9 \%$ of the respondents, and bureaucracy (Human Capital) and fear of restrictions (Cultural Capital) came in third and fourth at $17.1 \%$ and $16.5 \%$, respectively. There was a noticeable decline after the top four categories. Results for the secondary and third-most barriers had similar distributions (not pictured).

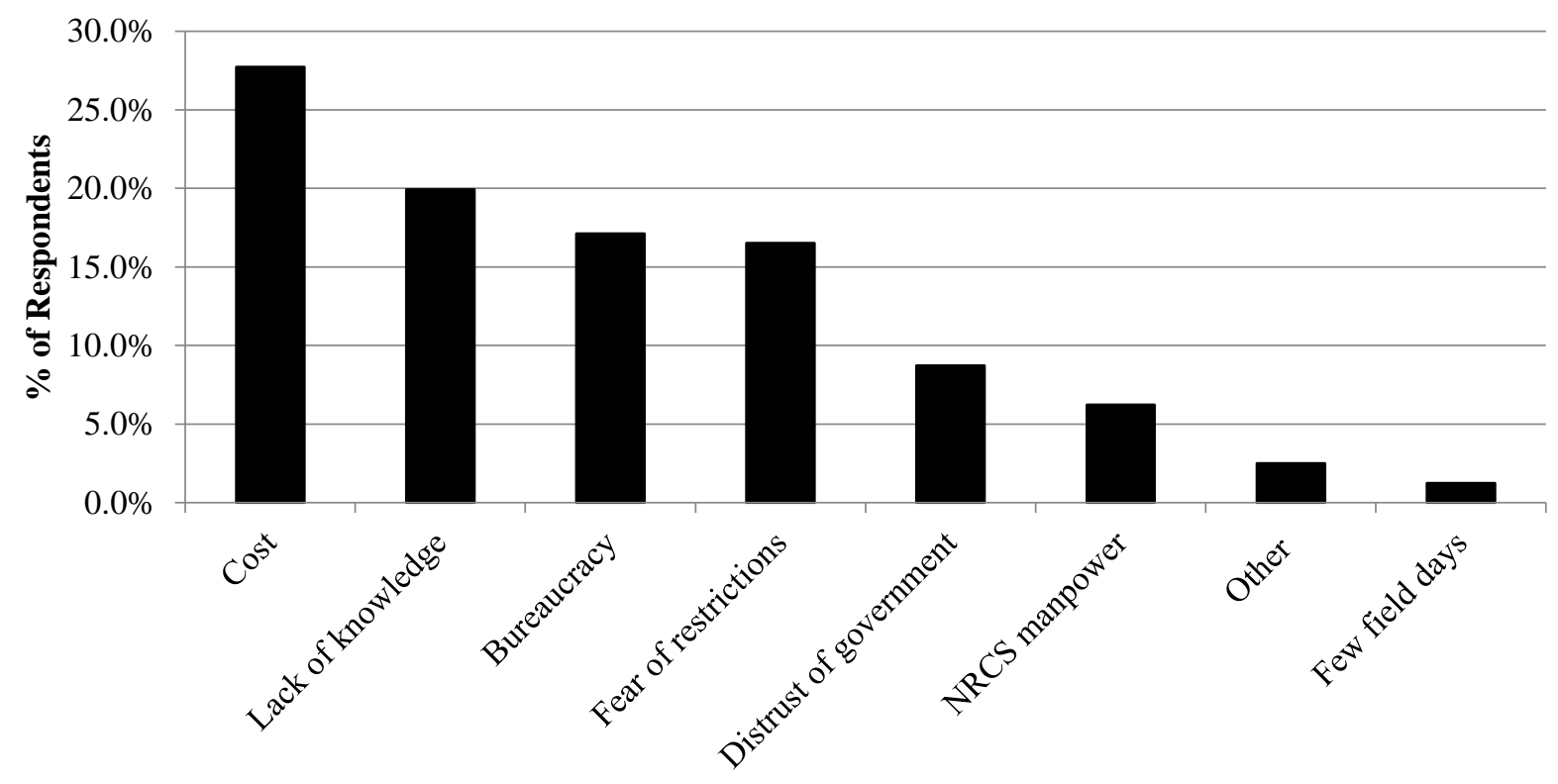

Figure 4.13: Primary barrier to NRCS conservation practice implementation as reported by farmland owners in Randolph and Pocahontas County, WV, 2018 (n=321).

In comparison to the other tenure categories, the vast majority $(66.0 \%)$ of respondents had owned their farmland (Financial Capital $^{l}$ ) for greater than 20 years (Figure 4.14). In addition, Figure 4.15 shows that most farmers $(60.8 \%)$ considered their farmland to be a monetary investment that would provide them economic returns in the long run (Financial Capital $^{l}$. 


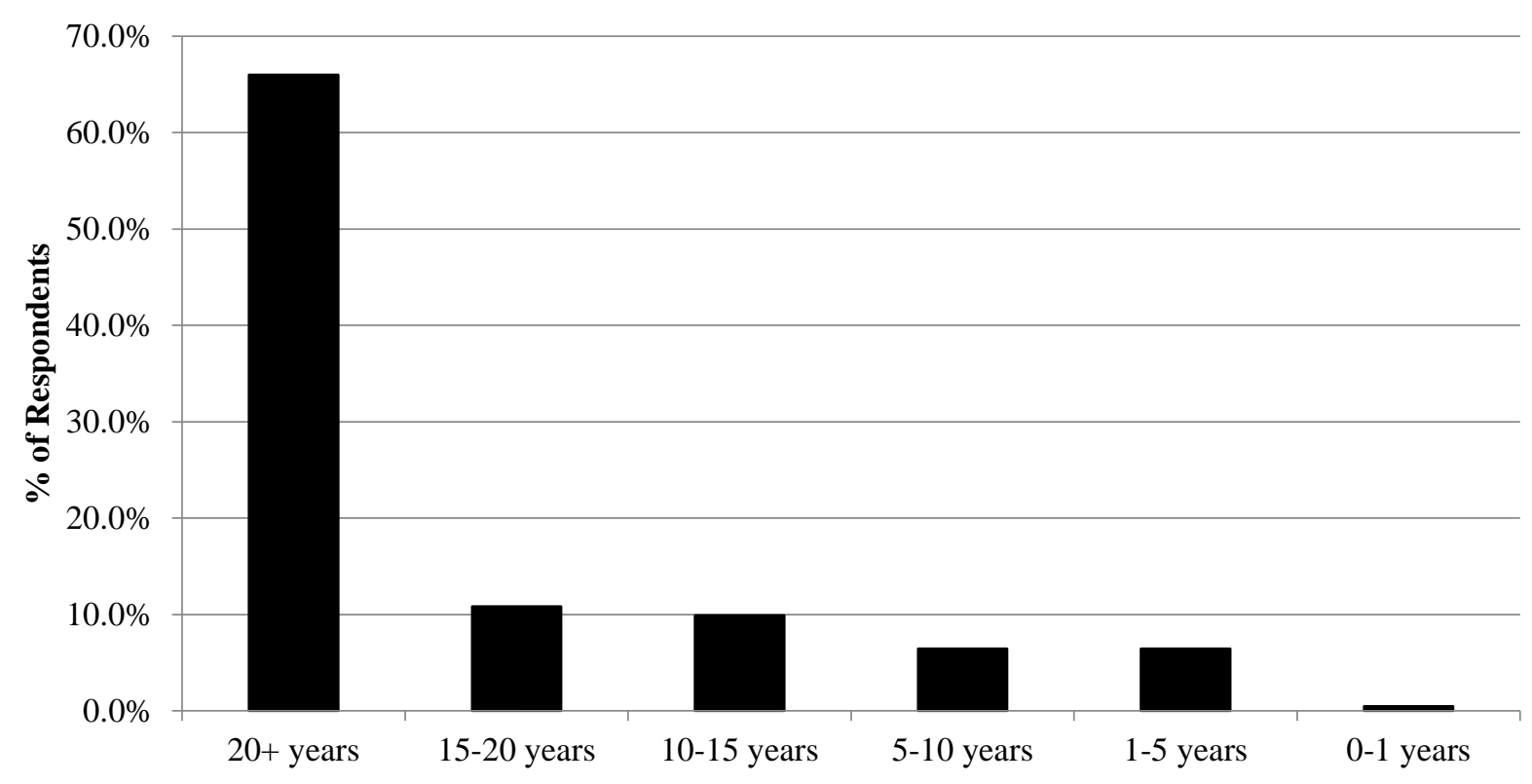

Figure 4.14: Length of ownership as reported by farmland owners in Randolph and Pocahontas County, WV, $2018(\mathrm{n}=435)$.

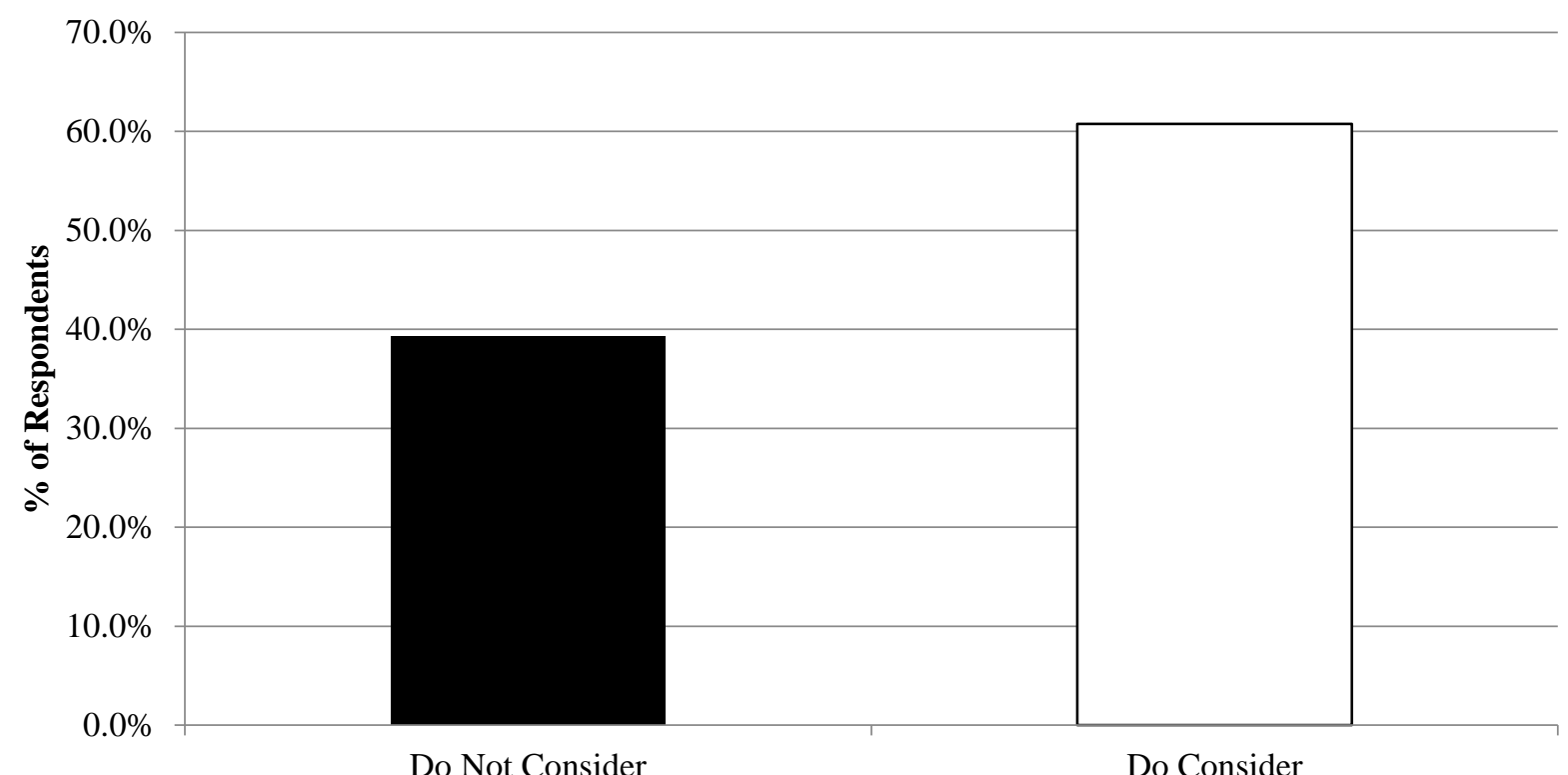

Figure 4.15: Whether respondents felt their property was a monetary investment as reported by farmland owners in Randolph and Pocahontas County, WV, 2018 (n=423)

The approximate percentage of income derived from the respondent's farmland was assessed as a Financial Capital ${ }^{1}$ measure. On average, respondents from Randolph and/or Pocahontas County obtain approximately $11.2 \%$ of their income from farm production. As 
illustrated in Figure 4.16, most farmers (67.6\%) felt rather positive about the cost-benefit ratio (Financial Capital $^{1}$ ) related to the implementation of conservation practices.

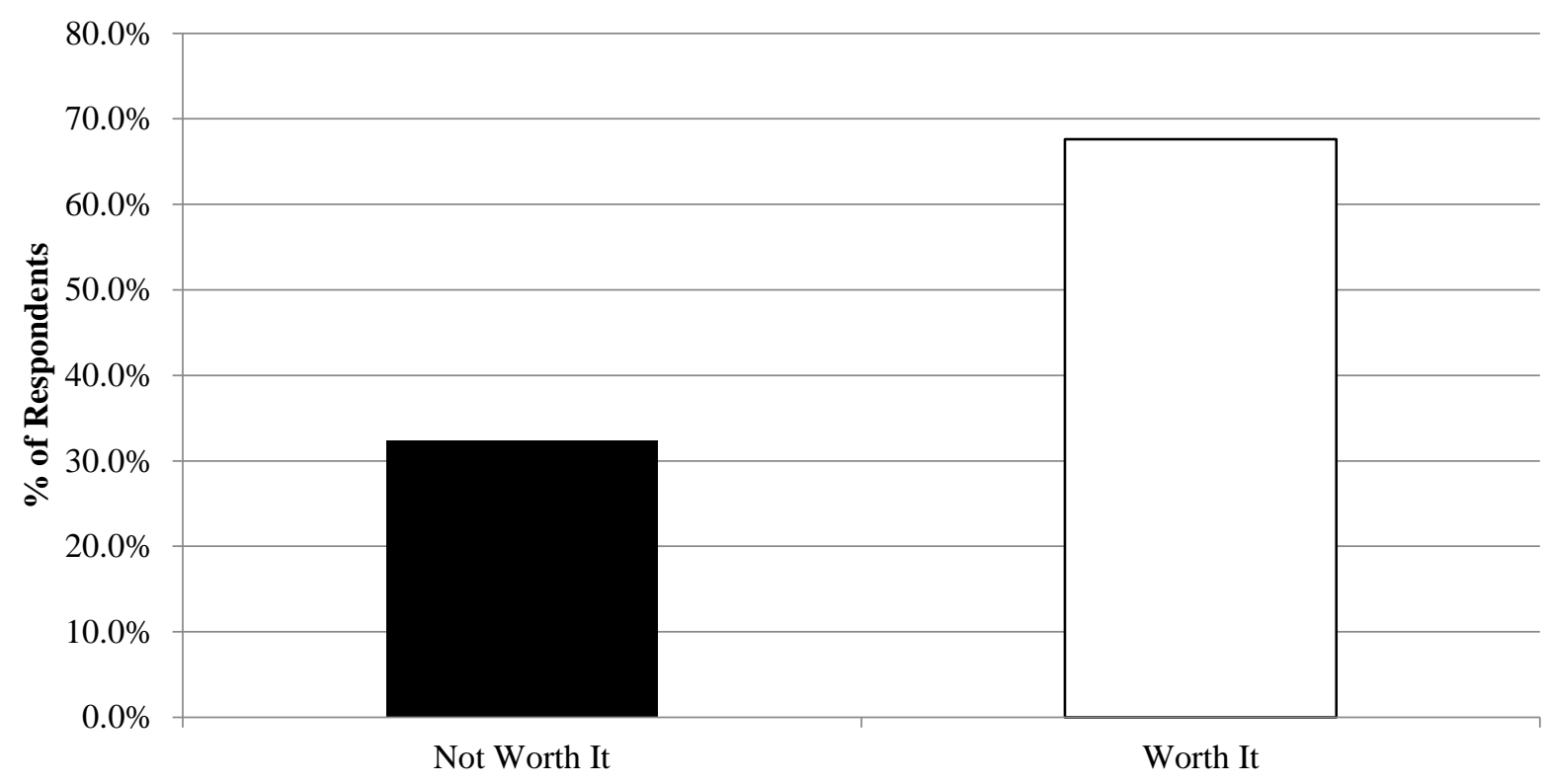

Figure 4.16: Whether the cost of implementing NRCS conservation practices is worth the benefit as reported by farmland owners in Randolph and Pocahontas County, WV, 2018 $(\mathbf{n}=349)$.

\subsubsection{Demographics}

Farmland owners do not always live in the same county as the property they own or farm.

With this in mind, respondents were questioned regarding the county in which their primary residence is located (Organizational Captial $\left.^{1}\right)$. Approximately 52.2\% of the population resided in Pocahontas County while about $29.6 \%$ lived in Randolph (Figure 4.17). The remainder were either located in-state but outside of the subject counties, or out-of-state all-together. 


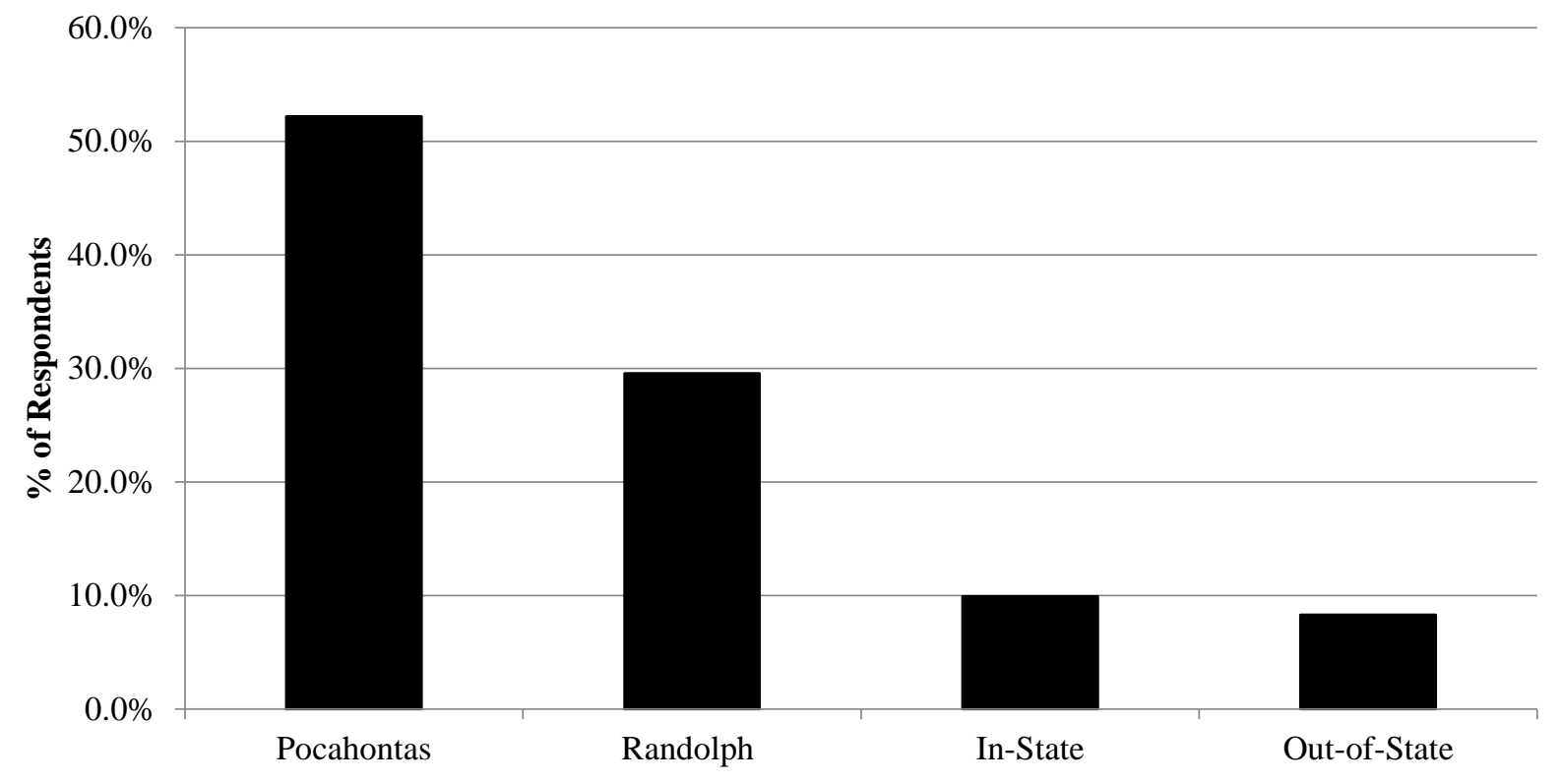

Figure 4.17: Location of primary residence as reported by farmland owners in Randolph and Pocahontas County, WV, $2018(n=433)$.

Respondents were asked to report their age (Human Capital). The findings revealed that the farmers in these counties were 65.52 years old on average. The demographics section of the survey also asked about levels of education (Human Capital). Figure 4.18 shows that most respondents held a high school diploma (37.6\%), bachelor's degree $(22.0 \%)$, or graduate degree (17.9\%). In addition, income levels (Financial Capital ${ }^{l}$ ) were reported as well (Figure 4.19). The results indicate that most of the farmers in this study earn less than $\$ 90,000$ per year. 


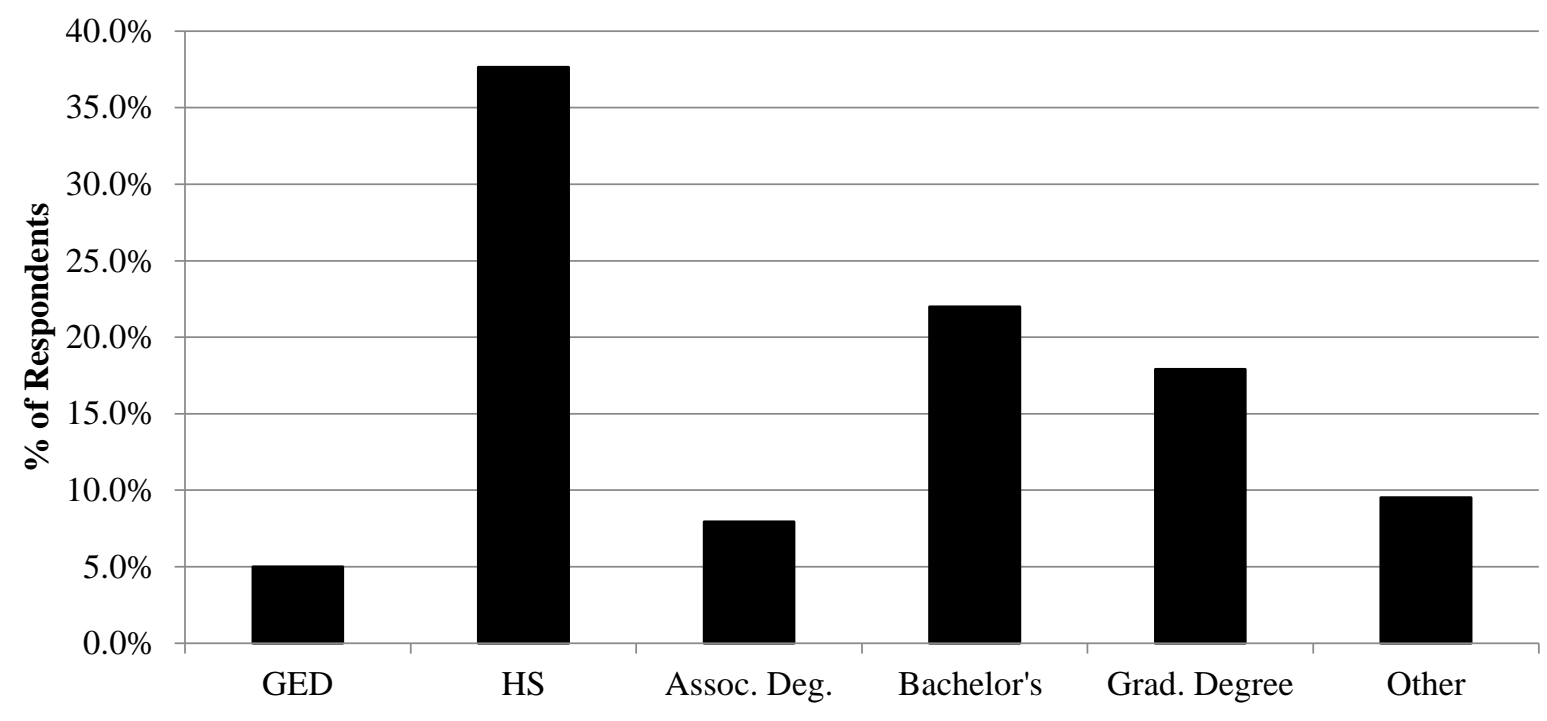

Education Level

Figure 4.18: Level of education as reported by farmland owners in Randolph and Pocahontas County, WV, 2018 (n=441).

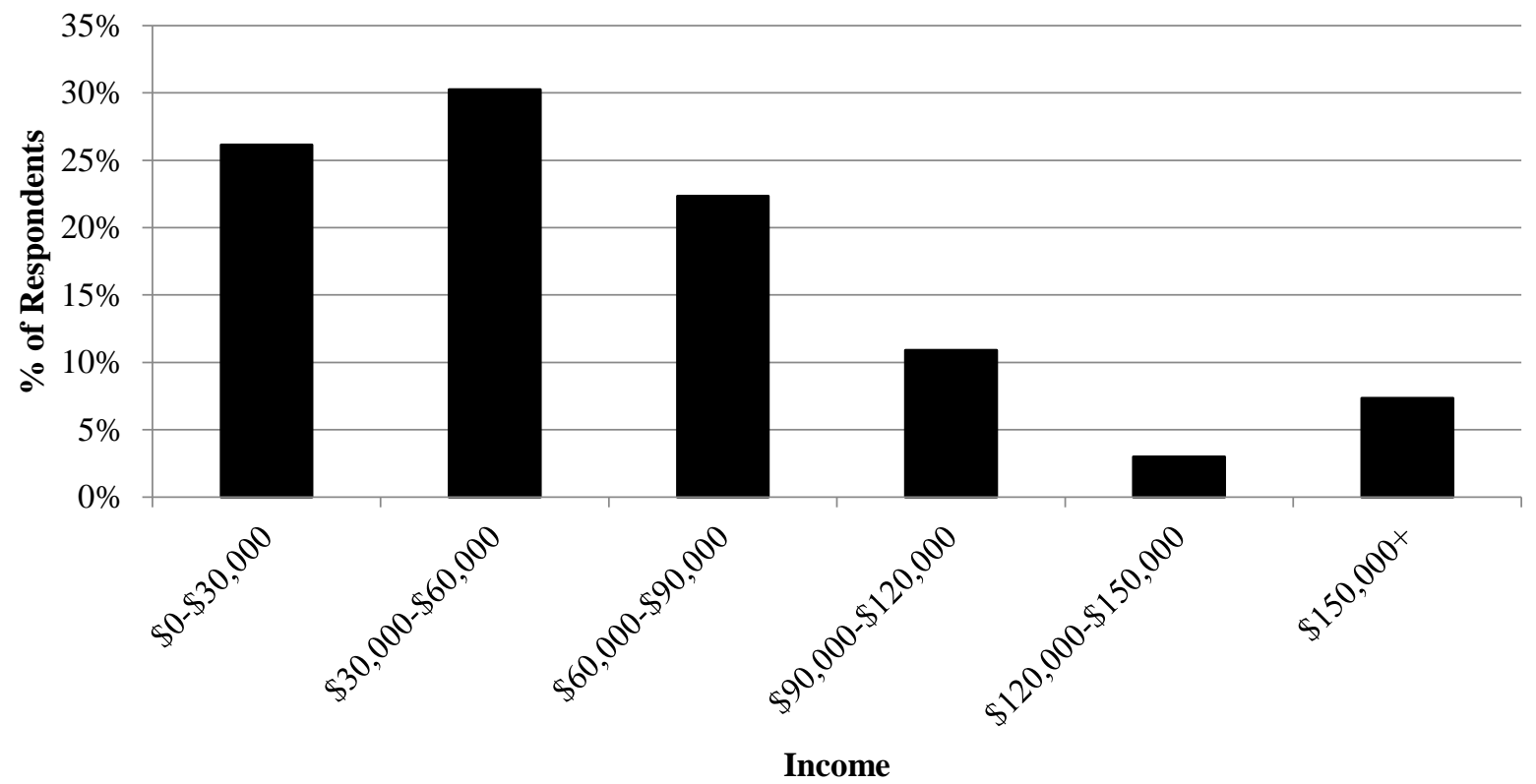

Figure 4.19: Level of income as reported by farmland owners in Randolph and Pocahontas County, WV, $2018(n=367)$.

Lastly, Figure 4.20 illustrates the distribution of gender in the subject population. Approximately three-quarters of the respondents were men $(76.0 \%)$ while the remainder consisted of women (24.0\%). 


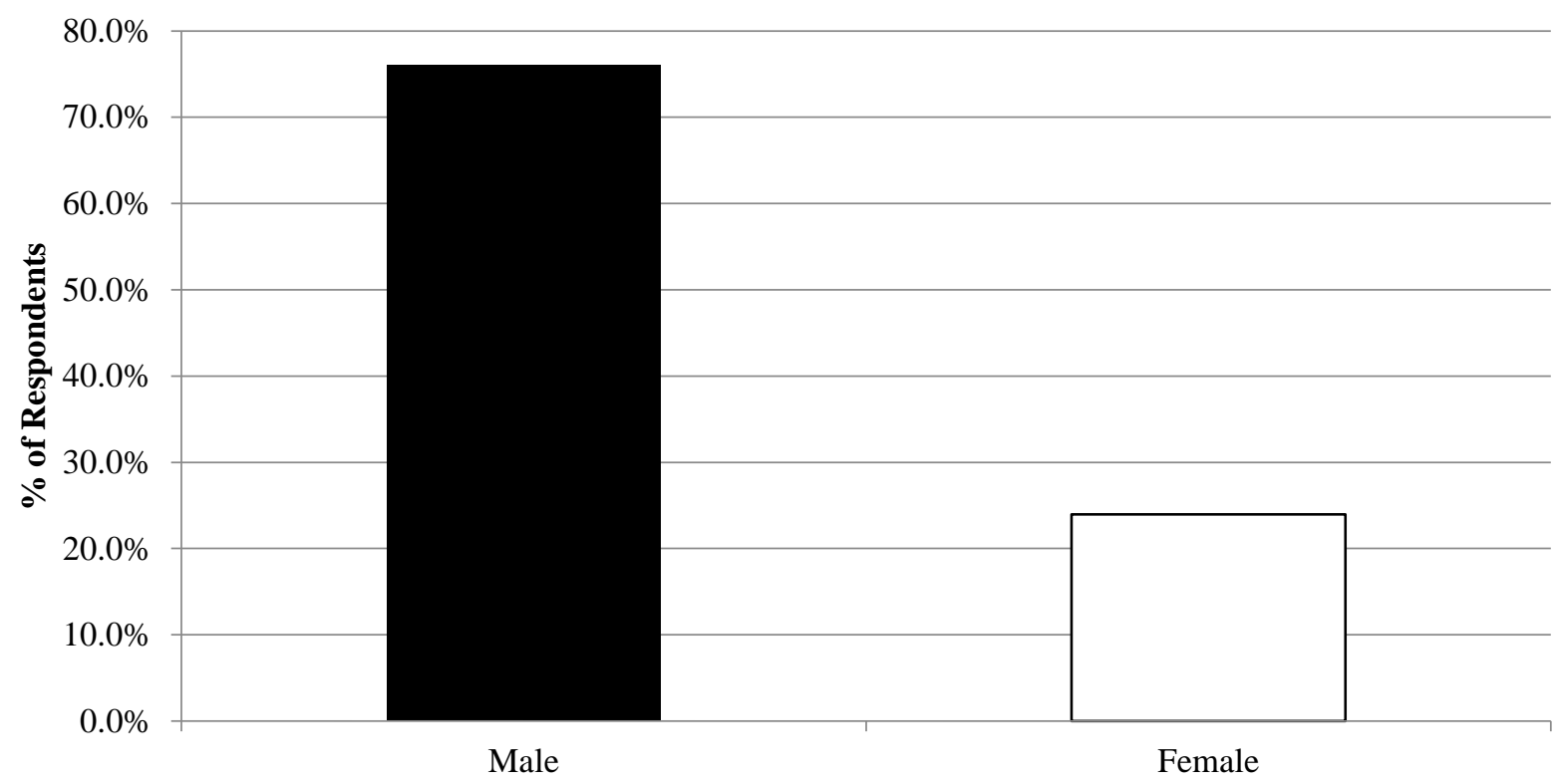

Figure 4.20: Gender as reported by farmland owners in Randolph and Pocahontas County, WV, $2018(n=434)$.

\subsubsection{Modeling Likelihood of CTA Participation}

The final model and its associated summary statistics are provided in this subsection, along with a brief discussion of this model's analytic meaning. Summary statistics for the final model are shown in Table 4.5. Two variables from the farm information section were significant (ACRES and GRSLND). In addition, there were ten significant variables that represented the motivations for participation section (TIDY, NONGOV, KNWLDG, NRCS1, FRMEDU, INFEDU, CAPCTY, TENURE, INVEST, and BENFIT). The final section of the survey, demographics, had two significant predictors (EDLVL and INCOME). Lastly, there were seventeen variables from the full model that were not significant (RNDCTY, FOCOV, DSTNCE, TRDITN, VALUES, SAWCON, STEWRD, GOVERN, FARMER, MEMBER, GROUP, WRKSHP, PRMOTE, PERSNL, COST, PERCNT, and AGE). 
Table 4.5: Final model summary statistics

\begin{tabular}{|c|c|c|c|c|c|}
\hline Variable & Community Capital & Mean & Std. Dev. & Min. & Max. \\
\hline \multicolumn{6}{|c|}{ Property Information Section } \\
\hline ACRES & Financial Capital $^{l}$ & 291.746 & 493.979 & 2.7 & $3,200.00$ \\
\hline GRSLND & Financial Capital $^{l}$ & 0.8695652 & 0.3386266 & 0 & 1 \\
\hline \multicolumn{6}{|c|}{ Motivations for Participation Section } \\
\hline TIDY & Cultural Capital & 3.923913 & 0.9519638 & 1 & 5 \\
\hline NONGOV & Cultural Capital & 3 & 0.9607689 & 1 & 5 \\
\hline KNWLDG & Human Capital & 3.086957 & 0.6898347 & 1 & 5 \\
\hline NRCS1 & Organizational Capital $^{2}$ & 0.3152174 & 0.4671482 & 0 & 1 \\
\hline FRMEDU & Human Capital & 1.913043 & 0.9681996 & 1 & 5 \\
\hline INFEDU & Human Capital & 2.413043 & 0.9510223 & 1 & 5 \\
\hline CAPCTY & Organizational Capital ${ }^{1}$ & 0.6413043 & 0.4822457 & 0 & 1 \\
\hline TENURE & Financial Capital $^{1}$ & 0.6195652 & 0.488154 & 0 & 1 \\
\hline INVEST & Financial Capital $^{l}$ & 0.7065217 & 0.4578508 & 0 & 1 \\
\hline BENFIT & Financial Capital $^{l}$ & 0.6956522 & 0.4626519 & 0 & 1 \\
\hline \multicolumn{6}{|c|}{ Demographics Section } \\
\hline EDLVL & Human Capital & 0.5978261 & 0.4930235 & 0 & 1 \\
\hline INCOME & Financial Capital $^{1}$ & 0.7391304 & 0.441515 & 0 & 1 \\
\hline
\end{tabular}

The individually significant variables together in the final model, as a whole, were significant at the 0.01 level (p-value 0.0000 ) which allows for rejection of the null hypothesis. Moreover, it correctly predicted $90.22 \%$ of the responses and had a pseudo r-squared value of 0.5961. Regarding diagnostics, this model passed the Homer-Lemeshow goodness-of-fit test (pvalue 0.9432). Furthermore, several scholars contend that, as a general rule, Variable Inflation Factors (VIFs) should be less than ten (Chatterjee et al. 2000; Chatterjee and Price 1991; Belsley et al. 1980). Accordingly, the highest VIF among all the model predictors was 1.86 . As such, no indications of multicollinearity were found. As shown in Table 4.6, fourteen variables were found to be statistically significant, of which nine had the hypothesized sign. 
Table 4.6: Factors affecting participation in the CTA program in WV, 2018

\begin{tabular}{|c|c|c|c|c|}
\hline Variable & Coefficient & Std Error & P-value & $\begin{array}{l}\text { Odds } \\
\text { Ratio }\end{array}$ \\
\hline Constant** & 10.9102 & 4.30732 & 0.011 & 54730.8 \\
\hline \multicolumn{5}{|c|}{ Property Information Section } \\
\hline ACRES** & 0.00248 & 0.00123 & 0.043 & 1.00248 \\
\hline GRSLND* & 2.62479 & 1.39436 & 0.060 & 13.8017 \\
\hline \multicolumn{5}{|c|}{ Motivations for Participation Section } \\
\hline TIDY** & -1.58536 & 0.63674 & 0.013 & 0.20487 \\
\hline NONGOV*** & -2.31985 & 0.76373 & 0.002 & 0.09829 \\
\hline KNWLDG** & -2.36752 & 0.93030 & 0.011 & 0.09371 \\
\hline NRCS1* & 1.59634 & 0.96721 & 0.099 & 4.93492 \\
\hline FRMEDU $* * *$ & -2.98880 & 1.00695 & 0.003 & 0.05035 \\
\hline INFEDU $* * *$ & 3.94900 & 1.24243 & 0.001 & 51.8834 \\
\hline CAPCTY $* * *$ & -4.42323 & 1.28221 & 0.001 & 0.01200 \\
\hline TENURE*** & -3.01622 & 1.12899 & 0.008 & 0.04899 \\
\hline INVEST** & 2.14857 & 1.05298 & 0.041 & 8.57259 \\
\hline BENFIT *** & 4.63660 & 1.43936 & 0.001 & 103.193 \\
\hline \multicolumn{5}{|c|}{ Demographics Section } \\
\hline EDLVL** & 2.39704 & 1.13945 & 0.035 & 10.9906 \\
\hline INCOME*** & 3.30092 & 1.17184 & 0.005 & 27.1375 \\
\hline Number of observations & 92 & & & \\
\hline Chi-square value & 72.86 & & & \\
\hline P-value & 0.0000 & & & \\
\hline Pseudo r-squared & 0.5961 & & & \\
\hline Observations correctly predicted & $90.22 \%$ & & & \\
\hline
\end{tabular}

As expected, ACRES was positively associated to the dependent variable (CNSDR). This implies that respondents with larger farms may be more willing to participate in the CTA program. In addition, GRSLND had a positive coefficient as predicted. This indicates farmers with hay and pastureland as their primary land use have a greater likelihood of participation than those with another primary land use.

TIDY was negative as presumed. This signifies that respondents who felt tidy farming landscapes were less important may be more willing to consider participating. Contrary to the hypothesis, NONGOV returned negative in the model. However, it follows that if a farmer 
believes NGOs are relatively less trustworthy, then participation in a governmental program may be comparatively more amenable to them. KNWLDG was unexpectedly negative also. It is understandable that the less one knows about conservation practices, the more receptive they might be to receiving technical assistance. It was hypothesized that farmers who learned about conservation practices from NRCS staff would be more likely to participate in the CTA program than those who learned about them elsewhere. This assumption was confirmed in the model provided NRCS1 had a positive coefficient.

FRMEDU was negative which was in contrast to the a priori assumption. The implication being the less formal training, such as conferences and seminars, that farmers receive then the greater the likelihood of participation. This may seem counterintuitive on its own merits, but one possible explanation is there may simply be fewer formal training opportunities accessible to rural community members (Flora et al. 2016, 147). Conversely, INFEDU was positively correlated to CNSDR as expected. This means that those with more informal education, such as field days and local meetings, have a greater likelihood to participate in the CTA program.

CAPCTY was predicted to return positive in the model, but the coefficient came back negative. The indication is that farmers who felt their community does not have enough conservation organizations to provide technical assistance may be more prone to participation. One potential reason for the unexpected result is that respondents who perceive technical assistance as a scarce commodity may be readier, and more willing, to take advantage of available opportunities. Results also indicate that those who have owned their farmland for less than twenty years are more likely to consider participating in the CTA program. Indeed, TENURE unexpectedly had a negative coefficient also. This could be indirectly related to other research findings that indicate younger farmers may be more receptive to outreach and the 
adoption of conservation practices than older farmers (Prokopy et al. 2008; Arbuckle et al. 2018).

INVEST had the expected positive sign, purporting landowners who consider their farmland to be a monetary investment, one that would provide them with economic returns in the long run, are more likely to participate than those who do not consider their property as such. Similarly, BENFIT was consistent with the hypothesis as well. The positive coefficient implies that farmers who think the benefits of conservation practices outweigh the costs have a greater likelihood of participation than those who think otherwise. Both demographic variables had their expected sign. Farmers with an associate degree or more (EDLVL) appear more willing to consider participation than those with less education. In addition, respondents with an approximate annual income over $\$ 90,000$ (INCOME) may be more likely to participate in the CTA program than those who earn a lower amount. 


\section{Chapter 5: Discussion, Conclusions, and Recommendations}

"I mean we're a very small percentage of the US population, and I don't know the true statistics here, but every one of us feeds 137 people or so, it's quite rewarding to really think about the bigger picture and what we are doing, not only for people of this country, but around the world." $\sim$ Farmer Participant 23

This chapter discusses the research findings and whether they support the causal relationships hypothesized in the theoretical model. Based on that evaluation, conclusions are derived and the assumptions, delimitations, and limitations that accompany those conclusions are explained. Lastly, recommendations for future research and NRCS practice are provided.

\subsection{Discussion of the Findings}

Findings from the sequential mix-methods research design were analyzed through the lens of the theory of change and theoretical model developed herein to test assumptions and evaluate the anticipated causal relationships. Figure 5.1 depicts the theoretical model with key findings from the organizational asset mapping, informant interviews, and farmer survey. 


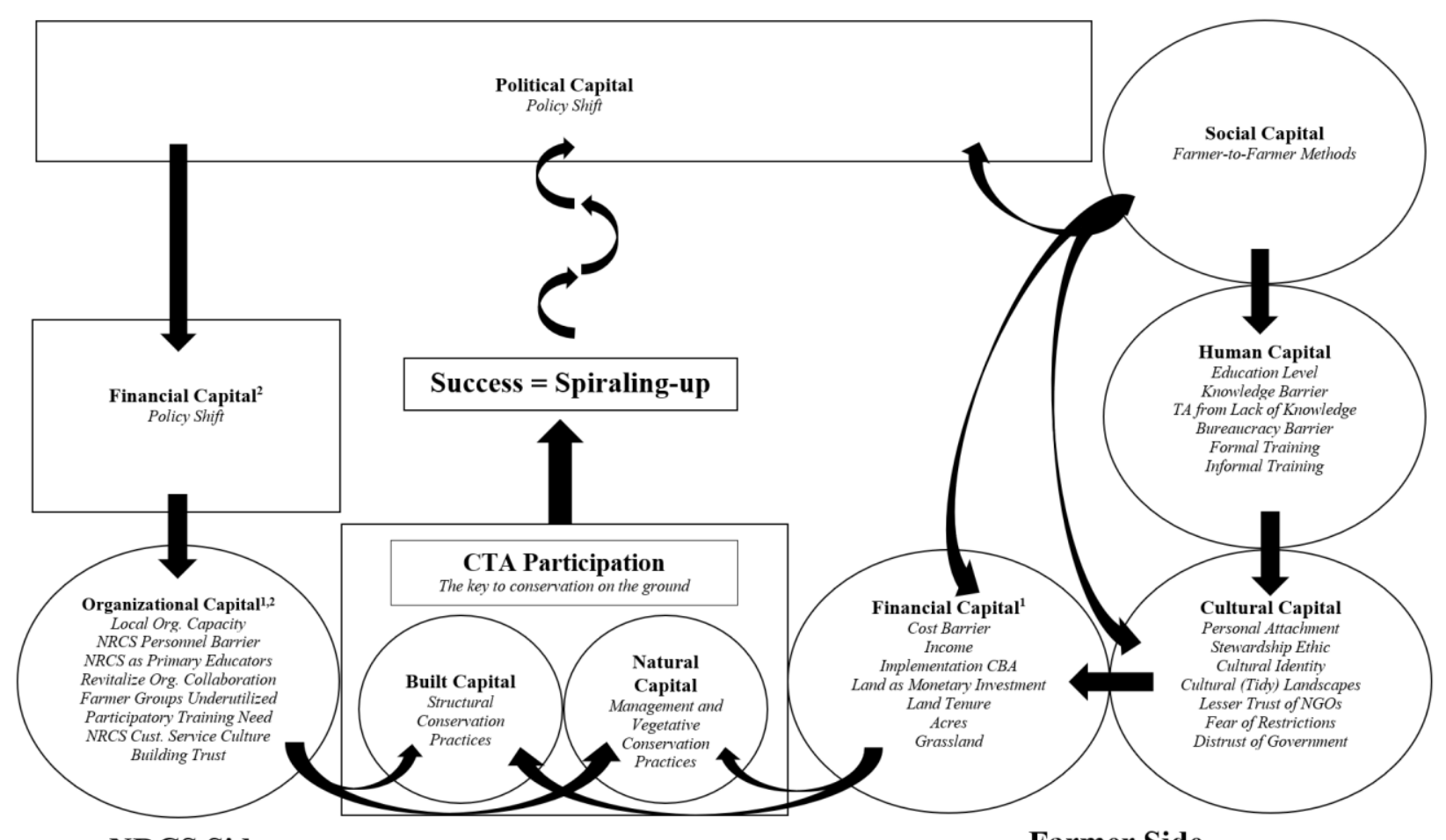

NRCS Side

Farmer Side

\section{Figure 5.1: Theoretical model with key findings}

To reiterate, at the center of the relational model, the dependent variable CTA

Participation includes changes to either Natural Capital, in the form of management and vegetative conservation practice implementation, and/or Built Capital, in the form of structural conservation practice implementation. There are two sides to the participation equation - the farmer side and the NRCS side. Theoretically, the primary independent variables influencing farmer participation are Social, Human, Cultural, and Financial ${ }^{1}$ Capitals. The secondary independent variables impacting NRCS organizational capacity are Political, Financial ${ }^{2}$, and Organizational Capital ${ }^{1,2}$, which are largely products of legislative processes that are outside the agency's direct control, but can be influenced by farmers through their own political capital.

In sum, NRCS investments in farmers' Social and Human Capital are thought to spiralup to produce increased Cultural and Financial Capital ${ }^{1}$, CTA Participation, and Political Capital, which in turn increase Financial Capital ${ }^{2}$ and Organizational Capital $^{1,2}$ within NRCS. It 
should be noted that NRCS can make direct investments in each capital on the farmer side of the theoretical model, but this may not always be necessary given the importance of farmer Social Capital and its compounding affects. Indeed, due to the centrality of social groups to farmer behavior (Arbuckle et al. 2018; Prokopy et al. 2014; Reimer et al. 2014; Reimer and Prokopy 2014; Baumgart-Getz et al. 2012; Prokopy et al. 2008; Knowler and Bradshaw 2007; Pannell et al. 2006; Mathijs 2003), Social Capital investment can garner coproduction in Human Capital that causes positive change in Cultural Capital which can spiral-up to inspire collective investment by farmers in Financial Capital ${ }^{1}$ and Political Capital. Ultimately, this relational theory of change is anticipated to generate a self-sustaining, ongoing increase in CTA

\section{Participation.}

\subsubsection{Farmer Side of the Theoretical Model}

Discussion of the implications derived from the overall findings begins with the primary independent variables situated on the farmer side of the CTA Participation equation.

\subsubsection{Social Capital}

"Farmer-to-farmer methods" was a major category in both the farmer and NRCS interviews. All the interview participants made it clear that farmers talk to one another about best practices, manners in which to maximize production, available programs, and much more. Yet, none of the variables derived from the survey related to farmer networks were significant in the empirical model. This could be due to the apparent obscurity of farmer groups in the study area as revealed by the descriptive statistics. Nearly seventy percent of respondents in the subject counties reported not being a group member. In fact, according to the average Likert score, respondents found such membership to be only moderately important. 
Furthermore, the few survey respondents that did indicate they belonged to a farmer social group typically cited Farm Bureau, or something similar, which is a more formal group than what is suggested by the farmer-to-farmer methodology. The origins of farmer-to-farmer consist of social networks comprised of extended family members and neighbors that shared work during busy agricultural seasons (Holt-Giménez 2006, 92). Therefore, the insignificance of farmer groups in the model could also be related to the type of farmer Social Capital currently available (i.e., formal versus informal). These findings also indicate there may have been operationalization problems with appropriately capturing the farmer-to-farmer themes from the interviews in the survey questions that were asked.

Nonetheless, about half of the survey respondents said they would be willing to promote conservation practices to other farmers. The literature indicates "farmer-to-farmer methods" are a valid strategy for coproducing technical assistance and diffusing conservation technologies among farmers (Sosa et al. 2013; Holt-Giménez 2006; Enshayan et al. 1992). Furthermore, the ability of social networks to influence farmer behavior is resoundingly evidenced in the literature (Arbuckle et al. 2018; Prokopy et al. 2014; Reimer et al. 2014; Reimer and Prokopy 2014; Baumgart-Getz et al. 2012; Prokopy et al. 2008; Knowler and Bradshaw 2007; Pannell et al. 2006; Mathijs 2003). Therefore, it is reasonable to be guided by what farmers expressed interest in, rather than experience with. These findings, then, indicate the theoretical model has a firm basis from which to propose that investments in Social Capital will lead to increased CTA

\section{Participation.}

\subsubsection{Human Capital}

The Human Capital variables in the empirical model should be considered in light of the "knowledge barrier" found in the farmer interviews. Education level appears to influence 
likelihood to participate. As expected, farmers with associate degrees or further (EDLVL) are almost eleven times (odds ratio of 10.99) more inclined to consider participation than those with less education, while holding all else constant. Other studies have also found a positive correlation between level of education and participation in conservation programs (Oliver 2011, 79). However, given the historical challenge of retaining well-educated residents in rural areas (Flora et al. 2016; Flora and Flora 2013), additional informal education within these communities is needed.

This informal education need implied by the survey results was supported by the farmer interview findings given the previously stated "knowledge barrier." Indeed, "increased use of management-intensive practices corresponds with higher education levels of farm operators and greater reliance on outside consultants, perhaps reflecting the human capital need" (Lambert et al. 2006, 13). To be sure, as Baumgart-Getz et al. (2012) found, farmer familiarity with program goals and operations has a considerable impact on the adoption of best management practices (23). Previous research has proven the benefits of educational programs, field days, and other onfarm training opportunities (Mancini et al. 2008; Bruening and Martin 1992). However, results from the farmer interviews also indicate participants were not aware of, and therefore had not attended, the informal trainings, EQIP LWG meetings, and on-farm educational opportunities currently provided by NRCS.

The survey results suggest conservation practice knowledge and training do indeed influence conservation practice adoption. According to their average Likert scores, farmers in the study area reported only a modest amount of knowledge regarding conservation practices. Other studies have shown knowledge and awareness to be a potential barrier as well (Prokopy et al. 2014; Oliver 201). The model results imply those with less knowledge (KNWLDG) are more 
willing to consider the CTA program—which was contrary to the hypothesis. However, it is reasonable to assume that farmers who do not know how to implement conservation practices would be more likely to seek technical assistance. This finding illustrates how knowledge and awareness of conservation practices is not synonymous with knowledge and awareness of conservation programs - an assumption that may have caused the hypothesis to go awry. This implies the "knowledge barrier" sub-concept in the farmer interviews may have been incorrectly operationalized to the survey. According to Prokopy et al. (2008), sub-categories of knowledge and awareness (e.g., environmental awareness, consequences of degradation, available programs, etc.) are important differentiations (304).

Similar to the "knowledge barrier," there was also a "bureaucracy barrier" expressed by the farmers during the interviews. Reimer and Prokopy (2014) contend that program name or acronym recognition does not preclude a clear understanding by farmers of programmatic specifics and requirements (325). Moreover, Ma et al. (2010) found that smaller operators felt "there were not enough acres to put up with the paperwork" when it came to enrollment in payment-for-environmental-services (PES) programs (17). However, it is logical to assume that more knowledge provided through informal education will reduce these "knowledge" and "bureaucracy" barriers as farmers develop familiarity with agency vernacular, program processes and requirements, and the necessary paperwork. As such, these findings indicate NRCS may need to provide more informal education, training, and communication opportunities to farmers through a variety of coproduction and public engagement strategies. For example, NRCS investments in farmer Social Capital may generate coproduction of Human Capital as farmers share knowledge — an important attribute of farmer-to-farmer methods (Holt-Giménez 2006, 112). 
Survey results revealed that farmers had received more informal training (e.g., field days, local meetings, etc.) than formal training (e.g., conferences, seminars, etc.). Both of these Human Capital indicators were hypothesized to have a positive correlation to CTA Participation. However, the model indicates that respondents with less formal training (FRMEDU) have a greater likelihood of participation, while willingness to consider participation increases as informal training (INFEDU) increases. The informal training finding is similar to results from previous research (Mancini et al. 2008; Bruening and Martin 1992). Indeed, the odds ratio implies that farmers receiving informal training are 51.88 times more likely to participate, while holding other factors constant. As found in other studies, informal trainings, such as on-farm demonstrations and local meetings, are a powerful way to instigate change (Enshayan 1992, 130). The implications are that informal trainings are the most appropriate pedagogical approach to increase awareness and overcome the "knowledge barrier" revealed in the farmer interviews.

Taken together, these results support the underlying assumption in the theory of change that increases in particular aspects of Human Capital, especially if coproduced by farmers, will raise CTA Participation levels.

\subsubsection{Cultural Capital}

As revealed by the farmer interviews, two categories are potential motivators to participation. It is evident that many participants had a "personal attachment to their land" that could be used to encourage conservation practice implementation. Moreover, a "stewardship ethic" was demonstrated in relation to the condition and/or fate of the participant's farmland. Mclaughlin (2004) found that a strong personal attachment and land stewardship were the underlying motives for conservation easement donation while the monetary benefits from tax incentives only played an ancillary role (45). Therefore, it is conceivable that these intrinsic 
motivators translate to, and positively influence, other conservation activities such as $C T A$

\section{Participation.}

There was a "cultural identity" theme that was evident in the farmer interviews. Farmer participants made it clear they believed there to be substantial differences between "country folk" and "city folk." Undoubtedly, if NRCS staff are considered outsiders, then this "cultural identity" could become a barrier to CTA participation. Vanclay and Lawrence (1994) contend that farming subcultures are inclined to reject ideas that are different than those held by that subculture (79). Consequently, if NRCS staff are seen as "city folk," or if the practices they recommend seemingly go against accepted rural values, then participation may be hindered. The prominence of the "cultural identity" category found in the farmer interviews led to further questioning survey respondents on Cultural Capital topics such as intergenerational traditions and values (Flora and Flora 2013, 55) and the difference between values held by rural and urban residents (Flora et al. 2016, 74).

The descriptive statistics from the survey results showed nearly three-quarters of the respondents reported learning farming practices from their parents and grandparents. In addition, nearly all farmers in the study felt that values differed between country folks and city folks. The literature implies these intrapersonal (Flora and Flora 2013, 55) and interpersonal (Flora et al. 2016, 74) cultural forces could influence decision-making. However, neither of these two Cultural Capital indicators were significant predictors in the empirical model. Moreover, as a whole, respondents held the importance of all five land conservation and stewardship categories listed on the survey in high regard, according to their average Likert scores. Nonetheless, the variables derived from these categories were not significant in the model either. 
So, in essence, the farmer interviews indicated "personal attachments to the land," a "stewardship ethic," and "cultural identities" play a role in conservation practice adoption, but the Cultural Capital variables representing these themes from the survey were not significant in the model. One possible explanation for this discrepancy could be the questions on the survey did not quite embody the categories that emerged from the farmer interviews. However, given the descriptive statistics, a more plausible explanation is that traditions are so often handed down, common rural values are so widely held, and that land conservation and stewardship is so highly regarded, that their impact on willingness to consider CTA participation may be statistically unremarkable in relation to other prominent factors. It should be noted that some Cultural Capital indicators were statistically significant. For example, the model indicates those who find tidy farming landscapes (TIDY) to be more important are less likely to participate in the CTA program. This result was expected based on the prominence of cultural landscapes (Burton 2012; Burton et al. 2008; Schmitzberger et al. 2005; Ryan et al. 2003) and the social judgement that is often tied to their symbolism (Burton 2012, 54).

The empirical model also revealed farmers who feel NGOs (NONGOV) are less trustworthy have a higher likelihood of participation. This was contrary to the hypothesis which was founded on prior research that showed a positive correlation between organizational trustworthiness and participation in conservation easement programs (Oliver 2011, 77). It is possible that the differences between these two different types of conservation programs caused the misinterpretation. Nonetheless, it is logical to assume that if a farmer feels one organization is more trustworthy than another-then they would be more inclined to participate in a program offered by the one they deem more reliable. This notion is indirectly supported by the descriptive statistics that showed respondents trust farmer groups and government agencies more than 
NGOs. All things considered, the essential component "in the promotion of environmental management is the acceptance of the practices and thinking within the [farming] subculture" (Vanclay and Lawrence 1994, 80). Therefore, peer advocacy is assuredly the best method for gaining entrée into the farming subculture to advocate for conservation practice implementation and has implications for the NRCS personnel barrier as it reduces the need for direct Cultural Capital investments by the agency.

It is not surprising the farmer interviews also revealed a "fear of restrictions," given the American people's well-known devotion to, and readiness to defend, private property rights. Relatedly, even long-term timber leases have been associated with the fear of losing control of one's land (McGill et al. 2008, 269). Furthermore, Oliver (2011) found private forest landowners who were less concerned with property rights infringement were more likely to participate in conservation easement programs (74). There was also a "distrust of government" that was evident in the farmer interviews. Based on these results, it would seem that "fear of outsiders" (Flora et al. 2016, 75) and farmer perceptions of organizational trustworthiness (Oliver 2011, 77) do indeed influence CTA participation in the study area.

Moreover, there is potential for relational disconnect between farmers and NRCS staff (Social Capital) given the great amount of office time required by financial assistance programs. "Farmer-to-farmer methods" may provide an opportunity to overcome Social, Human, Cultural and Financial ${ }^{1}$ Capital barriers from within farmer groups. It should be noted that key principles to "farmer-to-farmer methods" are solidarity and the sharing of knowledge (Human Capital) and resources (Financial Capital $^{1}$ ) (Holt-Giménez 2006, 112). Furthermore, an important axiom of farming subcultures is that adopting new practices is unlikely if they are not part of the subculture - while mass adoption may occur if they are accepted (Vanclay and Lawrence 1994, 
80). Therefore, finding local farmers who are willing to promote NRCS conservation practices may alleviate these notions of "us" versus "them" and help gain the necessary cultural acceptance. Overall, these results appear to be congruent with the theoretical model's assumption that investments in Cultural Capital, in particular by farmers and farmer networks, could be used to increase CTA Participation.

\section{$\underline{\text { 5.1.1.4 Financial Capital }}{ }^{1}$}

The farmer interview results and the descriptive statistics findings from the survey illustrated a cost barrier to the implementation of conservation practices. While the COST variable itself was not statistically significant in the empirical model, there were many other factors representing Financial Capital ${ }^{l}$ that indicated cost is an important factor. For starters, farmers who make $\$ 90,000$ or more per year (INCOME) are 27.13 times more likely to consider the program than those making less, if other factors are held constant. Unfortunately, the descriptive statistics reveal most farmers in the sample population are in the latter income brackets. Moreover, these farmers only derive a little more than ten percent of their income from agricultural activities, thereby depending more on off-farm income. This revenue composition often means they do not have the financial capacity to participate in conservation programs (Lambert et al. 2006, 10).

Indeed, survey respondents ranked cost the highest when asked to identify the biggest barrier to the implementation of conservation practices from a list obtained from the local interviews (e.g., NRCS personnel, lack of knowledge, distrust of government, bureaucracy, cost, etc.). These results are corroborated by Cook et al. (2013) who claim land managers do not lend much credibility to really expensive practices (671). Accordingly, the empirical model indicates that farmers who believe the benefits (BENFIT) outweigh the costs are much more willing to 
consider participation. In fact, while holding other factors constant, these farmers are over one hundred times (odds ratio of 103.19) more likely to adopt than farmers who feel the costs are greater. Survey results show most respondents do indeed find the cost-benefit ratio to be favorable, which implies there is strong potential for CTA Participation, despite financial constraints. Relatedly, the empirical model shows that respondents who consider their farmland a monetary investment (INVEST), one that will provide economic returns in the long run, have a greater likelihood to participate. The odds ratio here implies these farmers are almost nine times (8.57) more willing to consider than those who do not recognize their farmland to be a financial asset (while holding all else constant).

The majority of respondents reported owning their property for over twenty years (TENURE). The hypothesis predicted these farmers would be more willing to consider the CTA program. Inversely, the empirical model implies those who have owned their farm less than twenty years are more likely to participate. It is possible this was due to conflicting results found in the literature. For example, tenure was considered to be a Financial Capital $^{1}$ indicator because the economic returns from conservation practices often come in the long run and therefore insecure land holdings could create a barrier (Lutz et al. 1994, 278). However, other studies have found young farmers to be more open to learning and implementing conservation practices (Prokopy et al. 2008; Arbuckle et al. 2018). Based on this information, the coefficient for tenure could have been positive or negative. Nonetheless, the model for this study did not find a statistically significant relationship between AGE (Human Capital) and CTA Participation. However, this could be due to the population sample being older on average.

Farm size (ACRES) is another important aspect of Financial Capital ${ }^{1}$, which corroborates other findings that indicate farmer willingness to participate increases with acreage 
given larger farms can usually better afford the implementation costs (Ma et al. 2010; Lambert et al. 2006). Furthermore, the land uses on these acres represent financial assets as they are related to potential profits. For example, forest (FOCOV) is the most salient agricultural land use in West Virginia as it is the "third most heavily forested state in the nation" (Childs 2005, 2) consisting of approximately twelve million acres of forestland - ten million of which are privately owned (USDA Forest Service 2018). Consequently, most survey respondents' farms (92\%) had woodland on their property, at an average of $43 \%$ cover. Therefore, it follows that small variations in total forest were not found to be a significant variable in the empirical model.

Moreover, concerning agriculture in the traditional sense, West Virginia is a grassland state (GRSLND) where hayland acres are typically high and pasture is important for the leading industry, which is beef cattle (Sperow 2012; Frame 1940). This information was reflected by the survey results, which showed hay and pasture to be the leading land uses by far. Moreover, the odds ratio in the model suggests farmers reporting one of these two as their primary land useswhile holding all else constant —are almost fourteen times (13.80) more willing to consider CTA Participation than those listing different primary land uses.

In summary, these Financial Capital ${ }^{l}$ indicators represent various monetary factors that potentially play a role in a farmer's decision to implement no-fee conservation practices. Overall results indicate that, as expected, increases in Financial Capital ${ }^{l}$ increase the likelihood of CTA Participation — especially if those increases are derived from monetary support and mutual aid (Holt-Giménez 2006, 112) provided by farmer groups.

\subsubsection{NRCS Side of the Theoretical Model}

Discussion in the following sections turns to the NRCS side of the theoretical model. Consideration will be given first to the overarching political context (Political Capital and 
Financial Capital $^{2}$ ) and then to the secondary independent variable that depends on it (Organizational Capital $\left.^{1,2}\right)$.

\subsubsection{Political Capital and Financial Capital ${ }^{2}$}

The "shift in agricultural and conservation policy" noted in the interviews (Political Capital and Financial Capital ${ }^{2}$ ) is supported by the literature (Johnson and Monke 2017; Cox 2007; Helms 2005; Zinn 2005). While this shift was propelled by the conservation provisions in the 1985 Farm Bill, the findings in this study reveal that it did not fully impact CTA implementation at the field office level until NRCS' largest financial assistance program, EQIP, was added by the 1996 Farm Bill (Cox 2007, 118). Subsequently, the 2002 Farm Bill increased EQIP funding by a factor of six (Cox 2007, 117). This trend has continued and EQIP dollars have increased from 200 million in 2002 to 1.3 billion by 2007 (Zinn 2005, 5). Current levels are at approximately $\$ 1.5$ billion (USDA 2018, 52).

Unfortunately, CTA funding (Financial Capital ${ }^{2}$ ) remained relatively the same throughout this same time period, at about $\$ 750$ million (Reimer and Prokopy 2014; Stubbs 2010b; Cox 2007). Indeed, the expansion of financial assistance programs "affected the operations of field offices and the technical assistance program" (Helms 2005, 4). While this may have been an unintended consequence, the change in focus should not be viewed as a negative advancement overall. To the contrary, the resulting financial assistance programs have been, and continue to be, central to NRCS carrying out its mission. However, the results of this study indicate the administrative burden related to financial assistance programs has hindered NRCS' ability to provide technical assistance through the CTA program that is unrelated to a financial assistance contract—what NRCS Participant 2 referred to as "pure CTA.” Yet, "pure 
CTA" is acknowledged and well-established as a critical precursor to financial assistance programs, especially EQIP.

CTA program funds are used to support field staff and their technical expertise in nearly every county and territory of the United States to carry out conservation planning and programmatic implementation (Cowan and Johnson 2008; Stubbs 2010a; Stubbs 2010b). Unfortunately, there has been a decrease in NRCS staff between 1985 and 2005 despite the dramatic increase in financial assistance programs (Cox 2007, 134). As such, the National Association of State Departments of Agriculture (NASDA) has expressed concern over CTA funding levels (NASDA 2018, 1); as have other interest groups (Stubbs 2010b, 23). Simply put, the CTA program is essential to achieving conservation goals and an increase in funding is needed (NASDA 2018, 1).

Congress is challenged with determining the current organizational capacity of NRCS to provide technical assistance and how much is required to meet demand (Stubbs 2010b, 1). Both the farmer and NRCS staff participants, along with over half the survey respondents, indicate that current staffing levels are insufficient to satisfy the need. The 2002 Farm Bill did provide some technical assistance funds through individual financial assistance programs, but the results of this study support Cox's $(2007,136)$ assertation that it is not enough. Since 1996, NRCS has assumed the lead role for all aspects of conservation programs including, but not limited to: developing conservation practices, ranking and application processes, implementation follow-up, and providing payments to farmers (Helms 2005, 4). Furthermore, the addition of Technical Service Providers (TSPs) has not helped alleviate the problem either as there has been a large decrease in these individuals in recent years (Stubbs 2010b, 15). Moreover, given CTA provides support for financial assistance implementation, programs like EQIP suffer from the "NRCS 
personnel barrier" as well. Results from this research clearly illustrate the need for increased CTA funding.

\section{$\underline{\text { 5.1.2.2 Organizational Capital }}{ }^{1}$}

Kretzmann and McKnight (1993), contend some communities are "institution-rich" while others are poor (171). They do not quantify a standard to differentiate between these two categories which is likely due to the variable nature of communities themselves. This study revealed that Randolph County had less conservation organizations than Pocahontas $\left(\right.$ Organizational Capital $\left.^{1}\right)$. Respectively, the underserved county had seven institutions within its borders while the overserved county had ten. However, it should be noted there are organizations serving both counties that are not physically located in them.

Indeed, there are a number of organizations serving farmers that do not have offices within the borders of these counties. For example, NRCS Participant 9 identified Trout Unlimited (TU), Ducks Unlimited (DU), and the National Wild Turkey Federation (NWTF) as being located elsewhere, but still having an active presence. Furthermore, research from webbased and secondary sources substantiated this claim. In fact, many of these conservation organizations operate statewide— having local chapters, staff contacts, and/or projects in both Randolph and Pocahontas. Therefore, it does not appear that one county is "institution-rich" while the other is "institution-poor," as defined by Kretzmann and McKnight $(1993,171)$. Furthermore, both Randolph and Pocahontas Counties have "anchor institutions" (e.g., Conservation Districts, NRCS Field Offices, WVU Extension, etc.) that are so vital to community and economic development (Maurrasse 2016). All combined, these findings indicate that the availability of organizational assets in the study area does not seem to play a major role in CTA Participation. 
Moreover, while the spatial modeling based on secondary data indicated Randolph and Pocahontas Counties were under- and overserved, respectively; the logistic regression model results based on primary data (i.e., survey findings) did not reveal a significant difference between farmland location and willingness to consider CTA Participation. This makes sense given the survey results also showed that, on average, farmers in both subject counties live just a

little over ten miles from the nearest USDA Service Center. As such, it would appear the primary institutional asset related to the CTA program in the study area is relatively accessible. However, organizations will ultimately vary in "number, size and nature" from one community to another (Kretzmann and McKnight 1993, 171).

Furthermore, many survey respondents felt there were enough conservation organizations (CAPCTY) in their county to provide farming-related technical assistance (Organizational Capital $^{l}$ ). Yet, results from the empirical model imply that farmers who do not feel there are enough organizational assets to provide farming-related technical assistance are more willing to consider participation than those who feel the opposite. This was unexpected and could be related to an improper operationalization of the question on the survey. However, it makes more sense that it would be related to NRCS personnel limitations (Organizational Capital ${ }^{2}$ ) causing a shortage in technical services-thereby making them a more coveted resource.

In sum, these findings indicate that CTA Participation is not causally related to the physical presence of NRCS offices or the number of related organizations in the study area $\left(\right.$ Organizational Capital $\left.^{1}\right)$.

\section{$\underline{\text { 5.1.2.3 Organizational Capital }}{ }^{2}$}

Over half the farmers in Randolph and Pocahontas Counties felt NRCS does not have enough personnel to provide CTA. Several farmers made statements in the comments section of 
the survey such as: "Get more field staff out there," "More visits from staff to design systems [would encourage me to participate]," and "More outreach from [the] office [is needed]." Similarly, the "NRCS personnel barrier" was the most salient of the six sub-concepts to the higher-level "barriers to participation" theme found in the farmer interviews. Results from the NRCS staff interviews indicated the presence of this "personnel barrier" as well. Yet the variable representing this factor in the empirical model (PERSNL) was not statistically significant. This could be due to the fact that nearly half $(45.2 \%)$ of the respondents were unwilling to consider CTA Participation and therefore may not have any experience working with NRCS.

Nevertheless, other studies have alluded to this personnel barrier also (Reimer and Prokopy 2014; Stubbs 2010b; Cox 2007; Helms 2005). For example, Reimer and Prokopy (2014) found that most farmers reporting infrequent interactions with NRCS concluded it was likely due to "stretched conservation staff" (328). These results support the claim that the current NRCS technical assistance infrastructure is fraying (Cox 2007, 134). This is especially problematic because the descriptive statistics revealed that respondents learned about conservation practices from other farmers and NRCS staff often. This is because "farmers are innovators, and there is a wealth of information and knowledge among them" (Enshayan 1992, 130). Yet, Bruening and Martin (1992) discovered farmers ranked NRCS staff as "the most useful human resource" when it came to soil and water conservation (52). In fact, their research supports the model findings in this study, which show NRCS staff to be important educators regarding conservation practices.

To be sure, results demonstrate farmer likelihood to participate in the CTA program increases as NRCS assumes the primary teaching role (NRCS1). Moreover, the odds ratio indicates that, when holding all else constant, farmers who learn about conservation practices 
directly from NRCS staff have a willingness to consider that is nearly five times (4.93) greater than farmers who learn about them elsewhere. However, according to the farmer and NRCS interviews, there is a "personnel barrier" hindering NRCS teaching efforts due to insufficient staffing levels. As such, maintaining NRCS technical capacity in the field is imperative to achieving conservation goals (Helms 2005, 5). Not to mention NRCS staff are probably the most fitting to help farmers navigate the bureaucracy inherent to governmental programs given their familiarity with the administrative processes and requirements.

One strategy for alleviating the personnel barrier to CTA Participation is coproduction through organizational partnerships. Results from the NRCS interviews revealed that the current state of "organizational collaboration" at the field office level consists mostly of long-standing partnerships. Therefore, the agency may need to reinvigorate their current partnerships, while also seeking out new ones.

Another strategy for alleviating the personnel barrier is organizing and supporting volunteers - in this case, the farmer-to-farmer networks suggested by the literature (Sosa et al. 2013; Holt-Giménez 2006; Enshayan et al. 1992). The interview findings suggest "farmer-tofarmer methods" are a viable coproduction strategy in West Virginia. For example, NRCS Participant 2 discussed his experience with "farmer-to-farmer methods" in another state where the farmer group did not "traditionally avail themselves of federal programs." However, this changed after receiving CTA from NRCS. Notably, the group was not seeking financial assistance, but were only interested in technical assistance from the agency. The outcome of receiving technical assistance led them to "form a group on their own" that eventually “cooperated with another group" to "put on field days and stuff like that" (NRCS Participant 2). However, results also show that NRCS has "underutilized farmer groups" and therefore needs 
greater investment in them to coproduce CTA in a way that mitigates Social, Human, Cultural and Financial ${ }^{1}$ Capital barriers to participation.

Successful deployment of farmer-to-farmer methods is related to the "participatory training need" that emerged as a sub-concept in the NRCS interviews. The agency employs public engagement tactics through the CTA program to conduct outreach (NRCS 2010, 525A.11), identify local natural resource concerns, and to improve decision making (NRCS 2010, 525-A.1). However, the findings show that NRCS staff need more effective skills in outreach and group facilitation. According to NRCS Participant 9, the Areawide Conservation Planning Training just "touched on the iceberg, the tip of it, how it [participatory methods] could be used for FCA."

NRCS seeks to train its employees "to improve and maintain their technical proficiency and to provide leadership in natural resource conservation" (NRCS 2010, 525-B.10). While most NRCS staff have received training that runs the natural resource technical spectrum from "simple and basic cropping systems to complex buildings and animal trails and stream crossings, the works" (NRCS Participant 2), they must also develop the technical skills related to community development that are necessary to effectively conduct outreach, strengthen relationships, activate social networks, and facilitate public meetings. Activating and facilitating social networks of farmers is particularly important given the survey results showed few farmers in the study area are group members at present. Therefore, farmer-to-farmer methods would positively affect Social Capital on the farmer side of the participation equation as well. Moreover, farmer interviewees indicated a lack of awareness regarding NRCS informal trainings and local meetings - a barrier that will likely minimize with Social Capital investments and possibly even lead to coproduction of these informal trainings by farmers. Ultimately, focused and formal 
community development and public engagement training should be considered equally important as technical training in support of conservation planning and the design and installation of conservation practices. These results further indicate an increase in CTA funding is needed to provide staff training in public engagement and community development.

In regard to other characteristics of NRCS staff, the "NRCS customer service culture" category was an intuitive coding of interview results because all the NRCS participants appeared to enthusiastically embrace the agency motto of "helping people help the land." While customer service was not a clear theme in the farmer interviews, there were comments made by farmers that illustrated its impact. For example, Farmer Participant 15 said, "Whoever has cultivated the culture of what those [NRCS] offices ought to be like has done a good job." These combined results reinforce the idea that the "NRCS customer service culture" is a potential motivator for CTA Participation and has implications for both Social and Cultural Capital on the farmer side of the participation equation.

Relatedly, NRCS interviewees explained the importance of establishing meaningful relationships (Social Capital) with farmers. Therefore, "building trust" was a higher-level category also. Trust is essential if farmers are expected to adopt conservation practices (Prokopy et al. 2014, 3). However, "building trust" takes time and these findings also show NRCS staff do not have a lot of time since the "shift in agricultural and conservation policy." In fact, NRCS Participant 2 went as far as to say, "Now I spend all my time on contracting, well I can't say all. The greatest percentage of my time is spent on contracting." This implies that while "building trust" can facilitate CTA Participation, a lack of the same may detract from it, thereby depleting Social Capital on the farmer side of the participation equation which may spiral-down and decrease farmer Human, Cultural and Financial ${ }^{1}$ Capital as well. 
In sum, insufficient NRCS staffing levels paired with inadequate use of available coproduction methods reduces CTA Participation. Furthermore, without adequate NRCS staff training, Social, Human, Cultural and Financial ${ }^{1}$ Capitals on the farmer side of the participation equation all suffer, thereby reducing CTA Participation. Both aspects of Organizational Capital ${ }^{2}$ support the theoretical model.

\subsubsection{Center of the Theoretical Model}

Turning to the center of the theoretical model, consideration is now given to the summative implications of the findings for the dependent variable, CTA Participation.

\subsubsection{CTA Participation}

In the NRCS interviews, staff defined CTA Participation in a more comprehensive manner than what is described in the literature - that being the installation of at least one or more conservation practices on private land (Stubbs 2010a; Cowan and Johnson 2008). Interestingly, the Soil Conservation Act of 1935 authorized technical assistance, but it was not until an amendment to the 2008 Farm Bill that a formal definition was provided (Stubbs 2010b, 2): "The term 'technical assistance' includes technical services provided directly to farmers, ranchers, and other eligible entities, such as conservation planning, technical consultation, and assistance with design and implementation of conservation practices" (Public Law §110-246). This definition was likely based on the nearly seventy-five years of precedent in the field in which technical assistance ranged from only providing advice to assisting with complex engineering designs and practice installation. Therefore, the effect of the "shift in agricultural and conservation policy" on the CTA program (Political Capital and Financial Capital ${ }^{2}$ ) is significantly challenging, given the practical demands on staff time and resources to provide this broader range of technical assistance services. 
The descriptive statistics provided by the survey results showed that a little less than half the respondents were not willing to consider participation in the CTA program. The overall significance of the empirical model indicates farmers who are willing to consider CTA Participation (CNSDR) do not have the same characteristics as those who are unwilling. The model output then proceeded to illustrate the nature and strength of association related to these characteristics.

On the farmer side of the participation equation, CTA Participation is a function of adequate Social, Human, Cultural, and Financial Capital ${ }^{1}$. Results from both the interviews and survey imply that farmers may be more likely to participate if they have a personal attachment to their land or exhibit a stewardship ethic. Conversely, cultural identities and cultural landscapes might deter one from participation. Lack of knowledge and bureaucratic encumbrances were found to be barriers that, when coupled with distrust of government, can exacerbate a fear of restrictions. However, coupling informal NRCS trainings with farmer-to-farmer methods and their associated social groups can help build knowledge, change cultural attitudes, and supply resources in support of implementation. As such, NRCS investments in farmer Social Capital may synergistically influence all capitals (Social, Human, Cultural, Financial Capital ${ }^{1}$ ) on the farmer side of the CTA Participation equation thereby reducing the need for direct involvement by the agency in all causal aspects of the theoretical model.

On the NRCS side of the participation equation, several of the farmer participants reported they had either received technical assistance themselves or their parents cooperated with NRCS before financial assistance programs became the focus - what NRCS Participant 2 referred to as “pure CTA.” Indeed, from 1935 to 1994, NRCS' primary role was to provide CTA (Stubbs 2010b, 8). The findings showed that the "shift in agricultural and conservation policy" 
did not begin having a major impact on NRCS field staff until after the 1996 Farm Bill. As such, the CTA Participation identified by the interviewees took place before the policy shift when Organizational Capital ${ }^{2}$ was more robust. This is a result that supports the theoretical model's assertation that an increase CTA Participation is a function of Organizational Capital ${ }^{2}$.

Indeed, prior to the policy shift, NRCS had more staff, and therefore greater capacity, to maintain customer service, build trust, provide "pure CTA," collaborate inter-organizationally, and conduct outreach to farmers. These key investments in farmer Social, Human, and Cultural Capital facilitated greater voluntary conservation practice implementation. However, as a result of the policy shift, the "NRCS personnel barrier" has inadvertently hindered these investments which has decreased CTA Participation.

Closely related, in the interviews, "CTA participation: the key to conservation on the ground" was a higher-level concept that cross-cut both populations. Its supporting sub-concept originated from the "good contracts come from CTA" quote by NRCS Participant 1 that ultimately became a recurring sub-concept in both interview datasets. The familiarity and understanding that came from pre-policy shift CTA Participation often led to successful financial assistance contracts later on. Results indicate that technical assistance facilitates the identification of resource concerns before planning — or contracting — for landowner desires that may not necessarily be related to environmental problems. Therefore, undoubtedly, technical assistance is essential to establishing baselines, identifying resource concerns, and evaluating alternatives (USDA NRCS 2014, 600-B.5). Ultimately, the importance of CTA Participation to successful financial assistance program participation later on was also clear in the interview responses provided by both farmer and NRCS participants and augments the finding that 
implementation without financial assistance (CTA Participation) is positively associated with Organizational Capital ${ }^{2}$.

\subsection{Evaluating the Theoretical Model}

A major weakness in conservation practice adoption studies has been the absence of theoretical foundations and theory building (Arbuckle et al. 2018). Due to its voluntary nature and educational benefits, CTA would profit from stronger guidance from community development principles. Therefore, a theory of change that integrates the ABCD and CCF theoretical approaches was developed and applied to better understand motivations and barriers to participation in the CTA program. The ABCD framework's principles of asset-based, community-driven planning, decision making, and action place emphasis on the relationships between NRCS staff and the farmers they serve. Furthermore, the CCF focuses on the specific role of each community capital and how, based on their interactions, investments in certain capitals can improve the others. The integrated $\mathrm{ABCD} / \mathrm{CCF}$ approach to natural resource management and community development represented in the theoretical model was expected to help identify the many factors that influence the adoption of conservation practices by farmers (Arbuckle et al. 2018; Reimer et al. 2014; Baumgart-Getz et al. 2012; Prokopy et al. 2008; Knowler and Bradshaw 2007), considering both the farmer and NRCS side of the participation equation. Consequently, the findings provide empirical confirmation of the NRCS personnel barrier found in the literature (Reimer and Prokopy 2014; Stubbs 2010b; Cox 2007; Helms 2005).

Moreover, this approach has brought farmer participation in the CTA program together with NRCS organizational capacity in a holistic theoretical framework. Ultimately, the results largely supported the anticipated causal relationships. Therefore, this study has firmly rooted the 
theoretical model in empirical evidence. Furthermore, the findings were well supported by related literature. As such, the indications are that the theoretical model and its theory of change are valid.

\subsubsection{Assumptions, Delimitations, and Limitations}

It was assumed that natural resource management theory alone could not answer the research questions. NRCS must incentivize participation to accomplish its mission due to the voluntary nature of private lands conservation (USDA NRCS 2013), which can be particularly difficult for a no-fee program like CTA. Moreover, NRCS employs public participation to identify natural resource concerns, install conservation practices, and conduct follow-up evaluations (USDA NRCS 2010, 525-A.1). Therefore, community development theory was employed, based on the assumption that these strategies are better informed by that literature. Specifically, theory building and the operationalization of independent and dependent variables were guided by the ABCD (Kretzmann and McKnight 1993) and CCF (Flora and Flora 2013) theoretical frameworks. Together, these frameworks provide a holistic approach to natural resource management and community development, but is also a delimitation that is acknowledged.

A local level of analysis was assumed to be most appropriate for three reasons. First, Knowler and Bradshaw (2007) argue that, due to the importance of social groups to farmer decisions, research should seek results that are relevant to local management instead of global understanding (45). Second, NRCS as experts in natural resource management believe locallyled conservation is the best way to solve natural resource problems (USDA NRCS 2014, 600B.1). Third, community development practices usually take place at the local level. Therefore, two West Virginia counties were chosen as the sample population for which the potential 
constraints are hereby acknowledged. Relatedly, it was assumed that the secondary data used for the spatial modeling that identified the subject counties would be insufficient to answer the research questions. Lastly, another assumption that was made is the local interview participants, and the agricultural producer survey respondents, answered the questions that were asked of them truthfully. This is assumed due to the voluntary nature of participation in the study along with the anonymity and confidentiality that was provided, but it is acknowledged as a potentially inhibiting factor.

This research was delimited by several conditions. First, the objectives of the study were to: (1) determine the factors that influence farmers' decisions to participate in the CTA program; (2) consider NRCS's organizational capacity to deliver the CTA program; and (3) describe how NRCS might increase participation in the CTA program. Pursuits that were not clearly related to these stated objectives were excluded. It is understood and acknowledged that these parameters determined the scope of the study. More importantly, as an NRCS employee myself, there was an intentional focus on recommendations for practice that could be directly provided to the agency. In this sense, the research design was more applied in nature than many resource management dissertations.

A portion of the research was financed by the Division of Resource Economics and Management at WVU, while the remainder was personally funded. Therefore, funds were a salient constraint and a population sample was chosen for data collection rather than gathering information from the entire state. The geographic extent of the study was delimited to Randolph and Pocahontas Counties. This decision was made because the spatial modeling identified these areas as underserved (Randolph) and overserved (Pocahontas) in the CTA program. These results, coupled with their land use characteristics, led to these counties being selected as the 
sample population because they were believed to be most inclusive and representative of the whole state. However, it should be noted these findings were based on readily available secondary data that was unrelated to the theory of change — an intentional delimitation.

In addition, NRCS is the primary agency that provides technical assistance to farmers for conservation practice implementation. Therefore, other potential partners were not interviewed due to limited financial resources.

Concerning research methods, a limitation that is often related to qualitative studies is they are difficult to replicate (Wiersma 2000, 211). On the other hand, survey research is limited by the response categories provided on the questionnaire (Simon and Goes, 2013). Therefore, a sequential mixed-methods research design was employed to draw from the strengths found in both qualitative and quantitative methodological approaches.

However, time was delimited because the author was set to receive a workplace promotion upon graduation and therefore completion of the project sooner rather than later was a goal intricately related to personal financial matters. This delimitation generated unforeseen limitations to the research design and findings. A true sequential mixed-methods design would have allowed sufficient time for analysis of prior methods before variables were operationalized and data collection began through subsequent methods. In this case, survey design and empirical model operationalization were partially concurrent with the interview process. Consequently, some variables may have been poorly operationalized or incorrectly interpreted from the literature, as evidenced in unanticipated results (see Chapter 5). Removing these limitations may have produced a more predictive model and/or better anticipation of variable signs. 


\subsubsection{Recommendations for Further Research}

The findings of this study contribute to the conservation practice adoption literature and inform practitioners and communities working to improve both agricultural production and environmental quality. The theory of change developed herein has been found to be reasonably valid and therefore contributes to the theoretical foundations of the field. However, future research should continue to refine this theoretical model.

As it pertains to the farmer side of the theoretical model, future research should differentiate between the different types of farmer groups. For example, questions related to formal farmer organizations, such as Farm Bureau, should not be combined with informal farmer-to-farmer networks, as defined by Holt-Giménez (2006, 92), that mostly consist of family, friends, and neighbors. The lack of engagement in formal organizations does not necessarily mean a lack of engagement in informal groups. Conservation practice knowledge and awareness should be operationalized into different categories (e.g., conservation practice knowledge versus knowledge of the CTA program itself) in future studies to better capture the nuances embedded in the "knowledge barrier." The efficacy of readily available formal trainings as well as the kinds and types of informal trainings that are most impactful among farmers should be evaluated. Future research should also study the potential cultural differences between farmers in the subject counties versus those elsewhere in the state, such as in the eastern panhandle of West Virginia. "Distrust of government" was a "barrier to participation" in the farmer interviews, but farmer perception of NGOs needs further research to clarify the factors influencing levels of organizational trust for these types of entities as well.

Cost was identified as a primary barrier to CTA Participation. However, there are conflicting results in the literature as to the influence of tenure on conservation practice adoption. 
The economic returns on conservation practice investments indicate longer tenure is favorable (Lutz et al. 1994, 278) while other studies show younger farmers are more receptive (Prokopy et al. 2008; Arbuckle et al. 2018). As such, this contradiction should be examined in future research to determine which underlying assumption is really driving the tenure factor. Another result that needs clarification is how, despite the saliency of the cost barrier, most farmers felt the benefits of conservation practices outweighed those costs. Yet many farmers (45.2\%) were still unwilling to participate in the CTA program. Moreover, the matter becomes more complex when noting how farmer personal attachments to the land and their stewardship ethic increases their likelihood of participation. Therefore, future research should further investigate Financial Capital $^{l}$ and its inter-relationship to intrinsic Cultural Capital motivators.

Related to the NRCS side of the theoretical model, organizational asset mapping was conducted as part of this research. While a causal relationship was not evident in the subject counties for Organizational Capital $^{1}$, this variable could be influential if the disparity between the number of organizations in a different study area were large. Therefore, future research should continue to investigate this factor. Moreover, this study only consisted of identifying and mapping the location of conservation organizations that may have the capacity to coproduce technical assistance. More than a "barebones identification" is needed because institutions are "complex and multidimensional" with "asset collections" that vary (Kretzmann and McKnight 1993, 171). Future research efforts should take an in-depth look at these potential partners and how their strengths and weaknesses align with NRCS to maximize the mutual benefits of these potential relationships.

In addition to CTA allocations from Congress, National Headquarters (NHQ) for NRCS in Washington, D.C., develops staffing caps for each state. Future research should investigate 
how the findings of this study might inform the manner in which those staffing limitations are developed. Moreover, provided CTA Participation in the form of relationship-building and informal consultation between NRCS and farmers can be difficult to quantify for reporting, future research should examine metrics for capturing the demands on staff time and resources that these activities require.

Concerning the center of the theoretical model, the definition of CTA Participation was constrained as there are actually two possible interpretations of the term: (1) farmer conservation practice implementation; or (2) farmer engagement in any type of CTA activity. Collapsing the two does not consider the importance of the preliminary relationship-building between NRCS staff and farmers. Nor does it consider the possibility of engaging in conservation practices independently of NRCS. This understanding was revealed by analysis of the interview results and the meaning of "pure CTA," but after the survey's design and distribution, which used the meaning derived from the literature. Thus, future research would need to operationalize the meaning of CTA Participation and the potential causal relationships more appropriately among specific program activities. For example, CTA Participation should be separated into stages beginning with NRCS consultation regarding conservation practices as the first stage and actual conservation practice implementation as the second. The variables that influence movement from one stage to the next needs further research.

Once operationalization of the theoretical model is adjusted and improved, the study should be repeated, perhaps on a larger scale. Yet, as a reminder, similar research to that which was conducted herein should allow sufficient time for the benefits of a sequential mixed-methods design to be fully realized. There should be no overlap between methodologies and project timelines must reflect the need to exhaustively analyze the results of early methods, and the 
impact those findings have on the operationalization of important variables, before initiating and engaging in latter methods.

Lastly, the recommendations for practice described in the next section, if implemented, provide an opportunity for future program evaluation research to determine the efficacy of each recommendation and to supply information for additional adjustments.

\subsection{Conclusions and Recommendations for Practice}

An important objective of this study was to better understand farmer motivations and barriers to CTA participation and to provide recommendations for practice that are flexible and easy to implement.

NRCS has a long history of working with local communities in conservation efforts. This is because "locally led conservation is a process based on the principle that community stakeholders are best suited to resolve local natural resource problems" (USDA NRCS 2014, 600-B.1). An increase in CTA funds is very much needed for additional NRCS staff so this community-oriented customer service approach to natural resource conservation can continue. The implications of this study are the lack of CTA funding, exacerbated by the absence of coproduction and effective public engagement strategies, has caused a decrease in conservation practice implementation in a variety of ways including, but not limited to: an absence of peer advocates, inadequate knowledge, bureaucratic encumbrances, fewer informal trainings, strongly held cultural identities and cultural landscapes, fear of restrictions, distrust of government, lesser trust of NGOs, implementation costs, and a shortage in NRCS personnel. It follows, then, that additional CTA funds to support more NRCS staff, coupled with training focused on revitalizing organizational collaborations and facilitating participatory farmer-to-farmer methods, would have the reverse effect. 
Indeed, NRCS could build upon their rich tradition with additional methods that may increase participation in the CTA program, while simultaneously leveraging personnel from collaborating partners and farmer networks. Specifically, investments in the community capitals as described in the theoretical model presented herein could improve the agency's program design and service delivery methods by augmenting the foundational CTA program design with community development techniques that support independent and widespread implementation of conservation practices. Furthermore, "once in place, these systems are likely to stay in place without ongoing subsidies" (Cox 2007, 136).

Following from the theoretical model and its spiraling-up theory of change, investments in the secondary independent variable of Organizational Capital $^{2}$ enable NRCS and farmer network investments in the primary independent variables of Social and Human Capital. The results of these investments, in turn, increase CTA Participation. Furthermore, increases in Social Capital may also lead to increases in Cultural, Financial ${ }^{1}$, and Political Capital. Cultural and Financial $^{l}$ Capital enables an increase in CTA Participation. Political Capital enables an increase in Financial Capital ${ }^{2}$. Finally, an increase in Financial Capital $^{2}$ enables an increase in Organizational Capital $^{2}$, thereby closing the positive feedback loop in the spiraling-up theory of change. This is not to say NRCS cannot make direct investments in each of the primary independent variables on the farmer side of the participation equation (Social, Human, Cultural, and Financial ${ }^{1}$ Capitals), but rather, investments in farmer Social Capital may lessen their need to do so-which has implications for Organizational Capital ${ }^{2}$. In adherence with guidance to begin the process of spiraling-up with investments in Social Capital (Emery et al. 2006), the following recommendations for practice are offered based on the results of this study. 


\subsubsection{Investments in Social Capital}

Referring back to the importance of peers to farmer decisions, it would make sense for NRCS to build bridging social capital with farmers and bonding social capital among farmers by supporting the formation of farmer networks and their activities. Farmers within these networks who have participated in NRCS programs and adopted conservation practices could be invited to function as advocates for participation in the CTA program. Moreover, farmer willingness to promote conservation practices could be added into the informal training opportunities that appear to be most effective.

\subsubsection{Investments in Human Capital}

Provided the current NRCS personnel barrier found in these results, and indicated elsewhere (Reimer and Prokopy 2014; Stubbs 2010b; Cox 2007; Helms 2005), farmer-to-farmer methods may be the best manner of informal education delivery at present. To be sure, educational programs that view the farmers themselves as sources of knowledge can promote change in agricultural practices that restore and conserve the landscape (Enshayan et al. 1992, 130). Workshops could be employed to train farmer-to-farmer stakeholders and coordinators or to show the results of on-farm conservation experiments (Sosa et al. 2013, 22). Much like how Holt-Giménez (2006) and Sosa et al. (2013) describe, these farmer networks can be used to provide informal training opportunities, where farmers could tell their success stories and/or provide on-farm demonstrations promoting soil and water conservation.

\subsubsection{Investments in Cultural Capital}

Assuredly, the new community development skills acquired by NRCS staff, coupled with support from farmer groups, should be utilized to make investments in Cultural Capital. Culturally-rich outreach strategies, such as local celebrations and potluck dinners, that capitalize 
on farmer personal attachments to their land, and their stewardship ethic, should be employed to remove common barriers to CTA Participation such as cultural identities, cultural landscapes, distrust, and fear of restrictions. Indeed, tapping into farmer internal desires to care for the land may provide a new strategy for increasing participation in conservation programs (Ryan et al. $2003,35)$.

Similar to other findings (Vanclay and Lawrence 1994, 80), this study further indicates shared learning approaches like farmer-to-farmer methods are central to gaining acceptance within the farming subculture. Moreover, a shared worldview among technical staff and farmers is important in successful farmer-to-farmer networks (Stout and Love 2018). This acceptance becomes especially important since cultural identities are so prominent. Therefore, public engagement strategies should also honor common rural traits, such as hard work, frugality, independence, and patriotism (Flora et al. 2016, 75) to help break down these Cultural Capital barriers. Ultimately, building on existing cultural norms is critical to establishing trust in NRCS staff among farmers and, ultimately, to farmer implementation of voluntary conservation practices.

\subsubsection{Investments in Financial Capital ${ }^{1}$}

Eliminating the cost barrier would likely increase the implementation of conservation practices sought by the CTA program. However, because the CTA program does not offer financial incentives for participation, increasing the financial capital available to farmers would provide more capacity to implement conservation practices. Creating capital for investments within local farmer networks could allow increased implementation by mitigating these cost barriers. One method for building investment capital is to foster and support peer lending circles. Also called "group-based borrowing," "solidarity lending," or “cestas," lending circles are 
comprised of people that contribute to a collective pot of money that is subsequently distributed regularly, or upon request, to members of the group (Caplan 2014, 153). "The purpose of the loan is usually for emergencies, to pay other debts, for capital improvements on dwellings, or to start or improve businesses" (Caplan 2014, 153). This strategy is aligned with the farmer-tofarmer culture of mutual support (Holt-Giménez 2006, 112). Peer lending circles have been successful in providing people access to funds in the past and are one strategy that NRCS could use to help overcome the monetary barrier to CTA conservation practice implementation.

This approach coupled with additional technical support through increased NRCS staff could provide comprehensive conservation plans with conservation practice alternatives that have varying cost-benefit ratios for the farmer to evaluate. Providing farmers with the associated costs and benefits of various alternatives helps to lower the risk involved in adopting new practices and increases farmer willingness to change (Lambert et al. 2006, 28). This requires sufficient NRCS personnel. Therefore, increasing NRCS capacity through additional CTA funds and multiple approaches to coproduction of technical assistance should also help minimize the "cost barrier."

\subsubsection{Investments in Political and Financial Capital ${ }^{2}$}

CTA Participation that leads to successful implementation of conservation practices can increase political and financial support from Congress. Indeed, findings show that increased CTA Participation very well may gather the attention of lawmakers. However, NRCS has no mechanism, other than advocating for itself during the budgetary process, to make direct investments in Political Capital and Financial Capital ${ }^{2}$. Therefore, the agency must rely largely on external political advocacy, particularly from farmers and farmer groups. 
Investments in Social Capital have the potential to leverage the Political Capital of farmers. While federal employees are prohibited from engaging in lobbying activity, NRCS could inform agricultural producers about policy and budget issues that affect the CTA program and encourage them to be active in policy advocacy through their own local associations and organizations. Furthermore, farmer-to-farmer networks could engage in political advocacy for additional CTA budget allocations from Congress. Through either mechanism, more federal investment in technical assistance is needed to help alleviate barriers to sufficient NRCS staffing levels (Reimer and Prokopy 2014, 329).

\subsubsection{Investments in Organizational Capital ${ }^{1,2}$}

Based on the results of this study, Organizational Capital ${ }^{l}$ does not appear to be causally related to CTA Participation and therefore does not require expansion in the subject counties. In regard to the NRCS personnel barrier to participation (Organizational Capital ${ }^{2}$ ), the primary recommendation is for Congress to increase CTA funding based on the empirical evidence provided by this research. In the meantime, developing coproduction strategies through new and reinvigorated partnerships and farmer-to-farmer methods to offset the NRCS personnel barrier are potential avenues to increasing agency capacity.

An increase in CTA funds is also needed to diversify staff training to include public engagement and community development techniques to carry-out the recommended coproduction and farmer-to-farmer methods. There has been little to no training of this nature, despite the public engagement aspects of NRCS work-particularly as it relates to the FCA approach and its LWGs. These skills are needed to create and maintain coproduction efforts and farmer-to-farmer networks-effectively reducing the NRCS personnel barrier while also strengthening continuity within the community regarding the NRCS conservation message. 
According to Chaskin et al. (2001), organizational collaboration is an effective strategy for increasing internal capacity and production while also linking the community to outside resources (155). There are three core strategies to fostering organizational collaboration: (1) establishing broker organizations; (2) developing continuous mechanisms for interorganizational collaboration; and (3) creating specialized partnerships (Chaskin et al. 2001, 125). Undoubtedly, an inventory of local organizations available for collaboration, such as that which was conducted as part of this research, is vital information (Kretzmann and McKnight 1993, 171). Ultimately, a combination of these three core strategies in addition to investigating the assets provided by the organizations that are available may be necessary in order to maximize all the collaborative coproduction opportunities. Reinvigorating and expanding local partnerships is likely to be well received by the agency given its locally-led philosophy. NRCS should continue leveraging these other community resources.

Farmer-to-farmer methods of coproduction also requires the use of these community development skills. Social networks are very important to farmer decisions. However, results show that NRCS has underutilized farmer groups in the past. Therefore, engaging farmer networks with participatory techniques presents an opportunity for organizational innovation and growth that is accompanied by the potential for increased conservation practice implementation. Farmers who have participated in the CTA program and adopted conservation practices have the ability to become peer advocates with their friends and family. For example, if a farmer has become highly skilled at managing the nutrient cycle on their farm, they could become a peer trainer for the Nutrient Management conservation practice and possibly bring others to the table to discuss the benefits of this technique. As such, voluntary farmer-to-farmer networks could help alleviate some of the funding and personnel restraints that are barriers to organizational 
capacity within both NRCS and its potential partners. It would undeniably be worthwhile for NRCS to take full advantage of "farmer-to-farmer methods" in the future.

However, the results of this study show that NRCS also needs to hire more staff in order to implement the CTA program as originally designed. Having the ability to spend time with a farmer, walk the farm, and get to know the operation enables the development of a comprehensive conservation plan that also takes into account the farmer's financial position-a key aspect of conservation planning (USDA NRCS 2014, 600-B.12). According to the NRCS interviews, field offices are understaffed and most, if not all, of staff time is spent on financial assistance programs. Again, this should be considered a positive for both conservation and farmers, but the fact that this priority has inadvertently hindered NRCS capacity to provide "pure CTA" (NRCS Participant 2) should not be overlooked - especially because the CTA program is foundational to, and in support of, those financial assistance programs. Additional CTA funds would allow field personnel sufficient time to provide the one-on-one, customer-facing, technical assistance the agency has been well-known for in the past and that is necessary to solve natural resource concerns while improving on-farm production.

\subsubsection{Anticipated Return on Investments}

To summarize, additional CTA funds from Congress for increased NRCS staff and training for delivery of community development techniques that emphasize organizational and farmer-to-farmer coproduction of technical assistance (Organizational Capital ${ }^{2}$ ) are recommended to increase CTA Participation. These techniques make key investments in Social, Human, Cultural, and Financial ${ }^{1}$ Capital as proposed in the theory of change, and are fully expected to spiral-up through increased CTA Participation to increase Political Capital that will feed back into NRCS's Financial Capital ${ }^{2}$ and Organizational Capital ${ }^{2}$. 
This theory of change makes sense for NRCS because "politics, sociology, human values, and traditions are as much a part of agriculture as cover crops and soil chemistry; equal attention should be given to the humanity and culture of agriculture" (Enshayan et al. 1992, 129).

However, this must be accomplished through a philosophical approach to resource management and community development that emphasizes citizen collaboration - an "experts on tap, not on top" approach that allows the social network to form and inform (Stout 2013, 220), which is directly in-line with the NRCS locally-led philosophy. The overall result will be an increased capacity of the community as a whole to engage in conservation practices that benefit agriculture, rural communities, local economies, and natural resource sustainability in West Virginia. 


\section{References}

Agresti, Alan. 2002. Categorical Data Analysis. Second Edition. Hoboken: John Wiley \& Sons, Inc.

Alford, John. 2002. "Why Do Public-Sector Clients Coproduce? Toward a Contingency Theory." Administration and Society 34: 32-56.

Altieri, Miguel A. 1995. Agroecology: The Science of Sustainable Agriculture. Second Edition. Boca Raton: CRC Press.

American Farmland Trust. 2002. "Sprawling Development Threatens America's Best Farmland: West Virginia.” Accessed January 3, 2018 at: https://4aa2dc132bb150caf1aa7bb737f4349b47aa42dce777a72d5264.ssl.cf5.rackcdn.com/map_westvirginia300.jpg.

Anglin, Ronald V. 211. Promoting Sustainable Local and Community Economic Development. Boca Raton: CRC Press.

Ansell, Chris, and Alison Gash. 2007. "Collaborative Governance in Theory and Practice." Journal of Public Administration and Theory 18: 543-571.

Arbuckle, J., Sarah Church, Francis Eanes, Kristin Floress, Yuling Gao, Ben Gramig, Linda Prokopy, Pranay Ranjan, and Ajay Singh. "Meta-Review of Barriers and Motivations for Farmers to Adopt Conservation Practices.” Paper Presented at the $73^{\text {rd }}$ Soil and Water Conservation Society (SWCS) International Annual Conference, Albuquerque, NM, July 2018.

Baumgart-Getz, Adam, Linda Stalker Prokopy, and Kristin Floress. 2012. "Why farmers adopt best management practice in the United States: A meta-analysis of the adoption literature.” Journal of Environmental Management, 96: 17-25. 
Belsley, D.A., E. Kuh, and R.E. Welsch. 1980. Regression Diagnostics: Identifying Influential Data and Sources of Collinearity. New York: John Wiley \& Sons, Inc.

Benedict, M., and E. McMahon. 2002. “Green Infrastructure: Smart Conservation for the $21^{\text {st }}$ Century.” Renewable Resources Journal 20(3): 12-17.

Blum, Winfried E.H. 2013. "Soil and land resources for agricultural production: General trends and future scenarios- A worldwide perspective." International Soil and Water Conservation Research 3: 1-14.

Bovaird, Tony. 2007. "Beyond Engagement and Participation: User and Community Coproduction of Public Services." Public Administration Review 67: 846-860.

Brudney, Jeffrey L., and Robert E. England. 1983. "Toward a Definition of the Coproduction Concept." Public Administration Review 43: 59-65.

Bruening, Thomas H., and Robert A. Martin. "Farmer Perceptions of Soil and Water Conservation Issues: Implications to Agricultural and Extension Education.” Paper presented at the American Vocational Association Convention, St. Louis, MO, December 4, 1992.

Burton, Rob J.F. 2012. 'Understanding Farmers’ Aesthetic Preference for Tidy Agricultural Landscapes: A Bourdieusian Perspective.” Landscape Research 37: 51-71.

Burton, J.F., Carmen Kuczera, and Gerald Schwarz. 2008. 'Exploring Farmers' Cultural Resistance to Voluntary Agri-environmental Schemes.” European Society for Rural Sociology 48: 16-37.

Callicott, J.B. 1990. “Whither Conservation Ethics?” Conservation Biology 15-20.

Caplan, Mary Ager. 2014. “Communities Respond to Predatory Lending.” Social Work 59: 149156. 
Charlton, Martin, and A. Stewart Fotheringham. 2009. "Geographic Weighted Regression: A White Paper." Science Foundation Ireland 1-14.

Chaskin, Robert J, Prudence Brown, Sudhir Venkatesh, and Avis Vidal. 2001. Building Community Capacity. New York: Aldine De Gruyter.

Chatterjee, S., A.S. Hadi, and B. Price. 2000. Regression Analysis by Example. New York: John Wiley \& Sons, Inc.

Chatterjee, S., and B. Price. 1991. Regression Diagnostics. New York: John Wiley \& Sons, Inc. Childs, Randall A. 2005. “West Virginia's Forests: Growing West Virginia's Future.” Economic Impact Study. West Virginia University.

Cook, Carly N., Michael B. Mascia, Mark W. Schwartz, Hugh P. Possingham, and Richard A. Fuller. 2013. "Achieving Conservation Science that Bridges the Knowledge-Action Boundary." Conservation Biology 27: 669-678.

Corbin Juliet, and Anselm Strauss. 2008. Basics of Qualitative Research. $3^{\text {rd }}$ ed. Thousand Oaks: SAGE Publications.

Cowan, T., and Renee Johnson. 2008. "Agriculture Conservation Programs: A Scorecard.” Congressional Research Service 1-18.

Cox, Craig. "U.S. Agriculture Conservation Policy \& Programs: History, Trends, and Implications," In U.S. Agriculture Policy and the 2007 Farm Bill. Stanford University: 2007.

Cubbage, F., O’Laughlin, J., and C. Bullock III. 1993. Forest Resource Policy. New York: John Wiley \& Sons, Inc.

Dark, Shawna J., and Danielle Bram. 2007. "The modifiable areal unit problem (MUAP) in physical geography." Progress in Physical Geography 31(5): 471-479. 
de Snoo, Geert R., Irina Herzon, Henk Staats, Rob J.F. Burton, Stefan Schindler, Jerry Van Dijk, Anne Marike Lokhorst, James M. Bullock, Matt Lobley, Thomas Wrbka, Gerald Schwarz, and C.J.M. Musters. 2013. "Toward effective nature conservation on farmland: making farmers matter." Conservation Letters 6: 66-72.

Dillman, Don A., Jolene D. Smyth, and Leah Melani Christian. 2009. Internet, Mail, and MixedMode Surveys: The Tailored Design Method. Third Edition. Hoboken: John Wiley \& Sons, Inc.

Djoukeng, Henri Grisseur, Tankou, Christopher Mubeteneh, and Aurore Degre. 2015. "Siltation and Pollution of Rivers in the Western Highlands of Cameroon: a Consequence of Farmland Erosion and Runoff.” International Journal of Agricultural Research and Review 3: 206-212.

Emery, Mary, and Cornelia Flora. 2006. "Spiraling-Up: Mapping Community Transformation with Community Capitals Framework.” Journal of the Community Development Society 19-35.

Emery, Susan, Susan Fey, and Cornelia Flora. 2006. "Using Community Capitals to Develop Assets for Positive Community Change.” CD Practice 13: 1-19.

Encyclopedia of Earth. 2014. Accessed November 9, 2017 at: http://www.eoearth.org/view/article/152248/.

Enshayan, Kamyar, Deb Stinner, and Ben Stinner. 1992. "Farmer to Farmer." Journal of Soil and Water Conservation 47: 127-130.

EPA. 2017. “EPA’s Environmental Quality Index Supports Public Health.” Accessed December 31, 2017 at: https://www.epa.gov/healthresearch/epas-environmental-quality-indexsupports-public-health. 
ESRI. 2016. ArcGIS Desktop Help: Release 10.3. Redlands, CA: Environmental Systems Research Institute, Inc.

ESRI. 2009. "Regression analysis basics." Accessed on January 14, 2017 at: http://webhelp.esri.com/arcgisdesktop/9.3/index.cfm?TopicName=Regression_analysis_b asics.

ESRI. n.d. "Interpolation.” Accessed on December 28, 2016 at: https://support.esri.com/en/otherresources/gis-dictionary/term/interpolation.

Faraway, Julian J. 2006. Extending the Linear Model with R. Boca Raton: Chapman \& Hall/CRC.

Faraway, Julian J. 2005. Linear Models with R. Boca Raton: Chapman \& Hall/CRC.

Farmer, J.R. "Motivation for the Adoption of a Conservation Easement: A Midwestern Perspective." Diss. U of Indiana, 2009.

Flora, Cornelia Butler, Jan L. Flora. 2013. Rural Communities: Legacy + Change. $4^{\text {th }}$ ed. Boulder: Westview Press.

Flora, Cornelia Butler, Jan L. Flora, and Stephen P. Gasteyer. 2016. Rural Communities: Legacy + Change. $5^{\text {th }}$ ed. Boulder: Westview Press.

Flora, Cornelia Butler, Mary Emery, Susan Fey, and Corry Bregendahl. n.d. "Community Capitals: A Tool for Evaluating Strategic Interventions and Projects." Accessed November 4, 2016 at: http://oklahoma4h.okstate.edu/edu/docs/7-capitalshandout.pdf. Fotheringham, A.S., Brundson, C., and M.E. Charlton. 2002. Geographically Weighted Regression: The Analysis of Spatially Varying Relationships. Chichester: Wiley. Frame, N.T. 1940. West Virginia Agriculture and Rural Life. Inwood, WV: USDA Bureau of Agricultural Economics. 
Getis, Arthur. 2007. "Reflections on spatial autocorrelation.” Regional Science and Urban Economics 37: 491-496.

Greiner, Romy, and Daniel Gregg. 2011. "Farmers' intrinsic motivations, barriers to the adoption of conservation practices and effectiveness of policy instruments: Empirical evidence from northern Australia. Land Use Policy 28: 257-265.

Gustanski, Julie Ann, and Roderick H. Squires. 2000. Protecting the Land: Conservation Easements Past, Present, and Future. Washington, DC: Island Press.

Gutierrez-Montes, Isabel, Jackeline Siles, Patricia Bartol, and Alejandro C. Imbach. 2009. "Merging a Landscape Management Planning Approach with the Community Capitals Framework: Empowering Local Groups in Land Management Processes in Bocas del Toro, Panama." Community Development 40: 220-230.

Hays, S.P. 1959. Conservation and the Gospel of Efficiency. Harvard University Press.

Helms, J. Douglas. 2005. “Technical Assistance - The Engine of Conservation.” Prepared for the Partnership Meeting, Natural Resources Conservation Service, March 15, 2005.

Holt-Giménez, Eric. 2006. Campesino a Campesino: Voices from Latin America's Farmer to Farmer Movement for Sustainable Agriculture. Oakland: Food First Books.

Horrigan, Leo, Robert S. Lawrence, and Polly Walker. 2002. "How Sustainable Agriculture Can Address the Environmental and Human Health Harms of Industrial Agriculture.” Environmental Health Perspectives 110: 445-456.

Jacobs, Cheryl. 2007. "Measuring Success in Communities: Understanding the Community Capitals Framework." South Dakota State University Extension Extra 1-2.

Jelinski, Dennis E., and Jianguo Wu. 1996. "The modfiable areal unit problem and implications for landscape ecology." Landscape Ecology 11: 129-140. 
Johnson, Donald M., and Catherine W. Shoulders. 2017. "Power of Statistical Tests Used to Address Nonresponse Error in the Journal of Agricultural Education.” Journal of Agricultural Education 58: 300-312.

Johnson, Renee, and Jim Monke. 2017. "What is the Farm Bill?" Congressional Research Service 7-5700: 1-13.

Knowler, Duncan, and Ben Bradshaw. 2007. 'Farmers' adoption of conservation agriculture: A review and synthesis of recent research." ScienceDirect 32: 25-48.

Knowlton, Lisa Wyatt, and Cynthia C. Phillips. 2012. The logic model guidebook: Better strategies for great results, $2^{\text {nd }}$ Edition. Thousand Oaks, CA: SAGE Publications.

Kretzmann, John P., and John L. McKnight. 1993. Building Communities from the Inside Out: A Path Toward Finding and Mobilizing a Community's Assets. Skokie: ACTA Publications.

Krueger, William C., Matt A. Sanderson, James B. Cropper, Mary Miller-Goodman, Claudia E. Kelley, Rex D. Pieper, Pat L. Shaver, M.J. Trlica, Vivien G. Allen, Dwight Fisher, M. Havstad, and Phillip L. Sims. 2002. "Environmental Impacts of Livestock on U.S. Grazing Lands.” Council for Agricultural Science and Technology 22: 1-16.

Lambert, Dayton, Patrick Sullivan, Roger Claassen, and Linda Foreman. 2006. "ConservationCompatible Practices and Programs: Who Participates?" United States Department of Agriculture, Economic Research Service 14: 1-43.

LeSage, James P. 1999. The Theory and Practice of Spatial Econometrics.” Department of Economics: University of Toledo.

Lindner, James R., Tim H. Murphy, and Gary E. Briers. 2001. "Handling Nonresponse in Social Science Research.” Journal of Agricultural Education 42: 43-53. 
Loomis, R.S. 1984. “Traditional Agriculture in America.” Annual Review of Ecology and Systematics 15: 449-478.

Lutz, Ernst, Stefano Pagiola, and Carlos Reiche. 1994. “The Costs and Benefits of Soil Conservation: The Farmers' Viewpoint.” The World Bank Research Observer 9: 273295.

Ma, Shan, Scott M. Swinton, Frank Lupi, and Christina B. Jolejole. "Why Farmers Opt Not to Enroll in Payment-for-Environmental-Services Programs." Paper presented at the Agricultural \& Applied Economic Association's 2010 AAEA, CAES \& WAEA Joint Annual Meeting, Denver, Colorado, July 25-27, 2010.

Mancini, Francesca, Aad J. Termorshuizen, Janice L.S. Jiggins, and Ariena H.C. van Bruggen. 2008. "Increasing the environmental and social sustainability of cotton farming through farmer education in Andhra Pradesh, India." Agricultural Systems 96: 16-25.

Mariola, Matthew J. 2005. "Losing ground: Farmland preservation, economic utilitarianism, and the erosion of the agrarian ideal." Agriculture and Human Values 22: 209-223.

Mathie, Alison, and Gord Cunningham. 2002. "From Citizens to Clients: Asset-Based Community Development as a Strategy for Community-Driven Development.” Coady International Institute 4: 1-13.

Mathijs, Erik. 2003. “Social capital and farmers' willingness to adopt countryside stewardship schemes." Outlook on Agriculture 32: 13-16.

Matson, P.A., W.J. Parton, A.G. Power, and M.J. Swift. 1997. “Agricultural Intensification and Ecosystem Properties.” Science 277: 504-509.

Maurrasse, David. 2016. “Anchor Institutions and their Significance to Community Economic Development.” Accessed September 19, 2019 at: 
https://blogs.ei.columbia.edu/2016/03/08/anchor-institutions-and-their-significance-tocommunity-and-economic-development/.

McGill, David W., Shawn T. Grushecky, Stuart Moss, Chad Pierskalla, and Al Shuler. 2008. "Landowner Willingness to Engage in Long-Term Timber Leases in West Virginia, USA.” Small Scale Forestry 7: 105-116.

McLaughlin, N. 2004. "Increasing the Tax Incentives for Conservation Easement Donations: A responsible Approach.” Ecology Law Quarterly 31: 1-115.

Miller, Larry E., and Keith L. Smith. 1983. "Handling Nonresponse Issues.” Journal of Extension 45-50.

NASDA. 2018. "Conservation: Voluntary. Locally-Led. Incentive-Based." Farm Bill: Securing our Future.

NASDA. 2017. "West Virginia Department of Agriculture.” Accessed January 3, 2018 at: http://www.nasda.org/organizations/west-virginia-department-of-agriculture.

NCPP. n.d. "Conservation Planning." National Conservation Planning Partnership (NCPP): National Association of Resource Conservation \& Development Councils; United States Department of Agriculture, Natural Resources Conservation Service; National Association of State Conservation Agencies; National Conservation District Employees Association and the National Association of Conservation Districts. 1-20.

Oliver, Matt D. 2011. “An Evaluation of West Virginia's Non-Industrial Private Forest Landowner Participation in Conservation Easements.” Master's Thesis. Morgantown, WV: West Virginia University. 
Openshaw, S. and P. Taylor. "A million or so correlation coefficients: three experiments on the modifiable area unit problem.” In Statistical Applications in the Spatial Sciences. N. Wrigley (ed). London: 1979.

Pannell, D.J., G.R. Marshall, N. Barr, A. Curtis, F. Vanclay, and R. Wilkinson. 2006. "Understanding and promoting adoption of conservation practices by rural landowners." Australian Journal of Experimental Agriculture, 46: 1407-1424.

Perry-Hill, R., and L.S. Prokopy. 2014. “Comparing different types of rural landowners: Implications for conservation practice adoption." Journal of Soil and Water Conservation 69: 266-278.

Phillips, Rhonda, and Robert H. Pittman. 2015. "A Framework for Community and Economic Development." In An Introduction to Community Development, edited by Rhonda Phillips and Robert H. Pittman, 3-21. New York: Routledge.

Prager, Katrin, and Helena Posthumus. 2011. "Socio-economic factors influencing farmers' adoption of soil conservation practices in Europe." Human Dimensions of Soil and Water Conservation 1-21.

Prokopy, Linda S., Dan Towery, and Nicholas Batin. 2014. “Adoption of Agricultural Conservation Practices: Insights from Research and Practice.” Purdue Extension FNR488-W: 1-8.

Prokopy, Linda, K. Floress, D. Klotthor-Weinkauf, and A. Baumgart-Getz. 2008. "Determinants of agricultural best management practice adoption: Evidence from the literature." Journal of Soil and Water Conservation 63: 300-311.

Public Law. 2008. Food, Conservation, and Energy Act of $2008 \S 110-246$. “Technical Assistance." 
Putnam, Robert. 2000. Bowling alone: The Collapse and Revival of American Community. New York: Simon \& Schuster Paperbacks.

Putnam, Robert. 1995. “Bowling Alone: America's Declining Social Capital.” Journal of Democracy 6: 64-78.

Radhakrishna, Rama, and Prosper Doamekpor. 2008. "Strategies for Generalizing Findings in Survey Research.” Journal of Extension 73-76.

Reimer, Adam P., and Linda S. Prokopy. 2014. "Farmer Participation in U.S. Farm Bill Conservation Programs.” Environmental Management 53: 318-332.

Reimer, Adam, Aaron Thompson, Linda Stalker Prokopy, J. Gordon Arbuckle, Ken Genskow, Douglas Jackson-Smith, Gary Lynne, Laura McCann, Lois Wright Morton, and Pete Nowak. 2014. "People, place, behavior, and context: A research agenda for expanding our understanding of what motivates farmers' conservation behaviors." Journal of Soil and Water Conservation 69: 57A-61A.

Rivera, William McLeod, and M. Kalim Qamar. 2003. Agricultural Extension, Rural Development and the Food Security Challenge. Rome: Food and Agriculture Organization of the United States.

Ryan, Robert L., Donna L. Erickson, and Raymond De Young. 2003. "Farmers' Motivations for Adopting Conservation Practices along Riparian Zones in a Mid-western Agricultural Watershed.” Journal of Environmental Planning and Management 46(1): 19-37.

Sabatier, Paul A. 2007. Theories of the Policy Process. 2nd ed. Boulder: Westview Press. Sampson, R.N. 1985. For Love of the Land: A History of the National Association of Conservation Districts. League City: John Hopkins University Press. 
Schmitzberger, I., Th. Wrbka, B. Steurer, G. Aschenbrenner, J. Peterseil, and H.G. Zechmeister. 2005. "How farming styles influence biodiversity maintenance in Austrian agricultural landscapes." Agriculture, Ecosystems and Environment 108: 274-290.

Simon, Marilyn K., and Jim Goes. 2013. Dissertation and Scholarly Research: Recipes for Success. Seattle, WA: Dissertation Success LLC.

Smit, B. and J. Smithers. 1992. “Adoption of Soil Conservation Practices: An Empirical Analysis in Ontario, Canada." Land Degradation \& Rehabilitation 3: 1-14.

Sosa, Braulio Sosa, Adilen Maria Roque Jaime, Dana Rocio Avila Lozano, and Peter Michael Rosset. 2013. Agroecological Revolution: The Farmer-to-Farmer Movement of the ANAP in Cuba. The National Association of Small Farmers. La Via Campesina.

Sperow, C. 2012. “The West Virginia Encyclopedia - Agriculture.” Accessed May 12, 2015 at: http://www.wvencyclopedia.org/articles/166.

Stone, Deborah. 2002. Policy Paradox: The Art of Political Decision Making. New York: W.W. Norton \& Company, Inc.

Stone, Moren Tibabo, and Gyan Nyaupane. 2014. "Rethinking community in community-based natural resource management." Community Development 45: 17-31.

Stout, Margaret (Ed.). 2019a. From Austerity to Abundance? Creative Approaches to Coordinating the Common Good, Volume 6 of Critical Perspectives on International Public Sector Management. Bingley, UK: Emerald Group Publishing.

Stout, Margaret. 2019b. "Pursuing Community Change through Radically Democratic Practice." In Reframing Nonprofit Management: Democracy, Inclusion, and Social Change, edited by Angela M. Eikenberry, Billie Sandberg and Roseanne Mirabella. Irvine, CA: Melvin \& Leigh, Publishers. 
Stout, Margaret. 2013. "Delivering an MPA Emphasis in Local Governance and Community Development Through Service Learning and Action Research." Journal of Public Affairs Education 19(2): 217-238.

Stout, Margaret, and Jeannine M. Love. 2018. Community Development as Prefigurative, Radically Democratic Global Governance? Community Development: The Journal of the Community Development Society. (Early view December 2018.) DOI:

$10.1080 / 15575330.2018 .1557721$.

Strager, Michael P. 2016a. "Mapping Clusters." Lecture at West Virginia University on Geospatial Modeling, Morgantown, WV, September 25, 2016.

Strager, Michael P. 2016b. "Ordinary Least Squares (spatial data example).” Lecture at West Virginia University on Geospatial Modeling, Morgantown, WV, October 23, 2016.

Stubbs, Megan. 2014. "Conservation Provisions in the 2014 Farm Bill (P.L. 113-79).” Congressional Research Service 1-34.

Stubbs, Megan. 2010a. "Agricultural Conservation: A Guide to Programs." Congressional Research Service 1-20.

Stubbs, Megan. 2010b. “Technical Assistance for Agricultural Conservation.” Congressional Research Service 7-5700: 1-29.

Stubbs, Megan. 2010c. "Environmental Quality Incentives Program (EQIP): Status and Issues." Congressional Research Service 7-5700: 1-10.

The Cultural Landscape Foundation. n.d. "About Cultural Landscapes.” Accessed on February 22, 2017 at: http://tclf.org/places/about-cultural-landscapes. 
Tilman, David, Kenneth G. Cassman, Pamela A. Matson, Rosamond Naylor, and Stephen Polasky. 2002. "Agricultural sustainability and intensive production practices.” Nature 418: 671-677.

Tscharntke, Teja, Yann Clough, Thomas C. Wanger, Louise Jackson, Iris Motzke, Ivette Perfecto, John Vandermeer, and Anthony Whitbread. 2012. "Global food security, biodiversity conservation and the future of agricultural intensification." Biological Conservation 151: 53-59.

USDA. 2018. “FY 2018 Budget Summary.” Accessed on July 22, 2018 at: https://www.usda.gov/sites/default/files/documents/USDA-Budget-Summary-2018.pdf.

USDA Forest Service. 2018. "State and Private Forestry Fact Sheet: West Virginia 2018." Access on December 17, 2018 at: https://apps.fs.usda.gov/nicportal/temppdf/sfs/naweb/wv_std.pdf.

USDA NASS. 2012. "Census of Agriculture." Accessed on January 3, 2018 at: https://www.agcensus.usda.gov/.

USDA NRCS. 2017. "NRCS Conservation Programs: Conservation Technical Assistance (CTA).” Accessed on August 15, 2017 at: https://www.nrcs.usda.gov/Internet/NRCS_RCA/reports/srpt_cp_cta.html. 2014. National Planning Procedures Handbook (NPPH), Edition 1. US Department of Agriculture, Natural Resources Conservation Service. Title 180 - National Planning Procedures Handbook. . 2013. "2013 NRCS Organizational Chart.” Accessed November 13, 2017 at: https://www.nrcs.usda.gov/wps/portal/nrcs/detail/national/about/org/?cid=nrcs143_02140 $\underline{5}$. 
. 2010. "Conservation Technical Assistance Program.” Accessed on August 1, 2017 at: https://directives.sc.egov.usda.gov/.

. n.d.[a]. "More than 80 Years Helping People Help the Land: A Brief History of

NRCS.” Accessed November 13, 2016 at:

https://www.nrcs.usda.gov/wps/portal/nrcs/detail/national/about/history/?cid=nrcs143_02

1392.

. n.d.[b]. "Conservation Technical Assistance Overview." Accessed August 1, 2017 at:

https://www.nrcs.usda.gov/wps/portal/nrcs/detail/nj/farmerrancher/?cid=nrcs141p2_0187

27.

. n.d.[c]. "Focused Conservation Approach." Accessed November 13, 2016 at:

https://www.nrcs.usda.gov/wps/portal/nrcs/detail/wv/programs/financial/eqip/?cid=nrcse prd1167606.

. n.d.[d]. "Field Office Technical Guide (FOTG)." Accessed February 22, 2017 at:

https://www.nrcs.usda.gov/wps/portal/nrcs/main/national/technical/fotg/.

Vanclay, F., and G. Lawrence. 1994. "Farmer rationality and the adoption of environmentally sound practices; A critique of the assumptions of traditional agricultural extension." European Journal of Agricultural Education and Extension 1:1, 59-90.

West Virginia Code. 2000. Voluntary Farmland Protection Act § 8A-12-11. "Definitions."

Westlund, H. 2013. “A brief history of time, space and growth: Waldo Tobler's first law of geography revisited." Ann Reg Sci 51: 917-924.

Whitaker, Gordon P. 1980. "Coproduction: Citizen Participation in Service Delivery.” Public Administration Review 40: 240-246. 
Wiersma, W. 2000. Research Methods in Education: An Introduction. Boston, MA: Allyn and Bacon.

Williams, J.A. 1993. West Virginia: A History for Beginners. Charleston: Appalachian Editions. WVU. 2017. "Farming in West Virginia." Accessed on December 31, 2017 at: http://wvats.cedwvu.org/farm-and-garden/farming-in-west-virginia/.

Yang, Tse-Chuan. n.d. "Modifiable Areal Unit Problem.” Accessed on January 11, 2018 at: http://web.pop.psu.edu/projects/help_archive/help.pop.psu.edu/giaresources/giatips/MAUP.pdf/at_download/MAUP.pdf.

Zimmerman, Brianne, Alan Collins, and Donald Lacombe. 2016a. "Assessment of the Distribution of NRCS Assistance Programs in West Virginia and Strategic Enhancement of Future Outreach Efforts.” Project Update Material. West Virginia University, September 2016.

Zimmerman, Brianne, Alan Collins, and Donald Lacombe. 2016b "Spatial Distribution of NRCS Applied Practices in WV.” Project Update Material. West Virginia University, December 2016.

Zimmerman, Brianne, Alan Collins, and Donald Lacombe. 2016c. "Spatial Distribution of Applied NRCS Conservation Practices in West Virginia: Phase I.” Project Update Material. West Virginia University, December 2016.

Zinn, Jeffrey A. 2005. "Soil and Water Conservation Issues.” Congressional Research Service 114. 
Appendix A: Farmer Interview Protocol 
Farmer Interview Protocol

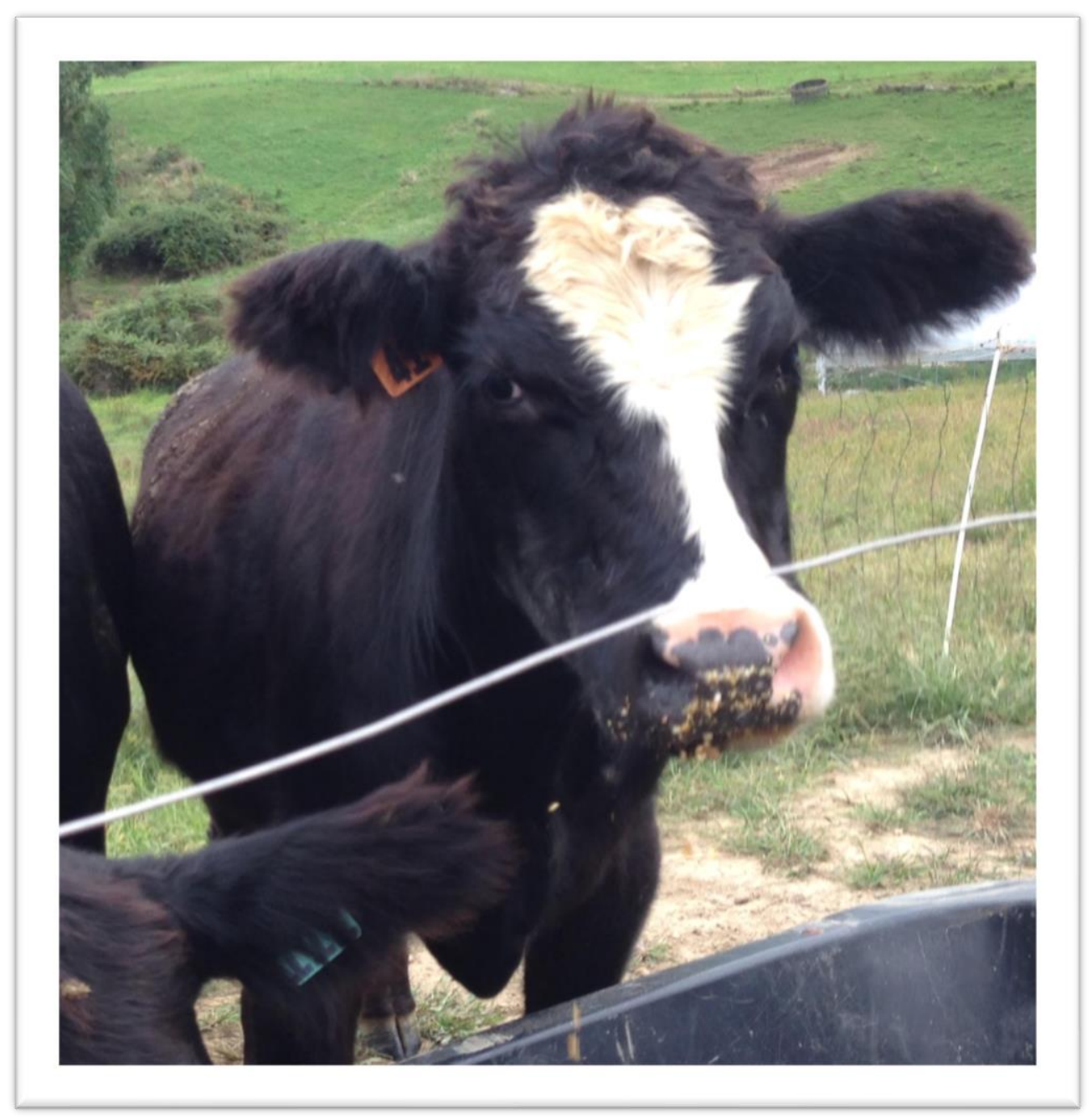

\section{West Virginia University}

Division of Resource Economics and Management

\section{8}




\section{INTRODUCTION}

Hello, my name is Matt Oliver. I'm a Doctoral Candidate in Resource Management and Sustainable Development at WVU. Thank you for participating in this study. Your time and effort are sincerely appreciated.

This study is an evaluation of the USDA NRCS Conservation Technical Assistance (or CTA) program in WV. Management of American farmland has a major influence on food and fiber production and the environment. The CTA program is foundational to the soil and water conservation services provided by NRCS. Participation in the program is defined as the voluntary implementation of one or more non-cost-shared conservation practices on private land.

Research has shown there are many factors that influence farmer participation in conservation programs. However, NRCS funding and personnel limitations are also a key factor to participation. So, an evaluation of farmer participation in the CTA program will be coupled with an assessment of NRCS organizational capacity. Together, this information will help me understand how to increase participation in the CTA program.

Your answers will help in understanding land management decisions made by WV farmers.

Your experience and insight will be very helpful to me in building this understanding and is greatly appreciated.

The interview should take about 30 minutes. If you are uncomfortable with a question, feel free to say so and we will move on to the next. The information you provide will be kept confidential, but to help me with my notes, do you mind if I record our conversation?

Do you have any questions before we begin?

\section{BUILD RAPPORT}

Allow me to tell you a little about myself first. I didn't grow up on a farm, but I have many fond on-farm memories and experiences. Years ago, I worked construction in North Carolina and my employer often hired me to help on the farm when business was slow. In addition, a good friend of mine here in West Virginia is a farmer and has taken the time to mentor me and show me a lot about farming. I love learning about it and he enjoys the hands-on help. I often feed the animals or "farm-sit" when he is away on business or family vacations. He has taught me a great deal about how conservation can be good for both the land and an agricultural enterprise.

I've always been passionate about conservation. My bachelor's degree is in Criminal Justice and my early career goal was to become a Conservation Officer. I eventually went back to school for Forestry and my master's research involved conservation on private forestland. I've worked over 450 hours as an NRCS Earth Team Volunteer in West Virginia and Indiana, served over 500 hours one summer as an NRCS temporary employee, spent a year working for NRCS in a Field Office helping farmers as a Soil Conservation Technician, and am currently stationed at the NRCS State Office managing the Agricultural Conservation Easement Program (i.e., farmland 
protection). Studying natural resource conservation, and helping landowners implement that conservation, is important to me. I consider it more than just my schoolwork or my job-it's my vocation.

1. Tell me about where you are from. (Jacob and Furgerson 2012, 3)

a. Did you grow up on a farm?

b. What influenced your decision to farm?

2. Describe your primary motivation for farming.

a. Why is that important to you?

b. Have you always felt this way?

3. Tell me about the most rewarding aspect of farming.

a. Can you give me an example?

b. What is significant about that to you?

\section{EVOKE STORIES}

4. Tell me about ways you've engaged with NRCS in the past.

a. Describe how you first came into contact with the agency.

b. Would you elaborate on that?

5. Tell me about a time when working with NRCS was helpful (i.e., outsiders are good).

a. Can you walk me through that process from design to practice implementation?

b. Who all was involved?

6. Can you remember a time when implementing a new NRCS conservation practice proved beneficial (i.e., change is good)?

a. What was your primary motivation for implementation?

b. Can you tell me more about that?

c. How do you feel about that experience?

7. Describe the biggest barrier you find to implementing the conservation practices recommended by NRCS.

a. Would you elaborate that?

b. Do you think other farmers feel the same way? 


\section{QUESTION STATEMENTS}

\section{Cultural Capital}

8. Thinking about the traditions and values handed down to you by your parents and grandparents, how would you describe your relationship to the land? (Flora and Flora 2013, 55)

a. Can you give me an example?

b. Would you elaborate on that?

9. Do you think values held by country folk are different from those who live in the city? (Flora et al. 2016, 74)

a. In what ways are these two things similar or different?

b. Why do you think that is?

c. Can you tell me more about that?

10. Do you feel that NRCS conservation practices reflect your values? (i.e., attitude toward conservation practices) (de Snoo et al. 2012; Schmitzberger et al. 2005)

a. Would you walk me through how you came to feel this way?

b. Would you elaborate on that?

\section{Human Capital}

11. Tell me about your general knowledge and level of exposure to conservation practices. (Prokopy et al. 2014; Oliver 2010)

a. Can you walk me through how you learned about these techniques?

i. Who taught you?

b. How has your knowledge and approach changed over time?

i. What contributed most to that change?

12. Can you describe any field demonstrations or on-farm educational opportunities you have attended for soil and water conservation? (Mancini et al. 2008;

Bruening and Martin 1992; Enshayan et al. 1992)
a. Who sponsored them?
b. What were the topics?
c. How often have they occurred?
d. Were they helpful? 


\section{Social Capital}

13. Describe your connections to other farmers in the area (i.e., bonding social capital).

a. Are there any farmer-initiated groups, associations, or unions?

i. Do you participate in them?

ii. Can you describe their activities?

iii. How strong is the connection between NRCS and these farmer groups in your area?

1. What about in general?

14. Walk me through how you share conservation and farming techniques with one another. (i.e., farmer-to-farmer methods)

a. Would you elaborate that?

b. Can you give me specific example?

15. Can you give me an example of a time where you learned about a conservation practice from another farmer? (Holt-Giménez 2006, 78)

a. Would you elaborate that?

b. How often has that occurred?

16. Tell me about any farmer-to-farmer workshops or similar trainings you've attended.

a. Who sponsored them?

b. How many have you attended?

c. Can you give me an example of how it has or has not been helpful on your farm?

17. Has another farmer ever referred you to NRCS? (i.e., bridging social capital)

a. How often do you think this happens?

b. Do you think it is helpful?

i. How so?

18. Have you ever participated in the Local Work Group (LWG) sessions associated with the NRCS Focused Conservation Approach (FCA)?

i. Tell me about that experience.

ii. Describe how it could be helpful to the CTA program.

iii. If you have not participated, can you describe what has kept you from joining? 


\section{CONCLUSION}

That concludes the interview. Do you have any questions for me, or final thoughts you'd like to share?

Your answers have been really helpful. If I have a follow-up question, do you mind if I contact you? May I have your contact information?

Thank you again for your time. I genuinely appreciate it. 
Appendix B: NRCS Interview Protocol 


\section{NRCS Interview Protocol}

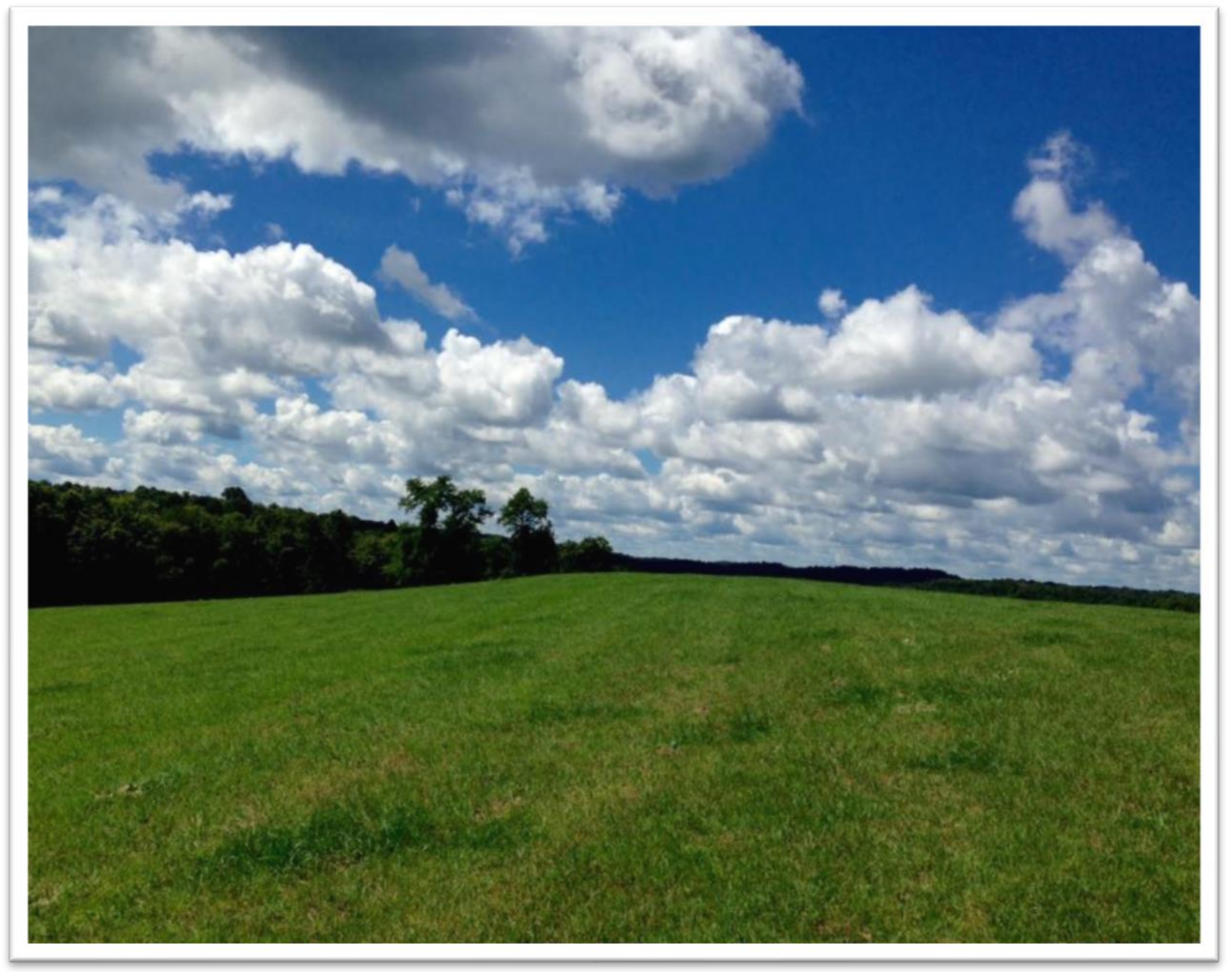

West Virginia University

Division of Resource Economics and Management

2018 


\section{INTRODUCTION}

Hello, my name is Matt Oliver. I'm a Doctoral Candidate in Resource Management and Sustainable Development at WVU. Thank you for agreeing to participate in this study. Your time and effort are sincerely appreciated.

This study is an evaluation of the USDA NRCS Conservation Technical Assistance (or CTA) program in WV. Management of American farmland has a major influence on food and fiber production and the environment. The CTA program is foundational to the soil and water conservation services provided by NRCS. Participation in the program is defined as the voluntary implementation of one or more non-cost-shared conservation practices on private land.

Research has shown there are many factors that influence farmer participation in conservation programs. However, NRCS funding and personnel limitations are also a key factor to participation. So, an evaluation of farmer participation in the CTA program will be coupled with an assessment of NRCS organizational capacity. Together, this information will help me understand how to increase participation in the CTA program.

Your experience and insight will be very helpful to me in building this understanding, and your input is sincerely appreciated.

The interview should take about 30 minutes. If you are uncomfortable with a question, feel free to say so and we will move on to the next one. The information you provide will be kept confidential, but to help me with my notes, do you mind if I record our conversation? Do you have any questions before we begin?

\section{BUILD RAPPORT}

Allow me to tell you a little about myself first. I didn't grow up on a farm, but I have many fond on-farm memories and experiences. Years ago, I worked construction in North Carolina and my employer often hired me to help on the farm when business was slow. In addition, a good friend of mine here in West Virginia is a farmer and has taken the time to mentor me and show me a lot about farming. I love learning about it and he enjoys the hands-on help. I often feed the animals or "farm-sit" when he is away on business or family vacations. He has taught me a great deal about how conservation can be good for both the land and an agricultural enterprise.

I've always been passionate about conservation. My bachelor's degree is in Criminal Justice and my early career goal was to become a Conservation Officer. I eventually went back to school for Forestry and my master's research involved conservation on private forestland. I've worked over 450 hours as an NRCS Earth Team Volunteer in West Virginia and Indiana, served over 500 hours one summer as an NRCS temporary employee, spent a year working for NRCS in a Field Office helping farmers as a Soil Conservation Technician, and am currently stationed at the NRCS State Office managing the Agricultural Conservation Easement Program (i.e., farmland protection). Studying natural resource conservation, and helping landowners implement that 
conservation, is important to me. I consider it more than just my schoolwork or my job-it's my vocation.

1. Tell me about where you are from. (Jacob and Furgerson 2012, 3)

a. Did you grow up on a farm?

b. How did your formative years influence your career path?

2. Describe your primary motivations for pursuing a career with NRCS.

a. Why is that important to you?

b. Have you always felt this way?

3. Tell me about the most rewarding aspect of your job.

a. Can you give me an example?

b. What is significant about this to you?

\section{EVOKE STORIES}

4. Describe a time when your work satisfaction was highest (i.e., stock in organizational capital was high). (Kretzmann and McKnight 1993, 8)

a. Can you describe your activities during an average work day during this period? (i.e., Time spent in the office versus time in the field) (USDA NRCS 2014, 600-A.2)

b. Tell me about your work unit during this time.

i. What was the year?

ii. How many people were on staff?

iii. Is there anything else you feel contributed to your sense of satisfaction?

5. Tell me about a time when your work was not satisfying (i.e., stock in organizational capital was low). (Kretzmann and McKnight 1993, 8)

a. Can you describe your activities during an average day at work during this period? (i.e., Time spent in the office versus time in the field) (USDA NRCS 2014, 600-A.2)

b. Tell me about your work unit during this time.

i. What was the year?

ii. How many people were on staff?

iii. Is there anything else you feel contributed to your sense of dissatisfaction? 
6. Can you remember a time when collaborating with other organizations helped solve a problem or achieve a goal (i.e., inter-organizational collaboration was good)? (Chaskin et al. 2001, 23).

a. Which organizations were involved?

i. Were any of them farmer-initiated groups, associations, or unions?

b. How often are these types of partnerships employed?

c. How do these partnerships come about?

\section{QUESTION STATEMENTS}

\section{Organizational Capital}

7. Describe what it means to provide technical assistance to NRCS customers. (USDA NRCS 2014, 600-A.19)

a. If I were watching you do this, what would I see?

b. Can you give me a specific example?

8. Tell me about the conservation planning process. (USDA NRCS 2014, 600-B.3)

a. What do you feel is the most important element?

b. How has your approach changed over time?

9. How would you define participation in the CTA program? (Stubbs 2010a, 6; Cowan and Johnson 2008, 4).

a. Can you tell me more about that?

b. Can you give me a specific example?

10. Describe the purpose of the CTA program. (USDA NRCS 2010, 525-A.1)

a. What role does it play in relation to NRCS financial assistance (FA) programs? (USDA NRCS 2010, 525-A.1)

b. Why does this relationship matter?

11. What percentage of time do you spend on CTA versus FA programs?

a. Describe how this has changed over time.

b. Can you explain to me how you feel about that?

12. Describe the kinds and types of training you have received throughout your career with NRCS.

a. What were the topics?

b. How often have they occurred?

c. How do you feel about that? 


\section{Social Capital}

In its simplest form, participatory approaches allow everyone involved to have a voice. An example of this would be the Local Work Groups (LWGs) that help develop proposals for the Focused Conservation Approach (FCA).

13. Tell me about your experiences utilizing participatory approaches with NRCS (USDA NRCS 2010, 525-A.1).

a. Describe how your LWG goes from project idea to FCA proposal.

b. How could this process be improved?

c. Describe how this approach could be used to benefit the CTA program?

i. Can you tell me more about that?

14. Could you tell me some other experiences you've had using public participation techniques in your job with NRCS?

a. How did your customers respond?

b. How often has this happened?

15. If you haven't used public participation approaches, do you think they would be helpful?

a. Why or why not?

b. Can you tell me more about that?

16. Have you received any public participation or community development related training during your career with NRCS?

a. What were the topics?

b. How often have they been offered?

c. How do you feel about that?

d. If you haven't had such training, do you think it would be useful?

Farmer-to-farmer methods are peer mobilization, education, and information sharing activities.

17. Can you give me an example of a time when you saw this kind of method help get the NRCS conservation message out?

a. How could this approach benefit CTA implementation?

i. What would that look like?

ii. I'm beginning to get the idea, but some more examples might help.

iii. How do you think others would respond to that? 
18. How do you or would you engage farmer-initiated groups, associations, or unions?

a. If I were watching you do this, what would I see?

b. How often does it occur?

c. Can you give me a specific example?

d. How strong is the connection between NRCS and these groups in your work area?

i. What about in general?

\section{CONCLUSION}

That concludes the interview. Do you have any questions for me, or final thoughts you'd like to share?

Your answers have been really helpful. If I have a follow-up question, do you mind if I contact you? May I have your correct contact information?

Thank you again for your time. I genuinely appreciate it. 
Appendix C: Farmer Survey 


\section{Agricultural Producer Survey}

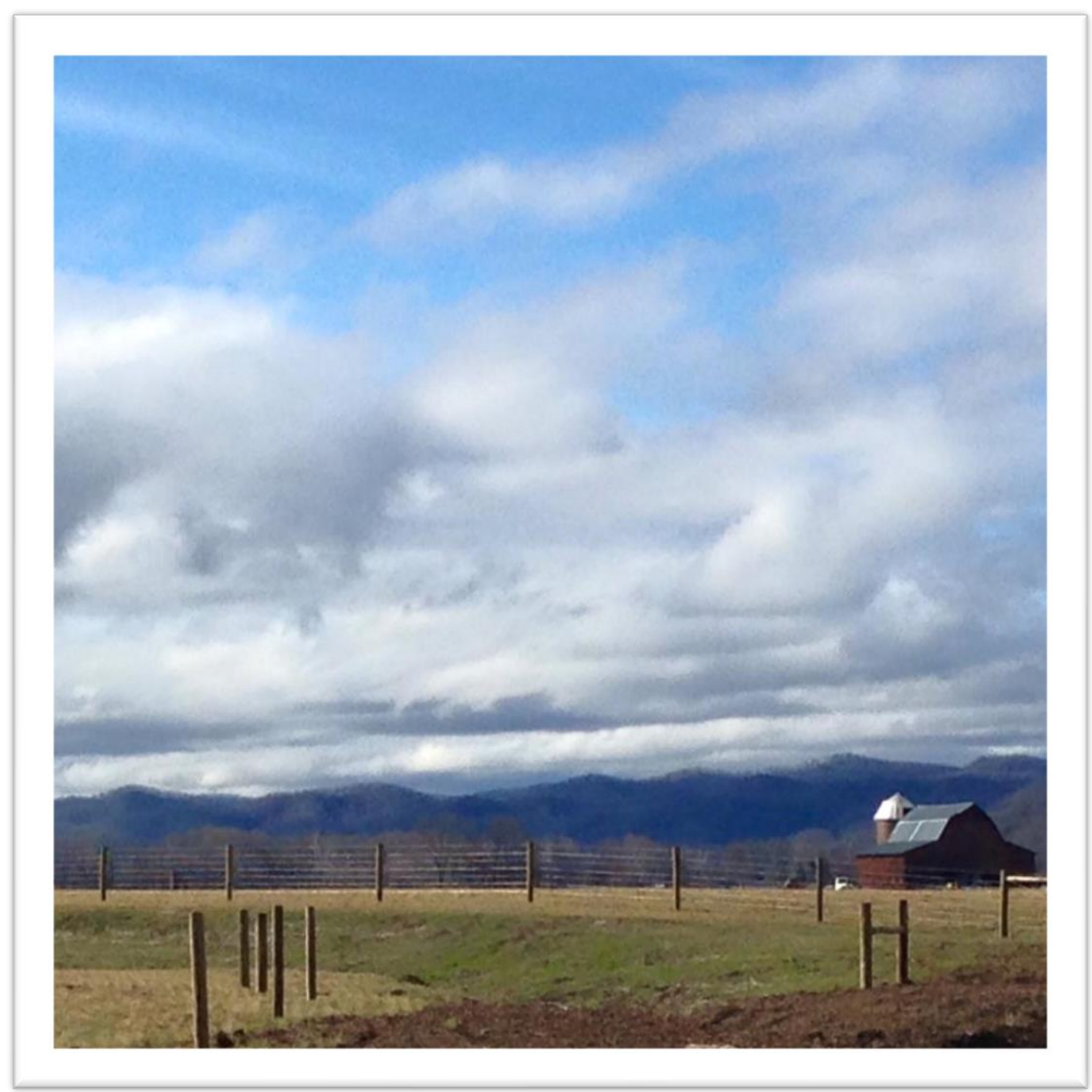

West Virginia University

Division of Resource Economics and Management

2018 
Thank you for participating in this study. Your answers will help me understand land management decisions made by West Virginia farmers with regard to the United States Department of Agriculture, Natural Resources Conservation Services' (USDA NRCS) Conservation Technical Assistance (CTA) program. If you are uncomfortable with a question, feel free to skip it and move to the next one. The information you provide will be kept confidential. Your time and effort are sincerely appreciated.

\section{FARM INFORMATION}

According to West Virginia law, Farmland is defined as real property, of any size, useable for cultivation or grazing together with any associated wetlands and forestlands.

1. Do you own or lease farmland in West Virginia? (Please select one.)

$\square$ Yes $\quad \square$ No

If you do not own or lease farmland, please send the survey back in the provided envelope. Thank you. If you own or lease more than one farm, please answer the following questions with your largest parcel in mind. Also, please answer the following questions with your management philosophy in mind.

2. In which county is your farmland located? (Please select one.)

$\square$ Randolph $\square$ Pocahontas

3. About how many acres are in the parcel? ___ Acres

4. Approximately, what percent of the parcel has forest cover? __ \%

5. Please rank the primary (1) and secondary (2) uses of your land. (Please select two by indicating 1 and 2 according to ranking.)

$\begin{array}{lll}\square \text { Pastureland } & \square \text { Timber production } & \square \text { Crop production } \\ \square \text { Hay production } & \square \text { Hunting } & \square \text { Other (please specify) }\end{array}$

\section{MOTIVATIONS FOR PARTICIPATION}

6. Have your farming techniques been influenced by your parents or grandparents? (Please select one.)
$\square$ Yes
No

7. Do you think the values held by rural folk are different than values held in urban areas? (Please select one.)

Yes

No 
8. How would you rate the importance of the following items? (Please circle one answer for each item.)

\section{Not Somewhat Neutral Very Extremely}
a. For the landscape on your farm to look tidy?
1
2
3
4
5
b. For the landscape on
your farm to look natural?
1
2
3
4
5
c. Soil and water conservation practices?
1
2
3
4
5
d. Your role as a land steward?
1
2
3
4
5
e. NRCS conservation practices?
1
2
3
4
5

9. How would you rate the trustworthiness of the following organizations? (Please circle one answer for each item.)

\section{Not Somewhat Neutral Very Extremely}

a. Federal agencies

(e.g., US Department of Agriculture)

12

3

4

5

b. Local agencies (e.g., Conservation Districts/WVCA)

2

3

4

5

c. Non-governmental organizations (e.g., The West Virginia Land Trust)

1

2

3

4

5

d. Farmer groups, associations, or unions (e.g., Farm Bureau)

1

2

3

4

5 
NRCS conservation practices can be categorized as either management practices (e.g., rotational grazing), vegetative practices (e.g., planting on stream banks), or structural practices (e.g., building a waste storage facility).

10. How much do you know about these three kinds of conservation practices? (Please circle one.)

$\begin{array}{ccccc}\text { Nothing } & \text { Very Little } & \text { Some } & \text { Very Much } & \text { Expert } \\ 1 & 2 & 3 & 4 & 5\end{array}$

11. Who has taught you the most about NRCS conservation practices? (Please rank the top three by indicating 1,2 , and 3 .)

$\begin{array}{lll}\square \text { Other farmers } & \square \text { Parents } & \square \text { Conservation Districts/WVCA } \\ \square \text { NRCS staff } & \square \text { Literature } & \square \text { Non-governmental organizations } \\ \square \text { Internet } & \square \text { WVU Extension } & \square \text { Other (please specify) }\end{array}$

12. How much training have you received regarding NRCS conservation practices? (Please circle one for each item.)

\section{None A Little Some A Lot Extensive}

a. Formal education such as trainings, conferences, workshops, seminars, etc?

b. Informal education such as field days, local meetings, brochures, internet, independent learning, etc.?

13. Are you a member of any local farmer group, association, bureau, or union? (Please select one.)
Yes
No

If yes, please specify which organization(s) in the space below. 
14. How would you rate the importance of being involved in your local farmer group, association, bureau, or union? (Please circle one.)

$\begin{array}{ccccc}\begin{array}{c}\text { Not } \\ \text { Important }\end{array} & \begin{array}{c}\text { Somewhat } \\ \text { Important }\end{array} & \text { Neutral } & \begin{array}{c}\text { Very } \\ \text { Important }\end{array} & \begin{array}{c}\text { Extremely } \\ \text { Important }\end{array} \\ 1 & 2 & 3 & 4 & 5\end{array}$

Farmer-to-farmer methods are peer mobilization, education, and information sharing activities.

15. Have you ever attended a farmer-to-farmer workshop or similar training? (Please select one.)
$\square$ Yes
No

16. Would you consider promoting NRCS conservation practices to other farmers? (Please select one.)
$\square$ Yes
$\square$ No

17. Do you feel your county has enough conservation organizations to provide farming-related technical support to everyone who wants it? (Please select one.)
$\square$ Yes
$\square$ No

18. Do you feel NRCS has enough personnel to provide conservation technical assistance to everyone in your county who wants it? (Please select one.)
$\square$ Yes
No

19. What do you find to be the biggest barrier to implementing the conservation practices recommended by NRCS? (Please rank the top three by indicating 1, 2, and 3.)
$\square$ NRCS personnel
Lack of knowledge
$\square$ Bureaucracy
Few field days
$\square$ Fear of restrictions
$\square$ Cost
Distrust of Government
Other (please specify)

20. How long have you owned or leased your farmland? (Please select one.)

$\begin{array}{ll}\square \text { 0- } 1 \text { years } & \square 10-15 \text { years } \\ \square \text { 1-5 years } & \square 15-20 \text { years } \\ \square \text { 5- } 10 \text { years } & \square 20+\text { years }\end{array}$


21. Do you consider your farmland a monetary investment that will provide economic returns in the long run? (Please select one.)
Yes
$\square$ No

22. Approximately what percent of your income comes from your farmland uses? $\%$

23. Generally, do you think the cost of implementing NRCS conservation practices is worth the benefit? (Please select one.)
$\square$ Yes
No

\section{DEMOGRAPHICS}

24. In which county is your primary residence located?

25. What is your age?

26. What is the highest education level you have completed? (Please select one.)

$\square$ GED
$\square$ High school diploma
$\square$ Associate degree
Bachelor's degree
$\checkmark$ Graduate degree
$\square$ Other (please specify)

27. What is your annual household income?
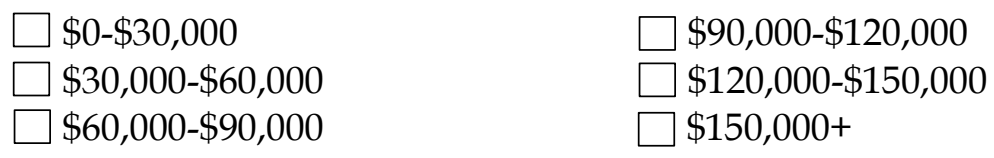

28. What is your gender identity?
Male
Female

Participation in the NRCS Conservation Technical Assistance program is defined as the voluntary implementation of one or more non-cost shared conservation practices on private land.

29. Would you ever consider participating in the NRCS Conservation Technical Assistance program? (Please select one.)

Yes

$$
\text { No }
$$


30. What barriers prevent you from participating in the NRCS Conservation Technical Assistance program? (Please use the space below.)

31. What would encourage you to participate in the NRCS Conservation Technical Assistance program? (Please use the space below.)

32. Please feel free to use the following space for any comments or suggestions regarding the research topic or survey questionnaire.

Please return your completed questionnaire in the enclosed self-addressed, stamped envelope as soon as you are able. Thank you for your participation! 
Office Address:

1550 Earl L. Core Rd.

Morgantown WV, 26505

matthew.oliver@wv.usda.gov

Work: 304-284-7564

\section{Curriculum Vitae}

Matt D. Oliver

\section{EDUCATION}

Doctor of Philosophy in Resource Management and Sustainable Development (2019)

West Virginia University-Division of Resource Economics and Management, Morgantown, WV

Concentration: Natural Resource Management/Human and Community Development

Dissertation: An Assessment of the United States Department of Agriculture, Natural Resources

Conservation Services' Conservation Technical Assistance Program in West Virginia

Chair: Dr. Margaret Stout

GPA: $3.9 / 4.0$

Master of Science in Forest Resource Management (2011)

West Virginia University-Division of Forestry and Natural Resources, Morgantown, WV

Concentration: Forest Resource Policy

Thesis: An Evaluation of West Virginia's Non-Industrial Private Forest Landowner Participation in

Conservation Easements

Chair: Dr. Kathryn Arano Gazal

GPA: $3.9 / 4.0$

Bachelor of Science in Criminal Justice and Criminology (2004)

Ball State University-Department of Criminal Justice and Criminology, Muncie, IN Major: Criminal Justice and Criminology

Minor: Religious Studies

GPA: $3.2 / 4.0$

\section{EMPLOYMENT}

\section{Acting Easement Specialist (2017-Present)}

US Department of Agriculture, Natural Resources Conservation Service-Morgantown, WV.

Managed all aspects of the Agricultural Conservation Easement Program (ACEP) including, but not limited to, closing conservation easements on private farmland, processing easement applications, resolving easement violations, and maintaining geospatial boundaries for acquisitions.

\section{Soil Conservation Technician (2015-2017)}

US Department of Agriculture, Natural Resources Conservation Service-Philippi, WV.

Designed conservation practices according to established standards. Inspected construction of completed practices to ensure adherence to specifications. Communicated Farm Bill programs and processes to landowners and community members. Assisted with conservation planning and Local Work Group (LWG) meetings. Facilitated implementation of the Focused Conservation Approach (FCA). 


\section{Graduate Teaching Assistant (2014-2015)}

West Virginia University-University College, Morgantown, WV.

Taught First-Year Experience (FYE) and Preparing to Achieve Student Success (PASS) courses designed to aid students in transitioning from secondary to post-secondary education. Assisted with Academic Success Initiatives (ASI) programs, such as the Mountaineer Success Academy (MSA), as needed.

\section{Intermittent Employee, WAE (2014)}

US Department of Agriculture, Natural Resources Conservation Service-Morgantown, WV.

Assisted with implementation of the Farm Bill Agricultural Conservation Easement Program (ACEP). Reviewed conservation easement deeds and program files for accuracy and assisted in resolving deficiencies in preparation for closing. Worked with NRCS programs staff to interpret policy and interim guidance related to the enactment of the 2014 Farm Bill.

\section{Program Director (2013)}

Indiana MENTOR—Daleville, IN.

Management of supported living for $20+$ adults with intellectual disabilities in 10+ homes. Supervised 6 Home Managers and facilitated teamwork, communication, and various organizational processes to improve efficiency. Completed goal tracking and finance accounting for clientele.

\section{Case Manager (2012-2013)}

Indiana Professional Licensing Agency-Real Estate Division, Indianapolis, IN.

Accurately processed and tracked license applications, criminal background checks, license transfers, and renewals while earning an Indiana real estate license.

\section{Graduate Research Assistant (2009-2011)}

West Virginia University-Division of Forestry and Natural Resources, Morgantown, WV.

Conducted research activities such as primary and secondary data entry and analysis. Successfully completed and defended an original and empirical masters level thesis.

\section{Shop Manager (2006-2008)}

Liberty House Utility Buildings-Asheville, NC

Responsibilities included supervision of twenty employees; maintaining inventory and managing construction of utility buildings while providing quality assurance for approximately 120 clients per month.

\section{Program Director (2005-2006)}

Indiana Mentor-Daleville, IN

Duties included, but were not limited to, management of supported living for mentally handicapped adults in 5 separate homes.

\section{PROFESSIONAL ACTIVITIES}

Farmland Protection Conference. October 17-19, 2018. Davis, WV. Presenter: Agricultural Conservation Easement Program Update.

Application \& Due Diligence Training. August 8 \& 9, 2018. Beckley \& Moorefield, WV. Trainer: Agricultural Conservation Easement Program Applications.

Farmland Protection Seminar. September 8 \& 22, 2017. Sutton \& Smoke Hole, WV. Presenter: Agricultural Land Easement Plans Overview. 
Preston County Farmland Protection Board's 10 Year Celebration. June 28, 2014. Reedsville, WV. Presenter: Attributes of Conservation Easement Participants in West Virginia.

Association of Farmland Protections Boards Quarterly Meeting. July 19, 2011. Cass, WV.

Presenter: An Evaluation of West Virginia's Non-Industrial Private Forest Landowner

Participation in Conservation Easements: Research Results.

Southern Forest Economics Workshop (SOFEW). March 20-22, 2011. Little Rock, AR.

Presenter: An Evaluation of West Virginia's Non-Industrial Private Forest Landowner

Participation in Conservation Easements: Preliminary Analysis.

\section{VOLUNTEER ACTIVITIES \& SERVICES}

400+ hours as an Earth Team Volunteer (ETV) in easement programs, USDA NRCS-Morgantown, WV

80+ hours as an ETV in a central Indiana USDA NRCS Field Office-Anderson, IN

130+ hours as a volunteer for the Indiana Department of Natural Resources (IDNR) Division of Forestry (DOF)—Indianapolis, IN

\section{ACADEMIC PRESENTATIONS}

Dissertation research defense (RESM 797). March 21, 2019. West Virginia University, Morgantown, WV.

Subject: Fifty-minute presentation over results of dissertation research project.

Dissertation proposal defense (RESM 797). November 11, 2017. West Virginia University, Morgantown, WV.

Subject: Fifty-minute presentation over proposed dissertation research project.

Graduate seminar presentation (RESM 797). November 11, 2017. West Virginia University, Morgantown, WV.

Subject: Fifty-minute presentation over proposed dissertation research project.

Thesis research defense (FOR 698). June 22, 2011. West Virginia University, Morgantown, WV.

Subject: Fifty-minute presentation over results of thesis research project.

Graduate seminar presentation (FMAN 796). March 18, 2011. West Virginia University, Morgantown, WV.

Subject: Thirty-minute presentation over preliminary results of thesis research project.

Graduate seminar presentation (FMAN 796). December 3, 2010.West Virginia University, Morgantown, WV.

Subject: Thirty-minute seminar presentation over introduction, literature review, and methodology of thesis research project.

\section{LICENSES \& CERTIFICATIONS}

Real Estate Broker(Indiana)_License Number: RB14039200; Expiration Date: June 30, 2020 


\section{RELEVANT COURSEWORK}

\section{Ph.D.}

Major: Resource Management \& Sustainable Development: HCD track Environmental Impact Assessment

Foundations of Applied GIS

Introduction to GIS Natural Sciences

Environmental GIS Modeling

GIS Watershed Analysis and Hydrologic Modeling

Program Evaluation in Community Development

Sustainable Community Development

US Environmental Policy

\section{M.S.}

Major: Forest Resources Management

Independent Study (NRCS)

Renewable Resource Policy and Governance

Elements of Silviculture

Public Administration and Policy Development

Public Planning

Geospatial Modeling

Soil Survey and Land Use

Watershed Management

Scope and Practice

\section{REFERENCES}

Margaret Stout, Ph.D.

Associate Professor

Department of Public Administration

West Virginia University

Morgantown, WV 26506

Margaret.Stout@mail.wvu.edu

304-293-7978

Kathryn Gazal, Ph.D.

Associate Professor

Division of Forestry and Natural Resources

West Virginia University

Morgantown, WV 26506

Kathryn.Arano@mail.wvu.edu

304-293-5321

Joseph Hatton, M.S.

Deputy Commissioner

West Virginia Department of Agriculture

State Capitol Building

Charleston, WV 25305

jhatton@wvda.us

304-558-3550

Statistical Methods 1

Categorical Data Analysis

Qualitative (Research) Methods

Vegetation of West Virginia 